Ang. 1.1910.

fituer Roure,

Shottendaue,

Marqate. UNIVERSITY OF CALIFOKNLA DAVIS

WILLIAM WESLEY \& SON,

38 Eoksellers \& Esblishers,
28 ssex Street, Strand

28 Essex Street, 


Digitized by the Internet Archive in 2007 with funding from Microsoft Corporation 


\section{BRITISH CONCHOLOGY.}


First Edition $\quad-\quad$ - $\quad$ - 1862.

Reprinted - - - April 1904. 


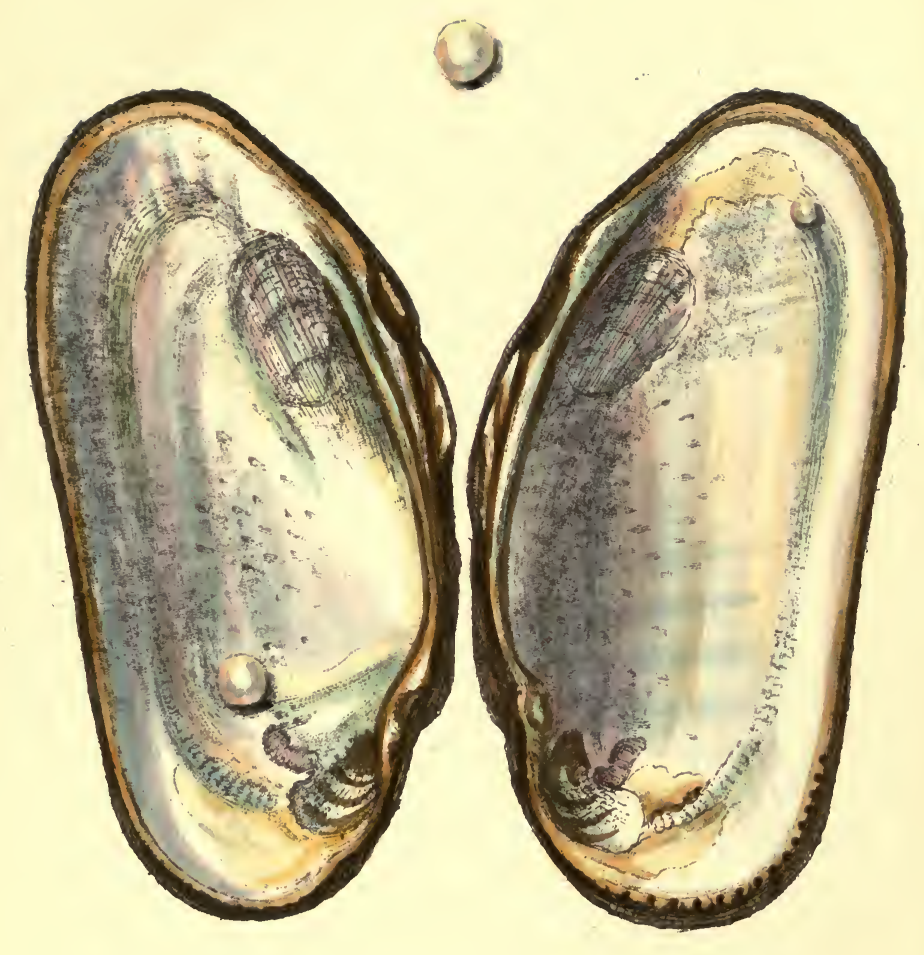

Then Margaritifer.

and pearl.

W. Sower by So. 


\title{
BRITISH CONOHAI
}

\author{
OR AN ACCOTBY
}

\section{THE MOLLCRE:A}

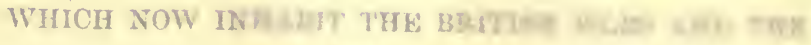

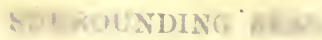

\section{VOY.XIME I}

LAND AND RERGHUVATEX EHKRIS.

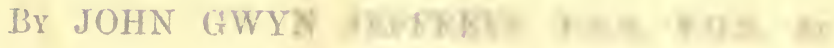

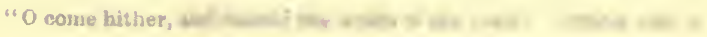

\section{LoB 1 BD:}

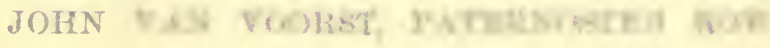
1564 


$$
00
$$




\section{BRITISH CONCHOLOGY}

OR AN ACCOUNT OF

\section{THE MOLLUSCA}

WHICH NOW INHABIT THE BRITISH ISLES AND THE SURROUNDING SEAS

VOLUME I.

LAND AND FRESHWATER SHELLS.

BY JOHN GWYN JEFFREYS, F.R.S., F.G.S., \&c.

"O come hither, and behold the worke of the Lord!"-Psalm xlvi. 8.

$$
\text { LON DON: }
$$

JOHN VAN VOORST, PATERNOSTER ROW. 1904.

[The right of Translation is reserved.]

$$
\text { DientKY }
$$




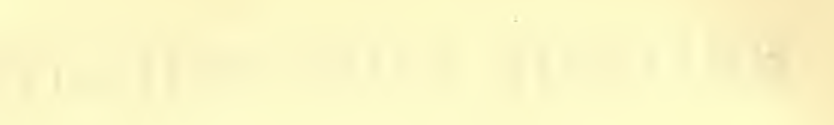




\section{TO THE MEMORY}

oF

MANY DISTINGUISHED NATURALISTS

AND VALUED FRIENDS,

WHO ARE NOW NO MORE,

AND IN GRATEFUL ACKNOWLEDGMENT OF THE

KIND SYMPATHY OF

THOSE WHO STILL HAPPILY SURVIVE,

FROM ALL OF WHOM I HAVE RECEIVEI

MUCH ASSISTANCE

IN THESE CONCHOLOGICAL STUDIES,

I DEDICATE

THE PRESENT WORK. 



\section{PREFACE.}

THE question whether another book on the British Mollusca is wanted by the scientific world, when there is at present a complete history of the subject by the late Professor Edward Forbes and Mr. Hanley, is answered by the notoriety of the fact that the price of that admirable work puts it beyond the reach of most naturalists ; and the enterprising publisher of those, as well as the present, volumes was so fully impressed with the necessity of another work at a more moderate price, that he invited me to undertake the task, which I fear I have inefficiently performed. In doing this, however, I have endeavoured to make the present work quite distinct from its predecessor, as may be seen by comparing the two; and those who are not fortunate enough to possess a copy of "A History of British Mollusca and their Shells," and who can afford the money for its purchase, will not regret the expenditure.

With regard to the animals or soft parts of the Mollusca described in this volume, I have been greatly 
indebted to the invaluable work of Moquin-Tandon, entitled "Histoire naturelle des Mollusques terrestres et fluviatiles de France," in which the physiology and anatomy of the land and freshwater Mollusca have been treated in a far more able and exhaustive manner than had been previously done by any author.

My old and esteemed friend, Mr. Alder, has most kindly promised to assist me with a notice of the Nudibranchs, so as to make that part of the subject as complete as possible; and the value of such cooperation will be fully appreciated by all naturalists.

A volume of supplementary plates will probably be published, to contain figures of every species and wellmarked variety. The figures now given illustrate the genera ; but the cost and price of the work would have been greatly increased by the other mode of illustration, except by resorting to the inartistic and unsatisfactory substitute of woodcuts.

In the prosecution of this task I have been actuated by what I trust will not be deemed a selfish consideration. The study of our native Mollusca has been to me from childhood such an inexhaustible source of pleasant and innocent occupation, it has given me so many happy hours, and it has taken away or alleviated the sting of so many sorrows, that I am desirous to assist in making it more an object of general cultivation than it has hitherto been. This field of research has by no means been exhausted; and whether regarded in a zoological 
or geological point of view, or as tending to increase our imperfect knowledge of the habits and instincts of these humble works of our Common Creator, very much yet remains to be done. No lover of nature need share in Alexander's sigh, or regret that he has no more work to do in any department to which he chooses to devote himself. "Nulla dies sine linea" was the favourite maxim of the great Linné ; and our days are too few for the accomplishment of all that we propose to do, let our aspirations be ever so modest.

A few explanatory remarks as to the scope of this work may be here introduced.

It was at first my intention to give, in an Introduction, a general outline of the subject, and to treat at considerable length some of the principal topics which are more especially interesting to naturalists and geologists. But the space which is necessarily occupied by the body of the work (although the synonymy has been compressed within the shortest limits and the descriptive characters have been printed in small type) will not admit of justice being done to this part of the subject, without making the volume too bulky ; and I must therefore content myself with offering in the proper place a few observations, so as to elicit further discussion.

In describing the dimensions of shells, I have taken the measurements from average and adult specimens, dividing inches into decimal and centesimal parts according to the size of each species. This mode of 
admeasurement I have considered preferable to statin the largest dimensions to which each species attains which would not give a fair idea of the usual size, or $t$ adopting the method used by some Continental author of giving the range or extreme limits of such dimensions Any extraordinary difference of size presented by speci mens or varieties will be noticed. In giving the ad measurement of bivalve shells, I have considered th length to correspond with the line of growth (viz. fror the apex or beak to the front margin), and the breadt. from one side of each valve to the other. In the case univalve shells I have adopted the same rule, viz. takin the line of growth for the length (the apex or point the spire representing each beak of the bivalve), and th widest part of the shell, or its greatest diameter, for th breadth.

At the end of the work I propose to give some prac tical hints to collectors.

For the benefit of such of my lady readers as have no added a knowledge of the classics to their other accom plishments, I have marked the accentuation of all th names of genera and species described in this work. On word of frequent occurrence I have noticed to be to often mispronounced by many who ought to know bette and that is the specific name of our common eatabl oyster, mussel, and cockle. This word (eduilis) has th middle syllable long, as is evident by remembering on of the various gastronomic maxims of Catius, "Vine 
submittit capreas non semper edules." My late friend, the Rev. Dr. Goodall, when he was Provost of Eton, impressed on my memory a rule of pronunciation, which it may be here useful to repeat. It is, that in words which end in inus, and are derived from the names of animals, the last syllable but one is generally long (as in Neritina and anatinus), while in those words which have a similar termination, but are derived from vegetable or mineral names (such as Ianthina and crystallinus), the penultimate syllable is generally short. The first are Latin, and the last are Greek forms. I have also endeavoured to render as literally as possible the English meaning of all generic and specific names, although the barbarisms are nearly as frequent in the nomenclature of natural history as they are in the materia medica.

The way in which the name of the great Swedish naturalist and founder of scientific classification ought to be spelt has been long the subject of controversy. It was originally Linnceus; but on his receiving a patent of nobility, he assumed the name of Linné. The latter name is given in the twelfth (and most perfect) edition of the "Systema Naturæ;" and in all his subsequent works and correspondence he always used this title of distinction. The learned Society which bears his name in this country is Linnean and not Linnæan, as appears by their charter and Transactions. Under these circumstances, I have adopted the name which he 
himself preferred, and which is prefixed to the work by which he is best known as a conchologist.

A parting word to the critics! When a mere youth, I was encouraged by my lamented friend, Mr. Dillwyn, to commit to print what little I then knew of the subject comprised in the present volume; and my first essay, entitled "A Synopsis of the Testaceous Pneumonobranchous Mollusca of Great Britain," was honoured by the Linnean Society by publication in their Transactions. Now, in mature years, I have become still more bold, and venture to appeal to the public. But, although I cannot hope to be exempt from the fate of all authors-criticism (and indeed, for the sake of science and the elucidation of truth, I would rather invite it, instead of considering it a calamity), I cannot send forth this little work without a mixture of the same feeling of hope and doubt, which made the ancient poet thus apostrophize his book :-

" Paucis ostendi gemis, et communia laudas, Non ita nutritus. Fuge, quo descendere gestis :

Non erit emisso reditus tibi."

25 Devonshire Place, London, 24 May, 1862. 


\title{
INTRODUCTION.
}

\section{CHAPTER I.}

\section{CLASSIFICATION.}

\begin{abstract}
DEFINITION OF THE TERM "CONCHOLOGY." - CONFORMITY OF SHELLS WITH THEIR INHABITANTS.-CEPHALIC MOLLUSKS OR UNIVALVES. - ACEPHALA OR BIVALVES. - TUNICATA. - SPECIES. - VARIETIES. - MONSTROSITIES. - REVERSED SHELLS. SYNONYMY.-NOMENCLATURE.
\end{abstract}

Definition of the term "Conchology."-Conchology *, as a branch of Natural History, treats of the Mollusca or that great division of invertebrate animals which have soft bodies and an organization superior to that of insects and only inferior to that of fishes. It properly comprises the study, not only of the shell or outer covering of the mollusk, but also of the whole animal,--although it has sometimes been used in a more limited sense, in contradistinction to the term "malacology," which has exclusive reference to the soft parts of the animal. Linné included the Mollusca in his great class Vermes-some of them as Vermes Mollusca and others as Vermes Testacea; but as the first of these divisions comprised a very heterogeneous assemblage of invertebrate animals, and as the testaceous Annelids were united with the latter, the classification proposed by him

* Compounded of two Greek words, kó $\gamma \chi \eta$,"a shellfish, and $\lambda o ́ \gamma o s$, a treatise. 
has not been adopted by modern naturalists. Cuvier was the first to restrict the term "Mollusca" to its present meaning. Nearly all the Mollusca have a shelly covering, which protects either the whole of their bodies or the more important organs. Even the Nudibranchs or Sea-slugs, in their embryonic state, are provided with a unispiral shell; and the Limacidae or Land-slugs possess a shelly plate, which is imbedded in the shield or mantle. The term "Conchology" may be therefore considered sufficiently appropriate to express the nature of this science, especially when the original meaning of the word is taken into account. I do not profess to be conversant with the anatomy and morphology of the Mollusca; and I must refer those who wish to study this part of the subject to the admirable treatises of Cuvier, Milne-Edwards, Quatrefages, Troschel, Von Siebald, Vrolik, and other Continental writers, as well as to those of our own equally eminent countrymen, Owen, Gray, Huxley, and Hancock. A complete knowledge of the Mollusca is of course unattainable without such study; but I must content myself with having made such progress as time and opportunities have permitted.

"Est quadam prodire tenus, si non datur ultra."

Conformity of shells with their inhabitants.-The importance of studying all the parts of the Mollusca is undeniable, and especially for the purpose of arranging them in generic and higher groups; but the distinctive characters afforded by the soft parts alone, which have been erroneously termed by some writers the "animal," cannot be much relied on in making out species. Philippi has completely demonstrated the insufficiency of such characters in the case of the genus Rissoa; and a careful comparison of the descriptions given in the following pages of our Land and Freshwater Mollusca 
ought to satisfy any naturalist, who is inclined to consider the question in an unprejudiced spirit, that the body or soft parts of the mollusk, taken without reference to the shell, offers an extremely slight and variable criterion of specific difference. The shell of itself generally enables the conchologist to distinguish one species from another, without regard to the soft parts; and as the latter are seldom observable, the convenience of such a mode of distinction is obvious. It would be rather difficult for a malacologist to describe any particular kind of testaceous mollusk without noticing the shell; and for the same reason a crab or seaegg would not be easily recognized by the description, if all mention of the carapace or test were omitted. The shell of the mollusk may be in some respects considered as a pseudo-skeleton, serving not only to protect the soft and tender body, but also to keep the whole frame together, like the true skeleton of any vertebrate animal. There is, besides, an intimate connexion between the shell and the tissues of the body, which is only dissolved by death or violence. The shell is (to use the words of Mr. Searles Wood) "part and parcel of the animal itself." I am aware that this opinion has been controverted by high authority, and especially by Dr. Gray, whose valuable contributions to the science of zoology, in many of its branches, are familiar to all. $\mathrm{He}$, at one time, disturbed the minds of geologists as well as students not a little, by a statement that some shells which were perfectly alike were inhabited by animals so extremely dissimilar as to be referable to very different orders of Mollusea*. This statement, however, he afterwards qualified to a considerable extent by admitting that, "in the distinction of the larger and smaller groups of Mollusca,

* Phil. Trans. 1834, p. 302. 
the characters derived from the animal, the shell, and the operculum, which all have a mutual relation to each other, are of equal value and constancy;" and he observed "how thoroughly they depend on each other, and what excellent and permanent characters they afford, both separately and in combination with each other*." Dr. Gray seems now to be quite sensible of the value of conchological characters, as nearly the whole of his numerous genera of Mollusca have no other foundation than the shell. I believe that the form and structure of the shell will be invariably found to correspond with the habits and wants of the animal which produces it. The mechanical principles involved in the construction of shells, and the adaptability of these habitations to the uses of their builders, have been admirably explained by the Rev. Canon Moseley, in an essay "On the Geometrical Form of Turbinated and Discoid Shells," which was published in the 'Philosophical Transactions' for 1838, and to which I would invite the attention of my readers. The uniformity of the laws which are here so ably expounded, and the correlation which exists between the mollusk and its shell, exhibit in no small degree the infinite wisdom of the Creator of all things, thus

\section{...... "dimly seen}

In these thy lowest works; yet these declare

Thy goodness beyond thought, and power divine!"

Cephalic Mollusks or Univalves.-The Mollusca may be considered in a general point of view as divided into Cephalic and Acephalous, and their shells into Univalves and Bivalves. The former arrangement was proposed by Lamarck, and the latter by his predecessor, Linné, who also added a third division-viz. that of Multivalves, which would almost be warranted by the anomalous

* Ann. \& Mag. Nat. Hist. Sept. 1855, p. 425. 
organization of Teredo and Chiton. All these divisions, however, are clearly artificial. The Cephalic or Cephalophorous Mollusks have a distinct head, and usually tentacles or horns, with eyes at their tips or base, and a foot or muscular disk for crawling or floating. A few of them have arms for swimming. Some inhabit the land, and others the water. The Snail, Whelk, and Cuttlefish are instances of this kind of Mollusca.

Acephala or Bivalves. - Although the bivalve Mollusca have no heads as a distinct part of their bodies, they are not deficient in those organs of outward sense which characterize other Mollusca, and their brain is as largely developed. Many of them have numerous eyes for seeing, otolites or ear-stones for hearing, filaments for touching, lips for tasting, a mouth for taking in their food, and (according to some physiologists) also an organ of smell. The fry of the Oyster, Terebratula, and other bivalves, which, in their adult state, are permanently attached to other substances, swim about freely, and are provided with distinct eyes, which afterwards disappear. All the Acephala are aquatic, and respire by means of gills, like fishes. The Oyster, Mussel, and Cockle are familiar examples of this kind of Mollusca.

Tunicata.-The Tunicata or Ascidians can scarcely be said to belong to the Mollusca, from which they differ, according to Milne-Edwards, in many essential particulars, especially as regards their circulation and reproduction. They appear to have a considerable affinity to the Polyzoa (or what are generally called "Polypes"), and may with them constitute the great and separate class of Molluscoidea. Each division of the animal kingdom has so many points of resemblance to others, and the network of organization is so closely interwoven, that it would be very difficult to define any one 
class by characters which others do not share in common with it. Mr. Alder is at present occupied with the subject of the British Tunicata; and it will doubtless receive from that talented and experienced naturalist the same elucidation as was bestowed on his celebrated Monograph of our native Nudibranchs.

Species. - I now venture to offer a few remarks on a very difficult and perhaps insoluble problem, viz. the nature of species. The difficulty of this investigation is greater in the study of the Mollusca and other Invertebrata than in that of more highly organized animals, because one characteristic element, from the nature of their reproductive system, is here wanting or beyond the reach of observation. Nearly all the land Mollusca, the habits of which it is comparatively easy to study, have both sexes united in the same individual; and not even the aquarium will enable us to make those experiments as to the fertility or sterility of hybrids to which such importance is attached in the discussion of this question in the case of vertebrate animals.

The forms of some shells appear to be more permanent or capable of being reproduced without any modification than others. The Silurian Lingula, which claims the precedence of all Mollusca in point of antiquity, is said to be undistinguishable from an existing species; and its mould must therefore have been continued from the womb of time to the present day without the slightest change. The secondary strata contain many wellknown instances of a similar persistence of form, especially those of Terebratula caput-serpentis and some Foraminifera, which are considered by competent authorities not to differ from species which now live in the adjacent seas. A large proportion of the fossil shells found in the lowermost of the Pliocene strata (or 
"Coralline Crag") are precisely similar in every respect to the recent shells of species which bear the same names and still survive; and it is impossible for the most critical species-maker to distinguish one from the other. Even their varieties and monstrosities or abnormal forms are still repeated. The opinion of the late Professor D'Orbigny, which has been adopted by Agassiz, that all tertiary species became extinct, and that they are only represented at present by analogous forms, evidently resulted from a preconceived theory, against which a concordance of fossil with recent species would have militated.

Without, however, entering into an abstruse (and perhaps useless) inquiry into the origin of species, or how far they have been modified during any period of time, however vast, by external circumstances or conditions, it is undeniable that certain definite forms, called "species," exist, and that they constitute more or less extensive groups of individuals, which resemble each other as well as their parents and offspring, to the same extent that we observe in the case of our own kind. These groups, to deserve the name of species, must be distinct from others; because if any of them are so intimately blended together by intermediate links as to make the line of separation too critical, the test fails, and a subordinate group, or what is called a "variety," is the result. For this reason it is indispensably necessary to compare as great a number of individuals as possible, and especially a series of different ages and sizes commencing $a b$ ovo, as well as specimens collected from various localities. The study of abnormal or monstrous forms is also important in order to ascertain the range of variation in growth. By such investigations a crying abuse of the present school of natural history (an excessive multiplication of species) would be avoided, 
juster views would prevail as to the distinction of species, and the well-deserved reproach of those philosophers who are confirmed in their denial that species have any real existence in nature by the notorious disagreement of naturalists as to their limits would thus cease. There is no judge or "arbiter specierum;" and every naturalist is at perfect liberty to follow the bent of his own discretion or inclination in the extension or reduction of species, subject only to the opinion of his scientific compeers. He is amenable to no other authority. Hence arises that great and continual diversity of opinion as to the determination of certain species among naturalists, whose opportunities or experience are more or less great, or whose minds are differently constitutedthe nature of some being rather analytical and of others synthetical. The same remark of course applies to the distribution of species into genera, and of these, again, into families and higher groups or sections. To a certain extent all classification is artificial and arbitrary; but the necessity for some arrangement of the kind is obvious, considering the immense number and variety of objects to which some name or symbol of distinction must be given for the sake of those who pursue or study any branch of natural history. Systems of classification are as indispensable to a naturalist as tools to a workman. This necessity of science equally applies to the discussion of the interesting question as to the origin and mutability of species, which in the absence of such data could not be satisfactorily conducted.

Varieties.-Besides species, and holding a subordinate rank to them in the great host of Nature's works, are certain forms called "varieties," which are not less definite, but more difficult to separate from the typical or specific forms. They are offshoots of species, and origi- 
nate in some peculiarity of climate, situation, composition of the soil or water which they inhabit, the nature or supply of food, and various other conditions. The characters by which they usually differ from species consist of size, comparative proportions of different parts, colour, and degree of sculpture; and the investigation of forms thus changed or modified is often extremely perplexing. Some species are more liable than others to variation; and, as might be expected, the tendency to variation is greater in those species which most abound in individuals, by reason of their offering a wider scope of observation to the naturalist. Varieties are of two kinds, permanent and local. The former are called "races," and have many of the characters of true or typical species, with which they associate. Great experience and good faith are essential to the investigation of this experimentum crucis; and the only reliable test of distinction between species and races appears to be the discovery of intermediate forms. In the absence of such discovery we may proceed to classify,-although after all we must not lose sight of the great probability that all species, and even higher groups, may have originally descended from races or permanent varieties, and these again from local varieties. The latter are more readily distinguished from species and are never found associated with them. I believe it may be now considered a well-established rule, that all distinct groups of individuals living together and having a common feeding-ground, and which are not connected or blended with each other by insensible gradations, are prima facie entitled to the rank of species. A contrary opinion used formerly to be entertained by some naturalists; and it was not unusual to found a claim to specific distinction on the fact that the specimens thus distinguished did not occur with the 
species from which it was proposed to separate them. They apparently forgot that the very difference of locality or habitat, with its accompanying conditions, caused the variation in question.

Monstrosities.-These abnormal forms of shells are frequently repeated, and even appear to be hereditary; and it is not easy at first to distinguish them from varieties. Both are probably owing to an irregularity, or an excessive or defective power, of secretion in the mantle of the animal. The monstrosity seldom, if ever, occurs in the first stage of growth; and the examination of the top whorls or apex of a univalve, or of one of the beaks of a bivalve (being in each case the nucleus of the shell), offers a good criterion to distinguish monstrosities from species. The normal or regular form becomes distorted at a subsequent stage of growth, instead of pursuing the usual course of formation.

Reversed shells.-Among the numerous cases of monstrosity to which the Mollusca are liable, by reason of their comparatively simple organization, none is more remarkable than the reversed turn and position which the spire of univalve shells and the valves of some Acephala not unfrequently assume. The twist of the spire in univalves is, with a few exceptions, dextral or from left to right, the shell being placed with its spire towards the observer and its mouth downwards. If the shell is held in this position before a mirror, the spire will of course appear to be sinistral or turning from right to left, which is termed "reversed." This phenomenon occurs in most species of Mollusca which have spiral shells; but it is more rare in some than in others. In certain genera the shell is naturally reversed; and a dextral spire becomes the exception or monstrosity. In a few species the spire is as frequently sinistral as dex- 
tral. The direction of the spire is attended by a corresponding change in the position of those organs of the animal which are usually placed on one particular side; and it may be compared to the case of a man having his heart on the right and his lungs on the left side of his body. The structure of a mollusk is, however, not so complicated; and the consequence of such a reversal in the position of its organs is probably not very important to its economy. One curious case of this kind of malformation is worth noticing. During the deposit of that part of our upper tertiary strata which is called the "Red Crag," nearly all the specimens of the almond whelk (Fusus antiquus) appear to have been sinistral or reversed, dextral specimens being comparatively very scarce in this formation. The same species still exists and is common in our seas; but the proportion of dextral to sinistral specimens is at present exactly the contrary to what it was in the Crag epoch-the former being now the rule and the latter the exception. A reversed specimen in a recent or fresh state is worth half a sovereign; while dextral specimens may be had at any street stall (with the fish) at the rate of four for a penny. A few bivalve species, which have one valve larger than the other and are therefore called inequivalve, have also their shells occasionally reversed,- their right or left valve being the largest, contrary to the usual rule in these species.

In the prosecution of any inquiry into the nature of species or varieties, or as to whether there have been any special or successive creations since this world was called into existence by the fiat of its Great Creator, I do not believe that it can have any irreligious or sceptical tendency. Holy Scripture is not a work of natural history, and it is silent on the subject of this investigation. 
As Dr. Carpenter has well observed, in his Researches on the Foraminifera*, "The creation of any organism seems to me just as much to require the exertion of Divine Power when it takes place in the ordinary course of generation, as it would do if that organism were to be called into existence de novo ; the question being in reality whether such exertion takes place in the way of continuous exercise according to a settled and comprehensive plan, or by a series of disconnected efforts."

Synonymy.-Although the prevalent habit of multiplying species is much to be deprecated, an equal amount of injury has been done to the cause of science by the unnecessary addition, from time to time, of fresh names for species which had been previously described; the consequence of which is that an overgrown mass of nomenclature encumbers most works on natural history. For our common Cockle and its varieties no less than sixteen, and for the Oyster fourteen different names have been given by British and Continental writers; a genus of minute shells (Odostomia) has received from various conchologists twenty different names; and in an essay of M. Bourguignat on the species of Pisidium (a small freshwater bivalve) the synonymy of $P$. amnicum comprises eighty specific names and extends over more than five octavo pages. The student may well stand aghast at this fearful array of names, which bewilder him and obstruct his entrance into the portals of the edifice of natural history! This redundancy of names for the same object has partly arisen from the want of intercourse which naturalists of this and other countries experienced formerly, and especially during that chronic state of international warfare which so long debarred us from any communication with foreigners. Such an 
unfortunate state of things certainly retarded scientific progress in Great Britain to a very great extent; and the friendly sympathy which now exists between the naturalists of all countries cannot be sufficiently appreciated. In one sense the multiplication of species and addition of synonyms are convertible terms; and that is, where local varieties have been described and raised to the rank of species. This evil it is impossible to prevent; but as science does not march "pede claudo," but regularly and steadily, it is to be hoped that each succeeding year will bring with further discoveries the occasional publication of monographs by experienced naturalists, so as gradually to rectify this crying evil. The introduction to the 'Flora Indica,' by Drs. Hooker and Thomson, contains a valuable remark which deserves the attention of zoologists as well as botanists, viz., "The discovery of a form uniting two others, previously thought distinct, is much more important than that of a totally new species, inasmuch as the correction of an error is a greater boon to science than a step in advance."

Nomenclature.-Very often the longest and most unpronounceable names have been bestowed on minute and almost microscopic species. When the student meets with such names as Cerithiopsis tubercularis and Omalogyra nitidissima, he is scarcely prepared to find that one of the objects designated by these more than sesquipedalian words is scarcely more than a quarter of an inch in length, and that the other is only about onefifteenth of an inch in diameter! There is, however, no way of preventing this abuse of language for scientific purposes, except by making a new coinage; and this would be attended with more inconvenience to naturalists in the substitution of new for old and familiar names, than in the retention of a few long words. 
The general rule is not to alter the name which has been first given to any species, in order to establish a conventional right of priority and to prevent confusion. But this rule is not without an exception-especially where the original name has been accidentally misspelt, either by the author or printer. Thus "Suediense" has been properly changed to Suecicum; and "Syndosmya" ought to be replaced by Syndesmia. Such trivial corrections are necessary in the works of our best authors; and in those which have largely benefited the cause of science,

\author{
Offendar maculis, quas aut incuria fudit \\ Aut humana parum cavit natura."
}

\title{
CH A P T E R II.
}

\section{ORGANIZATION AND HABITS.}

REPRODUCTIVE SYSTEM.- FECUNDITY. - HYBRIDISM. - PROGRESSIVE DEVELOPMENT.-ORGANS OF SIGHT-HEARING-SMELL-LOCOMOTION. - FOOD. - SIZE. - HABITAT. - CARE OF YOUNG. - SOCIABILITY.- AESTIVATION AND HIBERNATION.-NESTS.-MODES OF ATTACK AND DEFENCE. - RENEWAL OF PARTS. - PHOSPHORESCENCE.-PERFORATING POWERS.-OCCASIONAL APPEARANCE AND DISAPPEARANCE. - TENACITY OF LIFE.-AGE.-RESUME.

Reproductive system.-The modes of propagation among the Mollusca are various. In the case of univalves, many of them (e.g. the Whelk tribe) have distinct sexes, and are what botanists term "diœcious ;" while most of the land-snails are nearly "monœcious," each individual being at the same time male and female, but incapable of fertilizing itself. Some of these even change their sex at different periods,- - the Valvatida being at 
first male and afterwards becoming female. In the case of the Conchifera or bivalves, they are probably all strictly "monœcious" and fertilize themselves. It was at one time supposed that the Oyster and freshwater Mussel were exceptions to this rule, and that some individuals were male and others female; but the researches of Davaine, Moquin-Tandon, and other able physiologists have disproved this idea*. The external organization of the Conchifera, as well as the complete isolation of the Teredines and many other kinds from all intercourse with each other during the whole of their lives, would make it very unlikely that they are of different sexes. Some of the Mollusca are ovoviviparous, the eggs being hatched within the body and the fry excluded in a perfect form. This is the ease not only with "monœcious" kinds (such as Anodonta and Kellia), but also with some snails (Helix rupestris and Pupa umbilicata) and even with "diœcious" kinds, such as Paludina and certain species of Littorina. Some particulars will be found in the following pages with regard to the amours of the land and freshwater snails; and much more might be said on this curious subject. The tender passion seems to take up much of their time and attention. M. Turpin has observed a pair of the common garden-snail (Helix aspersa) engaged in love-making for the space of more than ten hours!

Fecundity.-The extreme fertility of some mollusks is not exceeded by that of fish. It has been estimated that the oyster spawns annually at least three millions. According to C. Pfeiffer the gills of a freshwater mussel of moderate size contain at least 400,000 eggs; and Jacobson has given a much higher figure (two millions) for the

* See also Hancock "On the Organization of the Brachiopoda," Phil. Trans. vol. cxlviii. p. 816 . 
product of a large individual of this kind. If this rate of increase were unchecked, our seas and rivers would in a comparatively short time (reckoning geologically) be filled up with the remains of shell-fish.

Hybridism.-Although many surmises have from time to time been hazarded as to the production of abnormal forms of Mollusca by means of an unnatural union between individuals of different species, the only direct experiments or observations that appear to have been published on the subject have been made by French naturalists. M. Gassies, in his descriptive Catalogue of the Land and Freshwater Mollusca found near Agen, mentioned several cases of what he called "accouplements adultérins," which he had observed between individuals of Helix virgata and H. Pisana, as well as between those species and Bulimus decollatus. M. Gassies enclosed the snails during a thunderstorm in a vessel covered with metallic gauze; and he believed that the electricity with which the air was then charged induced the unnatural union. Great care appears to have been taken to prevent any error in the result, by selecting individuals which had not been previously fertilized and keeping them after fecundation separate from any others. The product of these unions was as follows. The young of $H$. Pisana had perfectly white shells,-their mother having the usual coloured bands; and the young of $H$. virgata had shells of a darker colour than that of their mother. In the other case, the product of the Helices which had been coupled with the Bulimus was various. Many had shells which were almost scalariform; the shells of others were pyramidal; but the greater part of them had shells exactly like that of their mother. The product of the Bulimus did not differ from their maternal form. M. Gassies had also observed the product of a 
union between Helix nemoralis and $H$.hortensis, in which the colour of the lips of their shells in each case varied indifferently from brown or rose-colour to milk-white: Professor Lecoq and M. Miergue have celebrated the voluntary nuptials between individuals of Helix nemoralis and $H$. aspersa, as well as between Pupa cinerea and Clausilia papillaris; but these unions do not seem to have been blessed with any offspring. The fact, however, of such unions having taken place in a state of nature, and not under forced or accidental conditions, is remarkable, and the more so because the individuals belonged to what are considered different genera.

Progressive development.-The researches of geologists have established by positive evidence, that the organization of many animal and vegetable types has not become more specialized or rendered more perfect since the period to which we ascribe their creation, and that, notwithstanding the enormous lapse of time which is indicated by the accumulation of fossiliferous strata, the modification or change which these types have undergone has been remarkably slight. There is abundant evidence of variation, but none of what is usually understood as progression*. The theory of "progressive development" appears to have been very hastily advanced, and is by no means borne out by geological facts. It is a curious circumstance in the history of the growth of certain land and freshwater Mollusca, that the young of some species of Pupa resemble those of Helix, the young of the latter those of Zonites, and the young of the last those of Vitrina. These genera are enumerated in the order of their organization, $P u p a$ being the most, and Vitrina the least perfect of them.

* See Professor Huxley's Address delivered at the Anniversary Meeting of the Geological Society, 21st February, 1862. 
Organs of sight.-The eyes of a Cuttle are more perfect than those of many kinds of fish ; but the so-called eyes of land-snails are supposed to be only organs of touch and not of vision, although endued with a greater sensibility than the tentacles which support them. The coloured bulbs which fringe the mantle of a Scallop are also called eyes; but their structure is very simple. According to Mr. Lea, several kinds of Unio are sensitive to light. These organs are entirely wanting in many of the Mollusca, and even in some species of genera which usually have eyes.

Hearing.-In the Pectinibranch Mollusca the contents of the auditory capsules consist of spherical ear-stones, which in every respect but that of form are similar to the otolites of fishes. In the Pulmonobranch Mollusca they are called octoconia and consist of a chalky pulp, which is separable into minute elliptical granules. Frey has observed organs of hearing in many of the land and freshwater Mollusca, both univalve and bivalve. He counted as many as 200 otolites of different sizes in one of the auditory vessels (of which there were two) in an adult snail. In Sphcerium (or Cyclas) each individual appears to have never more than a single otolite. He believes that these bodies are formed by a subcrystallization of the liquid contained in the auditory vessels.

Smell.-In the Helicido, or land-snails, this sense is supposed to lie in the bulbs which surmount their tentacles. It is probable that the carnivorous or zoophagous Mollusks have the power of scenting out their prey or food. Quantities of the common "almond-whelk" of dealers in shell-fish (Fusus antiquus) are procured on the Cheshire coast by the fishermen placing a dead dog on the sands at low-water mark during spring tides. The bait is then completely covered with stones, which 
are piled up like a cairn, partly to prevent the carcase being carried away by the tide, and also because the fishermen have a scruple about eating shell-fish which have been fed on such carrion. On the next turn of the tide the heap of stones is visited and the whelks are found on the surface in great numbers, having been apparently attracted by the smell of the bait, but unable to get at it.

Locomotion.-The methods by which Mollusca move from place to place are exceedingly varied. Most univalves crawl on the lower part or disk of a large fleshy organ, which is the homologue of a foot and supports the body. The Melampus uses this organ in an unusual way, by first planting the front half, like a caterpillar, and then drawing up to it the other half, and repeating this alternate movement in a fashion called "looping." The celebrated French naturalist, Adanson, gave that genus the name of Pedipes on account of this peculiarity. Many of the aquatic univalves can swim, or rather creep underneath the surface of the water, the position of their bodies being reversed, with the point of the shell downwards. A few of the bivalves (e. g. species of Lepton and Galeomma) sometimes walk about with their valves spread out like the cover of a book when left on the table by an untidy person. The Cuttles and Pteropods swim as rapidly as fishes, but in a different mannerviz. by taking in and expelling by means of their mantle successive volumes of water, so as continually to propel them onwards. One kind of Cuttle is said even to possess the faculty of flying, and to dart for a considerable distance out of the water through the air like a flyingfish. Most of the Acephala or bivalves have a tongueshaped organ of progression, which is muscular and extremely flexible. By means of this kind of foot the 
Cockle, Razor-fish (Solen), and other kinds burrow in sand and mud. The Scallop and Lima fill their bodies with water, and then, suddenly collapsing and closing their valves, execute a series of leaps or jerks, by which they can traverse a considerable distance, although in an irregular course. Certain small bivalves (Sphcerium and Kellia), while floating on the surface of the water, spin filaments which serve to moor them and prevent their being drifted about. Several kinds of slug secrete glutinous threads by which they suspend themselves from trees and either remove from one branch to another or drop safely to the ground. Thus it will be seen that the Mollusca partake of all the modes of locomotion possessed by other animals - that they can walk like quadrupeds, fly like birds, crawl like serpents, swim like fishes, and even spin threads like spiders.

The action of creeping in a snail is performed by the close appression of its foot to the substance over which it moves, as well as by muscular force. Any unevenness in the surface to be traversed is filled up by folds of the foot, which is extremely flexible. This action may be compared to the application of one piece of flat glass to another. Musical sounds, resembling those which are given out by the Eolian harp, may be observed on a dry summer evening by putting a garden-snail to crawl outside a window; and this phenomenon has frightened many a timid or superstitious person, who could not imagine whence these mysterious sounds proceeded. A curious calculation was made by Mr. Thomas, an American conchologist, as to the rate of a snail's pace. He found that it takes 16 days and 14 hours for a moderately fast snail to do a mile.

Food.-By far the greater part of the Mollusca are zoophagous or animal-eaters. The food of the Acephala 
consists of Infusoria and other animalcules, which are conveyed to their mouths, by an action analogous to that of suction, through the inhalant tube or the outer folds of their mantle. The Buccinum or whelk tribe prey upon other mollusks (especially bivalves) by drilling holes in their shells with their proboscis, which is armed with a formidable apparatus of teeth. The whelks are also very troublesome to fishermen, being often found sucking and sticking to the bait when the lines are taken up. Numbers of them may be caught in lobster-pots baited with fish or meat, if laid down on a sandy instead of a rocky ground. Most of the littoral univalves feed on sea-weed. The common Limpet forms by means of its foot a shallow exeavation in the rock. When the tide returns it goes out to its pasture, browsing like an herbivorous quadruped; and it returns to its hole when the tide retires. The track left by its grazing on the submarine vegetation which clothes the adjoining rock is very perceptible and is sometimes tortuous or mazelike. Land and freshwater snails, as well as slugs, are for the most part herbivorous, as gardeners know to their cost in the former case; but some of them also devour animal matter, and a few are cannibals. The food of the Testacella consists almost exclusively of living earthworms; and a full account of its carnivorous and voracious propensities will be found in this volume. Snails have been taken with insects in their mouths, which they were swallowing by degrees; and, according to M. Bonnafoux, the Helix aspersa has been known to perforate birds' eggs in deserted nests, in order to feed on their contents. The number of curved siliceous teeth which arm the tongues or lingual plates of snails is prodigious (amounting in some species to many thousands), being arranged in several rows. Some 
of the marine Mollusca are parasitic, or live upon the secretions of other animals. Among the bivalves Montacuta substriata, and among the univalves Stylifer Turtoni, are instances of these parasitic habits.

Size.-This appears to depend on the supply of food; and it is probable that, owing to the vast shoals of mollusk-eating fish which abound in the northern seas, the shell-fish there are thinned to such an extent that the fortunate survivors have a proportionally larger share of food than those which inhabit southern seas, where both species and individuals are more numerous. Northern Mollusca are generally larger than those of the same species from the South*. The same law is observable with regard to cultivated fruits, - thinning being resorted to for the purpose of reducing the number and increasing the size of those which are allowed to remain.

Habitat.-There is probably not a square foot of land, either in a cultivated or uncultivated state, or covered with fresh, brackish, or salt water, that is not inhabited by Mollusca of various kinds. Trees, herbage, and sea-weeds are the chosen stations of many sorts, for the sake of the shelter or food which they afford; and even our cellars and kitchens are not free from them. Some live only in the ocean, and never approach land unless when driven on shore by the winds and waves. These are called "pelagic." Among them are the Ianthina, or "blue-snail," and a few small Pteropods, which are occasionally found in our seas. The former is provided with a cellular apparatus, by which

* See also Draparnaud (Tabl. Moll. p. 35) as to the comparative size of land shells inhabiting the North and South of France. "Le climat influe beaucoup sur la grandeur des individus. Chez les Mollusques, comme chez les Mousses et un grand nombre d'autres plantes, la même espèce acquiert un volume d'autant moindre, qu'elle habite dans un pays plus chaud." 
it is enabled to keep always in a floating position on the surface of the water, with the point or spire of its shell downwards, and which apparatus also serves as a nidus for its spawn. A description of this curious appendage or "float," as well as of the equally remarkable habits of the Ianthina, will be found in its proper place. The Pteropods have feet like wings, and flutter through the water like butterflies. They have conical, and sometimes spiral, shells as fragile and transparent as the finest blown glass.

Care of young.-Many of the bivalve Mollusca, inhabiting the sea as well as fresh water (e. g. Teredo and Anodonta), retain for some time their fry, after being excluded from the egg, in the folds of their mantle, this being in some degree an analogous provision to that which is possessed by the marsupial quadrupeds. The common Limpet and some kinds of Pupa (small landsnails) have also been observed to carry about their young, the former within the folds of its foot, and the latter attached to the shells of their mother. These cases of Molluscan $\sigma \tau о \rho \gamma \eta े$ are nearly as wonderful as any which have been adduced in accounts of much more highly organized animals.

Sociability.-Although many of the Mollusca are gregarious and assemble together on the same feedinggrounds, it does not appear that they ever associate for a common object, like bees or ants. Each Pholas and Teredo makes a hole for itself; and although the common garden-snail often fastens itself to the shell of its companion, when they hibernate and form clusters, a smooth stone or any other object is used for the same purpose.

Astivation and Hibernation.-Manyanimals in a state of nature have their periodical seasons of repose, espe- 
cially in the winter when there is a deficiency of food. For this reason it may be supposed that all the Mollusca hibernate; and we know that the land-snails in this country have such a habit. Most of them bury themselves in the ground, or nestle in the crevices of rocks, under the bark of trees, or even in the hollow stems of the larger umbelliferous plants. They also cover the mouths of their shells with a calcareous plate of various degrees of thickness, which they secrete, in the same way as the shells, by means of their mantle. This plate is called an "epiphragm," and in the apple-snail (Helix pomatia) is of considerable thickness. But in dry weather and during the heat of summer they form another and slighter kind of epiphragm, in order to keep their bodies always moist and lubricated, as without such protection the tissues would soon dry up and the snails perish. The Rev. H. B. Tristram, in his account of the Great Sahara, says that the snail-shells which he found there were much thicker than those of the same species from more temperate parts of Europe, apparently as an additional means of preventing evaporation in so dry a climate. The simile in the 58th Psalm (verse 8) which is rendered in our translation for the 'Common Prayer,' "consume away like a snail," may have had reference to the inability of these Mollusca to endure exposure to the great heat of the sun in an Eastern climate. None of the naked Slugs occur in the lists of land Mollusca collected by Professor Roth in Palestine, and by Dr. Schläfli and M. Mousson in the East. The circulation of land-snails is affected to a great extent by the temperature. In some kinds the rate of pulsation varies from 30 to 110 per minute during summer; and it ceases altogether in winter. Although the temperature of the sea is nearly the same in summer 
and winter, except at its surface, the circumstance that most sea-weeds are annual would lead us to conclude that the marine phytophagous Mollusca also retire into winter quarters, and that, as these are preyed upon by the zoophagous kinds, the habit of hibernating is common to all shell-fish. In shallow seas near the land, the number of marine animals is perceptibly diminished during cold and inclement seasons ; and this was noticed by several naturalists to have been the case in the wet year of 1860 . The period of hibernation differs among the Mollusca. Some retire earlier or emerge later than others. According to M. Drouet the Anodontce or freshwater mussels hibernate before the close of autumn, and bury themselves deep in the mud until the middle of spring, when the water begins to get warmer.

Nests. - A few marine bivalves, which do not spin a byssus or bundle of threads with which they can moor themselves to rocks, or which have not the power of excavating for themselves a place of residence in stone, wood, the tunic of Ascidians, or other substances, form a kind of rude nest out of broken shells and zoophytes, which they cement and line internally with a slimy exudation from their bodies; and thus they remain snugly ensconced and protected from their natural enemies. Among these nest-builders are the Modiola radiata, Lima Loscombii, and the northern form of $L$. hians. So little is known of the habits of the marine Mollusca, that I am not prepared to say whether these are proper nests and used for the protection of the young, as in the case of sticklebacks and other small fishes, or are constructed solely for the use of the adult shell-fish.

Modes of attack and defence.-Some aquatic mollusks have the faculty of emitting from their bodies a purple or dark fluid, apparently for the purpose of securing 
their prey or concealing themselves from fishes or other predaceous animals. The inky cloud which the Cuttle ejects is of a glutinous or viscous nature, and does not readily mix with the water. It seems to be better adapted for entangling small fishes than to cover the retreat of the Cuttle, which is extremely rapid in its movements. The Aplysia, or sea-hare, gives out a purple dye which is also glutinous and has an offensive smell. As this mollusk crawls but slowly, it may use the dye to obfuscate some more active animal which it may have taken a fancy to make a meal of, all the Nudibranchs being said to be carnivorous. Several kinds of Planorbis (freshwater snails) yield, on being irritated, a quantity of their own purple blood. These are vegetable-eaters; and we can therefore conceive no other object in this voluntary blood-letting than to elude observation. A few land-snails (e. g. Bulimus obscurus and Pupa secale) in their young state, as well as some small freshwater bivalves belonging to the genus Pisidium, have their shells covered with mud and other extraneous matter; but it is difficult to say whether this is the result of design or accident. One might suppose that the sharp eyes of a bird or a frog would easily detect their prey through this feeble disguise. Some marine bivalves (as Lyonsia Norvegica and species of Necera) are covered with a coat of sand, which may to some extent answer the purpose of concealment. If the safety of these animals is ensured by such means, how great must be our admiration of that wonderful yet varied plan of contrivance which makes the humble Mollusk, as well as Man, the object of Divine care!

Renewal of parts.-Some Mollusca, which had been accidentally deprived of their feet, tentacles, eyes, and even of their entire heads, have been known to repro- 
duce them. Nearly a century ago, the experiment of decapitating unfortunate slugs and snails was conducted on a wholesale scale on the Continent, and every philosopher was anxious to cut off a head. Even the great Voltaire followed the universal fashion; and his experiences were published in the "Questions sur l'Encyclopédie." In these he mentions having operated on twenty brown slugs and a dozen snails; and he afterwards records with great pride and satisfaction "mes Limaces" and "mes Escargots" showing their budding heads and horns, and doing as well as might be expected under the circumstances.

Phosphorescence.-Although a great many animals, from the highest order of fishes to the imperfectly organized Noctiluca miliaris, as well as several of the Tunicata, emit or exhibit a phosphorescent light, I am not aware that any of the Mollusca possess the same property, except some kinds of Pholas; and it is possible that the phenomenon in their case may be owing to animalcula which infest them or are found in their holes. The eggs of a common slug (Arion hortensis) are said to be luminous for the first fifteen days after they have been laid. But both the nature and object of this common phenomenon requires further investigation.

Perforating powers.-Many shell-fish, and especially bivalves, burrow in sand or mud for protection against their natural enemies; but some of them excavate wood, peat, or stone of various degrees of hardness, for the same purpose. The process of burrowing is undoubtedly performed by the foot of the Mollusk. It is exemplified by the case of the common Cockle, which uses its tongueshaped and flexible foot in the same way as a gardener uses his dibble, and, having thrust it into the sand and expanded it, thus makes a hole large enough to contain 
the shell. The limpet (Patella vulgata) slightly perforates calcareous rocks by the muscular action of its suckerlike foot or disk, which occupies all the lower part of the body. The shell exactly fits the space thus excavated, so as to prevent the limpet being easily dislodged by a bird or a crab. The common garden-snail excavates hard limestone rocks for the purpose of hibernation; and as its shell is covered with a delicate epidermis, which remains on specimens having just emerged from their winter quarters, it may be safely inferred that the shell is not the instrument of perforation in this case. But with respect to the Teredo or ship-worm (which tunnels through wood), the Pholas (which pierces wood, peat, clay, and chalk), the Gastrochona (which penetrates hard sandstone, chalk, and limestone, as well as old oyster-shells), and the Saxicava (which perforates the hardest calcareous rocks), it is not so easy to form a definite conclusion. This volume would scarcely contain all that might be said on the subject. Forbes and Hanley have given an excellent account of the discussion which had taken place up to the time of publishing their work; and I will content myself with stating briefly the result of their investigation and adding a few remarks suggested by my own inquiries.

The opinions which had been expressed on this subject when the 'History of the British Mollusca' was published, were classed by its authors, when treating of the Pholas, under five conclusions, which are as follows:-

" 1 . That the boring Mollusca perforate by means of the rotation of the valves of their shells, which serve as augers. 2. That the holes are made by rasping, effected by siliceous particles studding the substance of certain parts of the animal. 3. That currents of water, set in action by the motion of vibratile cilia, are the agents. 
4. That the animal secretes a chemical solvent-an acid which dissolves the substance into which it bores. 5. That the combined action of a secreted solvent and rasping by the valves effects the perforations *."

The first of these views is advocated by Forbes and Hanley; and the other naturalists to whom they have referred as having expressed an opinion on the subject are as follows, taking the several views in their order of succession :-l. Dr. Gray, Dr. Fleming, Mr. Osler. 2. Mr. Hancock. 3. Mr. Garner. 4. Dr. Gray, Dr. Drummond, M. Deshayes, M. Cailliaud. 5. Mr. Thompson, M. Necker.

As I believe that all these different views, except the first, have been successfully refuted by the arguments of Forbes and Hanley, it only remains for me to adopt their view, or to substitute another for it.

If we only consider the shell of Pholas, with respect to its efficiency as an instrument of mechanical perforation, there might be sufficient reason for supposing that it can by this mode drill a hole in peat, submerged wood, clay, or even in chalk when softened by the continual contact of water. The shell is certainly harder than any of these substances ; and the animal is provided with muscles of unusual strength for effecting the rotatory motion which would be necessary for such an operation. But we must also consider the cases of other perforating mollusks whose shells are not so hard. The shell of Gastrochoena is more fragile than that of the oyster into which it bores, and very much more so than the limestone in which it not unfrequently lodges itself. The helmet-shaped valves of Teredo could only be used to rasp the sides of the tube which this mollusk forms in wood ; and they are not adapted for excavating the con-

* 'British Mollusca,' vol. i. p. 104. 
cave end of the tube. The shell of Saxicava is coated with a delicate epidermis, which would unquestionably be scraped away in perforating the solid limestone rock, if the theory advocated by Forbes and Hanley is applicable to this case. And, to take the case of other marine animals which excavate rocks and shells for the same purpose as the Mollusca, we know that the boring Annelids or sea-worms have no hard substance in their composition. For these reasons, I do not think that the mechanical theory (viz. that the shell is the sole instrument of perforation) has been established.

Since the publication of Forbes and Hanley's work, the controversy has been continucd with unabated ardour; and to the list of naturalists who have taken a part in it, other names may be added as supporters of the undermentioned theories.

Mechanical. Mr. Robertson and M. Fischer.

Chemical. Dr. Mantell, M. Thorent, and Mr. Reeve.

M. Cailliaud now contends that both methods of perforation are adopted by the same kind of mollusk according to the material acted upon; and M. BouchardChantereaux, who was at first in favour of the mechanical theory, is now strongly of opinion that a corrosive secretion of the animal is the agent of perforation.

But there is another point of view in which the question may be considered, and which does not appear to have received any attention, although in my humble judgment fully deserving it.

Nearly 130 years ago, a very learned but eccentric Dutch philosopher, named Sellius, wrote and published, for the benefit of his country, an elaborate monograph on the Teredo. In this remarkable production he discussed at great length, and in the most exhaustive style, all the various theories which had been propounded up to 
that time as to the means by which the ship-worm bores into wood. He showed conclusively that their shells could not be the instruments of perforation; and he asked how it was possible that the extremely tender shell of the young Teredo (in fact a mere film) could make a hole in solid oak, a material ten times harder than itself. Besides, as he justly remarked, the form of the tube is evidently not the result of an auger-like instrument, because it is broader at the bottom than at the top and sides. The conclusion he formed, after a most laborious and impartial investigation, was that the Teredo perforates by suction, aided by continual maceration and softening of the wood. One of his numerous quotations from the ancient poets, in support of his argument, may be here appropriately repeated. It is from his favourite, Ovid :-

"Quid magis est durum saxo? quid mollius undâ ?

Dura tamen molli saxa cavantur aquâ."

I profess myself to be a follower of Sellius; and I am convinced that the sole instrument of perforation by the Mollusca of stone, wood, and other substances, is in every case their foot or muscular disk, which is closely applied to the concave end of the hole and is constantly supplied with moisture through the glandular tissues of the body. The strength of this organ may be easily tested by any one who tries to remove a limpet from its native rock, after having touched it and thus given it due notice of his intention. By this simple, yet gradual, process the fibres of wood or grains of sandstone may easily be detached or disintegrated, time and patience being allowed for the operation. When it is considered that the hole made by an adult Pholas or Saxicara is only a few inches deep, and that an aged Patella scarcely penetrates a quarter of an inch into a limestone rock, 
there can scarcely be a question that these mollusks have abundance of time to effect their purpose. It is said that even the hardest marble is not proof against the softest impressions, and that the big toe of St. Peter's statue in the Vatican has been nearly worn away by the lips of fair devotees. The osculatory process is not unlike that of suction.

Occasional appearance and disappearance.-Both sea and land furnish instances (some of which are difficult to explain) of the periodical appearance and disappearance of certain species of Mollusca in particular places. Their arrival and departure are often sudden and seemingly capricious. In the case of marine species, this phenomenon is probably the result of changes in the course of tidal and other currents, as well as of the migratory habits of fish. These currents, by accumulating or removing deposits of mud, sand, and gravel, which afford shelter and food to Mollusca, conduce greatly to their congregation or dispersal. When such deposits are rapidly formed, the shell-bed becomes covered up or silted; and the Mollusca are entombed alive for the benefit of future geologists. When their chief enemies, the fish, desert their former quarters and migrate to another feeding-ground, the Mollusca then increase and multiply, being unthinned except by the tigers of their own kind, or occasionally by the curious conchologist, or by all-devouring death. The destruction of shell-beds by marine currents may account for the prevalent notion that some parts of our sea-coast (as for example South Devon), which used to yield such regular and plentiful harvests of shells to collectors, are now scarcely worth searching,-it being said that the shells have "deserted" the coast. The unexpected occurrence of some kinds of land and freshwater Mol- 
lusca in places where they had not been previously noticed is not unfrequent. Many a wonderful tale of a "shower of snails" has helped to fill the pages of country newspapers, arising out of the sudden appearance in a limited area of Helix virgata and Bulimus acutus, which are abundant on most of our sandy downs and plains. This has been sometimes caused by a mere change of wind to the south-west, in consequence of which the air has become charged with moisture, and tempted all the snails to leave their retreat at the roots of grass during the night, and to present themselves in the morning to the eyes of astonished rustics. It is not, however, so easy to account for some kinds of freshwater snails (e. g. Limncea glutinosa) being found in the same spots so abundantly some years, and scarcely at all in others, as has been noticed by Mr. Bridgman of Norwich. This is one of the minor, but numerous, problems in the present branch of Natural History which still remains to be worked out, and the solution of which will reward the diligent and observant conchologist.

Tenacity of life.-Many of the Mollusca, as before remarked, pass the winter in a state of torpidity, their vital functions being apparently suspended during hibernation. But some of the land-snails have been known to live many years shut up in boxes and drawers, or affixed to tablets as specimens. This capability of subsisting for a long period without food is probably owing to the snail being able to close its shell by an epiphragm, which not only prevents the evaporation of its natural moisture, but also produces a kind of protracted hibernation. Muiller relates that some snails, from which he had cut off their heads, lived more than a year in this state without food, crawling about, and at the usual time forming their winter epiphragms. Some marine 
Mollusca, both univalve and bivalve, possess also a certain power of endurance under altered conditions. Thus Trochus lineatus, which inhabits rocks only uncovered at low water, can live in a warm room for a fortnight; and specimens of Mya arenaria, which burrows into muddy gravel in the sublittoral zone, have been noticed by Mr. Rich (an intelligent collector and dealer) to survive their captivity for three weeks, being all that time in apparently a healthy state (evidenced by the withdrawal of their tubes when touched), at the end of which period they were killed for commercial purposes. No sea-water was supplied in any of the above cases. The gills must have been kept moist by the fluid contained within the mantle-a provision nearly similar to that by which the camel is able to endure the heat and fatigue of a journey across the desert after having filled its paunch with a stock of water. M. Joly observed with respect to somefreshwater mollusca (Anodonta cygnea and Paludina vivipara), that they may be frozen up, and kept for some time enclosed in ice, without being killed. Some of the Paludince even produced young after being thawed*.

Age.-Little or nothing is known with respect to the duration of life in the Mollusca. According to Sir Emerson Tennent, the pearl oysters of Ceylon only live seven or eight years; and it is said that snails do not attain a greater age. This is not improbable as regards the latter, because most of them become adult at the end of their first year. Whether the numerous laminæ of old oyster-shells afford the same indication of annual growth as the rings of a forest tree is another question.

Résumé.-In concluding this chapter, I cannot do better than quote the résumé given by M. Moquin-Tandon

* Comptes Rendus, 1843, xvi. p. 460. 
of his admirable observations on the land and freshwater Mollusea of France :-

"Les Mollusques ont des ruses et des industries, des sympathies et des inimitiés, des guerres acharnées et des amours bizarres. Beaucoup sont à la fois mâle et femelle, et par suite père et mère . . . . Malgré leur apathie apparente, les Mollusques sont des êtres qui ne manquent pas d'intelligence. Leur vie privée et leur vie commune nous montrent des détails extrêmement curieux."

\section{CHA PTER III.}

SHELLS.

FORMATION. - COMPOSITION. - SHAPE. - NUCLEUS. - GROWTH. COLOUR. - DECOLLATION.-EROSION.—OPERCULUM. - EPIDERMIS.

Formation.-The shells of Mollusca are formed by a secretion from glands of the mantle or cloak. In univalves this part of the body only covers the front, and in most cases surrounds the head like a loose collar; but it is very flexible, and it can be withdrawn or folded back nearly to the top of the spire to repair a fracture of the shell in that part. In bivalves it is double, like the cover of a book.

Composition.-Carbonate of lime is the main ingredient; and the shells of Mollusca differ from the bones of vertebrate animals, as well as from the shells of crabs, sea-eggs, and birds' eggs, in the absence of phosphate of lime. In all these cases, however, the mineral ingredients are cemented together by an animal gluten. According to M. Delacroix, the shell of a Helix pomatia 
is composed of the following materials, in every 100 parts :-

Organic matter $18 \cdot 64$

Carbonate of lime $.64 \cdot 96$

Other mineral substances, undetermined $16 \cdot 40\} 81 \cdot 36$

$100 \cdot 00$

The structure of some shells is fibrous, and of others crystalline; and they differ considerably in the degree of compactness. Nearly all the secrets of this wonderful laboratory have been made known through the researches of Mr. Hatchett, Dr. Carpenter, and others; but no philosopher has been able to explain why this process of formation has continued from generation to generation in the same uniform mould, according to the nature of each species, or how the newly-born Mollusk works out, with unerring and undeviating instinct, the pattern which was originally designed by its Creator. Humboldt justly observed that there are mysteries beyond our comprehension ; and it might be good for us that some check should be put on the overweening pride of intelligence in the "audax Iäpeti genus."

Shape.-All shells assume the form of a cone. Univalves are generally spiral, so as to accommodate the folds of the body. Even the common limpet (Patella vulgata) has a distinct spire in its embryonic state, resembling that of Fissurella or Emarginula. The Chitons are in some respects abnormal, having several testaceous joints, which overlap each other, like the plates of ancient armour or the scales of a fish ; but all these joints taken together may be considered as forming a depressed cone of greater length than that of a Patella, the lines of growth on each side of the apex (which is compound in Chiton) being equally symmetrical in both cases. Bivalves offer no exception to this conical law of growth, 
the apex or nucleus of each valve being analogous to the same part in a spiral shell ; but in bivalves the deposit of shelly layers is formed on both sides, in consequence of the mantle or organ of secretion being double. Every part of the shell, whether univalve or bivalve, enlarges by growth in the same relative proportion.

Nucleus. - This part of the shell furnishes the conchologist with an important character of distinction. Odostomia, Nassa, Cerithiopsis, Ianthina, and many other genera of univalve shells have the apex of their spire differently formed. In the adult Cyprca (or Cowry), the whole of the spire, including the apex or nucleus, is covered and concealed by an extraneous deposit of shelly matter; and the same process, although to a partial extent only, takes place with regard to the genus Marginella. In many spiral shells the upper whorls (which originally formed the nucleus) are deserted by the animal, in consequence of the volume of its body having increased so rapidly that these whorls were too small to receive any part of it, and they therefore became unnecessary.

Growth.-Owing to the difficulty which exists in keeping and observing Mollusks in a state of confinement for any length of time, and especially those which live in the open sea, very little is known as to the mode and rate of their increase. Some interesting experiments on the growth of land-shells were, however, made by Mr. E. J. Lowe and communicated to the Royal Society in 1854*. The result of his observations is as follows:-1st, The shells of Helicida increase but little for a considerable period, never arriving at maturity before the animal has once become dormant (or hibernated). 2nd, Shells do not grow whilst the animal remains dormant. 3rd, The

* Proceedings, vol. vii. p. 8. 
growth of shells is very rapid when it does take place. 4th, Most species bury themselves in the ground to increase the dimensions of their shells. Helix pomatia and many other shells retreat for that purpose in summer, having their heads and the mouths of their shells downwards (this position being reversed during hibernation); $H$. rotundata burrows into decayed wood for the same purpose; while Pupa umbilicata, Clausilia nigricans ( $C$. rugosa), and Bulimus obscurus bury their heads only while the increase takes place. With regard to marine shells it may be observed that sea-water does not everywhere contain the same relative proportion of mineral and chemical ingredients, and that the admixture of fresh water has a material effect on the substance, texture, and composition of sea-shells. In estuaries, where the water is brackish, oyster-shells are smaller and thinner than usual, owing to the deficiency of calcareous salts; while the shells of oysters procured from considerable depths in the open sea and at some distance from the land are remarkably large, thick, and heavy.

Colour.-The dye by which the outer layer of shells is stained, and which often forms bands, streaks, spots, and other markings of the most beautiful and varied hues, is secreted by special glands of the mantle. Owing, however, to some defect in this organ of secretion, the colouring-matter is occasionally wanting; and nearly every kind of shell, which is usually tinted, has what is termed an "albino" or white variety. This is the case with regard both to land and marine Testacea.

The late Professor Forbes, in a paper which was published in the 'Proceedings' of the Royal Society*, entitled "Note on an indication of depth of Primæval Seas, afforded by the remains of colour in fossil Tes-

* Vol. vii. p. 21. 
tacea," observed that, "in our own seas, Testacea, taken from below 100 fathoms, even when they were individuals of species vividly striped or banded in shallower zones, were quite white or colourless; that between 60 and 80 fathoms striping and banding were rarely presented by our own shells, especially in the northern provinces; but from 50 fathoms shallow-wards, colours and patterns were well marked."

I cannot help thinking that there must have been some mistake as to the first and second of these observations. At least, my own experience induces me to form a different conclusion.

Instances of depths exceeding 100 fathoms in our seas are very rare. I only know of two. One of them is a submarine trough off the Mull of Galloway, called "Beaufort's Dyke," where the depth is 145 fathoms; and the other is a pit in the Sound or Sleat of Skye. The results of dredging in Beaufort's Dyke are recorded in the 'Annals of Natural History*'. Although shells usually inhabiting comparatively shallow water, and distinctly striped or banded (Tapes virginea and Venus ovata), were obtained alive from this remarkable depth, no deficiency of colour or markings is noticed in the account of these results. In the other case, I can state from my own knowledge that the shells were as highly coloured and the markings quite as vivid as in specimens found at a depth of 30 fathoms in another part of the Sleat of Skye. Soundings were taken with Massey's patent log, and living Testacea were brought up in the dredge from 118 fathoms. On this occasion Captain Otter was with me, and I had the benefit of his great experience in such matters. Last year I dredged for some weeks off the Shetland Isles at depths between 60 and

* Vol. x., Sept. 1842, p. 21. 
80 fathoms; and not only were live shells which I procured from those depths as brightly coloured and marked with as distinct patterns as shells of the same species (e. g. of Trochus ziziphinus), taken at low-water mark, but colourless or white varieties of such species were found in the same spots. The Star-fishes lately got by Dr. Wallich in the Arctic Sea from a depth of 1260 fathoms still retain their former colours; and, during the recent expedition of Torell and other Swedish naturalists to Spitzbergen, a portion of the sea-bottom was brought up from a depth of 1400 fathoms, when, among other animals of different types, a Crustacean of bright colours is said to have made its appearance. The extent to which light penetrates into the abysses of the ocean, as well as the mode of its transmission, does not seem to be known.

Decollation.--Some univalve Mollusca, both terrestrial and aquatic, the shells of which have a long and slowly enlarging spire, desert the first or top whorls, and get rid of them by a process called decollation or truncature. The suture, or point of junction between this part of the spire and the rest of the shell, is usually very slight; and the animal effects the process of decollation by burying itself in the earth if a land-snail, or rubbing its shell against a stone or other hard substance if a freshwater or marine species, in order to disengage itself from the empty and useless whorls. Before doing this, however, it reconstructs the top of its spire by forming a hemispherical plate of shelly matter between that part of the shell which is to be retained and the empty top. Among land-snails Bulimus decollatus is a well-known instance of this peculiarity, among freshwater snails Limncea glabra, and among the marine univalves Truncatella truncatula.

Erosion.-The outer layers of the shells of aquatic 
Mollusca, as well bivalve as univalve, are frequently excoriated or decorticated, and sometimes to a considerable depth when the shell is thick, as in Unio margaritifer, or the pearl-mussel. Several marine species, especially those of Astarte, Mytilus, and Littorina, are also affected in the same way. Various theories have been put forward to account for this erosion. In the case of freshwater shells, many naturalists have supposed that it is caused by gaseous action, some have attributed it to the attacks of Myriapodous insects, a few to excavation by the eggs of Neritina fluviatilis, MM. de Saulcy and Fischer, as well as Mr. Bland, to other Mollusca eating away the calcareous matter for the purpose of constructing and repairing their own shells, and MM. Cuigneau and Lespinasse to parasitic Confervæ and other hydrophytes. But as this phenomenon is not confined to freshwater shells, some other explanation must be sought for. It is very probable that the former class of cases may be attributable to chemical action, and especially that of sulphuretted hydrogen; but in the other, and perhaps all the cases, the effect may be produced by another cause. Mr. Grove suggests that it may be owing to the want of homogeneity in the substance of the shell, and that the slightest and almost imperceptible inequality in the surface would result in an electrolytic action of the water, which would gradually dissolve portions of the shell. Sea-water is more likely to produce this effect than fresh water, by reason of the stronger galvanic property of the former. Corrosion of metals by water or moisture may be due to the same cause. As the subject does not appear to have received much attention in a chemical point of view, I trust the following remarks, from so great an authority as Mr. Grove, will help to throw some light upon it. The shells which I submitted 
to his examination were those of Littorina litorea, or the common periwinkle.

“"March 26, 1862.

"Dear Jeffreys,-As you wish me to put on paper the suggested explanation of your difficulty, viz. why it is that substances apparently homogeneous are corroded in patches or irregular hollows, I endeavour to do so, premising that it is only theoretical and may be found not to accord with all your facts.

"If a plate of pure zinc be immersed in dilute sulphuric acid, little or no chemical action takes place; but keep in contact with the zinc another metal, say an iron nail, and the zinc is rapidly oxidated and dissolved, hydrogen being evolved from the surface of the iron. The action is most rapid at the points most proximate to the iron; so that, if the nail be laid upon the zinc, both being immersed in the liquid, the iron would seem to eat its way into the zinc. If a few iron filings be placed upon the zinc, the action will be similar, but will begin more slowly and increase as the points of iron are exposed, these latter being protected to a great extent by their being negative and coated with hydrogen. If an infinitesimal quantity of copper be dissolved in the acid, it will be precipitated in a metallic state on the negative points and make these permanent centres of action. So, if no iron be made to touch the zinc, after a time some want of absolute homogeneity is sure to determine a chemical action ; and as any trace of metal existing in the solution will by this chemical (or, rather, electrolytic) action be deposited on the negative points, or those least attacked, the action will continually increase, and, instead of being uniform, will be in patches around the negative centres. Thus a piece of common zinc of commerce which contains small portions of iron and tin will 
be corroded in pits or holes. With imperfectly conducting bodies the action is similar; at very short distances they conduct, and the action spreads or extends from a point to the surrounding points. Sometimes, instead of forming a patch, the chemical action eats its way in a dendritic form, pursuing the ramifications of either the more oxidable portion of the substances or of the more accessible negative points. The slightest superficial change will produce a corresponding corrosion : thus, if you were to breathe on a polished plate of iron and wipe away the condensed moisture from half the plate, leaving that on the other half to evaporate, the iron would subsequently rust in a different manner on the two parts. If you electrify a plate of glass having letters cut in paper on it, and subsequently expose it without the paper to hydrofluoric acid, the parts previously uncovered will be attacked; and so, if you simply allow the paper letters to remain on the glass for some time (say a day or two), and then blow them off by breathing on the glass, or by the vapour of hydrofluoric acid, the letters will be made manifest. You may easily imagine a number of other instances. The effects all proceed from a want of perfect homogeneity, either original or impressed by some very trifling circumstance, and from the fact that, points of action having once been established, the corrosion is increased by the effects it itself produces and the deposits it forms. A dentist, to cure a carious tooth, scrapes out all the diseased parts, \&c. Another cause of localized destructive agency is that of crystallization: if a plate of common earthenware has been used to contain saline solutions and is then allowed to dry and is put aside, it will effloresce in spots and a sort of vegetation will sprout up here and there, disintegrating the plate in patches. I have now in my 
laboratory a piece of earthenware, which was used merely to hold a small voltaic battery and catch the chance spillings of sulphate of zinc from the cells, which is here and there eaten out in deep pits, and in other places pockmarked with small spots. If this dish had been exposed to alternations of sea-water and air, a similar effect would have taken place; and yet there was no perceptible want of homogeneity in the dish at first.

"The tree-like corrosions between the object-lenses of old telescopes are probably due to the same causes, or one of them. The old experiments of the zinc and silver tree are instances of the same sort of action. Wet a glass plate with nitrate of silver and hold the point of a pin in it, the acid leaves the silver for the copper; but the silver is not deposited in a uniform circle, but in a beautiful arborescent form. Old wine-bottles are frequently found corroded, some in spots, others in treelike figures.

"I believe the above will help to solve the problem you are investigating; at all events, I can offer no better solution.

"Ever yours,

$$
\text { "W. R. Grove." }
$$

I may add that limestone rocks are fretted in the same way as the shells of Purpura lapillus and a stunted variety of Mytilus edulis which are found on these rocks, all having the same calcareous basis. The erosion of bivalves is greater at their beaks, where the connexion between the animal and the shell is weaker than in other parts. This is also the case with the points of univalves. The action appears to be prevented by the epidermis.

Operculum.-The horny or shelly plate ("pot-lid") by which many univalve Mollusca close the mouths of their shells is attached by a strong muscle to the back or upper surface of the foot; and it serves to protect the 
mollusk from the attacks or intrusion of other animals. It is often formed on the same plan as the spire of the shell, but it differs from the latter in being nearly always compressed instead of tubular. The only exception to this rule of which I am aware, as far as regards European Mollusca, is that of Zanclea, where the operculum is pyramidal. It has, indeed, been stated that the operculum of Adeorbis subcarinata is cellular; but the supposed operculum of this rather common shell belongs to the Foraminifera and is the Spirillina perforata of Williamson. The nistake arose from the shells and Foraminifera having been found by the late Mr. William Clark in the same parcel of dredged sand; and as the latter exactly fitted the mouths of the former, he concluded that the Foraminifera were the opercula of the shells. The original specimens are now in my collection. A few of our native Mollusca, as well land as freshwater and marine (e. g. species of Cyclostoma, Neritina, Bythinia, and Phasianella), have calcareous or shelly opercula. The opercula of other kinds are horny and usually thin. The operculum of Neritina and Jeffreysia is furnished with an excentric process, or apophysis, which enables it to fit more closely into the shell, like the bolt of a lock into the box. In most cases the operculum is spiral; but in Paludina, Pluasianella, and a few other genera it is concentric. The whorls on some of the horny opercula nearly correspond in number with those of the shell, being multispiral in Trochus and paucispiral in Littorina; but this rule is not universal. There is a difference of opinion among physiologists as to the mode in which the operculum is formed. Some consider the mantle as the organ of secretion, others the foot, while according to a few it is formed by the glands of a special organ called the operculigerous lobe. Adanson and lately Dr. Gray 
have likened the operculum to the second valve of bivalve shells; but these do not appear to be homologous organs, although equally serving to cover the body of the mollusk. Calcareous processes, which answer the purpose of opercula, occur in a genus of land snails (Clausilia), as well as in marine bivalves belonging to the genus Teredo. In the former case this process consists of a twisted plate, which is not attached to the animal, but acts like a springdoor in closing the interior of the shell; and in Teredo there are two such processes, each shaped like a spatula, and attached to the body by strong muscles. Specimens of Buccinum undatum and Fusus antiquus are sometimes bioperculate; and occasionally one of these opercula is divided into two, or even three laminæ, which are piled upon each other, so as to give the specimen the appearance of having three or four opercula. In some cases of this malformation in Buccinum undatum, the two opercula are too large to be contained within the shell, and overlap each other; but in others they are abortive and widely separate from each other. They are found in individuals of all ages; and they appear to be congenital, and not the result of accidental loss and renewal. In one instance of malformation connected with this subject, which fell under my observation, a deficiency, instead of a redundancy, of opercular formation occurred, and may have been caused by disease. A living specimen of Fusus gracilis, which I procured last year in the Shetland Isles, had no operculum or even the scar or trace of any such process. The back of the foot, where the operculum was placed in other specimens of the same kind, was merely hardened by exposure. In Buccinum Humphreysianum the operculum is very small, and only covers part of the aperture or mouth of the shell when the animal withdraws itself. In some species of the genus Mangelia 
it is entirely wanting. M. nivalis has a distinct operculum; while $M$. Ginnaniana (which belongs to the same section of this genus and is found in company with $M$. nivalis in our northern sea) has not the slightest vestige of an operculum. Exceptional instances of the same kind occur in the tropical genera Voluta, Conus, and Oliva. But a remarkable peculiarity is presented by some species of Ianthina, which are furnished in their embryonic state with perfect opercula. These processes afterwards disappear, being probably absorbed by the animal when the shell becomes too large to be thus closed. Sars, Van Beneden, and Vogt have shown that the fry of many Nudibranchs, as well as of that anomalous mollusk Elysia viridis, have Nautiliform and operculated shells. The fry of Dolium perdix, which has also an operculated shell in this stage of growth only, is so unlike the adult, that the late Professor Forbes constituted for it a new genus of another order, under the name of Macgillivrayia. The fry of a curious land mollusk (Parmacella), which partakes more of the nature of a slug than a snail, is said to be enclosed in an operculated shell. In the adult this shell becomes more rudimentary and only covers a small part of the body. This is a case of retrogressive, rather than of "progressive development."

Epidermis.-Most shells have an outer horny covering, called an "epidermis" or " periostracon," which appears to be analogous to the periosteum of bones in vertebrate animals. Its office is probably to protect the shell from the chemical action of the air or water inhabited by the mollusk. It is formed simultaneously with the shell, and probably by the same organ of secretion. It is usually glossy, and sometimes resembles a coat of varnish. In Astarte (a genus of marine bivalves) it is thick and strong. In some of the whelks and land snails it re- 
sembles the pile of cloth, and is occasionally produced into bristles or hairs; but in most cases it is very thin and only forms a delicate film. It exists also in shells which are internal, as those of Limax and Lamellaria, but not in Cyprcea or the cowry, which is constantly being lubricated by the mantle. In its nature it appears to be persistent and almost indestructible, being not unfrequently found still adhering to shells in upper tertiary strata.

\section{CHAPTER IV.}

\section{EXTERNAL RELATIONS.}

ENEMIES OF MOLLUSCA.-PARASITES.-USES TO MAN : VIZ. FOOD, MEDICINE, ORNAMENT, AND ECONOMY.-INJURIES TO MAN.STUDY OF CONCHOLOGY.-PLEASURES AND DRAWBACKS.-INCIDENTS OF THE PURSUIT.

Enemies of Mollusca.-These soft creatures are the favourite food of many animals. Man is not the only one that finds them savoury and digestible, and that hunts them down with insatiable voracity. The slowness of their movements makes them an easy prey ; and their shells afford them no protection against their larger enemies. On land, hedgehogs (and it is said the fox also), rats, thrushes, ducks and other birds, snakes, lizards, toads, zoophagous beetles and centipedes pursue them and greatly thin their numbers. An insect (the Cochleoctonus vorax) lays an egg in the body of different species of snails, which, when hatched, eats up by slow degrees the whole of its unwilling host, and then curls itself up in the spire of the empty shell, until it is turned into a chrysalis. The Mollusca which live in fresh water are devoured by wild ducks and other birds of that class, frogs, fishes, leeches, and the larvæ of the 
dragon-fly. The innumerable host of marine Mollusca afford a constant supply of food to sea-fowl of various sorts, fish (especially the cod, haddock, mullet, gurnard, halibut, and sole), crabs and other crustacea, star-fishes, sea-cucumbers, and Actinice. No less than 35,000 specimens of a small bivalve (Turtonia minuta) were estimated by Mr. Hyndman to be contained in the stomach of a single mullet which had been taken in Larne Lough. They are not even spared by their own kind. M. Deshayes fed some pet snails with chopped-up morsels of one of their companions, which appeared to be unhealthy and not likely to survive. Many instances of such cannibal propensities in the land and freshwater Mollusca will be found in this volume. Bulla lignaria is a great tyrant among the smaller marine shell-fish, and uses the strong plates of its singular gizzard to crush them. All the whelk-tribe, as well as the Natica, enfold their testaceous prey in their large feet, and drill holes in the shells, as before observed, in order to feed on their contents. The great strength of the shells possessed by some whelks does not save them from becoming victims in their turn. I have been informed by intelligent fishermen, that, if their lobster-pots (in which the Buccinum undatum is often caught) are left a few hours longer than usual, the shells of the whelks are found cracked "like nuts," having been cleared out by the lobsters and crabs while they were fellow-prisoners. Quantities of this kind of whelk are caught on the Dogger-bank as bait for the codfisheries of Iceland and Greenland. The way in which gold-fish contrive to extract the animals from freshwater shells is curious. When the shell is too large to be swallowed, the fish puts its mouth to it, and then, sucking it for some minutes, lets it go. After a while the snail recovers and withdraws itself from its shell, 
when the fish again seizes and sucks it, repeating this operation for hours and sometimes for days, until its victim is exhausted. Whether the fish kills its prey by means of any poisonous injection is a question which might be answered by some observant naturalist who not only has an aquarium but makes good use of it. In consequence of this continual and internecine warfare, an excessive increase in the number of mollusks, both on land and in water, is checked.

Parasites.-Very little appears to be known with respect to the animal and vegetable parasites which are nourished by the juices or excretions of living Mollusca. On land, several kinds of slug are infested by a small white mite (Philodromus limacum, Jenyns), which may often be seen in considerable numbers running actively over their bodies, but apparently not doing the slugs any harm, except, perhaps, in slightly lessening or interfering with their secretion of slime, on which these insects probably feed. The Rev. Leonard. Jenyns says that the most striking feature in the history of this kind of parasitic mite is "the circumstance of its not confining its abode to the external surface of the slug, but often retiring within the body of that animal-effecting its entrance by means of the lateral foramen which leads to the cavity of the lungs." And he observes, "Indeed I am inclined to think that this cavity is its principal residence, whence it only comes forth occasionally to ramble about the surface of the body. In one instance I confined in a close box a slug which, to all appearance, was free from parasites. On opening the box a day or two afterwards, I observed very many crawling about the slug externally, all of which would seem to have proceeded from the pulmonary cavity. On another occasion I observed these insects running in and out of the 
cavity at pleasure; and some which I saw retire into it never reappeared, although I watched the slug narrowly for a considerable time. It is remarkable that the slug appears to suffer no particular inconvenience from these parasites, and even allows them to run in and out of the lateral orifice without betraying the slightest symptoms of irritation." M. Barthélemy has noticed in the eggs of one kind of slug numbers of a small Nematoid worm, which he has named Ascarioides limacis. These worms are present in the egg at the moment of its being laid, having been previously deposited by the parent worm while living in the ovary of the slug. The young worms must therefore have been introduced into the egg while it was being formed. They appear to adopt the same course as the parasitic larvæ of the Ichneumon when they are deposited in the body of a grub, and to spare the vital parts of the embryo on which they feed, until the period has arrived for their own development. In fresh water, the pond-mussel (Anodonta) constantly entertains a large party of parasites, consisting of another kind of mite (Atax ypsilophora, Buntz), which are so tenacious of life, that after their host has been put into boiling water and killed they survive and crawl about as if nothing had happened to them. A kind of hair-worm (Gordius inquilinus, Miiller) attaches itself in clusters to Limnaca stagnalis and many other freshwater snails. In all probability, however, these are not true parasites, and only attach themselves to the Mollusca for the sake of the shelter afforded by their shells or mantles, obtaining their food from the water and not from the suails, because their heads are always seen outside and in active motion when the suails are crawling. Each genus, if not every species, of freshwater snail may have its own pseudoparasite. Limnca, Planorbis, Physa, Ancylus, 
and Bythinia are similarly infested; but they are of various sizes, and some of them have different habitats. In the sea, a small kind of pea-crab (Pinnoteres veterum) is frequently found inside the mantle of Cyprina Islandica, Modiola modiolus (or the great horse-mussel), and Pinna pectinata, taking up its abode in these snug quarters for parasitic purposes, and not (as was imagined by the too credulous Pliny) in order to warn the Pinna of the approach of its foes, like a faithful friend or watchdog. Professor Kölliker has lately noticed in the shells of several kinds of Mollusca, both univalve and bivalve, certain vegetable parasites, which he regards as unicellular fungi. They form minute tubes, which run straight through the pores or fibres of the shell. He thought it probable that these vegetable parasites dissolve the carbonate of lime contained in the shell by means of an acid which they may have the power of secreting. But the process by which shells are perforated by vegetable as well as animal organisms does not seem to be understood, and requires much elucidation in a chemical point of view.

Uses to Man.-(Food.) - We naturally consider ourselves (as the "lords of the creation") the sole pivot round which all other creatures turn, without much sympathy with them or regard for their wants and feelings. But the countless and complicated links of the chainwork in which all Nature is involved are so closely and wonderfully connected together, that not one of them can be broken or displaced without interfering with the economy of the whole. Much of the animal food which we consume has been nourished at the expense of other creatures, which in their turn have subsisted upon smaller organisms; and this process of destruction is repeated until the bottom of the scale of animal life has been reached. Then the varied and inexhaustible stores of 
inorganic substances are called into requisition, and these again are supplied and renewed from decayed particles of once living matter. Thus a never-ending cycle of waste and renewal takes place in accordance with the beneficent design of the Author of all things !

The principal use which the Mollusca subserve, so far as man is concerned, is to supply him, directly and indirectly, with an abundance of food. It is true that this kind of food is not so grateful to us in a civilized as in an uncivilized state ; but one of our most favourite luxuries is derived from this source, and the oyster, fortunately, inhabits those regions where civilization has attained its present height of perfection. Many other kinds of shell-fish, such as scallops and cockles, are not less wholesome than the king of the Mollusks, and are by no means to be despised; and the ormer (Haliotis tuberculata) is reckoned a delicacy in the Channel Isles, when properly cooked. The salt flavour which is so much relished by a maritime population is imparted by all the marine Mollusca. The quantity (amounting to many hundreds of tons) of whelks, mussels, and periwinkles which is every year disposed of in Billingsgate market alone is almost incredible; and there is no seaport or adjoining tract of country, especially in the manufacturing and mining districts, but has a considerable traffic carried on within it by a numerous and industrious class of itinerant dealers in such wares. On many parts of the Scotch and Irish coasts shell-fish form a considerable portion of the food of the poorer inhabitants ; and in a few of our more remote and almost inaccessible islets (such as Fair Isle and some of the Western Hebrides) positive starvation would ensue in winter, if it were not for these unfailing and easy supplies. In an indirect way, the Mollusca contribute still 
more to the sustenance of man, by supporting the innumerable shoals of cod, ling, haddock, halibut, and various other sorts of fish which abound in our seas and provide a constant livelihood for a hardy race, and through them for a great part of our population, who, both from necessity and choice, are fish-eaters. Our Continental neighbours, not being so well supplied as we are with sea-fish, do not disdain any "frutti del mare." The date-shell (Lithodomus dactylus), which is extracted with much labour from the solid rock on the coasts of the Mediterranean, is reckoned a dish fit for an emperor; and M. Récluz says of a kind of cockle (Cardium lovigatum), "Sa chair est savoureuse et prisée du gourmet."

The Romans had their oyster-beds, as well as their Cochlearia or snail-preserves; and Varro, in his 3rd Book ("De villaticis pastionibus"), describes fully the method adopted by his countrymen for improving the different breeds of oysters by crossing. The improvement of the breed of oysters, as well as their preservation, ranks in France as a science, and has received the name of "huitreculture," its professor being M. Coste. We can, but (alas!) do not, manage these things so well. Even land-snails are pressed into the service of the French, and enter rather largely into their cookery. No one can have traversed the streets of Paris, or of the larger towns in France, without seeing dishes of Helix pomatia temptingly displayed in the shops of restaurants, like kidneys and white-bait in the windows of London eating-houses. The list of eatable snails in France is very considerable and comprises some comparatively small species. "Chacun a son gout!"

(Medicine.)-In our pharmacopœia of former times a decoction of snails was much esteemed as a remedy in pulmonary complaints; and great numbers of them were 
unmercifully pounded alive for that purpose. Even in the present day snail-broth is said to be serviceable as a lenitive. In France an extract from snails, called 'Hélicine,' is used in similar cases. The spongy plate of the common cuttle (Sepia officinalis), calcined oystershells, and the Limacella of the large slug (Limax maximus), as well as "crabs'-eyes" (or the concretions of calcareous matter found in the stomach of the eatable crab), were used during the last century in the preparation of certain medicines.

(Ornament.) - When the Romans were the masters of these islands they ransacked not only our seas and estuaries for oysters (those from the Mediterranean being very scarce and inferior in quality) but also our northern rivers for pearls, which were extracted from the Unio margaritifer. This shell, with its accompanying product, is represented in the Frontispiece to the present volume. The search for native pearls continued until a comparatively modern period, when it was superseded by the successful prosecution of the true pearl-fishery in Eastern seas, the valuable and lustrous produce of which threw into the shade our comparatively worthless and dull jewel. Other species of freshwater mussel, as well as the oyster, ormer, sea-mussel, and cockle, and even the periwinkle, occasionally yield pearls, but of an unserviceable kind. It is evident, from an examination of the shells in which such excrescences are formed, that they are owing to an irregular and partial secretion by the mantle of the nacreous and lamellar substance which lines the inside of the shell. In all probability the proximate cause is some extraneous body, and not disease as was formerly supposed. In freshwater bivalves the irritating tenacity of parasitic insects and worms (Limnochares Anodontee and Distoma duplicatum), and 
in marine bivalves the attacks of perforating annelids, would be sufficient inducements for the shell-fish endeavouring to smother or keep out its assailants by secreting an extra quantity of nacreous matter. The nucleus of many pearls reveals the origin of their formation. A communication made by Signor Antonio Villa in 1860 to the Literary and Scientific Athenæum at Milan (entitled "Sull' origine delle perle"), and another by Mr. Robert Garner to the Linnean Society in December 1861 ("Note on the formation of pearls"), will well repay a perusal by those who are interested in this curious subject. The unsuccessful experiments made a century ago by Linné for the artificial production of pearls by the Unio margaritifer in the rivers of Sweden (and for which he took out a patent), and the ingenious process invented by the Chinese, of putting little josses or images of some incorrodible metal between the mantle and shell of another freshwater mussel, so as to have them coated over with several layers of pearly matter, are now well known. Great quantities of the Mytilus edulis are said to have been collected a few years ago in the estuary of the Conway, as well as in the North of Ireland, and exported on account of the Jews, for the purpose of fabricating mock pearls out of their nacreous linings.

Another testaceous article of commerce in this country for ornamental purposes is the "ormer" or ear-shell (Haliotis tuberculata), which is found abundantly in the Channel Isles. Many tons of these shells are annually gathered for the Birmingham market; and their inner coats of mother-of-pearl are sufficiently thick to make buttons and studs, or for inlaying.

Shells of various kinds are collected wholesale from the famous beach of the islet of Herm, and sent to England for fancy-work. The Romans used shells for 
ornamenting their dwellings. Gell's 'Pompeiana' (vol. i. pp. 195, 196) contains an interesting description of the celebrated "Fountain of Shells," which appears to have been decorated with the Tyrian murex and pilgrim scallop; and these shells are stated to have been " neither calcined by the heat of the eruption nor changed by the lapse of so many centuries." Cicero is said to have also used shells in decorating a fountain at his Formian villa. In our own country it was once the fashion to ornament grottos in the same way.

Among other ornamental uses may be mentioned the purple dye which is yielded by many shell-fish. The Greeks and Romans extracted it from Murex trunculus and other species which we do not possess; and the process of dyeing constituted one of their most important manufactures. An excellent article on this subject, considered in a scientific and artistic point of view, and entitled "Natural History of the Purple of the Ancients," by Professor Duthiers of Lille, will be found in the 'Proceedings of the Royal Society' for 1860*. Dr. Bizio, a distinguished chemist, has also investigated the nature and properties of these dyes; and a learned Scotch divine, the Rev. James Smith, has given, in the 'Zoologist' for 1849, a classical and elaborate disquisition on the same subject. The common dog-whelk (Purpura lapillus) of our own rocky coasts, as well as Murex erinaceus, Scalaria communis, and Ianthina communis produce the same colouring-matter, but in a smaller quantity and of a much less vivid hue; and it has never been turned to any account. More than a century ago, Borlaise, in his ' Natural History of Cornwall,' mentions "The purple-marking whelke." He says, "the juice which marks is in a separate bag, of a yellowish-

$$
\text { * Vol. x. p. } 579 .
$$


green when first drawn upon linen, grows a little ruddy afterwards, till it comes to a faint purple; when dry, and the linen washed, it is of a good purple, and rather betters by age and frequent washing." A cambric handkerchief, which I stained more than twenty years ago with the dye from the purpuriferous gland of a dog-whelk, still retains its violet hue. The pillar lip of this shell often exhibits the same tinge of colour. Nearly two centuries ago Lister tried, but in vain, to fix the purple dye which is yielded in such quantity by the Planorbis corneus, a freshwater snail.

(Economy.)-Other uses to which the shells of Mollusea are sometimes applied in this country are numerous and varied, although not very important. The valves of the great pond-mussel (Anodonta cygnea) make here, as well as in the. North of France, excellent creamskimmers. The mussels are procured by means of a long pointed stick, which is inserted between the gaping valves when the animal is feeding, and these closing on the stick allow it to be drawn up out of the water. The shell of the almond-whelk (Fusus antiquus) serves our northern fishermen for a lamp, being suspended from a nail in the wall or ceiling of their hut by a piece of string, which is fastened round the shell in a triangular fashion. The inside is filled with fish-oil, and a wick of cotton or tow is put into the canal at the extremity of the mouth. This I have seen prepared and used in the Shetland Isles; and I doubt whether any antique lamp could excel it in elegance of shape. In the palmy days of the Italian and Flemish schools, valves of a freshwater mussel (named for this reason Unio pictorum) were used by the great masters to hold their colours. Although they have been superseded by palettes for this purpose, they are sold by many artists'-colourmen in London, 
containing a preparation of gold or silver leaf for emblazoning. The valves of Pecten maximus and $P$. opercularis make an ornamental as well as a useful little dish for scalloped oysters. Ormers are used in Guernsey by farmers to frighten away small birds from the standing corn, two or three of these shells being strung together and suspended by a string from the end of a long stick, so as to make a clattering noise when moved by the wind. Among other services which the Mollusca render to man is their indicating an approach of rain or a change of temperature. Several interesting facts with respect to this hygrometrical property have been recorded by Mr. B. Thomas of Cincinnati, U.S., in Dingler's 'Polytechnisches Journal;' and as I am not aware that similar observations have been made or published in Great Britain, I venture to direct the attention of naturalists who live in the country to this curious inquiry. Mr. Thomas states that snails are more reliable than leaves as natural barometers; that, in consequence of their never drinking, all the moisture they receive is by absorption of rain, mist, or dew through the tissues of their bodies, and this they afterwards exude at regular intervals, until they obtain a fresh supply; that the colour of certain kinds of snail varies according to the quantity of moisture retained; that two days before rain is about to fall they climb trees, which they never do on other occasions; and that when they are observed to leave the herbage and get on rocks, it is a certain prognostication of wet weather. Not many years ago some wonderful stories were afloat as to the galvanic nature of snails, which it was proposed to turn to account as a medium of communication between distant friends; but this mystery has been eclipsed by that of spirit-rapping, with which the molluscan phe- 
nomenon may perhaps be classed. I have no doubt that both of these mysteries will in due time become equally obsolete and superseded by some other preternatural manifestation.

Injuries to Man.-The sum total of the mischief inflicted by the Mollusca upon Man is easily told and reckoned; and it by no means counterbalances the benefit he derives from them. At sea, the damage done to the woodwork of our piers by some kinds of shipworm (Teredo), as well as by species of an allied genus (Xylophaga), is indeed not inconsiderable ; and, before copper or yellow-metal sheathing was used for protecting the bottoms of our outward-bound vessels, these marine scourges used to be justly dreaded. The noble breakwater at Plymouth has also suffered, although not to any extent, from the excavations made in its more exposed parts by a small bivalve (Saxicava rugosa); and, on some parts of the coast, beds of clay, which served as natural barriers to ward off the action of tidal waves on our harbours, have disappeared in consequence of Pholades having chosen to take up their abode in them. On land, our molluscan foes are more troublesome than formidable. Turnips and cabbages occasionally suffer from the partiality of slugs to such succulent food; and of course we cannot help sympathizing with the gentle florist who sees her pet carnation nipped in the bud and ruined, in consequence of its having been selected by a hungry or dainty snail for its supper. But the wireworm, fly, and grub are far more formidable pests to the farmer and gardener, and no mollusk has been known to attach itself parasitically to Man; so that we may safely challenge the entomologist in favour of the comparatively harmless subjects of this inquiry. Various remedies have been proposed for preventing the ravages 
of slugs and snails in gardens. The application of lime has only a temporary effect; and it may do as much harm as good by overstimulating the chemical ingredients of some soils. An ingenious method has been proposed for protecting flowers by surrounding the bed with copper and zinc wire, the former being outermost. The wire should be laid on the ground and kept clear of dirt, or fixed in such a way that the snails and slugs must crawl over it to reach the flower-bed. In attempting to do this, they receive an electric shock, and they find the sensation so uncomfortable or unusual, that they never venture to transgress the forbidden boundary. Professor Wheatstone assures me that he has no doubt such a galvanic battery, or "slug-shocker," would answer the desired purpose.

Study of Conchology.-As Wordsworth nobly says,

........ "Know that pride,

Howe'er disguised in its own majesty,

Is littleness; that he who feels contempt

For any living thing, hath faculties

Which he has never used; that thought with him

Is in its infancy."

Besides the interest which belongs to the study of any branch of Natural History for its own sake, Conchology has other claims on our attention in consequence of its important relation to Geology. The first consideration leads us to admire (if our limited sphere of mental vision does not enable us to fully comprehend) the infinite wisdom, harmony, and variety of that wonderful scheme of creation which connects us with all our fellow-creatures in one common bond of sympathy; and it also teaches us a lesson of humility, by showing that all our physical, and perhaps even our mental, faculties are shared with us by other animals, far indeed inferior to us in organization, but equally enjoying the prescient and 
beneficent care of Him through whom "we all live and move and have our being." The second consideration discloses to us the ancient history of the globe which we inhabit; and, by reason of the durable nature of molluscous shells, which is capable of resisting the action of many forces that destroy other organisms, we can apply our knowledge of their living structure and habits to the elucidation of some of those difficult problems which are necessarily involved in the study of Geology. For this reason shells have been aptly called the "Medals of Creation;" and they are as important to this science as coins are for making us acquainted with the history of past nations. The advantages and pleasures of the fascinating pursuit of Natural history have been so often and so forcibly expatiated upon by popular writers on the subject, that I can hardly hope to add anything to promote its interest. As a branch of education, the benefit of such studies is incalculable. They impart and inculcate, in the most agreeable form, the faculty of sound reasoning, the continual exercise of memory, a love of order, habits of observation, and, above all, the necessity of truth. No one can hope to be a naturalist who is wanting in accuracy. As a source of intellectual gratification, no pursuit of any other kind can excel it. It is entitled to bear equal rank with the pleasures of "Hope," "Memory," "Imagination," and "Literature," all of which have had able poets and writers to celebrate their praises; and, although the great orator of ancient days had letters especially in his view, his admirable remarks will apply with equal force to the study and love of Natural science. After premising that such pursuits are most worthy of the dignity of a thinking being, as well as most humanizing and liberal in their tendency, he says, "Other mental 
occupations are not suited either to every time, or to every age or place: these studies, however, foster our earlier years and impart pleasure to our declining ones; they adorn our prosperity, and afford a refuge and solace in adversity; they delight us at home, but do not hinder us in the discharge of our public duties; they are our companions in the evening, abroad, and in the country *."

We are, I fear, too prone to indulge in a patriotic boast, that our naturalists are more painstaking and numerous than those of other nations; but, with regard to conchology, I must admit that we are far excelled by the French. Moquin-Tandon stands preeminent in the elucidation of the anatomy, physiology, and habits of his native land and freshwater Mollusca; and the number of his countrymen to whose works on the subject of conchology he has referred in his admirable 'Histoire Naturelle des Mollusques terrestres et fluviatiles de France' is no less than 168. Can we show any work at all equal to his as regards knowledge or labour on our own land and freshwater Mollusca, or one-half of the above number as British writers on conchology, from Lister to the present time? It is true that the marine fauna of France has not been studied with equal assiduity and success; but our superiority in this respect may be owing to the greater extent and variety of sea-coast which we possess, as well as to our habits as a maritime people, evidenced by the fleet of yachts and pleasure-boats which crowd many of our harbours. In the thinly populated and comparatively isolated region of Scandinavia, but where opportunities of marine investigation are peculiarly favourable, we find a host of able and zealous conchologists (such as Nilsson, Lovén, Sars, Hisinger, Steenstrup, Oersted, Möller, Mörch, Asbjörnsen, Malm, Torell,

\footnotetext{
* Cicero, Or. pro Arch. poet. (ed. Anth.) p. 158.
} 
and Bergh), who are not far, if at all, behind us in the race, and are worthy successors of the great Linné, Muiller, and Fabricius. Nor are the conchologists in Germany, Italy, and other parts of the European continent few or unknown, as may be seen by reference to the list of authors which is appended to this volume.

Pleasures and drawbacks. - In the pursuit of this as well as of other branches of Natural History, not the least part of our enjoyment is derived from sympathy with other naturalists, or from what may be, perhaps not inappropriately, termed "the freemasonry of the craft." In my occasional visits to the Continent, I have invariably experienced the greatest kindness from many who were only known to me by name; nor is such good-fellowship less hearty at home than it is abroad. On one occasion my hobby of snail-hunting perhaps saved me from some trouble or annoyance. In the spring of 1850 I was travelling with my wife through Lombardy, when, during a mid-day halt at Rovigo to bait the horses, I could not resist taking a walk outside the barriers, accompanied by our courier, who had been previously useful to me in assisting to collect shells. At the end of an hour or so we returned, but found at the barriergate an Austrian official who demanded our passports This was at first a poser, as I had left in the carriage at Rovigo the document which was at that time so indispensable for passing through the North of Italy. All explanations appeared to be unavailing, when the courier pulled out of his pocket a collecting-box full of live snails, and at once satisfied the smiling official by showing this proof of our innocence with the remark, "Ecco, Signore, i nostri passaporti!"

The reminiscences and association of ideas arising out of the work of collection are often very pleasant, but 
occasionally not unfraught with sadness. A specimen will in after days bring back to our minds many an incident, which else had been forgotten, of woodland and seaside rambles, of nautical adventure, of excursions in foreign lands, and (above all) the companionship of beloved but lost friends, who have, alas! left this fair world and us. The bitter drop will arise from the midst of the sweet and bubbling spring of pleasure, and give us pain even among the encircling flowers. It is still the same as when Lucretius wrote-

". . . . . coronæ, serta parantur;

Nequicquam: quoniam medio de fonte leporum

Surgit amari aliquid, quod in ipsis floribus angat."

Incidents of the pursuit.-It is not always easy to enlist fishermen in the cause of science. Most of them readily promise, but seldom keep their word; and they do not seem to comprehend how any sensible person can take an interest in such pursuits, as they regard all the products of the sea, which are not fish, as "trash." In the Shetlands, however, I have received much assistance from the long-line fishermen, who brought me all the whelks (or "buckies") which were caught sticking to the bait on the deep-sea (or "haaf") fishing-banks; and they did this regularly and for several weeks together. M. Drouet complained bitterly of the difficulty which he experienced in inducing the native fishermen at the Azores to bring him any shells, even although he offered to pay them liberally for their trouble. They told him they did not choose to alter their habits ; and one of them, after seeing the French conchologist very busy collecting some small land-shells, said to his muleteer one day in confidence, "C'est bien dommage, mais ce seigneur français est pris de là!" and, while saying this, he significantly touched his forehead. How far some persons, 
who affect to consider themselves as more enlightened than the poor fisherman, may share in his remark, I will not pretend to inquire,-although it is by no means certain that, by their so doing, they are not themselves greater objects of pity than the crazy naturalist.

A curious question may be raised as to the right of any person to collect and appropriate shells or other objects of Natural history. According to the strict interpretation of the law, all trespasses upon private lands without the consent of the occupier are unjustifiable; and it makes no difference whether the trespasser is a naturalist in pursuit of his amusement, or whether he is simply taking a walk for the sake of exercise. Fortunately for scientific research, great forbearance is almost invariably shown to naturalists by the proprietors or occupiers of land, even although the latter may take no interest in such pursuits; and the instance to the contrary, of which the gifted Hugh Miller complained, in his "Cruise of the Betsey," was probably owing to his not having exercised the common courtesy of requesting, from a sectarian opponent, permission to collect fossils on his land. I could also very well imagine that the owner of a "neat villa" might have a decided objection to his favourite fish-pond being invaded by a party of conchologists or entomologists armed with ladles or nets, especially if they considered it quite unnecessary to go through the ceremony of asking leave. In the case of manorial wastes or commons, over which the lord and his tenants have certain and well-defined rights, not extending to such things as objects of Natural history, no question of this kind is ever likely to arise; and the legal maxim, "de minimis non curat lex," would probably apply to this case. The majesty of the law would not condescend to notice such trifles as a few shells, in- 
sects, or plants. The same rule would, in all probability, hold good in the case of researches for Natural-history purposes on those parts of the sea-shore which lie between high and low-water mark, and especially if they were made exclusively in the pursuit of science and not for commercial gain. In a seigniory or honour, comprising several manors, which has an extensive frontage to the sea, on the coast of Gower in South Wales, the lord is entitled to receive small annual sums, varying from sixpence to half-a-crown, by way of acknowledgment of his rights, for the privilege of gathering cockles, mussels, lobsters, and crabs, as well as ore-weed or wrack which is used as manure in that part of the country; and distinct licenses are granted for these privileges. With respect to the vast tracts of the sea-bottom which extend beyond the low-water mark of spring tides, the right of the public to explore them with the dredge or any other device for scientific purposes has never yet been questioned. Even in France, where the garde-marine have strict orders not to allow any net or similar implement to be on board of a vessel or boat on that coast when oysters are out of season, I have found no difficulty in obtaining the requisite permission to use mydredge, and it was granted readily and with the utmost courtesy.

In a commercial point of view, British shells do not fetch high prices, compared with what is given by collectors for some exotic rarities. The late Dr. Turton stated, in his useful but unsystematic little book called 'A Conchological Dictionary of the British Islands,' that a complete collection of our native shells had been estimated to be .worth its weight in silver. This was certainly a singular mode of valuing such property, considering that many of our minute shells, which are so light that hundreds of them would scarcely balance the 
smallest weight used by apothecaries, are among our greatest treasures. As is not uncommon in such cases, beauty of form or brilliancy of colour does not always represent the same value as rarity and the consequent difficulty of acquisition. As much as $£ 8$ has been given for a single specimen of Panopaca Norvegica, which would be considered by all but conchologists as a very ugly and coarse shell. Some of our scarcer kinds of Fusus also command good prices; and it is said that the magnificent specimen of Buccinum acuminatum, which once belonged to Lord Kilcoursie and is now in our National Museum, cost the Trustees (or rather the country) no less than $£ 12$. Mr. Damon of Weymouth, as well as Mr. Rich, Mr. Sowerby, and Mr. Wright, all of Great Russell Street, London, are the principal dealers in this line; and a priced list of British shells may be had of the first-named enterprising person.

\section{CHAPTER V.}

\section{DISTRIBUTION.}

EXTENT. - ORIGIN OF BRITISH MOLLUSCA. - FOSSILS. - GULFSTREAM.

Extent.-It has long been notorious that distinct groups of Mollusca, as well as of other animals and of plants, occupy more or less extensive areas of the earth's surface. This distribution is generally more limited with regard to terrestrial kinds than to those which have an aquatic habitat. The temperature of the sea at certain depths is constantly the same everywhere, and it does not appear to be affected by that of the surface. One species 
of the marine Testacea (Saxicava arctica or rugosa) is said to be almost "cosmopolite," being diffused over all seas from Baffin's Bay to that which washes the shores of Australia. It has also a wide range of habitat in the same seas, extending from low-water mark down to a depth of 100 fathoms and upwards. The distribution of Terebratula caputserpentis is nearly as extensive in respect of area and depth of water. This is spread not only over all the European seas, but also (although under other names, viz. septentrionalis and Japonica) over a great part of the North and South Atlantic, Pacific, and Indian Oceans. In both of these instances the variation of form and sculpture is very considerable, being coincident with, and probably caused by, the extent of habitat. Philine aperta is found in every part of the seas of Europe, as well as in Simon's Bay at the Cape of Good Hope, and in the Australian seas. Saxicava, Terebratula, and Philine represent three different orders of Mollusca; and I have cited them, for that reason, as examples of the extent of what is termed "geographical distribution." The limits within which some other kinds of Mollusca occur are also very wide ; and the Gulf-stream transports to great distances pelagic or floating kinds, such as Hyaloca, Ianthina, and Spirula. But, considering all these to be exceptions, it may be assumed as a general rule, that there is no specific conformity between the marine products of the temperate and tropical regions, especially between the Mollusca which inhabit that part of the North Atlantic Ocean which confines the coasts of Europe, on the one hand, and the rest of the Atlantic Ocean, as well as the Pacific, Indian, and great Southern Oceans, on the other hand. No authenticated case has been recorded of any marine West Indian species having been found living in the European 
seas, or vice versa. The most striking difference appears to be with respect to those species called "littoral," which are more subject to climatal influence than the inhabitants of deep water. In the case of freshwater shells, the same rule and exceptions seem to prevail. The common pond-snail (Limnaca peregra) is diffused over the whole of Europe, as well as over considerable tracts of North America and Northern Asia; and it is only by calling them "representative" species and giving them other names that any pretence can be made for distinguishing certain British species of Limncea, Physa, and Pisidium from those which are brought from very distant parts of the world. This diffusion of freshwater shells has been attributed to the chance transport by birds; but I am inclined to believe that it had a different and very remote origin, and that it took place long before the present distribution of land and water. Land-shells are much more restricted in their range; and with the exception of two minute species (Helix pulchella and Cochlicopa lubrica), besides a fow other snails which have been introduced, and as it were domesticated, by Man, I am not aware of any kinds which are common to both hemispheres. In Thibet and Cashnir, indeed, many of the land-shells are said to belong to the same species as inhabit Great Britain; but these are probably the descendants of ancient immigrants during the Glacial epoch from more northern latitudes. The mode by which the Mollusca have become distributed throughout the different and remote areas in which they are now found living or in a fossil state has in all probability been the same from the time of their creation. Their natural tendency is to disperse either in search of food or from a migratory instinct; and, although the pace of a snail is proverbially slow, time and the action 
of marine currents will effect for their countless race and generations that which is denied to animals of greater locomotive powers but of less number. A small tribe of gigantic animals would be far more easily exterminated than a host of puny shell-fish. When the Mollusca have, in the course of ages, become thus spread over a certain space, their further progress is arrested by some geological convulsion or change. The land or sea-bed which they inhabited or roamed over, is either suddenly or gradually covered with water or dried up; plains are raised and converted into mountains; trees and succulent vegetation disappear; deserts become swamps, and rivers estuaries; the sea-shore sinks many fathoms deep; the climate of the land and the temperature of the sea are altered; and conditions unfavourable to molluscan life succeed. By' some of these means many species are entirely destroyed within the area which is the scene of such a convulsion or change; others are reduced in number and dwindle away; while a few of a more hardy nature survive and continue to flourish. Frequent alterations in the relative level of sea and land, accompanying the alternate elevation or depression of more or less extensive districts, will doubtless account in a great measure for the irregular distribution of some species and groups of Mollusca. But shell-fish do not "retire" or "retreat," as has been conjectured by some naturalists. Their instinctive impulse is to advance only. When aquatic mollusks suddenly and unwillingly find themselves on dry land, or snails are immersed in a sea-bath for a long time, they have no alternative but to die at their posts like brave soldiers; while their comrades are starved to death, owing to the failure of the commissariat.

With respect to the distribution of the marine Mol- 
lusca in the European seas, many theories have been from time to time advanced, each of which would divide this great area into several distinct parts, or what are called "provinces." Professor Milne-Edwards, in the 'Annales des Sciences Naturelles' for 1838, proposed the following division-1. Scandinavian, 2. Celtic, 3. Mediterranean. Mr. S. P. Woodward, in his very useful little treatise, entitled 'Manual of the Mollusca' (the last edition of which was published in 1856), considered that there are four provinces, viz. 1. Arctic, 2. Boreal, 3. Celtic, 4. Lusitanian; and these, according to this writer, were "framed upon the widest possible basis." In a posthumous work of the late Professor Edward Forbes, which was most ably continued and edited by Mr. Godwin-Austen in 1859, under the title of 'The Natural History of the European Seas,' a fifth province (the "Mediteranean") has been added to those above enumerated. The latter scheme of distribution has been recently adopted by $\mathrm{Mr}$. M'Andrew in the 'Annals of Natural History' for December 1861.

Now, although such a division into "provinces" or separate areas of distribution is very plausible, and possibly may be maintainable in the same sense as the division of Mankind into distinct races, a definite principle seems to be wanting in their construction. If we compare any one of these schemes with another, a very material discrepancy is observable as to the relative limits of the provinces. For instance (not to travel far from home), Milne-Edwards considered that the Celtic province had its southern boundary in the Straits of Gibraltar; Woodward restricted the same limit of this province to our own coasts ; while Forbes advocated its extension "from the Bay of Biscay to the Baltic Sea."

The principle of definition, as well as of construction, 
has been also left in an unsettled and unsatisfactory state. Woodward lays it down as a rule, that, "in order to constitute a distinct province, it is considered necessary that at least one-half the species should be peculiar, a rule which applies equally to plants and animals." On the other hand, M'Andrew, after admitting that a considerable portion of the species of Mollusca inhabiting any one zoological province may be found in other provinces, says, "It is not by a simple comparison of the list of species that we can determine the similarity or divergence of the fauna of separate localities, as the difference between them may consist in a few characteristic forms, which may be especially developed in each." This wide divergence of opinion as to the rule or "law" of distribution, between two such able and experienced naturalists, renders further inquiry into the facts of the case indispensable, especially when it is considered that so many of the "species" referred to by Woodward and of the "forms" (by which it is presumed genera are meant) indicated by $\mathrm{M}^{\prime}$ Andrew are questionable or still sub judice. That genera-makers may be found who will separate such forms as Trivia from Cyprcea, Erato from Marginella, and Admete from Cancellaria, cannot be helped,- - although most naturalists deprecate and disavow such trifling distinctions. But until a complete concordance has been established and recognized between all the forms, whether generic or specific, of the Mollusca which inhabit any one area, a solid and reliable foundation cannot be obtained for erecting the superstructure of distribution. No conchologist, whose mind is free from prejudice, either as regards the authority of names or of theories on the subject in question, can detect any greater difference between specimens of Mitra Gronlandica from Spitzbergen and Mitra ebenus from Naples, than he can 
between recent shells of Natica clausa from the North Cape and fossil shells of the same species from Palermo. It is an indisputable fact that whenever the Mollusca of any part of the European sea-coast have been carefully examined, the species which are there found exhibit a greater conformity than had been previously supposed with the species inhabiting more remote parts, the general area being thus widened and every portion of it brought into closer relation to the others. The former test of percentage is in that case fallacious and no longer to be depended upon. Thus we find that in Philippi's invaluable work on the Sicilian Mollusca, which was completed in 1844, 513 species of marine Testacea are described. After making a small deduction for duplicates (e. g. six out of eight species of Anomia, and some Rissoce), about 500 species may be regarded as distinct. The treatise appended to the last volume of that work contains a table of comparison between the Mollusca of the Mediterranean and those of the British seas; and in this table 127 out of the above number of 500 are set down as belonging to our fauna. This gives a rate of only about 25 per cent. The result of my own examination of the marine Testacea of another part of the Mediterranean* is very different from that of Philippiespecially when it is taken into account that my examination only occupied three or four weeks, while Philippi was engaged for many years in a continuous investigation. The total number of species which I found or examined on the Piedmontese coast in 1855 was 375 ; and of this number I identified no less than 205 as British. This gives a rate of nearly 55 per cent.; and taking

* "On the Marine Testacea of the Piedmontese Coast," Ann. \& Mag. N.H., February 1856, p. 155-188. An Italian translation by Professor Capellini has been published at Genoa. 
Philippi's number of 500 as the standard of comparison it is 41 per cent., after making some allowance on the one hand for species unnoticed by Philippi but included in my list, and on the other hand for species described by him but not observed by me, although many of the latter are unquestionably British. The discrepancy in these results is the more remarkable when it is considered that only twelve years elapsed between the publication by Philippi and myself of our respective researches. When the number and extent of similar investigations have been increased, and sufficient attention has been paid to the discrimination of species, in order to their identification with the names imposed upon them by different authors, it is highly probable that a still further correspondence will be found to exist between the Testacea of the Mediterranean and British seas than has been imperfectly indicated by me. One great difficulty in making such a concordance has arisen from the habit of merely collating the names given by authors, instead of examining and comparing the specimens described by them; and I believe that many an unsuspected link in the chain of specific identity would be detected by pursuing the latter course of investigation. It was only by mere accident, while I was lately looking over the excellent collections of French sea-shells belonging to M. Petit de la Saussaye at Paris and to Dr. Baudon at Mouy, that I recognized, among some specimens which they had received from M. Martin of Martigues, and which he had procured by dredging in a deep part of the Mediterranean off the coast of Provence, not only the Buccinum Humphreysianum of our northern sea (under the name of B. Fusiforme, Kiener), but also the Rissoa abyssicola of Forbes, which had hitherto been supposed to be exclusively confined to the Hebridean 
channel. This last was called "Rissoa scabra," although it was not the species so named and described by Philippi. Bulla Cranchii and other "northern" forms also occurred among these Mediterranean shells, but under names distinct from those which British conchologists have given to them. If we can divest our minds of the popular or received impression, that the diversity between species which inhabit the extreme northern and southern portions of the European seas is both general and wellmarked, we shall not be surprised at the discovery that many species of Mollusca which at present bear different names (such as Mitra Gronlandica and M. ebenus) are really the same or undistinguishable from each other, or that even the Astarte incrassata of the Mediterranean is only a variety of that polymorphous and northern species, A. sulcata.

The testaceous Mollusca of our own seas have been separated by Forbes and Hanley into no less than nine different types-viz. Lusitanian, South British, European, Celtic, British, Atlantic, Oceanic, Boreal, and Arctic. The limits of these so-called types have not been defined with any degree of precision; and, although the proposed division is highly ingenious, it can scarcely be considered as justified by the present state of our information on the subject. It seems to me, after a long and careful study of the question, that no more than two groups (which are apparently distinct from each other) can be recognized in a geographical point of view ; and for these I would suggest the general, but not inappropriate, names of "Northern" or NorthEuropean, and "Southern" or South-European. It is extremely difficult to fix the limits of even these comparatively wide areas of distribution; but the "facies" of each group is manifest to some extent in the lit- 
toral or shallow-water species, and especially in such conspicuous and striking forms as those of Trichotropis and Necera in our northern seas and Haliotis and Galeomma on our southern coast. Taking the wider basis of the European seas, I am not aware that any species of Conus or Ringicula is found living in the North, or that any species of Margarita or Lacuna inhabits the South. It is, however, not unlikely that when the sphere of our observation has been enlarged, and a complete concordance obtained between the species of Testacea from different parts of Europe, the exceptions from a general distribution will become fewer and at last disappear, and perhaps that only one common area may be hereafter recognized. The distribution which at present exists must be referred to a past state of things. There can be no doubt that the area of diffusion was formerly much more extensive than it is at present, and that it has been restricted by subsequent causes.

Reverting, however, to the proposed scheme of distribution by Forbes and Hanley, as well as to the suggestion now advanced by me, our marine Testacea may be classed as follows :-

1. Northern ;

2. Southern ;

3. Oceanic, or occasional visitants.

The first of these divisions corresponds with the "Arctic" and "Boreal" types of Forbes and Hanley, and the second to their "Atlantic" and "Lusitanian" types. Their "South British," "European," "Celtic," and "British" types indicate mixed or neutral ground, and partake both of northern and southern characters. The third division answers to their "oceanic" type, but it can hardly be regarded as indigenous to the British seas, 
The same basis of classification may be adopted for our land and freshwater shells. These have been separated by Forbes and Hanley into only three types, viz. North European, Central European, and South European. The third division of the foregoing category (viz. Oceanic) is of course inapplicable to this group; but in other respects the principles which regulate their distribution are nearly the same as in the case of their marine analogues. The difference of aspect between these and marine species, so far as regards their distribution, is very noticeable, although, in this point of view, many of the land and freshwater shells exhibit a greater resemblance to littoral species than to those which inhabit deeper water, by reason of their external conditions. Temperature or climate is one of the principal agents in regulating the diffusion of land and freshwater Mollusca; and their limits are often sharply defined by a strait of the sea or a mountain range. Some conspicuous land-shells (as Helix fruticum and H. incarnata) live in the North of France, although they have never been found in this country unless in a subfossil state and as the relics of a past state of things. Some of our common snails do not pass the Grampian Hills. In Zetland the Helix aspersa is a total stranger, fortunately for the poor gardens of the natives; and only a scanty remnant of the tribe have succeeded in crossing the Pentland Firth or maintaining their existence in these barren isles. Freshwater shells are not so restricted in their distribution, although one of our native species (Limncea involuta) has hitherto been discovered in only one locality-assuming that this species is distinct from L. glutinosa, which does not appear to have been found in the same district. A table of distribution of the land and freshwater shells which inhabit the British 
Isles, with reference to other countries and to our upper tertiary deposits, will be subjoined to this volume; and I propose to give in the succeeding volumes similar tables to show also the distribution of our marine Testacea.

Origin of British Mollusca.-As regards the "history" or proximate origin of the British Mollusca, I fully agree with Forbes and Hanley, who stated in the Introduction to their work (vol. i. p. xxxv), that "the true source of our Molluscan fauna was first manifested by the assemblage of Testacea preserved in the deposit called Coralline Crag," although my investigation of the Crag shells has not led me to form the same conclusion that they did, viz. that most of these ancestors of our living shell-fish are "of those forms which we regard as Southern types."

The opportunities afforded by a study of the Crag strata are far superior to any, that we at present possess, for the investigation of our marine Mollusca. We can explore the ancient sea-bottom for many miles on dry land, and as leisurely as if the bed of the present ocean were uncovered and laid dry by some violent convulsion of nature; and this examination can be extended not only superficially, but also by making sections of the bed to a depth of thirty feet, so as to have the whole of its contents exposed to view. In attempting a similar exploration of the present sea-bottom, we are only able, at considerable expense, with some personal discomfort, and in such weather as we too frequently meet with in this climate, to scrape up with the dredge a few bagfuls of sand or mud mixed with shells; nor can we hope to examine in this way more than a very few inches in depth. Many deep-burrowing shell-fish altogether escape our observation, or are only procured by chance.

In order to ascertain the exact nature of the relations 
which exist between this ancient Molluscan fauna and that which at present inhabits our seas and coasts, I have not only examined the Crag strata in company with Mr. Prestwich, whose experience in this important branch of geological science is so well known, but I have also carefully gone over the extensive collection of Crag shells made by Mr. Searles Wood and presented by him to the British Museum. In pursuing the latter examination, I compared the collection with the valuable and elaborate work of Mr. Wood, published by the Palæontographical Society, in which the specimens were described and figured, as well as with Mr. Davidson's memoir on the Tertiary Brachiopoda in the same series of publications; and I afterwards collated the result of this examination with a great many books and special treatises on the recent conchology of Europe and the Arctic regions. I likewise derived no small assistance in the investigation from the opportunity I had of consulting the large collection of recent shells in our National Museum, and for which I wonld here return my best thanks to Dr. Baird, the courteous and able Curator of this department. This examination has satisfied me that, out of 286 species of marine shells belonging to the Coralline Crag formation, no less than 167 are identical with those which still live in the British seas. Of the remaining 119 species, 7 are said to be exclusively Northern, and 19 Southern forms, while 93 appear to be extinct or are as yet unascertained to be existing. This gives a proportion of very nearly 60 per cent. for those marine species of the Coralline Crag which at present inhabit our seas. Out of the 167 species which I have recognised as British, 27 have been described or recorded by different authors as Northern, and only 24 as Southern forms,-taking the Arctic circle as the 
southern limit of the one, and the Bay of Biscay as the northern limit of the other area. The greater part are common to the North and South. In considering the Crag Mollusca, the percentage of existing or recent species would be very much larger if we were to include the Red Crag and the Mammaliferous or Norwich beds, and especially if we were to add the pleistocene or postpliocene strata which immediately overlie those bedsin fact the whole of our upper tertiaries. It is highly probable that all the Mollusca which lived during the periods represented by the newer strata still survive in some part or other of those vast tracts of sea-bed which lie between the North Pole and the Pillars of Hercules. The discovery which is continually being made of missing links, as well as the increase of experience which results from a more extensive and perfect knowledge of the Mollusca, must tend to alter the rate of percentage as between recent and fossil forms. I am aware that the late Professor D'Orbigny (in his 'Paléontologie Française'), Professor Agassiz (in his 'Essay on Classification'), as well as Hall, Pictet, and others, have contended that there is no specific identity between any of the Tertiary and recent Mollusca; but the peculiar views which some of those naturalists entertained and advocated, as to the successive creation of species, may have influenced their judgment. At all events he must be a bold speciesmaker who can pretend to distinguish Crag specimens of the common European cowry, and of many other species, from those which now live in the adjacent seas; and their varieties and monstrosities also, both in a fossil and recent state, coincide in the most minute particulars, the only difference being that the latter are glossy and comparatively transparent, while the former are dull and opaque. Even the Lingula of the Wenlock Silurians could not be 
distinguished by Mr. Davidson (who has especially and so thoroughly studied the fossil Brachiopoda) from a living species (L. anatina) by any characters which he could recognize as constituting a valid specific difference.

These considerations, however, involve the difficult question of the origin of species; and I will not pursue them further, except by suggesting the very great probability that all existing species have descended by modification from primeval forms, but at the same time not admitting the hypothesis of Mr. Darwin that such forms were very few or perhaps unique. In those strata which contain our earliest records of the world's history, as great a diversity of form is exhibited in the groups which we call genera and species as in the existing fauna; and it seems evident that the plan of the Creator, so far as we can comprehend it, has not been that of progressive development.

Nor will I here venture to touch upon the equally abstruse, and more speculative, hypothesis as to the radiation of species from several centres of creation.

But I am digressing. For the reasons above stated with regard to the connexion between the Coralline Crag and British shells, I am inclined to regard this formation as the starting-point, and as it were the cradle of our molluscan race. The fauna of Europe, Northern Asia, the Cis-Atlantic zone of Africa, and a great part of North America appears to have been closely related at a comparatively recent epoch, and to constitute only one area of origin. Many species of Mollusca once existed at both extremities of this vast district. Mya truncata, Cyprina Islandica, and Buccinum undatum live in the Aretic and North Atlantic as well as in our own seas, and their remains or shells are found in Sicily. Cancellaria costellifera occurs in 
our Coralline Crag beds; and it survives in the North Atlantic under the name of $C$. Couthouyi. The Cardita senilis of the same beds is the $C$. sulcata of the Mediterranean; and the Crag $C$. scalaris is the $C$. borealis of Conrad and inhabits the coast of Massachusetts and the Arctic Sea. Many other instances of a similar kind might be given. Some species appear to be more hardy than others and have consequently resisted considerable, and perhaps frequent, changes of temperature or climate. Littoral or shallow-water species are of course the most liable to be exterminated or affected by such changes, and the instances above given are of that kind. Many of the Thibetan and Algerian land-shells belong to European species; and thus the chain of relationship to which I have referred is complete.

Our upper Tertiary fossils offer tolerable evidence that the climate of this country was, previously to or at the time of their being deposited, of a Glacial or Arctic character, as will be seen by referring to the table of distribution of our land and freshwater Mollusca at the end of this volume. Nearly all the land-shells which occur in the pleistocene strata, but are not now living in Great Britain (e. g. Helix fruticum, H. incarnata, and H. ruderata), are decidedly Northern species, inhabiting Finland and Scandinavia; and even the Alpine variety of $H$. arbustorum appears to be the only form of that species which has been found in our Tertiaries. Among the freshwater shells in this same formation, Corbicula (or Cyrena) fluminalis presents, however, an apparent but remarkable exception from the above indication of our ancient climate having been so severe, if the habits of that species have not undergone any change. The Corbicula is only known to live at present in Asia. But it may be observed that a common European freshwater 
shell (Physa acuta) inhabits the West Indies, and that such Mollusca seem to have a greater aptitude for diffusion, or a greater capability of enduring different climates, than land Mollusca, being (as some naturalists would call it) more "mundane."

Fossils.-It is sometimes very difficult, if not impossible, to distinguish what are called "fossil" from "recent" shells of marine species, if they are "dead" or found in an empty state. When the shells in question belong to species which are not known to inhabit the locality where they occur, this difficulty may give rise to some interesting questions. In most cases, the nature of these shells is manifest from their dull appearance and greater opacity, contrasted with fresh shells of the same species; and it does not require much experience to determine whether single valves of Pecten Islandicus, which are not unfrequently taken at comparatively great depths in our northern seas, are fossil or recent, although they occasionally retain their coloured markings. This species is abundant in the Arctic regions, and during the Glacial epoch appears to have been diffused over a large tract of the European sea-bed; but I am not aware that it is now found in a living state south of the Bohuslän district of the Swedish coast. But a perplexing case has occurred with respect to some shells which were taken by the dredge in the Irish Sea off the coast of Antrim. The locality is a submarine deposit called the "Turbot bank," lying about five miles south of Larne and having a depth of about 20 fathoms at low water. This bank was repeatedly and diligently explored during several successive years by $\mathrm{Mr}$. Waller, $\mathrm{Mr}$. Hyndman, and other naturalists ; and I had the advantage of not only examining the produce of their labours, but of taking part in an expedition which was made in the 
autumn of 1859 for the express purpose of endeavouring to ascertain the nature of this submarine deposit. The result of these researches was recorded by Mr. Hyndman in the 'Reports of the British Association' for 1857 and 1858 ; and some observations on the same subject by Mr. Waller will be found in the 'Journal of the Royal Dublin Society' for 1858 (vol. ii. p. 29-34), as well as by myself in the 'Annals and Magazine of Natural History' for August 1858 and February and September 1859. The association or collection in the same spot of forms which have been usually regarded as Northern and Southern is one of the most peculiar features of this inquiry. Columbella Holböllii, Scalaria (?) Eschrichti, Natica clausa, Margarita cinerea, and Trophon Scalariformis (all of which are decidedly "Arctic" species), Cranic anomala, Trichotropis borealis, and Puncturella Noachina (which were regarded by Forbes and Hanley as "boreal" types), Terebratula caputserpentis, Lima subauriculata, and Fissurella reticulata (being, according to the same authors, "Atlantic"), Argiope cistellula, Trochus Montagui, and Pecten tigrinus ("British"), Astarte sulcata, Buccinum undatum, and Venus Casina ("Celtic"), Artemis lincta, Corbula nucleus, and Trochus cinerarius ("European "), together with Rissoa striatula ("Lusitanian"), all of them in the same fresh and apparently recent condition and (with the exception of those included in the first and last categories) in a living state, were congregated together in this locality, as if on purpose to refute certain theories of geographical distribution. With respect to those species which were not taken there in a living state, it was surmised that they were fossil, or had been carried to the spot by marine currents. Some of the specimens in question I submitted to Dr. Carpenter, whose researches on the microscopical structure of mol- 
luscous shells entitle his opinion to the greatest possible weight; and he professed that he was unable to detect any apparent difference between the texture of these specimens and of others (which were unquestionably recent) belonging to the same species and placed with them for the sake of comparison. No chemical or other test seems to be known, by which the texture of shells called fossil, and certainly of very remote antiquity, can be distinguished from that of recent shells. The gloss and the greater or less transparency of the latter, contrasted with the dull aspect and opacity of the former, afford the only criteria of distinction; but it is not known how far the continued submersion of shells for many ages in the sea, where they are placed beyond the reach of atmospheric influence, may have prevented any change in their external appearance. The shells of Mollusca would seem to be nearly indestructible by the ordinary action of air and water, and especially when their structure is crystalline and compact. The term " recent" is, of course, comparative in point of time. But a few of the shells from the Turbot bank, belonging as well to some of the species in question as to other species which are undoubtedly indigenous and exist there in a living state, have every sign of being fossil, and are precisely similar in appearance to the shells which are found in the Clyde and other beds of a pleistocene formation. Some of these beds occur in the neighbourhood of the Turbot bank, and contain Yoldia lanceolata, Leda pygmaea, Hypothyris psittacea, and other shells of a decidedly Arctic character ; but only one of these species (viz. Leda pygmска) has been observed in the Turbot-bank dredgings, and of this species Mr. Waller found a living specimen. Columbella Holböllii, Scalaria (?) Eschrichti, and Margarita cinerea (being three out of the five Arctic species 
which have been taken on the bank) have not, so far as I am aware, ever been detected in any of our Tertiary strata. The two other Arctic species (Natica clausa and Trophon Scalariformis) inhabit the upper coasts of Norway, as well as more northern seas. The first-named species has a range, according to $M^{6}$ Andrew and Barrett, from the shore to $\mathbf{1 5 0}$ fathoms. It occurs in the Red Crag, as well as in almost every pleistocene bed which has been examined in this country; and I noticed it in the collection of Dr. Van Geuns at Utrecht, among some shells which he had found in the Subapennine deposit of Palermo. This species is not included in Philippi's list of Sicilian fossils. The distribution of the other species appears to have been equally extensive; and I have a fresh specimen, recently inhabited by a hermit crab, which was dredged from deep water off the Aberdeen coast and obligingly presented to me by the late Professor Macgillivray. It is quite possible that a pleistocene bed may have formerly existed in the spot which is now occupied by the Turbot bank, and that the contents of this bed may, by the action of the tide or marine currents, have become mixed up with the existing products of the adjacent sea-bed; and the appearance of some of the shells to which I have referred might warrant such a conclusion. But, inasmuch as many relics of the Glacial epoch, such as Leda pygmoea and Arca raridentata, still survive in a few and widely separated parts of that extensive area which was once subject to Aretic conditions, it will not be surprising if all the species I have thus mentioned as doubtful inhabitants of our seas should also have lingered on in their old quarters and be really British. The conjecture that these shells may have been accidentally transported by submarine currents from the Arctic Sea to the Irish 
coast does not rest upon any foundation. I was satisfied, by information which I obtained on the spot and in the course of my dredging-operations, that no submarine current sets in that direction, nor any which could have brought the shells from a distance; and the same conviction is entertained by the able and zealous naturalists who have so carefully and during several years in succession explored many square leagues of this remarkable sea-bed.

Gulf-stream.-This "deus ex machinâ" seems always to be called into requisition, in order to explain any apparent anomaly in the distribution of marine Mollusca. In the minds of many persons it ranks with the comet in its mysterious effects. It is quite true that the scientific world, and indeed all who take any interest in the works of Nature, are under the greatest obligations to Commodore Maury for the lucid account he has given, in his 'Physical Geography of the Sea,' of this really wonderful phenomenon. But with regard to the subject of the present inquiry, I cannot help expressing a doubt whether the effects of this great "river in the ocean" have not been much overrated.

The partial glimpse which we have hitherto been able to obtain of the results from the recent expedition of Otto Torell and other Swedish naturalists to Spitzbergen shows that the Gulf-stream was found not to exert any influence on animal life in that region, it appearing to be entirely of a glacial nature*. From careful inquiries which I made in several parts of the eastern coast of Zetland last year, I was satisfied that the Gulf-

* While this last sheet is passing through the press (22 May, 1862), Professor Förchhammer has read before the Royal Society a valuable paper on the composition and density of sea-water. His observations as to the Gulf-stream tend to show that it cannot affect the distribution of animal life in the lower zones of the sea. 
stream does not set upon any part of that coast. All the driftwood that was washed ashore was of Norway fir, and came from the opposite coast. Dr. Lukis informs me that the Gulf-stream has now been ascertained not to impinge on any part of the Channel Isles, although the Sargasso weed and the seeds of tropical plants are occasionally thrown up on those shores, after having been deflected and drifted by marine currents. Much evidently remains to be done in defining its exact course in northern latitudes, and in making accurate observations as to its influence on the fauna and flora, as well as on the temperature, of different parts of Europe.

\section{CHAPTER VI.}

HABITAT.

STATIONS.-ZONES. - ABUNDANCE OF MOLLUSCAN LIFE.-GEOLOGICAL RELATIONS.-CHANNEL ISLES.-EXOTIC AND SPURIOUS SPECIES.SEA-SIDE SKETCH.

Stations.-The subject of this chapter is closely connected with that of the last; but it seems more convenient to divide it. Having considered the British Mollusca with reference to their European and general distribution, I now propose to give a short account of their native habitats and to take a home view of the matter.

The Mollusca may be divided into land, freshwater, and marine. Their respiratory organization mainly results from the nature of their habitat, or, as botanists would term it, their "station." All land-snails breathe the free 
air, by means of lung-like cavities or pouches which they possess. Some kinds of fresh-water snails have a similar apparatus; but they are also enabled to extract occasional supplies of oxygen from the water, and are thus not entirely dependent on their air-pouches. Others of this kind are furnished only with gills, which they use like fishes. In the genus Valvata the gill is external and shaped like a feather; and the animal has also an auxiliary branchial organ, which resembles another tentacle. The respiratory system of the marine Mollusca, with the exception of a very few littoral species, is branchial; and in some kinds the gills are external. Bivalves have usually two leaf-like gills, which are arranged symmetrically, one on each side of the body. In the Brachiopoda, however, the brachial organs (according to Mr. Hancock) subserve the function of gills, although in one genus (Lingula) the lobes of the mantle may, to a certain extent, be considered specialized breathingorgans.

There are some peculiarities with respect to habitat that are interesting to geologists. Some kinds of freshwater univalves, both those called Pulmonobranch (i.e. respiring by means of lung-like pouches), and Pectinibranch (i.e. respiring by means of comb-like gills), have the faculty of enduring a partial change or difference in their usual habitat, which would be fatal to other kinds. The Swedish naturalist Nilsson relates that two species of Limnaca described by him, as well as Neritina fluviatilis, live in the Baltic, adhering to sea-weeds, and sometimes at a distance from the mouth of any river. With these live certain marine Mollusca, such as the common mussel and cockle, Mya arenaria and Tellina Balthica (or soli$d u l a$ ), all of which, however, are of a dwarf size. Lim noea is Pulmonobranch, and Neritina is Pectinibranch. 
The same peculiarity, but not of so permanent a character, has been observed in the case of a freshwater bivalve. The common pond-mussel (Anodonta cygnea) is said to live in the river Trent at Bottesford in Lincolnshire, which is salt at high water. The fresh water, being lighter, forms the upper stratum; while the seawater covers the bed of the river inhabited by the Anodonta. A small Pectinibranch univalve (Hydrobia ulvce) inhabits indifferently salt and brackish water; another (H. ventrosa) frequents only the latter; while a third (H. similis) lives, in company with Bythinia tentaculata and other freshwater univalves, in water which is nearly fresh. The usual habitat of the genus Melampus (which is Pulmonobranch) is the sea-shore; but one species occurs high up in estuaries, where the water is more fresh than salt. M. Marcel de Serres is of opinion that the habitat of Dreissena polymorpha (a kind of mussel which abounds in many of our rivers and canals) was originally marine, from the circumstance of the shells being found in tertiary strata of marine formation. The Russian traveller, Pallas, who first discovered or made known this species, described one variety of it as marine and the other as inhabiting fresh water. Many of the marine Mollusca which live on the sea-shore (some of them even beyond the reach of the tide) pass the greater part of their time out of water; and the same remark applies to some freshwater snails, such as Limnoca peregra and Ancylus fluviatilis, which are as often found on dry land as in their natural element. Succinea putris (a land-snail) appears to be almost amphibious. Many genera of bivalve Mollusca contain certain species which are marine and others which have a freshwater habitat. Even Teredo, Pholas, and Arca are in this category. The smaller Crustaceans seem also to be very indifferent to the 
nature of their habitat in this respect. Mr. Spence Bate, who has so diligently and successfully studied our native shrimps, informs me that Gammarus locusta, which only inhabits the sea, is scarcely distinguishable from $G$. $f u$ viatilis, which would be instantly killed by being put into salt water. Professor Lilljeborg has discovered in some of the inland freshwater lakes of Denmark several Arctic species of marine Crustacea, which appear to have survived the Glacial epoch, and to have adopted from necessity a new habitat, in consequence of the gradual elevation of the land. And the result of the researches made by Dr. E. von Martens on the occurrence of marine animal forms in fresh water, which was published in 'Wiegmann's Archiv' for 1857, shows that 10 out of 44 divisions or groups of Crustacea, and 6 out of 52 divisions of Mollusca, are common to the sea and fresh water. Fish have no less than 23 out of 55 divisions similarly circumstanced as to habitat; but some of these are well known to migrate annually from the sea to rivers that flow into it, for the purpose of depositing their spawn. Such peculiarities of habitat form one of the stumblingblocks of geology; and it is fortunate that the cultivators of this science are not obliged to place their sole reliance on the palæontological contents of the strata which they wish to investigate, as they have also the mineral composition, as well as the relative juxtaposition, of those strata to guide them in the investigation.

Zones.-It had long been known that different parts of the sea-bed were inhabited by special forms of animal life; but Risso, the celebrated naturalist of Nice, was the first who proposed its distribution into zones of depth. His theory was derived from observations on the Mediterranean fishes. The late Professor Edward Forbes added much to our knowledge of such distribution; and 
his valuable researches on the Invertebrata of the Egean and our own Seas enabled him to define these zones with considerable precision. Professors Lovén and Sars, as well as Oersted, have made us acquainted with the range and limits of marine life in the Scandinavian seas.

In framing any scheme for dividing the sea-bed into separate areas of molluscan habitability, according to their depth, it must be borne in mind that the extent and produce of these areas vary greatly, and depend upon the inclination and mineral nature of the coast. That part of our sea-bed which is circumscribed by the line of soundings may be divided into four distinct areas or zones, of different width and depth ; and I will endeavour to define briefly their limits, nature, and contents.

The first is the LitToral zone, or the shore, which fringes every part of our coast and lies between tidemarks, being laid bare when the tide retires. Wherever the coast is steep and rocky, this zone is very narrow. Where it shelves gradually and is sandy (each of these conditions being probably consequent on the other), the strand frequently extends seaward for a mile or even further. Where it is composed of cliffs, such as chalk or boulder-clay, the beach is pebbly, and its width is usually intermediate between that of the two other cases I have mentioned. The pebbles are derived from the wearing-away of the cliffs, either in the course of their original elevation above the sea-level (which in many cases appears to have been slow and gradual), or else by the combined action of the atmosphere, rain and frost, or of the tide and waves. This pebbly beach is sometimes succeeded by a belt of larger stones or boulders, and that again by a strip of sand, mud, or clay, as we advance to meet the tide. In each of these cases the nature of 
the shore, strand, or beach depends on the composition of the strata which form that part of the land which is opposed to the sea. The rocks lying between tidemarks are elothed with seaweed, which supports a numerous and peculiar group of Mollusea. Among those on our own coasts may be enumerated various species of Littorina (or periwinkle), Lacuna, Trochus, Rissoa, Chiton, Patella (or limpet), Purpura lapillus (or dogs'-whelk), and a stunted variety or form of the common mussel. In the small rock-pools, which are left by the receding tide, and are generally lined with Corallina officinalis and other small seaweeds, as well as under loose stones, will be found many small shells of various sorts, including Poronia rubra, Modiola discors, Skenea planorbis, Rissoa parta, Cerithium reticulatum, and the fry of other species. The highest part of this zone, which the sea does not cover for more than two or three hours out of every twelve, is inhabited by two kinds of Melampus (M. bidentatus and a variety of M. myosotis), Otina otis, Assiminia littorea, Truncatella truncatula, a variety of the common limpet, Littorina Neritoides, and some of the numerous varieties of $L$. rudis. The first three of the above species are Pulmonobranch. That part of the littoral zone which consists of sand, gravel, or mud is frequented by various genera of bivalve Mollusea, such as Mya, Solen, Tellina, Donax, Mactra and Tapes, as well as by Mytilus edulis. Within this zone submarine peat, chalk, and trias or new red sandstone, harbour several kinds of Pholas; Serobicularia piperata burrows into clay; calcareous rocks are perforated by Saxicava rugosa; and fixed wood is drilled in every direction by the destructive Teredines or shipworms. Wherever a river or stream empties itself into the sea, a strong reflux is caused by the advancing tide, 
which has the effect of casting on the shore a collection of spolia marina, dislodged by the ground-swell from considerable depths, as well as of many land and freshwater shells, which have been washed down by the river or stream and thus become mixed with those from the sea. This phenomenon frequently occurs in some of our upper tertiary and more recent deposits, and shows the regularity with which such physical operations have been repeated during periods of the duration of which we can form no conception. In the same zone are also comprised estuaries, which form deep but narrow indentations of the sea-coast, and are the channels, as well as the outlet, of tidal rivers. The water of these estuaries is always more or less brackish. They are inhabited by peculiar Mollusca, viz. Assiminia Grayana, Melampus myosotis, and the several species of Hydrobia above mentioned. The few pelagic mollusks which occasionally, but unwillingly, visit our seas, are also met with in the littoral zone, being cast on shore generally after a continuance of westerly gales. These consist of species of Ianthina, Spirula Peronii, and a few Pteropods, some of which have but a doubtful claim to be considered indigenous productions of our seas. The present zone has been subdivided by Forbes and Hanley into four intermediate lines or strips, each of which is said to be inhabited by its own peculiar set of Mollusca; but the great variety exhibited by our seaboard, as well as its geological formation, seems scarcely to warrant such a subdivision. For instance, Trochus umbilicatus and T. lineatus, which are assigned by these authors to the fourth or lowermost line, in which they usually occur on our western and south-western coasts, inhabit the second line on the shores of the Bristol Channel, as well as those of the north-west of Ireland. 
The second zone is called the Laminarian, from the belt of that kind of seaweed which girds all the rocky parts of our coast-line. It is seldom laid bare, except at very low spring-tides; and it is generally much narrower than the littoral zone, in consequence of the rocks, to which the Laminaria or tangle is attached, dipping seaward and being covered with sand beyond the direct and more immediate influence of the tide. This zone may be said to extend from low-water mark to 10 fathoms. The mollusca which inhabit it chiefly belong to Patella, Acmoca, Trochus, Lacuna, Rissoa, and Jeffreysia, all of which are phytophagous or vegetable-eaters, as well as the Nudibranchs or sea-slugs, which are mostly zoophagous. Where the coast is sandy, this zone is entirely wanting and is merged into the one above or below it, so far as regards its zoological contents. The extent of each zone mainly depends on its capability as a feedingground; and the same species are frequently common to every zone, when their nature is alike and they are not prevented by an intervening barrier of sand or rock from spreading from one zone to another. To this cause is probably owing the great variation in the depth to which many species attain. The common mussel, which is usually found within tide-marks, has been recorded by Dr. Walker as living in the North Sea at a depth of 140 fathoms or 840 feet. Cyprina Islandica, which in most seas inhabits depths of from 30 to 140 fathoms, occurs on the coast of South Wales at low-water mark; and our little cowry (Cyprca Europcea) has a range from low-water mark to 100 fathoms.

The third zone has received the name of "Coralline," from the quantity of nullipore (Melobesia polymorpha), which is a stony coral-like plant, and in many places covers large tracts of the sea-bed. Its width varies con- 
siderably; but its vertical range may be stated as extending from 10 to 50 fathoms. As a general rule, rocks do not occur in this zone, especially in the deeper part of it-stones, gravel and sand (sometimes mixed with mud) being its chief characteristics. These mineral conditions to some extent regulate the nature of the Mollusca which are here found. The whelk-tribe, as well as many Nudibranchs, frequent the stony or, as it is called, "hard" ground ; and different sorts of bivalves take up their quarters in the other, or "soft," ground. Seaweeds are scarce in this zone and are generally absent from its lower regions ; so that most of the Mollusca which inhabit it are animal-eaters,--some being sarcophagous, others zoophagous, and many of them preying on each other.

The fourth and last is called the DeEP-SEA zone, and reaches from 50 fathoms to the greatest depth comprised within the line of soundings. Both this and the lastmentioned zone contain our most productive fishingbanks; and the floor of these submarine areas is exceedingly uneven, and diversified by many an unseen hill and dale. The deep-sea zone appears to have nearly always a soft bottom, consisting of a much finer sediment than that which covers the bed of the coralline zone. The only vegetable organisms which are found in it are tiny and almost microscopic Diatoms. It is inhabited by various kinds of Mollusca, all of which are, probably from necessity, animal-eaters. They appear to exceed in number, as well as in variety, the inhabitants of any of the other zones, judging from the scanty opportunities which occur for investigating the contents of this extensive sea-bed. The point of zero in the scale of submarine life has not yet been, and perhaps never will be, found. 
Abundance of Molluscan life.-The whole surface of our globe teems with a mass of animal and vegetable life, to which the Mollusca contribute by no means an inconsiderable quota. Owing to the solid and permanent nature of their shells, many fossiliferous strata are almost entirely composed of such exuviæ; and this process of accumulation is still going on in the existing sea-bed to an enormous extent. No one can have had any experience in exploring the bottom of our own seas, and examining our tertiary strata, without noticing how closely the contents of a well-filled dredge, taken from a submarine shell-bank, resemble the same quantity of material dug out of a crag-pit; and perhaps nothing can give a more striking idea of the incalculable lapse of time which must have taken place in the history of the world, than the formation of these strata which, after all, are only a few pages of the great book. We here see layer upon layer of organic remains heaped up and compressed, to a depth of thirty feet, each layer being only a few inches deep, but representing numerous and successive generations that have long passed away.

It has not yet been ascertained to what depths molluscan life extends. The late Sir James Clark Ross, in the interesting account of his Antarctic Voyage (vol. i. p. 202), says, "I have no doubt that, from however great a depth we may be enabled to bring up the mud and stones of the bed of the ocean, we shall find them teeming with animal life; the extreme pressure at the greatest depth does not appear to affect these creatures. Hitherto we have not been able to determine this point beyond a thousand fathoms; but from that depth shellfish have been brought up with the mud." Still greater depths have been lately reached in recovering the Me- 
diterranean telegraph-cable, and with the same results; and the forthcoming work of Dr. Wallich on "The North-Atlantic Sea-bed" will doubtless contain some important observations on the existence and forms of animal life at extreme depths in the Arctic Sea.

Although it does not come strictly within the scope of the present treatise, I cannot help contrasting the fecundity of the sea with the comparative sterility of the land, as regards animal life-if we consider the countless shoals which swarm in every part of the ocean and thickly cover its bed, and that the air, even in its lower zones, is almost lifeless. The lines in the 12th Canto of the 'Faërie Queene' seem to corroborate this idea, although not so intended by the poet:-

"O what an endlesse worke have $I$ in hand,

To count the seas abundant progeny,

Whose fruitfull seede farre passeth those in land, And also those which wonne in th' azure sky!

For much more eath to tell the starres on hy,

Albe they endless seeme in estimation,

Then to recount the seas posterity:

So fertile be the flouds in generation,

So huge their numbers, and so numberlesse their nation.

Witnesse th' exceeding fry which there are fed, And wondrous sholes which may of none be red."

Geological relations.-In local lists of Mollusca, and even in more elaborate works on this subject, it has been the custom to state that the habitat of certain species is restricted to "calcareous soils," "oolitic formations," "limestone," " chalk," " trap," and other strata. I believe, however, that mineralogical conditions have very little to do with the habitat of any of the Mollusca, nor with their comparative abundance or scarcity in any locality, except so far as food, moisture, or shelter, as well as the secretion of their shells, is concerned. Such conditions 
are merely what logicians call "accidents." All the earth (even granite and felspar) is said to contain calcareous matter, although the proportion is of course greater in some formations than in others. The case of two common and conspicuous land-shells occurs to me with reference to this question. Helix lapicida is directed by Forbes and Hanley* "to be sought for in limestone and chalky districts." It is common, however, in the trap formation of the Lower Harz, as well as in the molasse of Switzerland. According to Moquin-Tandon the Cyclostomata "aiment surtout les terrains calcaires †;" but our only species (C. elegans) is tolerably abundant in Jersey, where there are no calcareous strata. It would be easy to adduce many similar instances to prove that the habitat of Mollusca is not so restricted, as has been stated, in their geological relations. But there is no doubt that, with regard to land-shells, both granite and peat (which are at the opposite ends of the geological scale) are equally unfavourable to molluscan life; because the former is not easily disintegrated and converted into mould, so as to support vegetation, and the latter, being chiefly composed of the bogmoss (or Sphagnum), is either innutritious or distasteful to snails. The same observation applies to fir-woods, which do not appear to be inhabited by the Mollusca. With respect to the marine Mollusca, it may be observed that the phytophagous kinds will be found in abundance wherever sea-weeds flourish, and that in the deeper zones of the sea, in which such vegetation is absent, an ample supply of animal food is not wanting. But the substance of molluscous shells undoubtedly depends on the nature of the soil; and carbonate of lime seems to be as necessary to most snails for the secretion

* Brit. Moll. iv. p. 66.

† Hist. Moll. Fr. t. ii. p. 492. 
and formation of their dwellings, as egg-shells, or lime, are to laying-hens. The shells of our common gardensnail ( $H$. aspersa) in Guernsey are remarkably thin, owing to the deficiency of calcareous material ; and specimens of $H$. pomatia, from granite formations in alpine districts, are far inferior in weight to those from our chalk downs, although they do not differ in size.

Channel Isles.-Some conchologists entertain a doubt whether the Mollusca of Guernsey and the other Channel Isles ought to be included in the British fauna, because of their greater proximity to the French than to the English coast. The Sarnic fauna and flora (although undoubtedly peculiar) have, however, been hitherto considered by our best naturalists as belonging to Great Britain; and our Continental neighbours have never claimed them as their own, although they have appropriated Corsica, or "annexed" it to France, in a Naturalhistory point of view. Some of the Mollusca, taken in that part of the English Channel which is adjacent to Guernsey, are peculiarly Southern forms and have not occurred in any other part of our seas. Nearly all of them are very conspicuous and handsome. They are Cardium papillosum, Argiope decollata, Haliotis tuberculata, Murex corallinus, Triton cutaceus, and T. nodiferus. Of these six species only three (viz. Haliotis tuberculata, Triton cutaceus, and T. nodiferus) are noticed by either De Gerville, or Collard des Cherres, as having been found on the opposite coast of Brittany ; and BouchardChantereaux has not included any of them in his list of marine shells found on the coast of Normandy. Dr. Bowerbank has identified some of the sponges from Sark as northern species. In respect of geographical position, some of the Channel Isles are not so very much nearer France than England. Guernsey is distant about 
sixty miles from the Bill of Portland, and about thirtyfive miles from Cape Carteret on the coast of Brittany. All the six species which I have above mentioned are found on our side of the Guernsey coast.

Exotic and spurious species.-The fauna of any particular country (although isolated, like Great Britain) cannot be satisfactorily studied by itself and without reference to the fauna of other parts of the same district. The habit of observing and comparing the Mollusca of different countries is of undeniable advantage; and it may be favourably contrasted with the tendency of local naturalists and collectors to exaggerate trifling differences, which would have disappeared on a more extended survey. The enlargement and increase of such experience have the same beneficial effect on a mind inclined to the cultivation of science, as travelling in a foreign land, with one's eyes open, has in expanding the intellect and improving our social nature. By such means our notions become in each case less contracted; and (which is perhaps of more importance) our ideas with regard to the labours of other naturalists are imbued with a spirit of greater liberality and charity than if we had pursued the selfish course of working in our own sphere without any intercourse or sympathy with them.

The "index expurgatorius," containing the species of Mollusca which are termed "spurious" (being those which have been admitted into catalogues of British shells, but have not been proved to be indigenous to this country), is now very small, owing to the labours of Dr. Gray in revising the list of our land and freshwater shells, and of the authors of the 'British Mollusca' in a similar revision of our marine shells. The casual introduction of tropical or foreign shells by means of shipwrecks or ballast is not so frequent as has been supposed, 
-although it sometimes occurs, and I have several times picked up on the sea-strand, near a port resorted to by foreign vessels, shells which had evidently come from ballast. Strangers of this kind may, however, be detected without much difficulty by the application of intrinsic evidence. A much more fertile and perplexing source of error, as regards the introduction of spurious species, consists in collectors of Mediterranean, as well as British, shells not taking sufficient care to keep these collections separate; and too much praise cannot be given to Mr. M'Andrew, whose labours and experience in the investigation of the European Mollusca are so well known, for his extreme accuracy in the above respect.

Sea-side sketch.-Having offered this imperfect view of the British Mollusca, with regard to their structure and habits, and their relation to other animals and ourselves, as well as to their distribution, I cannot refrain from adding another page to this unusually long introduction, to exhibit a charming and truthful picture by my lamented and highly gifted friend, Professor Edward Forbes:"To sit down by the sea-side at the commencement of ebb, and watch the shore gradually uncovered by the retiring water, is as if a great sheet of hieroglyphicsstrange picture-writing-were being unfolded before us. Each line of the rock and strand has its peculiar characters inscribed upon it in living figures, and each figure is a mystery, which, though we may describe the appearance in precise and formal terms, has a meaning in its life and being beyond the wisdom of man to unravel. How many and how curious problems concern the commonest of the sea-snails creeping over the wet sea-weed! In how many points of view may its history be considered! There are its origin and development-the mystery of 
its generation-the phenomena of its growth-all concerning each apparently insignificant individual; there is the history of the species-the value of its distinctive marks - the features which link it with higher and lower creatures-the reason why it takes its stand where we place it in the scale of creation-the course of its distribution-the causes of its diffusion-its antiquity or novelty-the mystery (deepest of mysteries) of its first appearance-the changes of the outline of continents and of oceans which have taken place since its advent, and their influence on its own wanderings. Some of these questions may be clearly and fairly solved; some of them may be theoretically or hypothetically accounted for; some are beyond all the subtlety of human intellect to unriddle. I cannot revolve in my mind the many queries which the consideration of the most insignificant of organized creatures, whether animal or vegetable, suggests, without feeling that the rejection of a mystery, because it is a mystery, is the most besotted form of human pride *."

* Nat. Hist. Eur. Seas, p. 12.

In his tam parvis, atque tam nullis, quæ ratio! quanta vis! quam inextricabilis perfectio!-PLINY. 


\section{A Q U A TIC.}

\section{Class I. CONCHIFERA, or BIVALVES.}

BoDy of an oval form, and usually compressed at its sides : mantle divided into two lobes which correspond with the valves of the shell. It has no distinct head : but inside the mantle, and within its folds, is contained a mouth ; and the edges of the mantle in those bivalves which have it open, or of the tubes which are formed by it in those which have it closed, are often fringed with short filaments, which serve the purpose of tentacles or feelers. Some kinds have also imperfect or rudimentary eyes,' which are set in the interstices of those filaments where the mantle is open. The foot is tongue-shaped, and sometimes capable of considerable extension. It is used by the animal for creeping or attaching itself to other bodies by a byssus or bundle of muscular threads. Reproductive system similar to that of the monœeia among plants-both sexes being united in the same individual, which is capable of fertilizing itself. The whole, or most important part, of the body is covered by a shell, formed of two valves which are connected behind by a hinge or ligament. Respiratory organs consisting of gills.

\section{Order LAMELLIBRANCHIATA*.}

Gills 4, semicircular or leaf-shaped, arranged in pairs on each side of the body.

This Order comprises all the freshwater bivalves of Great Britain; and they are divided into three families.

\section{Family I. SPHARIID $Æ$.}

BODY subglobular: mantle open in front, and forming at the posterior side a cylinder, which is often divided near its opening into two tubes. The cylinder or tubes are

* So called from the leaf-like form of the gills. 
contractile and extensile,- the longer tube (when there are two) being used for respiration and nutrition, and the shorter tube for excretion. The outer edges of the mantle, as well as of the cylinder or tubes, are simple, and not furnished with papillæ or filaments. The mouth consists of a slit which is placed between the anterior adductor muscle and the base of the foot, and it has two small triangular lips. Foot wedge-shaped, thin, and capable of great extension.

SHell composed of two thin, oval or subtriangular valves, which are more or less inequilateral. The valves are of equal size. The outer surface of the shell is protected by a delicate epidermis, and the inside is slightly lined with nacre. The hinge is furnished with cardinal and lateral teeth to enable the valves to lock more closely into each other when the shell is shut. The ligament is external, although it is sometimes seated so far within the hinge as to be scarcely visible on the outside : it is placed at the longer, or posterior, side of the hinge.

The animals of this family are ovoviviparous, retaining the fry for some time between the mantle and gills. They are tolerably active in their habits, using their foot for crawling like a leech; and some of them float with the beaks of their shell downwards, or suspend themselves in that position to the under surface of the water by means of a very fine byssus which they secrete and spin with their foot. In the winter they appear to be torpid, and bury themselves in the mud, like other freshwater bivalves. During this period they probably cannot procure their food, which consists of animalcula. Specimens which I had in confinement soon after Christmas never put out their tubes, and only used their foot to creep under some moss which was in the vessel. This they did as often as I removed them from their place of shelter.

The Sphceriida closely resemble their marine representatives, the Kelliada, which are also ovoviviparous : but the mantle is more open and the ligament external in the present family; while the ligament is internal in the 
Kelliado, and the beaks of their shell are much more acute. This curious and distinct group of freshwater bivalves has been carefully investigated by our countryman, the Rev. Leonard Jenyns; and his monograph on the British species of Cyclas and Pisidium, which was published in the Transactions of the Cambridge Philosophical Society for 1832, is full of valuable and interesting information. Since that time the labours of naturalists have been divided even in this humble and comparatively obscure study. Several French conchologists, especially MM. Normand and Gassies, have separately devoted themselves to a critical examination of their native species of the above genera; and lately M. Bourguignat has favoured the scientific world with an elaborate essay on the recent and fossil species of Sphoerium (or Cyclas) which have been found in France. This essay was published in the 'Mémoires de la Société des Sciences physiques et naturelles de Bordeaux,' tome i. 1854. The only recent species described or noticed by him, which is not also found in this country, is the Cyclas solida of Normand. It appears to form an intermediate link between Sphcerium and Cyrena; and M. Bourguignat has separated it from the former under the generic name of Cyrenastrum. I mention this in consequence of the Cyrena (or Corbicula) fluminalis occurring so frequently as a fossil in our upper tertiary beds, and in the hope that the Cyrenastrum solidum may also turn up in the same deposits, and lead to an elucidation of the question how the limits of the true Cyrena, in its living state, have become so restricted since the glacial epoch. The only other genus of this family (Pisidium) has lately had an equal amount of laborious attention bestowed on it by an eminent member of the French corps of conchologists. The 'Essai monographique sur 
les Pisidies Françaises,' by Dr. A. Baudon of Mouy, may be profitably consulted by those who take a particular interest in this subject. It was published at Paris in 1857 , and contains fifty-five pages, and five plates of admirably executed figures. All the species of Pisidium described by Dr. Baudon, with the exception of $P$. conicum, appear to be also common to this country; but one of them (the P. Recluzianum of Bourguignat), which was at that time imperfectly known to the author of this essay, and its generic relation to Pisidium properly questioned by him, happens to be a marine shell, viz. the Turtonia minuta, M. Gassies having procured specimens from Belfast, where it is abundant.

\section{Genus I. SPHE'RIUM*, Scopoli. PI. I. f. 1, 2.}

Bopy nearly equilateral: mantle having a double tube.

Shell slightly inequilateral ; beaks placed near the centre of the dorsal margin.

This genus was founded in 1777 by Scopoli (Introd. ad Hist. Nat. p. 397, no. 88) in sufficiently explicit terms, taking the Tellina cornea of Linné as the type; but Bruguière (who was followed by Draparnaud and other authors) afterwards proposed for the same genus the name of Cyclas, by which it has been more generally known. Owing, however, to the bibliographical researches of Dr. Gray, the older and equally appropriate name of Sphcerium was restored by him in 1847; and this latter name has since been adopted by Mörch, Bourguignat, and other continental conchologists. The law of priority seems to require the recognition and use of this name. I am aware that in thus advocating the substitution of another (although an older) name for that

* From its spherical shape. 
of Cyclas, which has so long received the sanction of naturalists, the principle of usage may be to some extent violated, and that it may be urged, with great reason, that Limnaca and Succinea ought to give place to Neritostoma and Auricula, which Klein had previously proposed, as well as Physa to that of Adanson's genus Bulin; but I am only in the present case following the lead of experienced naturalists, and the conflict of authorities ought to be determined by the strict rules of justice. The word being derived from $\sigma$ paıpiov, it ought not to be spelt Sphcerium, as has been done by some authors.

\section{Sphartum cor'neum *, Linné.}

Tellina cornea, Linn. Syst. Nat. ed. xii. p. 1120. Cyclas cornea, Forbes \& Hanley, Brit. Moll. ii. p. 113, pl. xxvii. f. 3, 4, 5, 6 .

BoDy white, greyish, brown, or yellowish : tubes rather long, slightly tinged with flesh-colour : foot somewhat longer than the shell, of a faint rosy hue towards its extremity.

SHELL subglobular, nearly equilateral, compressed in front, rather thin, glossy, yellowish horn-colour, with often paler bands or zones which denote the periods of growth, and occasionally having faint streaks of brown which radiate from the beaks towards the front margin, slightly but closely striate transversely, and marked by obscure lines in a longitudinal direction, so as to give the surface a reticulated appearance under a high magnifying power: epidermis rather thin: beaks almost central: ligament short and narrow, scarcely visible on the outside: inside bluish-white: hinge strong, having a double cardinal tooth in each valve, besides two lateral teeth in the right, and four in the left valve; the cardinal teeth are very small, but distinct; the lateral teeth form elevated ridges or plates, and are subtriangular at their extremities, those on the anterior side being the largest: muscular scars or impressions faint, owing to the thinness of the interior lining: pallial scar scarcely discernible. Length $0 \cdot 35$. Breadth $0 \cdot 45$.

Var. 1. flavescens. Smaller and rounder; body and shell

* Horn-colour. 
straw.colour. C. flavescens, Macgillivray, Moll. Aberd. p. 246. S. citrinum, Normand, Coup d'œil Cycl. p. 1.

Var. 2. nucleus. Smaller and much more globular. C. nu cleus, Studer, Kurz. Verzeichn. p. 93.

Var. 3. Scaldiana. Shell more oval and of a paler colour. C. Scaldiana, Norm. Cycl. p. 5, f. 1, 2.

Var. 4. Pisidioides. Shell subtriangular, and rather more producedatits posterior slope ; transverse (or concentric)striæ coarser: ligament slightly perceptible on the outside. S. Pisidioides, Gray in Ann. \& Mag. Nat. Hist. July 1856, p. 25.

Habitat : Slow rivers, lakes, ponds, and ditches, as well as open drains in woods, everywhere in this country; and it occurs in a fossil state in the upper tertiary deposits at Copford in Essex and other places. Var. 1. is from Cumberland (Gilbertson); Westmoreland (Glover); Grand Canal, Dublin (Warren); Aberdeenshire (Macgillivray \& Taylor); in a lake near Lerwick (Norman). Var. 2. Crymlyn bog, near Swansea (J. G. J.); Barton run, Norfolk (Gunn); Richmond (Choules). Var. 3. Oxwich marsh, near Swansea, and Thames at Clifden Hampden (J.G.J.). The colour of the body in this variety is yellowish-white; tubes close together, irregularly jagged at their edges, but not fringed, the branchial tube being double the breadth of the other, which is funnel-shaped; foot white and broad. Var. 4. Grand Junction Canal at Paddington. The shells of this remarkable variety are much eroded, probably on account of the water being charged with the refuse from manufactories or sewers. The result of a careful comparison of these shells with other varieties and the typical form, and the circumstance that no other form of this variable species has been found associated with it, incline me to believe that it has not sufficient claims to rank as a distinct species. It closely resembles the Cyclas rivalis of Dupuy (Hist. nat. Moll. terr. et fluv. France, p. 668, tab. 29. f. 5), 
which is another variety of the present species. Dr. Baudon and M. Bourguignat both agree with me in the above opinion. This species is widely distributed in Europe; its northern limit being (according to Von Wallenberg) Lapland, and its southern limit being (according to Philippi) Sicily. Young shells are extremely flat, and might be easily mistaken for a different species.

This common species was first made known by our countryman, the celebrated Dr. Lister, in his Treatises on the history of English animals, in 1678. It is the Tellina rivalis of 0 . F. Muiller, and the Cyclas rivalis of Draparnaud, who evidently described and figured the next species (S. rivicola) as the Tellina cornea of Linné.

\section{S. RIVI'COLA*, Leach.}

Cyclas rivicola, (Leach) Lamarck, An. sans Vert. vi. p. 267 ; F. \& H. ii. p. 111, pl. xxvii. f. 1, 2, and (animal) pl. Q. f. 1.

Bopy yellowish-grey, or light brown: tubes short, white, and nearly of equal length : foot thick, and capable of great extension, greyish-white: gills sometimes slightly tinged with red.

SHELl oval, ventricose, nearly equilateral, much compressed in front, rather solid, glossy, yellowish horn-colour, or olivegreen, with often darker bands or zones, deeply ridged concentrically, especially towards the lower or front margin, the ridges being crossed by obscure lines which radiate from the beaks : epidermis rather thick: anterior side rounded: posterior side more produced and subtruncate: beaks central, small, and flattened: ligament short, prominent, and distinctly visible on the outside: inside white and nacreous, with sometimes a yellowish tinge: hinge and teeth stronger than in S. corneum, but nearly of the same form : muscular and pallial scars distinct. L. $0 \cdot 7$. B. $0 \cdot 9$.

HABITAT: Slow rivers and canals in the metropolitan, midland, and northern counties of England, as well as

* Inhabiting brooks. 
near Dublin; and it is one of our upper tertiary fossils. It is a local species. On the continent it ranges from Holland to Italy.

This fine species may be distinguished from S. corneum by its much greater size, its form being oval instead of globular, the strong transverse ridges, and the conspicuous ligament. The young of this are also much flatter in proportion to their size. Both species occur together. S. rivicola was first indicated by Lister as having been found at Doncaster.

\section{S. ova'LE *, Férussac.}

Cyclas ovalis, Fér. in Ess. Méth. 1807, pp. 128, 136. S. pallidum, Gray in Ann. N. H. ser. 2. xvii. p. 465, woodcut.

BoDy milk-white: tubes long, united nearly all the way: foot tongue-shaped, very extensile and flexible: gills of a faint blush-colour.

SHELl oblong, somewhat compressed, not so equilateral as the two preceding species, owing to the greater development of the posterior side, thin, semitransparent, not very glossy, yellowish, with sometimes a brown tint and darker zones of growth, with occasionally some faint rays in the direction of the lower margin, finely striate concentrically: epidermis thin: anterior side rounded: posterior side truncate, and sloping towards the lower margin, which is curved and sharp : beaks small, nearly central, and slightly prominent: ligament long and narrow, distinctly visible on the outside: inside ashy-white: hinge straight on the posterior side, and incurved on the other side; cardinal and lateral teeth arranged as in $S$. corneum, but the former are exceedingly small and difficult to distinguish : muscular and pallial scars very faint. L. $0 \cdot 4$. B. $0 \cdot 6$.

Habitat: Exmouth (Clark); Paddington Canal (J.G.J.); canals and ponds in Lancashire (Darbishire). A specimen also exists in the late Dr. Turton's collection of British shells, but without any note of the locality. * Egg-shaped. 
Mr. Daniel says that he found this species in the Grand Surrey Canal some years before it was noticed by Dr. Gray, but that he then considered it to be a variety of $C$. rivicola. It is found in company with all the other species of Spharium. A living specimen, which had been taken early in February, and kept in a vessel by itself, gave birth about three weeks afterwards to some young ones at intervals of two or three days. Immediately on being excluded, they were very active, and used their long foot as an organ of progression, by extending it to its full length; and, after attaching its point to the bottom of the vessel, like a leech, they drew up their shell to it; and by repeating this several times they contrived to travel along for some little distance. They seemed to be fond of nestling under their mother for the sake of shelter or shade.

There cannot be much doubt that this elegant and very distinct species is the same as that which Draparnaud, in his 'Histoire naturelle des Mollusques terrestres et fluviatiles de la France' (p. 130, pl. x. f. 6, 7), described and figured under the name of Cyclas lacustris. He distinguished it from $S$. corneum and S. rivicola by its being "plus mince, plus transparente, plus pâle et beaucoup plus aplatie." His description of the beaks and hinge also exactly agrees with that of our species; and the very different terms in which he characterized his $C$. caliculata preclude our supposing that this accurate naturalist could have taken for it a variety of the last-named species. Férussac, being aware of the error which Draparnaud had committed in referring the species in question to the Tellina lacustris of Muiller, gave it the appropriate name which I have now adopted. The species appears, however, to have been lost in France; and all the continental conchologists have applied the 
name given by Draparnaud to some one of the numerous varieties of either Miiller's species or S. corneum. The Cyclas rhomboidea of Say, to which Dr. Gray supposed our shell to be allied, is only a fourth of an inch long, and, according to Gould, is an obscure or doubtful species. Its nearest congener in this country appears to be S. rivicola; but it may be readily distinguished from that species by its oblong and subangular shape, thinner texture, much paler colour and fainter striæ, and especially by its straight hinge-line. The Devonshire and Lancashire specimens are of a darker colour than those from the Paddington Canal. The young exhibit the same form as the adult; and, like the other species, their shells are slightly iridescent.

\section{S. LACUS'TRE*, Müller.}

Tellina lacustris, Müll. Verm. Hist. pt. ii. p. 204. Cyclas caliculata, F. \& H. ii. p. 115, pl. xxxvii. f. 7 (as C.lacustris), and (animal) pl. 0 . f. 7.

BoDy whitish, slightly tinged with grey or rose-colour: tubes long; the branchial one cylindrical and truncate at its orifice, which is large ; the other rather conical, and having a smaller opening: foot nearly twice the length of the shell, obtuse at its extremity: mantle fringed with grey.

Shell nearly round, or subrhombic, equilateral, compressed, especially towards the lower and side margins, extremely thin, glossy and semitransparent, light horn-colour, or greyish, with sometimes a few darker zones and an iridescent hue, very faintly striated concentrically: epidermis very thin: anterior and posterior sides cut off and sloping from shoulders on the upper or dorsal side towards the front margin, which is slightly curved and has sharp edges : beaks central, very prominent, and capped with the fry or nucleus of the shell, which is more globular than in the subsequent stages of growth : ligament narrow, thin, and just discernible on the outside: inside bluish-white, with very little nacre, owing to the thin texture of the shell: hinge

\footnotetext{
* Inhabiting lakes.
} 
rather strong; teeth arranged as in the other species, but the cardinal teeth are smaller and the lateral ones shorter in proportion: muscular and pallial scars scarcely perceptible. L. $0 \cdot 3$. B. $0 \cdot 4$.

Var. 1. Brochoniana. Shell much larger and flatter; beaks smaller and less prominent. S. Brochonianum, Bourguignat, Monogr. p. 20, pl. 3. f. 1, 2, 3.

Var. 2. rotunda. Shell rounder and flatter; epidermis yellowish-green.

Var. 3. Ryckholtii. Shell small, triangular, and globular; beaks very prominent. C. Ryckholtii, Norm. Cycl. p. 7, f. 5, 6 .

HaвiтAт: Lakes, ponds, and canals, and stagnant water everywhere in England, Wales, and Ireland; but I have not observed it in Scotland, nor seen any notice of its having been found there. Var. 1. Clumber lake, Notts (J. G. J.). This considerably exceeds the usual form in size, being in length 0.45 , and in breadth 0.6 , although its depth or thickness is only 0.25 . Var. 2. Singleton, near Swansea (J. G. J.). Var. 3. Marsh between Exmouth and Budleigh Salterton (J. G. J.). In another piece of stagnant water near Exmouth a small globular variety occurs, in which the beaks are not prominent. A monstrosity is also sometimes met with, in which the lower or front margin is constricted or divided by a groove. Mr. Kenyon found it in the North of England; and I have also taken it in Crymlyn bog, near Swansea. Some shells, which Mr. Choules has found near Richmond, partake of the characters both of this species and $S$. ovale, and apparently form an intermediate link between them. According to Middendorff this species inhabits Siberia; and Philippi and Terver have recorded it from Sicily and North Africa. It has also a wide range in the intermediate parts of Europe. It often occurs in company with $S$. corneum; and I have found it alive in the hardened mud of a pond which had been drained and its bed so completely dried up 
by the sun as scarcely to show the marks of any footsteps on it.

This differs from all the other species of Sphorium in the shell being rounder and of a subquadrate form, its great tenuity, and especially in the singular caps or calyces which surmount the beaks.

I cannot agree with the learned authors of the 'British Mollusca' in preferring Draparnaud's name of caliculata to that which had been long before assigned to this species by Muiller. The description given by the illustrious Danish naturalist does not appear to me at all deficient in that accuracy and precision which characterize all his writings; and if some continental authors have erroneously confounded this species with the Cyclas lacustris of Draparnaud, this cannot be a sufficient reason for continuing the mistake. At any rate, the best French authorities (including Férussac, Blainville, and MoquinTandon), as well as nearly all the conchologists of our own country, have adopted Muiller's name in preference to that of Draparnaud.

Although Mr. Jenyns has, in his excellent Monograph, given an interesting notice of the habits of this mollusk in a state of confinement, some further details, which have been communicated to me by my friend Dr. Lukis, of Guernsey, of its natatory, spinning, and other performances, may not be unacceptable. In one of his letters to me he says, "I placed a number in a small fish-globe in clear water taken from the sluggish stream in which they were captured. In a short time they commenced crawling about and actually ascending the slippery concave glass. In a few days a considerable number of the fry had been cast, which proved far more active than their parents, readily climbing the sides of the globe, and rarely missing their foot- 
ing, while the adults made many ineffectual attempts; but both fry and adults, when they reach the edge of the water, take to the surface easily, and creep along slowly, and apparently with caution, as if in search of some floating substance, near which they will rest for hours. The exserted foot moves, during this under-surface progression, by a gentle vermicular action, the siphons being at the same time protruded. The foot during repose is usually retracted, and does not seem necessary for mere floating-purposes." And he adds, "An interesting little scene occurred in the globe the other evening. Several individuals had reached a few leaves and hanging roots of minute water-plants which floated in the centre of the globe, down the stems of which three or four had crept to a depth of about an inch and a half. There they reposed: but they were not labsolutely motionless ; for, to my surprise, the whole group, plants and all, were dreamingly enjoying the delights of a slow but long-continued rotation. At first I thought some minute water-insect had found its way unbidden into the globe, and was thus illustrating, like some learned lecturer to his sleepy audience, the laws of planetary motions. But no such lecturer was there: yet, as the revolution brought two of the little mollusks closer under inspection, I observed their siphons to be curved exactly in the opposite direction to the line of motion. Here was a solution at once of the nymph-like $\sigma \tau \rho o ́ \beta \iota \lambda o s$, which was evidently due to the recoil consequent upon the circulation and expulsion of the water through the siphons. The fortuitous position of the two individuals and the combined action of their expulsive tubes may not occur again; but the whole incident was so interesting and remarkable that I could not help recording it. The fry are growing rapidly; and I opine the 
amount of exercise they indulge in is conducive to their health. I have observed the Eulima distorta, Rissoa parva and cingillus, as well as the Odostomice and Jeffreysice, ascend to the edge of a basin and creep along the under-surface of the water, in the same manner as the Lymnoxadce. But it is singular that bivalves should imitate their less unwieldy molluscan brethren in this seemingly unsuitable mode of progression." In another letter he says, "Sometimes a single individual will suspend itself to a little bit of the stem of a Lemna, and whirl quite alone for hours, even rapidly - say fifteen to twenty revolutions in a minute." And in a subsequent letter he goes on to say, "The young are far more active than the parents. I do not perceive their siphons to be ever exserted, while this is almost constantly the habit of the older ones. They all continue to climb the glass globe, and rather more so in the evening, probably preferring to roam in the dark. I have had a fresh supply of about half a dozen, which, soon after being immersed, began an inspection of their new domain, and continued for a day or two more restless than the others. On climbing the glass, the front margin of the valves is applied to it, and at the same time both the foot and the siphons are exserted. The foot being extended to its full length, its extremity is cautiously pressed against the glass, and after a short pause the upward movement of the body commences, which is the work of a second of time; then another short pause, after which the front margin of the valves and the point of the foot are again applied cautiously to the glass, and the foot is again protruded to repeat the same process. When the edge of the water is reached the pauses are longer, and it is necessary for the creature to be doubly cautious, for here is the point of greatest difficulty. However, the foot is conveyed 
horizontally along the surface of the water, which appears to recede partially from it. On examining it with a lens, the foot is distinctly seen to have an undulating action on the surface, as well as an irregular and imperfect contraction and elongation along its whole extent; but it is never quite retracted, excepting when its base and the front margin of the valves are in contact with some floating weed which is capable of supporting the whole. Thus this elegant shell traverses the still surface. But it is most curious to see it descending the thread-like stems of the Lemna, or some assemblage of these delicate fibres: even a single stem is quite sufficient; and if the shell is free from any other contact, it immediately begins its rotatory movement. A single shell, thus suspended, revolves upon its axis in a direction which is most frequently from right to left of the observer, or in the opposite direction from that of a teetotum when made to spin by the fingers of the right hand. I have suspended single threads to circular pieces of cork in the water; but the stems of the Lemna are preferred. Cyclas cornea is much less active or inclined to ascend the glass; in fact I have not yet seen it accomplish the feat of its congener. Several of the C. calyculata (Spharium lacustre) will remain among the stems of the duckweed for hours perfectly inactive, with closed valves, as if sleeping or resting after their previous fatigue. When the valves are pressed against the glass while ascending, there seems to be a fulness about the base of the foot, as if the mantle served for adhesion to the glass." Dr. Lukis afterwards informed me that he had detected the byssal filament in S. lacustre. He says, "I have this morning watched one, which had reached the surface, spin its filament, and descend to 
half an inch below the surface, where it remained suspended for some time. It occupied three hours in spinning this short thread. I think it consists of more than a single filament; for some minute particles, which were floating in the water, became entangled in it. The surface of the water was again depressed or cupped." And he concluded by saying that he found the number of filaments to vary from one to at least four, which in one instance were far apart, the siphons or tubes and foot being at the same time exposed; and that the animal had the power of raising itself by means of this byssus again to the surface, after having been suspended for some time below it. The filaments appeared not to exceed half an inch in length; and rarely could more than a single thread be seen. M. Bouchard-Chantereaux has likewise, in his extremely interesting Catalogue of the Land and Freshwater Mollusks which inhabit the Department of the Pas-de-Calais, noticed that the young of $S$. corneum possess the same faculty of spinning a transparent thread and attaching themselves by means of it to water-plants.

\section{Genus II. PISI'DIUM*, C. Pfeiffer. Pl. I. f. 3, 4.}

BoDy inequilateral : mantle having only a single tube.

SHELL inequilateral : beaks placed near the shorter or anterior end.

This genus was established by Carl Pfeiffer in 1821, to separate from Sphorium the smaller species which have only one tube or siphon, and whose shells are not so equilateral. This generic distinction seems to be well founded, in respect both of the soft parts of these mol-

* Pea-shaped. 
lusks and of their shells; and it has received almost the universal assent of conchologists. The habits of the little Pea shells are the same as those of the larger members of the same family; and they inhabit nearly the same situations. One species $(P$. pusillum $)$ does not seem to require a constant, or even a frequent supply of water, being often found living at the roots of bog-moss which is dried up in the summer, and of grass in meadows which are only irrigated in the spring; and Nilsson noticed, in his history of the land and river mollusks of Sweden, that he had frequently found the same species (which he erroneously referred to the $P$. fontinale of C. Pfeiffer) living between the bark and wood of fallen trees in moist places. They possess the same faculty as the Sphcria, of floating, or creeping in an inverted position under the surface of the water. These tiny Pea shells, or cockles, swarm in every slow river, streamlet, lake, pool, horse-pond, ditch, and open drain; and they are greedily devoured by fish and ducks. In their turn, they are fond of animal food; and Dr. Baudon, in his admirable Monograph, says that he has often observed Pisidia attached to the drowned carcases of small animals, as well as to bones which had been thrown into ditches and streams, and from which the muscular fibres had not been removed. Perhaps, however, animalcula fed upon the meat, and were the real objects of attraction to the Pisidia. Their shells are sometimes so thickly encrusted with a ferruginous or mineral deposit from the muddy sediment of the water which they inhabit as to resemble small lumps of dirt. This deposit appears to be partly owing to a secretion of the animal, aided by its generally inactive habits. Water-beetles do not allow themselves to be clogged in the same manner. Whether this is one of the artifices by which animals 
escape the observation of their natural enemies is a question which requires a molluscan mind to solve.

The critical investigation of the different species which compose this genus is quite as difficult as it is with regard to the large freshwater mussels. Little reliance can be placed on the characters afforded by an examination of the body, or soft parts, of the animal. The form and comparative length of the tube are especially liable to vary even in the same individual; and under the influence of heat and light the most Protean changes with respect to this organ may be observed. The size of the foot is equally a deceptive character; and colour is always a most uncertain test. The general shape and appearance of the shells, as well as the position of their beaks, appear to offer almost the only reliable grounds of distinction. Size, substance, sculpture, and lustre are not of much account, as they mainly depend on the chemical ingredients of the water inhabited by these mollusks, as well as on their supply of food. In making an investigation like the present, there appear to be four courses open to the naturalist. The first, which is, perhaps, the easiest, is to reduce all hitherto described species to one or two, and thus to cut the Gordian knot without further ceremony. The second, which has been pursued to such an extent on the Continent and in the United States of America, is to multiply the number of species ad infinitum. The only check which can be imposed on this method of wholesale and indiscriminate fabrication is the bar of scientific opinion ; and in countries where nearly all the naturalists are culprits, there is not much likelihood of justice being so severely administered as to prevent the repetition of such venial offences. The third course is, to adopt the labours of preceding writers without any inquiry. And the fourth 
is, honestly and to the best of one's ability carefully to work out the subject and to submit the result to the free criticism of other naturalists. This last course I have endeavoured to pursue; and I shall not feel in the least degree mortified or discouraged if the conclusions I have arrived at, with much pains and great hesitation, are not accepted by all my scientific brethren.

To give some idea of the labour involved in this investigation, I may mention that my own cabinet contains no less than 274 parcels of Pisidia, which have been, in the course of the last thirty or forty years, collected from different localities and sources, and comprise many thousands of specimens; that I have personally examined the types of those species which have been described by Dr. Turton, Mr. Jenyns, Mr. Alder, Dr. Baudon, and other conchologists who have published on the subject; that I have collected these tiny shells in many parts of Holland, Germany, France, Switzerland, and Italy, for the sake of comparison with British forms; and that I have had to refer to numerous works in many languages in order to collate the descriptions of fortyone different species which have been proposed by European writers within the last century. Of these, I cannot conscientiously recognize more than six as distinct.

It will be convenient to divide the British species, which are five in number, according to their shape, as follows :-
A. Triangular. 1. P. amnicum.
2. P. fontinale.
B. Oval. 3. P. pusillum.
C. Round. 4. P. nitidum.
D. Oblong. 5. P. roseum. 


\section{A. Triangular.}

\section{Pisidium am'nicum*, Müller.}

Tellina amnica, Müll. Verm. Hist. p. 205. P. amnicum, F. \& H. ii. p. 133, pl. xxxvii. f. 8, 9, and (animal) pl. 0. f. 8 .

BoDy greyish-white, rather transparent: tube short, subconical, obliquely truncate at its orifice: foot broad at its base, abruptly pointed, and very extensible: mantle bordered with grey.

Shell subtriangular, rather ventricose and solid, glossy, strongly grooved concentrically, horn-colour or yellowishgrey : epidermis rather thick: anterior side abruptly truncate: posterior side much produced, and sloping towards the lower margin, which is obliquely curved : beaks rather prominent, but obtuse : ligament short, conspicuous : inside bluish-white and nacreous : hinge strong and curved; teeth arranged as in Spharium, but the lateral teeth in this and other species of $P$ isidium are exceedingly strong and developed in proportion to the size of their shells : muscular and pallial scars well marked. L. $0 \cdot 3$. B. $0 \cdot 375$.

Varieties occur in which the striæ are more numerous, fewer, stronger or fainter than usual.

Habitat : Slow rivers, lakes, canals, and streams in all parts of the kingdom. It is also one of our commonest upper tertiary fossils. Its continental range extends from Siberia to Naples, and it is also found in Algeria. This is the largest kind of Pisidium.

\section{P. fontina'lef, Draparnaud.}

Cyclas fontinalis, Drap. Hist. Moll. p. 130, pl. x. f. 8-12. P. Henslowianum (var. without appendages), Jenyns in Ann. Nat. Hist. Aug. 1858, p. 104.

BoDY whitish or grey, rather transparent: tube generally short, but capable of considerable extension and dilatation, conical, obliquely truncate at its orifice, where it is so flexible that the edges are sometimes entire and at other times jagged: foot long and curved : mantle bordered with grey.

* Inhabiting rivers. † Inhabiting fountains. 
SHell subtriangular, somewhat ventricose, thin, rather glossy, finely but irregularly striate concentrically, greyishwhite : epidermis very thin : anterior side abruptly truncate : posterior side rounded, and sloping gently towards the lower margin ; the anterior and posterior margins are compressed, especially towards the beaks, on each side of which they form a kind of shoulder : beaks prominent and rather acute : ligament very short and scarcely perceptible : inside white and nacreous : hinge short, but very strong; dentition as in $P$. amnicum, except that the cardinal teeth do not assume the shape of an inverted V : muscular and pallial scars the same as in that species. L. $0 \cdot 15$. B. $0 \cdot 175$.

Var. 1. Henslowana. Each valve furnished with a platelike appendage near the beaks. Tellina Henslowana, Sheppard in Linn. Trans. xiv. p. 150. P. Henslowianum, F. \& H. ii. p. 131, pl. xxxvii. f. 11.

Var. 2. pulchella. Shell more glossy, strongly and regularly grooved; beaks less acute. P. pulchellum, Jen. p. 18, tab. xxi. f. 1-5 ; F. \& H. ii. p. 128, pl. xxxvii. f. 12, 13.

Var. 3. pallida. Shell more ventricose, irregularly striate, and of a paler colour, with occasionally a few darker rays which diverge from the direction of the beaks to the lower margin.

Var. 4. cinerea. Shell larger and flatter, with fainter striæ. $\quad P$. cinereum, Alder, Suppl. Cat. Moll. Northumb. p. 4 ; F. \& H. ii. p. 125, pl. xxxvi. f. 2.

НАвітAт: Slow streams and standing water everywhere in these isles; and it is one of our upper tertiary fossils. It also ranges from Siberia to Sicily. Var. 1. occurs in many of the northern, eastern, home, and south-western counties of England, as well as in South Wales and Cork. This is also one of our tertiary fossils, and extends from Sweden to the South of France. Specimens from the Swansea Canal, near some tinworks, have the beaks more or less eroded, in consequence probably of the water containing an extremely diluted portion of sulphuric acid, which is used in that manufacture. The fact, which has been noticed and considered 
remarkable by some authors, of the eave-like projection appearing in the middle of young shells, agrees with its position in adult shells, because this curious appendage is never placed close to the beak. Var. 2. More common than the last variety, and also inhabiting Sweden and France. It deserves its name, being a very pretty object. Mr. Jenyns now considers it to be the same species as his $P$. Henslowianum. Var. 3. Marshes and pools near Swansea. It is probably the $P$. pallidum of Gassies. Var. 4. Widely diffused in this country, and also inhabiting France and Italy. The outline of some specimens of this last variety is that of an equilateral triangle. It is the $P$. australe of Philippi, and the Cyclas lenticularis of Normand.

This species is extremely variable, and has consequently received a great number of names. Out of the 41 so-called species of Pisidium which have been described by European conchologists, no less than 21 belong to the present form. On the Continent the type is generally known by Poli's name of Casertanum.

If the diagnosis, characters, and figures given by Draparnaud for his Cyclas fontinalis had been more carefully studied, it would, I think, have been obvious that they do not apply to the Tellina pusilla of Gmelin, with which this species has been generally (but with doubt) allocated by so many authors. The principal difference between these two species consists in the former $(P$. fontinale) being triangular and somewhat depressed, and having prominent beaks; while the other (P. pusillum) is oval and ventricose, and has obtuse beaks. Draparnaud's diagnosis is as follows: " C. testa globosa, subdepressa, subinæquilaterali; umbone subacuto." Gmelin says his shell is "ovata, ventricosa;" and his description of its colour as "sordide alba" is 
PISIDIUM.

peculiarly appropriate to the $P$. pusillum of modern authors. C. Pfeiffer, in 1821, appears to have recognized Draparnaud's shell by the same specific name of "fontinale;" and the only distinction which he makes between this species and his own $P$. obtusale (which I regard as a variety of $P$. pusillum) is that the former is described "umbone subacuto", and the latter "umbone obtusissimo."

It chiefly differs from $P$. amnicum in being very much smaller (although the variety cinerea is nearly as large), in the shell being thinner, the posterior margin much less produced, the beaks being more prominent, and the ligament scarcely conspicuous. The cardinal teeth are also more separate, and do not diverge from a common base or root as in that species and Sphcerium.

\section{B. Oval.}

\section{P. PUSIL'LUM*, Gmelin.}

Tellina pusilla, Gmelin, Syst. Nat. p. 3231. P. pusillum, F. \& H. ii. p. 123, pl. xxxvii. f. 10, and (animal) pl. O. f. 9 .

BoDY whitish, with occasionally a faint tinge of yellow or red : tube short, subconical or cylindrical, truncate, orifice small and its edges plain : foot longer than the shell, narrow and slender: mantle bordered with reddish-grey.

Shell oval, compressed but swollen, thin, not so glossy as in the other species, finely but irregularly striate concentrically, a few of the strix being larger than the others and denoting the successive stages of growth, yellowish-white or cinereous : epidermis very thin : anterior side rounded : posterior side also rounded, and sloping very gradually below ; this side is very little more produced than the other, which makes the contour of the shell more equilateral than in the foregoing species; both these sides are compressed, and especially above: lower margin rounded : beaks not prominent, but blunt : ligament short and inconspicuous : inside greyish-white, with 
scarcely any nacreous lustre; other internal characters the same as in $P$. fontinale. L. $0 \cdot 175$. B. $0 \cdot 2$.

Var. obtusalis. Shell smaller and much more ventricose; beaks prominent, very obtuse. $P$. obtusale, C. Pfeiffer, Deutsch. Land- und Suissw.-Moll. i. p. 125, t. 5. f. 21, 22 ; F. \& H. ii. p. 120 , pl. xxxvi. f. 1 .

Habitat : Mossy swamps, shallow ditches, drains, grassy pools, and similar situations throughout all the country; and it is one of our upper tertiary fossils. It ranges from Lapland to Corsica, and is generally diffused in Europe. Dr. Baudon says that it is the same species as the $P$. ventricosum of Prime; so that it appears to be also a native of the United States of America. The variety obtusalis occurs in similar situations with the typical form; but it is more local and not so abundant. The intermediate gradation between the two forms is almost infinite; but the essential and common character of both is the same, viz. the beaks being nearly central and obtuse.

Having carefully studied the description and figure given by Poli of his Cardium Casertanum, I have not been able to arrive at the same conclusion which MoquinTandon and other French conchologists have formed, that this species is the type of the one which I have described as $P$. fontinale; and I consider that it ought more properly to be referred to the present species. Poli says his shell is "subrotunda;" and his figure shows that it is much more equilateral than $P$. fontinale. $\mathrm{He}$ also remarked the irregularity of the striæ arising from the marks of growth, which appears to be more characteristic of this than of the other species. As, however, he did not notice any other species, it is of course very difficult to say precisely which species he meant; and under these circumstances I think it is preferable not to revive an obscure and doubtful species, indicated 
by a local name, when we have at least equally good reasons and authority for adopting a name bestowed by an earlier writer, and which, besides, is not liable to the same objection. This species differs from $P$. fontinale in its shape being oval instead of triangular, and in its beaks being more central, and blunt or compressed. Its colour is also yellowish-white instead of grey; and it has much less lustre. It is the Cyclas fontinalis of Nilsson.

\section{Round.}

4. P. NI'TIDUM* ${ }^{*}$, Jenyns.

P. nitidum, Jen. p. 16, tab. xx.f. 7,8; F. \& H. ii. p. 126, pl. xxxvii. f. 14.

Bony whitish, with sometimes a faint tinge of yellow, caused by the colour of the liver: tube short, funnel-shaped; orifice wide, and its edges notched or puckered : foot rather long, thin, slender, and finely pointed : mantle bordered with grey.

Shell suborbicular, compressed except in the upper part where it is rather ventricose, thin, extremely glossy, iridescent (especially in the young state and near the beaks), finely and regularly striated or ribbed concentrically, with from 3 to 5 separate and deeper grooves which encircle the umbonal region, the striæ or ribs being rather broad; yellowish-white or light horn-colour : epidermis a mere film : anterior side somewhat truncate, but rounded : posterior side slightly produced and sloping abruptly below : lower margin rounded : beaks nearly central, rather prominent, but obtuse : ligament very short, and scarcely discernible : inside whitish, and plainly showing the scars of the adductor muscles and mantle: hinge and teeth as in the two last species. L. 0-15. B. 0-15.

Var. splendens. Shell of a lemon-colour, nearly half as large again as that of the ordinary form, stronger, less glossy, rather more oblique, and less deeply striated, with the beaks more swollen and the ligament stronger and perceptible.

HABitat: Lakes, ponds, and standing water in all parts of the kingdom from Zetland to the Channel Isles. Malm has described and figured it as a Swedish ${ }^{*}$ Glossy. 
species ; and Moquin-Tandon has noticed it as Corsican. I have found it also on all parts of the Continent. The variety splendens of Bandon occurs in lakes near Lerwick, and at Balmacarra in West Ross. A monstrosity or distortion of this species, as well as of $P$. fontinale (var. Henslowana), is sometimes met with, which has the valves constricted or divided by a longitudinal groove. This accidental phenomenon in the typical form of $P$. fontinale induced M. Bourguignat to consider it a distinct species, and to give it the name of $P$. sinuatum. It is caused by a laceration or injury of the front margin of the mantle.

This may be distinguished from all the preceding species by its rounded outline, much more glossy and iridescent appearance, and by a few separate and deeper grooves or lines which encircle the beak and are especially perceptible in young shells. This is also the only kind of Pisidium which has the tube funnel-shaped and its outer margin crenulated or plaited. For the discovery of this species science is indebted to Mr. Jenyns.

\section{Oblong.}

\section{P. Ro'SEUM* ${ }^{*}$, Scholtz.}

P. roseum, Scholtz, Schlesien's L. - und W.-Moll. p. 140 ; Jeffr. in Ann. Nat. Hist. s. 3. vol. iii. p. 38, pl. ii. f. 3.

BoDy opaline white, orange-yellow, red, or rose-colour in the upper part: tubelong, slender, subconical, and truncate at its orifice : foot long, semitransparent.

SHell subrhombic, ventricose, thin, very glossy, deeply and regularly striated concentrically : yellowish-white or light horn-colour: epidermis extremely thin: anterior side truncate and sloping abruptly below: posterior side much produced and rounded : lower margin nearly straight : beaks placed considerably on one side, rather prominent, but obtuse: ligament

\footnotetext{
${ }^{*}$ Rose-colour.
} 
inconspicuous: inside nacreous-white: hinge-line nearly straight; cardinal teeth very minute and almost imperceptible; lateral teeth not well developed, except towards their outer edges, which are strong and sharp: muscular and pallial scar's scarcely visible. L. $0 \cdot 1$. B. $0 \cdot 15$.

Habitat: Marshes, ponds, ditches, and stagnant water from Zetland to Guernsey. It also occurs in Silesia, Sweden, and France; and I have found it in Prussia. It has probably escaped notice in other parts of the Continent.

This species differs from all its congeners in its oblong or rhomboid shape, which is principally owing to the greater extension of the posterior side, and to the beaks being consequently placed so much out of the centre, as well as to the compression and nearly straight outline of the lower or front margin. It is considerably more ventricose than $P$. nitidum, which it resembles in its gloss and sculpture. The umbonal striæ are, besides, not perceptible in the species under consideration; and the tube does not appear to have the margin of its orifice plaited. The body has usually a rosy or reddish hue in the upper part, which is discernible in the dried animal.

It was not without much hesitation that I adopted the name given by Scholtz for this species, because in a Supplement to the second edition of his work he considered it to be a variety of $P$. fontinale; but the colour of the animal, which at first induced him to propose this as a distinct species, appears to form a good and constant mark of distinction, and one of the epithets which he applied to the shell ("länglichrundlich") is very appropriate. The only other species of Pisidium besides this, which Scholtz has noticed, are fontinale, amnicum, and obtusale. Whether it may ultimately be united with nitidum is, however, a question which I, for 
one, shall not consider unreasonable, although my present impression is that they are distinct species. The variation of form and sculpture is undeniably very great in all freshwater shells; and this is probably caused not only by the greater or less supply of food procurable by these mollusks, but also by the chemical ingredients of the water from which their materials are secreted or extracted. Development of size, and of particular portions of the shell (by which its shape is determined), seems to depend on the former condition, while its solidity and sculpture are affected by the nature of the fluid which these mollusks inhabit. The present species is the $P$. tetragonum of Normand and the $P$. arcaforme of Malm.

As some test of specific distinction, I would remark that the following species of Pisidium are often found living together: viz., amnicum and fontinale (var. Henslowana); fontinale and pusillum; and fontinale (var. pallida), nitidum, and roseum. Each of the above is also sometimes found solitary, or in company with various species of Spharium.

\section{Family II. UNIONID $Æ$.}

BoDy oblong, compressed: mantle open on all sides except at the back, but forming at the posterior side two orifices, which correspond with the cylinder or tubes of the Sphceriidce. The smaller and upper, or excretal, orifice is separated from the larger and lower, or branchial, orifice by an intermediate fold of the mantle. The margin of the first-mentioned orifice is plain; but the other is fringed with several rows of cirri or tentacles. Mouth placed as in the last family. Foot large, broad, and tongue-shaped.

ShELr equivalve, oblong, inequilateral, compressed : epidermis thick : beaks (which form the nucleus or young shell) plaited or wrinkled : ligament external, strong, and always conspicuous: inside pearly: hinge furnished with lateral teeth 
only; those on the anterior side being sometimes so much developed as to resemble cardinal teeth.

Some of these mollusks, which are often called "freshwater Mussels," are ovoviviparous, like those of the last family, and retain their young within the folds of the mantle for some time before they are finally excluded; while others are oviparous, like the majority of mollusks. It was for a long time supposed that they were of separate sexes, and Von Siebold distinguished Anodonta cygnea as the male, and A.Cellensis as the female, of the same species; but Moquin-Tandon seems to have now proved satisfactorily that both sexes are common to each individual or that they are all monœcious. They inhabit rivers and other large pieces of water. Their habits are tolerably active in the spring, or when in search of a suitable feeding-place ; and by means of their large fleshy foot they are able to traverse considerable distances, leaving a track or furrow in the soft mud. When the water is slowly drained off, or dried up by the heat of summer, as well as in the winter, they bury themselves in the mud. Their food consists of Entomostraca and other minute animals. According to Mr. Anthony, an American conchologist, who has especially studied the members of this family, some species spin a byssus. It is difficult to separate this family from their marine analogues, the true Mussels, on merely malacological grounds; but I believe a good conchological distinction (considering the shell to form an integral and important part of the animal) is maintainable in the position of the ligament and beaks. The former is external in the Unionider, while it is internal in the Mytilides; and the beaks are nearly terminal in the latter, but in the former they are seldom placed at a less distance than one-fourth from the anterior end. Besides these marks of distinc- 
tion, there are no lateral teeth in Mytilida, and in $M y$ tilus the cardinal teeth are conspicuous. In the Unionidde, on the other hand, the lateral teeth are always, and the cardinal teeth never, present. I am quite aware that this last statement will be objected to by all those conchologists who believe that, at all events, the shells of Unio are furnished with cardinal teeth. But I venture to submit that these teeth are lateral, and not cardinal; that they are not, like the cardinal teeth in the Sphocriidos, placed at a right angle to the hinge-line, but that they are, on the contrary, parallel to it; and that they are always lamellar and form more or less elevated ridges, like the true lateral teeth in other bivalves. In the genus Anodonta, indeed, the lateral teeth are not so strongly developed as in Unio, and they may in some cases be considered as rudimentary; but in nearly all the species of Anodonta these teeth form a well-defined and often sharp crest, especially on the posterior or ligamental side. The unusually great length and strength of the ligament in Anodonta seems to render the use of lateral teeth in supporting the hinge almost unnecessary; and in this, as well as in many other cases of a similar kind, the original form of such organs is retained in an imperfect state, although their use has ceased to exist.

The study of the European members of this family has for a long time attracted the attention of continental naturalists ; and Carl Pfeiffer, Rossmässler, and Henri Drouet have especially applied themselves to this difficult task. A valuable monograph has been published by the last-named naturalist, entitled "Etudes sur les Naïades de la France ;" the work being dedicated to the late King of Portugal, whose devotion to conchology was the more remarkable because this branch of natural history has not been cultivated by many crowned heads. 
In this country very little has been done to advance our knowledge of the Unionidas; and it would be extremely desirable if naturalists who reside in the country would carefully notice and record any instances of different kinds occurring in the same waters, and whether any intermediate forms are found in such localities.

\section{Genus I. U'NIO*, Philippsson. PI. I. f. 5, 6.}

BoDy elongated, rather ventricose : gills nearly straight: labial palps ovate.

SHell elongated, solid: lateral teeth strong: lunule or heart-shaped depression on the anterior side distinct.

This genus was founded by Philippsson in 1788 in an inaugural Lecture entitled "Dissertatio historico-naturalis sistens nova Testaceorum genera;" but, owing to the circumstance of its having been delivered at a meeting of which Retz was the president, the latter has usually had the credit of founding the genus. From this genus it has been since proposed to separate the Pearl-Mussel, under the name of Margaritana, or Alasmodon, on account of the teeth being less developed; but there does not appear to be sufficient reason, on conchological grounds, for this separation. The animals, or bodies, of these so-called genera cannot be distinguished from each other. All the species are, according to Moquin-Tandon, oviparous.

Many species of Unio have been described by Continental writers; and even Moquin-Tandon, who is by no means addicted to this kind of manufacture, has admitted no less than eleven. Two of these (viz. U. Batavus, and $U$. rhomboideus [or littoralis]), which are widely diffused throughout France, have not yet been detected in 
this country, although the latter is not uncommon, in a fossil state, in our upper freshwater tertiary beds.

That part of the shell which surrounds the beaks (called the "umbonal region") is sometimes eroded or excoriated in these, as well as in other members of the family. I believe it is caused by the chemical action of gases which are evolved from the mud in which this portion of the shell is usually imbedded. No reliance can therefore be placed on such a feature as a mark of specific distinction.

The word "Unio" is, according to Pliny, masculine.

\section{Unıo 'Tu'Mrdus*, Philippsson.}

U. tumidus, Philipps. Nov. Test. Gen.p. 17; F. \& H.ii.p. 140, pl. xl.f. 1.

BoDy greyish : mantle bordered with white; the excretal orifice being produced into a short tube, and of a brownish colour with sometimes a few purplish streaks; the branchial orifice mottled with orange-brown : foot milk-white, with a pale orange tint, thick and broad: gills pale grey: labial palps rather broad.

Shell oval, very convex above, solid, rather glossy, yellowish-brown, transversely wrinkled: epidermis rather thick: beaks slightly incurved, and placed at a distance of about onefourth from the anterior side: umbonal region prominent and strongly plaited in a wave-like manner, the folds sometimes rising into sharp knobs or tubercles: lunule lance-shaped and narrow: ligament short, strong, and prominent: anterior side rounded and regularly sloping towards the front: posterior side gradually sloping to a wedge-like point: lower margin regularly curved : inside white and nacreous, with a faint tinge of blue: hinge strong; the right valve having on its anterior side a broad, thick, and bifid tooth, which is slightly bent forwards, and irregularly grooved so as to make its crest notched, and having on its posterior side a long and deep channel or groove, formed by a double plate, to receive the corresponding tooth of the other valve; left valve furnished at its anterior side with a single wedge shaped and strong

* Swollen. 
tooth, which is also grooved and notched like the double tooth of the right valve into which it locks; this valve has also a long, sharp and crest-like plate on the posterior side which is morticed into the channel or groove above mentioned: muscular and pallial scars very deep and distinct. L. 1-5. B. 3.

Var. 1. radiata. Shell thinner: epidermis green, marked with divergent yellow rays, which are interrupted by transverse narrow zones of the latter colour : posterior side more compressed above: hinge-line nearly straight, especially in half-grown specimens.

Var. 2. ovalis. Shell triangular-oval, or wedge-shaped, compressed and somewhat incurved in the middle, rather inequivalve in consequence of the right valve slightly overlapping the other, dark olive-brown : anterior side much broader and abruptly truncate: lunule very broad, deep, and oblique. Mya ovalis, Montagu, Test. Brit. pp. 34 \& 563.

HabiтAт : Rivers, canals, and ponds in England as. far north as the Went in Yorkshire, and also in South Wales; and it is one of our upper tertiary fossils. Its range extends northwards as far as Finland; but it does not appear to have been met with south of the Rhone. Var. 1. R. Avon, near Bath (Clark); Railway lake near Oxford (Whiteaves). Var. 2. R. Avon, Wilts (Montagu); R. Brent (Metcalfe); and from Mrs. Loscombe's collection of British shells. The late Mr. Clark also found this variety near Bath, having a green epidermis which is marked longitudinally with yellow rays, and transversely with alternate zones of green and yellow. My cabinet contains a specimen of the last variety, which was sent by Col. Montagu to my late friend Mr. Dillwyn, and by the latter presented to me with a few other typical specimens from that excellent British zoologist. The inside of each valve bears, in his well-known handwriting, the words "Mya ovalis, Wiltshire." This, therefore, shows what Montagu's species really was; and it is the more interesting because the authors of the 'British 
Mollusca' referred it both to U. tumidus and U. pictorum, while Moquin-Tandon considered it to be a variety of $U$. Batavus. It is more strictly a monstrosity, or abnormal form, than a variety.

This species sometimes occurs in company with the next. The Rev. A. M. Norman has recorded in the 'Zoologist' for 1857 having taken specimens at Fleckney and Wistow in Leicestershire of the extraordinary dimensions of nearly $4 \frac{1}{2}$ inches in breadth and more than 2 inches in length, the weight being over 3 ounces. Beneath the epidermis the colour of the shell in this and the next species is cream-white. A single individual of $U$. tumidus has been known to lay 1500 eggs in two or three days. They are deposited in small clusters, each .of which contains about 100 eggs.

\section{U. PICTO'RUM*, Linné.}

Mya pictorum, Linn. Syst. Nat. ed. xii. p. 1112. U. pictorum, F. \&. H. ii. p. 142 , pl. xxxix. f. 1 , and (animal) pl. Q. f. 2.

BoDy clear red, with a more or less greyish tint: mantle bordered with brown; orifices of the same form and colour as in the last species : foot reddish or yellowish-white, large and tongue-shaped : gills grey : labial palps oval.

SHeLl oblong, compressed, not so solid as the last species, glossy, yellow, with narrow zones of brown which denote the marks of growth, transversely wrinkled, with stronger furrows on the posterior side : epidermis rather thin : beaks very little incurved, and placed at a distance of between onefourth and one-fifth from the anterior side: umbonal region not so prominent nor so strongly wrinkled as in the preceding species: lunule long and narrow: ligament longer than in $U$. tumidus: upper margin or hinge-linenearly straight: anterior side rounded: posterior side very gradually sloping and rounded atits extremity, compressed or pinched-up above: lower margin nearly straight: inside cream-white or salmon-colour, highly nacreous: hinge not so strong as in the last species; the teeth 
similarlyarranged, but they are finer, sharper, and more erect: muscular scars distinct: pallial scar faint, owing to the greater thickness of the nacreous lining. L. 1-33. B. 3.

Var. 1. radiata. Shell having faint and narrow rays of green which diverge from the beak.

Var. 2. curvirostris. Shell smaller, shorter, and flatter: epidermis yellowish-green, with brown zones: posterior side curved and wedge-shaped. U. curvirostris, Normand.

Var. 3. latior. Shell broader and shorter, yellowish-brown.

Var. 4. compressa. Shell very broad and flat; upper margin raised and curved: posterior side greatly compressed and attenuated, assuming a beak-like form, and having a double ridge and furrow which runs from the beak in the younger state of growth : lower margin straight: lunule broad, and extending between the beaks, so as to separate them from each other.

Навітат : Rivers, ponds, and canals throughout England; but it does not appear to have been found north of Yorkshire. It is also one of our upper tertiary fossils. It ranges from Finland to Algeria and Sicily. Var. 1. R. Avon, Bath (Clark). Var. 2. From Clark's and Mrs. Loscombe's collections of British shells, but without any indication of locality. Var. 3. Canal near Oxford (Whiteaves). Var. 4. Norwich (Bridgman). This remarkable form might easily be raised to the rank of a distinct species; but I can only regard it as abnormal, and analogous to the variety ovalis of $U$. tumidus.

This species was confounded by Lister, Linné, Müller, Draparnaud, and all the older writers with $U$.tumidus. It differs from that species in the form of the shell, which is oblong instead of oval ; in its much greater proportionate breadth; its thinner texture; in the upper and lower margins being nearly straight and parallel, instead of being curved and wedge-shaped; in the umbonal region being much less prominent and swollen; and in 
the hinge not being so strong, nor the teeth so thick, as in U. tumidus. It has been noticed by Mr. Norman to attain, in ponds at Fleckney and Wistow in Leicestershire, the great size of $4 \frac{7}{10}$ inches in breadth and $2 \frac{1}{5}$ in length, and to weigh $2 \mathrm{oz} .6 \mathrm{dr}$.

It is, however, by no means easy to draw a satisfactory line of separation between this and the last species, which are connected by several intermediate forms, and especially by the U. Philippi of Dupuy. The fact of their inhabiting the same spot shows, at all events, that one of them is not a local variety of the other; and this ought, I think, to weigh in the scale of specific distinction. Whether one, or both, of these now reputed species have become in course of time permanent varieties or "races" of the same or some other species, may be regarded as an antiquarian (although interesting) question, which does not properly belong to the province of the zoologist.

Both of these species produce pearls, though of very small size and inferior lustre. A consolidated mass of pearly secretion is sometimes formed inside the right valve near the margin of the posterior side. The shells were used by Dutch painters (from which the specific name of pictorum originated) for holding their colours ; and they are still to be had of any artists'-colourman in this country, containing a preparation of ground gold and silver leaf, for illuminating work, the other purpose having been superseded by palettes. Bouchard-Chantereaux calculated that each individual of $U$. pictorum produced, in the breeding-season of May, June, and July, no less than 220,000 eggs.

The variety curvirostris bears a strong resemblance to some of the varieties of $U$. Batavus; but there is no satisfactory proof of that species having been found in 
Great Britain. A specimen named Unio Batavus in Dr. Turton's collection of British shells is clearly a dwarf variety of that species, and is the Unio nana of Lamarck, U. amnicus of Ziegler, U. Batavus var. є. pusillus of Rossmässler, and $U$. nanus of Dupuy. This specimen does not at all agree with the description or figure given by Turton of his Mysca Batava in his 'Manual'; and it was not accompanied by any note of the locality. I do not, however, despair of this species, as well as of $U$. rhomboideus (or littoralis), being discovered in this country. Both of them inhabit the North of France; and the latter once lived in our eastern counties.

\section{U. MARGARI'TIFER*, Linné.}

Mya margaritifera, Linn. Syst. Nat. ed. xii. p. 1112. U. margaritiferus, F. \& H. ii. p. 146, pl. xxxviii (as Alasmodonta margaritifera).

BoDy dirty grey, with sometimes a tint of flesh-colour; mantle bordered below with brown, and above with white; cirri oblong and dark brown : foot large, tongue-shaped, greyish-yellow, or dirty red: gills greyish-brown, with whitish streaks : labial palps broader than long, and united for twothirds of their length.

SHELL oblong, much compressed, solid, having adullsurface, dark brown, or nearly black, transversely and irregularly wrinkled, especially on the posterior side, with very fine but obscure longitudinal striæ, which are interrupted by the lines of growth : epidermis thick : beaks incurved, and placed at a distance of about one-fourth from the anterior side: umbonal region not prominent, always decorticated or eroded, and to such an extent as to expose several of the inner layers: lunule narrow and indistinct: ligament very long, and extending to the anterior side: hinge-line curved: anterior side rounded: posterior side very gradually sloping and rounded at itsextremity, pinched-up above into a blunt keel or ridge: lower margin straight: inside pearly-white, with a tint of flesh-colour and blotches of olive-green in the region of the adductor muscles, pitted in the middle by tubercular folds of the mantle: hinge

$$
\text { * Pearl-bearer. }
$$


strong; the right valve having on its anterior sidea very broad, thick, and blunt double tooth, the crest of which is irregularly tubercled, and on its posterior side a blunt and obscure ridgelike plate, which in young specimens is grooved or double; left valve furnished at its anterior side with a single, conical, strong and blunt tooth which locks into the double tooth, the posterior tooth in this valve being similar to thecorresponding one in the right valve: muscular and pallial scars very deep and distinct. L. $2 \cdot 4$. B. 5 .

Var. 1. sinuata. Shell rather broader in proportion to its length than in the type, yellowish-brown: lower margin incurved towards the middle. U. sinuata, Lam. Hist. An. s. v. vi. pt. i. p. 70 .

Var. 2. Roissyi. Shell proportionablylonger: lower margin convex, or rounded. U. Roissyi, Michaud, Compl. p. 112. pl. xvi. f. $27,28$.

HaвiтAт: Mountain rivers and streams throughout the British Isles. It is found in several parts of the Swansea Canal where the bottom is gravelly, having been carried in by the water-courses which supply it. It also ranges through the mountainous and hilly parts of the Continent from Lapland to the Pyrenees. Var. 1. West of Scotland (Bedford and J. G. J.) ; West of Ireland (Humphreys and Barlee). A specimen of this form from Co. Kerry measures nearly 6 inches in breadth or width. Var. 2. Yorkshire (Sowerby). A monstrosity also occurs having a longitudinal ridge in the middle of the shell.

This species differs from all the others in its shell being much longer (measured from the beak to the lower or front margin) as well as more depressed, in its dull aspect and much darker colour, the extensive erosion of its umbonal region, and especially in the posterior teeth being scarcely developed.

The lining of mother-of-pearl is equal to half the entire thickness of the shell, as may be seen by grinding 
and polishing one of the valves. The surface of the shell is of a dull white beneath the epidermis. Pearls obtained from this kind of Mussel are mostly white; but they are sometimes green or brown and occasionally (but very seldom) they are met with of a lovely pink colour and worth being set in a brooch or ring.

In Forbes and Hanley's work will be found a full and interesting account of the freshwater pearl-fisheries, which have been for so many centuries, though with little success, prosecuted in these Islands. But to amuse my readers, and to give some idea of the state of Natural History in Camden's time, I will add the following extract from his 'Britannia,' under the head of "Cumberland."

"Higher up, the little river Irt runs into the sea, in which the shell-fish having by a kind of irregular motion (oscitatione) taken in the dew, which they are extremely fond of, are impregnated, and produce pearls, or to use the Poet's phrase, baccee concheae, shell-berries, which the inhabitants, when the tide is out, search for, and our Jewellers buy of the poor for a trifle, and sell again at a very great price. Of these and the like Marmodeus seems to speak in that line,

"Gignis et insignes, antiqua Britannia, baccas."

It seems that Marmodeus wrote a Latin poem on jewels and precious stones, which was published at Cologne in 1539.

Genus II. ANODON"TA*, Lamarck. Pl. II. f. 1, 2.

BoDy oblong-oval, compressed : gills flexuous : labial palps lanceolate.

SHeLL oblong-oval, thin : hinge having only rudimentary teeth: lunule slight and indistinct.

\section{* Toothless.}


The habits of the Anodontce are the same as those of the Uniones; but they differ, according to Moquin-Tandon, in being ovoviviparous.

It is by no means an easy task to distinguish some of the species of Unio; but the difficulty is much greater in attempting to separate the various forms of Anodonta. Even the great Danish naturalist, Muiller, entertained grave doubts, nearly a century ago, whether there existed more than one Scandinavian species; although his hesitation was not participated in by Nilsson and subsequent writers on the Mollusca of that country. In other parts of the Continent, the long array of specific names, which have been recorded by $H$. Drouet, shows that the tendency of modern conchologists has been vastly to increase the number of European species. In this country, Montagu, with all his powers of discrimination, evidently entertained considerable doubt as to the specific difference between $A$. cygnea and $A$. anatina; and Turton, more than thirty years ago, expressed his opinion "that all our supposed species of this genus may be justly resolved into one, varying in their outline, consistence, and colour, from age and local circumstances." This view has been adopted by Dr. Gray and the authors of the 'British Mollusca.' However, as long as any distinction of species is recognized, we must endeavour to deduce from the observation of natural phenomena any facts which may facilitate such investigation. One of these facts seems to consist in ascertaining whether any different forms inhabit together the same spot and under exactly similar conditions, without any appearance of an intermediate link or gradation. Montagu has recorded such a fact with respect to his Mytilus avonensis and $M$. anatinus; Drouet has given other instances of the collocation of several species of Anodonta in French 
waters; and Baudon has also noticed the same circumstance in the Département de l'Oise. All these cases would lead us to infer that there exist at least two distinct species of Anodonta in the North of Europe; and I am only at present prepared to go to this extent. At the same time, I do not dispute the claims of other forms to specific rank. It would be unseemly, as well as unjust, thus to depreciate the labours of those naturalists who have so ably and carefully endeavoured to solve this perplexing problem; and there is quite as good reason for believing that their views as to the extension, are as correct as ours as to the reduction, of the specific line. Although, therefore, I only propose to admit two old Linnean species (A. cygnea and A. anatina), some at least of the varieties hereafter indicated may be considered distinct species by those of my readers who from experience or choice may be inclined to take another view of the case.

\section{Anodonta Cyg'neA*, Linné.}

Mytilus cygneus, Linn. Syst. Nat. ed. xii. p. 1158. A. cygnea (partly), F. \& H. ii. p. 155, pl. xl. f. 2, 3, \& xli, and (animal) pl. Q. f. 3.

BoDy grey, with a yellowish or reddish tint: mantle bordered with tawny-brown: foot large, broad, dirty-yellow, with a tinge of orange or red: gills grey, with occasionally a reddish hue, of a gauze-like texture : labial palps broadly triangular.

SHELL oblong, rather ventricose, thin, moderately glossy, yellowish-green or brown, transversely and irregularly grooved by the lines of growth, and wrinkled in the same direction on the posterior and lower sides: epidermis thin: beaks straight, placed at a distance of about one-fourth from the anterior extremity: umbonal region compressed, strongly plaited: ligament rather long, strong, partly concealed within the overlapping edges of the upper margin or hinge-line, which is straight: anterior side not gaping, rounded, and abruptly

* Belonging to (e. g. food for) swans. 
sloping below : posterior side gradually sloping and compressed above, produced into a rounded wedge-like point, and gaping: lower margin nearly straight: inside pearl-white and highly iridescent: hinge slight, having a rather sharp ridgelike plate on the posterior side in each valve: muscular and pallial scars very slight and indistinct. L. $2 \cdot 75$. B. 5·35.

Var. 1. radiata. Shell larger, yellowish-green, beautifully marked with longitudinal rays or streaks of the same colour, which are sometimes alternate: beaks placed at a distance of only one-third from the anterior side. Mytilus radiatus, Müll. Verm. Hist. pt. ii. p. 209.

Var. 2. incrassata. Shell more swollen and solid, olivebrown: upper margin, or hinge-line, rather curved on the posterior side. Mytilus incrassatus, Shepp. in Linn. Trans. xiii. p. 85, pl. 5. f. 4.

Var. 3. Zellensis. Shell broader, yellowish-brown, having the upper and lower sides nearly parallel; posterior side much produced. Mytilus Zellensis, Gmel. Syst. Nat. p. 3262.

Var. 4. pallida. Shell light yellow or fawn-colour: hingeline rather curved, and raised on the posterior side, which is produced to a long wedge-like point: lower margin rounded.

Var. 5. rostrata. Shell oblong-oval, somewhat resembling in shape Modiola vulgaris: upper margin forming a dorsal crest, which is slightly raised and curved: anterior side rounded: posterior side attenuated, and ending in a long curved wedge-like point: lower margin nearly straight. $A$. rostrata, (Kokeil) Rossmässler, Iconogr. iv. p. 25, f. 284.

Habitat: Slow rivers, lakes, canals, and ponds throughout the kingdom as far north as Banffshire; and it is one of our upper tertiary fossils. It ranges from Siberia to the Pyrenees. Var. l. Bog of Allen, Ireland (Turton); Clumber lake, Notts (J. G. J.). This variety is the Mytilus stagnalis of Gmelin, the M. dentatus of Turton's Conchological Dictionary, and the M. paludosus of his work on the British Bivalves. Specimens of this variety measure upwards of 6 inches in breadth. Dr. Turton's type (of which only one valve remains) has a small pearly tubercle on the ridge of the laminar tooth; 
and I suspect that the Doctor mistook this excrescence for a cardinal tooth, and therefore applied the specific epithet "dentatus." He omitted any mention of this character in his Dithyra, when he changed the name to "paludosus." Var. 2. Scarborough (Bean); Otters pool, Lancaster (Tyler); Oxwich marsh, near Swansea (J. G. J.). This is the A. ponderosa of C. Pfeiffer. Var. 3. Bog of Allen, Ireland (Humphreys); Clumber lake, Notts (J. G. J.). It is the A. Cellensis of C. Pfeiffer. Var. 4. West of Ireland (Humphreys). Var. 5. R. Corfe, Dorset (J. G. J.); ponds at Wistow in Leicestershire, Wynyard Park, Co. Durham, and Oxford (Norman). This appears to be the Mytilus Avonensis of Montagu (Test. Brit. p. 172), judging from his description and the figure of that species which is given by Maton and Rackett in the 'Linnean Transactions,' vol. viii. pl. 3. A. f. 4. The shell of this species is also liable to be distorted; and I have a specimen in which the lower part of the left valve is deeply notched opposite the beak, owing to an injury of the mantle on that side, the other valve being entire.

The fry have triangular and pearly shells, which might easily be mistaken for the valves of a Cypris or smaller Entomostracan. The epidermis only is coloured in this, as well as in the other species: the surface of the shell itself, under the epidermis, is white or colourless.

\section{A. ANATI'NA*, Linné.}

Mytilus anatinus, Linn. Syst. Nat. ed. xii. p. 1158. A. cygnea (partly), F. \& H. ii. p. 155, pl. xxxix. f. 3.

Bopygrey, of differentshades of intensity: mantle bordered with dark brown: foot yellowish-grey, or red: gills greyishbrown.

* Belonging to (e. g. food for) ducks. 
Shell oval, rather compressed, not so thin as in the usual or typical form of the last species, olive-green or brown, with darker transverse bands denoting the lines of growth, and irregularly wrinkled in the same direction: epidermis rather thicker than in A. cygnea: beaks straight, placed at a distance of about one-third from the anterior end : umbonal region compressed, closely plaited : ligament short and prominent: upper margin or hinge-line raised into a kind of crest, and curved: anterior side rounded and gaping below, with an oblique slope towards the lower edge: posterior side curved and abruptly sloping to a wedge-like point: lower margin gently curved: inside and hinge as in A. cygnea; but the lining is much thicker in the present species, and the muscular impressions are consequently much more deep and distinct. L. $2 \cdot 1$. B. $3 \cdot 5$.

Var. 1. radiata. Shell (or rather the epidermis) marked with green and yellow rays.

Var. 2. ventricosa. Shell larger, more solid, exceedingly tumid, especially in the middle and towards the umbonal region, also marked with green and yellow rays. A. ventricosa, C. Pfeiffer, ii. p. 30, pl. iii.

Var. 3. complanata. Shell oval, greatly compressed, brown: beaks placed close to the anterior margin: upper margin raised and curved: anterior side abruptly truncate. A. complanata, (Ziegler) Rossmässler, iv. p. 24, f. 283.

Habitat : Same as that of $A$. cygnea; but it ranges further to the south, being a Sicilian species. It has not been noticed in this country as a tertiary fossil. Var. 1. The rayed markings form scarcely a varietal character, being common to half-grown individuals of the last, as well as of this, species. Var. 2. R. Exe (Clark). This variety has been referred by Moquin-Tandon to A. cygnea; but it evidently belongs to the short form, or what is generally called A. anatina. None of my specimens (of which I possess a series) are as broad as the one represented by Pfeiffer in his figure 4. This variety attains a larger size than the typical form, being more than 3 inches long, 5 wide, and 2 in depth. Var. 3. 
Gumfrieston, near Tenby (Smith). A monstrosity, or distortion, of this last variety is also in my cabinet, which is flatter and has a rounded outline above in consequence of the umbonal region not projecting. A young specimen of the same variety is nearly round. This appears to be analogous to the variety rostrata of A. cygnea, and tends to confirm the idea of the two species being distinct.

The chief points of difference between A. cygnea and A. anatina are, that the shells of the latter species are smaller and comparatively longer; the hinge-line or crest is raised in that species, instead of being straight or parallel to the lower margin; and the posterior side slopes abruptly instead of (as in A. cygnea) gradually.

\section{Family III. DREISSENID $A$.}

BoDy nearly rhomboidal, compressed : mantle closed, except at the posterior side, where it is folded into two orifices, one for respiratory and nutritive, and the other for excretal purposes, besides an opening at the lower or front margin for the passage of the foot. The upper, or excretal, fold is the smallest, and is not much produced: the other fold is extended into a pyramidal tube, which has a thickened or reflected margin and is fringed with numerous short spineshaped cirri or tentacles: foot long and tongue-shaped, furnished with a byssal groove.

SHeLL equivalve, oblong, triangular, very inequilateral, ventricose, covered with a thick and horny epidermis : beaks placed at theanterior end: ligament internal: inside porcelainwhite: hinge furnished with minute cardinal teeth, but sometimes toothless; below the beak in each valve is a triangular shelf or hollow plate(as in the marine genus Crepidula)for the reception of the anterior muscle.

These characters are also generic, as the family contains but one genus. In their general aspect the Dreissenida bear a closer resemblance than the last to the 
Mytilida; but the mantle of the animal in the present family is nearly closed, and the hinge of the shell is furnished inside with a transverse plate or septum, which is a peculiar and unmistakeable feature. Mytilus has also several cardinal teeth; but I have failed to detect any in the British species of Dreissena, although the authors of the 'British Mollusca' and Moquin-Tandon mention an "obscure apical elevation," or "dent cardinale à peine saillante," in the right valve of this species. However, cardinal teeth certainly do exist in three species of Dreissena from the Indian and Pacific Oceans, which have been described by Erichson in Wiegmann's 'Archiv für Naturgeschichte' for 1836. The same author also incidentally remarks that the European species (which he called Tichogonia fluviatilis) has a rudimentary tooth. The mantle is for the most part closed and produced into tubes on the posterior side, instead of being open throughout as is the case in Mytilus.

Genus DREISSE'NA*, Van Beneden. Pl. II. f. 3, 4, 5.

Although the establishment of this genus is due to Van Beneden, the probability of its separation from Mytilus was first suggested by an equally distinguished zoologist of our own country, Dr. Gray. The Dreissence may be called "freshwater Mussels" with greater propriety than the Uniones, or Anodonta ; and the habit and faculty which the Dreissence possess, in common with the true Mussels, of mooring or attaching themselves by a strong byssus to extraneous substances, put us very much in mind of their marine analogues. They are also equally gregarious and capable of living for a long time out of water.

* Named after M. Dreissens, a druggist at Mazeylh. 
Only one species is known in Europe; and it was first noticed (in 1754) by the Russian traveller and naturalist, Pallas, in the River Wolga, as well as in the Black Sea. The epithets of "fluviatilis" and "marinus" which he applied to these two forms, coupled with the circumstance that this was antecedent to the era and usage of binomial appellations, have given rise to considerable controversy as to whether these forms belong to different species or to varieties of the same species, one of which has a freshwater, and the other a marine, habitat. The last supposition would be quite consistent with the fact observed by Nilsson, that several shells, which are usually inhabitants only of fresh water, live in the Baltic Sea together with other shells which are peculiarly marine.

\section{Dreissena Polymor'PHA*, Pallas.}

Mytilus polymorphus, \&c., Pallas, It. Russ. i. p. 478. Dreissena polymorpha, F. \& H. ii. p. 165, pl. xlii. f. 4, 5, and (animal) pl. Q. f. 4.

BoDy dark-coloured: mantle borderedinfront with greyishwhite, at the posterior side being yellowish or fawn-colour, and striped like the shell with zigzag marks of reddish-brown; cirri of the branchial orifice arranged in concentric rows, reddish-grey, with a tint of brown at their base: foot oblong and cylindrical, grey, with a slight rosy hue : gills greyish : labial palps ratherlarge, triangular, and lanceolate: byssus composed of several stout and flexible threads.

SHELl oblong, rising into a sharp keel in the middle of each valve and flattened below, pointed at the end or beak, and gradually, but obliquely, widening towards the front, rather solid but not glossy, yellowish-brown, and often marked transversely on the upper part with undulating or zigzag streaks of purple or dark brown, strongly but irregularly wrinkled in the same direction, and longitudinally but slightly puckered at irregular intervals : epidermis silky; beneath the epidermis the surface is purplish-brown: beaks small, quite terminal, and

* Many-shaped. 
much incurved: ligament long and narrow, fitting intoa groove of the hinge in each valve: upper margin angular: anterior side nearly straight: posterior side curved: lower margin incurved, and forming in the middle a large slit for the passage of the foot and byssus: inside slightly nacreous: hinge strong, toothless, but furnished inside each valve with a triangular and concave plate which is placed under the beak: muscular and pallial scars indistinct. L. 1·4. $\quad$ B. 066.

HaвiтAт: Slow rivers, canals, and lakes in the eastern, home, midland, and northern counties of England, as well as in a canal near Worcester (Reece), Bath (Hutton), and at Edinburgh. In the North of France, Belgium, and Germany it is also common and widely diffused. In one respect this species may be said to be truly metropolitan; for it has been found in the most frequented streets of London, after they have been flushed with water from the New River, where it abounds. Mr. Norman informs me that he saw immense numbers of the Dreissena in a living state, lining some of the iron water-pipes which had been taken up in Oxford Street, and that the colouring of the shells was as vivid as if the animal had lived in the light of day.

It is difficult to believe, in the absence of some proof to the contrary, that this species is not indigenous to the whole of the North of Europe, as well as to Russia. The circumstance of its not having been noticed in this country before 1824, and then only in a metropolitan locality, does not preclude the possibility of its having previously existed in some other part of Great Britain ; and its not having been previously recorded as British rather proves a want of observation or opportunity than its non-existence. Helix Cartusiana, H. obvoluta, and Clausilia Rolphii, all of which are conspicuous land shells, were not known to the observant Montagu, although they are not uncommon in some parts of this country 
and are clearly indigenous species; and many other similar instances, both at home and abroad, might be eited on this point, as well as with respect to the sudden and unaccountable appearance and disappearance of certain species in particular spots. With regard to the period at which the Dreissena first made its appearance or was noticed on the Continent, M. Moerch has lately investigated its geographical history and has ascertained that it was common in the interior of Germany before 1780 , and that it then inhabited streams which flowed into the Rhine. In a work by $\mathrm{H}$. Sander of Carlsruhe, published in that year, and entitled "Vaterländische Bemerkungen fuir alle Theile der Naturgeschichte," he described in unscientific, but intelligible, terms a freshwater Mussel which was not uncommon in that district, and to which he gave the name of Pinna fluviatilis. This description clearly applies to our Dreissena. In draining the Haarlem See, the Dreissena was found in abundance; and it appears that no communication ever existed between that great lake and any port or harbour. It has also been found in an inland lake near Copenhagen. It was at one period thought (and even by the unimaginative Linné) that the Teredo, or ship-worm, had been imported into Europe from India; but that idea has been quite dispelled, as much for the reason that some species of Teredo which are found in Europe also occur there in tertiary formations, as because they are different from oriental or tropical kinds. The first of these reasons may again, and with the like success, be urged in favour of the Dreissena being a native of the North of France; for, in a recent article by $M$. Charles D'Orbigny, published in the "Bulletin de la Société Géologique de France' ( $2^{\circ}$ sér. t. xvii. p. 66), and entitled "Sur le diluvium à coquilles lacustres de Joinville," Dreissena 
polymorpha is enumerated as one of the fossils. Mr. Prestwich informs me that this deposit was in all probability contemporaneous with those of St. Acheul and Amiens, and that at all events it belongs to what is termed by modern geologists the upper tertiary formation. I am therefore not without hope that this remarkable shell may be discovered in the corresponding strata in this country. It is frequently found, in a recent or living state, with the Anacharis alsinastrum, an aquatic plant which chokes up our canals and is said to have been imported from North America. Respecting the Anacharis, Messrs. Hooker and Arnott, in their excellent work on the British Flora, remark that "it seems inexplicable how this plant should have occurred in so many different places at the same time." Perhaps if the Eriocaulon septangulare, or Naias flexilis, both of which are also North-American water-plants, and are at present confined to a very few stations in the Hebrides and West of Ireland, had been placed in conditions which were more favourable to their growth and propagation, each of them might have spread with as great rapidity as the $A n a$ charis. If, as I believe, the indigenousness of the Dreissena as regards this country should hereafter be established, the ingenious theories which have been proposed to account for the mode of its transport across the seas will not require further discussion. 


\section{Class II.}

\section{GASTEROPODA*, or UNIVALVES.}

Bopy of a conical shape : mantle forming a single lobe, which only covers the front: head usually distinct, and furnished with tentacles, of which the upper pair (in those kinds which have four), or the single pair, have in most cases two eyes, placed either at their tips or base, or on separate stalks : foot a muscular disk, by means of which the animal generally crawls, or sometimes floats in an inverted position on the under surface of the water: reproductive system various; some kinds being hermaphrodite, and having both sexes united in the same individual, but requiring impregnation by another individual; while in other kinds the sexes are separate, each individual being either maleor female: respiratorysystem consisting of gills, or lung-like organs ; the former, and some of the latter, being possessed by aquatic kinds; while the terrestrial kinds are only furnished with the lung-like organ: those kinds which are aquatic, and have this last organ, eliminate oxygen from the water and also respire atmospheric air; but the terrestrial kinds, or Snails, breathe only the pure air, like vertebrated land animals.

SheLL usually present, conical or spiral, and covering the whole, or most important parts, of the body.

The only two Orders which we have to deal with in this division of the subject are as follows :-

\section{Pectinibranchiata. \\ II. Pulmonobranchiata.}

\section{Order I. PECTINIBRANCHIATA $\dagger$}

BoDY spiral : respiratory apparatus consisting of a single comb-like gill, which is placed within the mantle, on the upper side of the head.

Shell external and spiral.

* Foot forming the belly.

† Having comb-like gills. 
Only three families of this Order inhabit the fresh waters of this country. They are,-
I. Neritid 平.
II. Paludinidas.
III. Valvatid A.

All these freshwater Snails have two tentacles, and the same number of eyes, which are placed at the base of the tentacles. Their shells are furnished with an epidermis and operculum.

\section{Family I. NERITID $Æ$.}

BoDY oval, having a short spiral turn at the end: eyes placed outside the tentacles at their base: gill inside the mantle: sexes separate.

SHell semiglobose, with an excentric spireanda semicircular mouth : operculum having an excentric and short spire, and furnished underneath with an apophysisor projecting process which locks into the columellar or pillar lip.

Although the members of this family are very numerous and widely dispersed beyond the limits of our seas, we have only a solitary representative, forming the single species of one genus.

\section{NERITI'NA*, Lamarck. Pl. III. f. 1, 2, 3, 4.}

Bopy furnished with a strong and prominent snout or muzzle : tentacles long: eyes placed on footstalks : foot broad.

Shell triangular-oblong : operculum calcareous and solid.

The mollusks of this genus inhabit waters which have a stony or gravelly bottom. Their habits are sluggish; raising their shell but little during their march, and then only showing their tentacles, eyes, and the front of their

* Diminutive of Nerita, a genus of marine shells. 
mantle. They have not been observed to float, or creep on the under surface of the water, which may account for the shells being so often found encrusted with calcareous matter. Their tentacles, however, appear to be extremely sensitive and always in motion. They are vegetable feeders. Their eggs are generally deposited and carried on the shell until they are hatched or developed. These are rounded, of a yellow colour, and provided with a thick and leathery covering, which splits in two when the fry are excluded, the upper half being detached and the other part left adhering to the parent shell. Moquin-Tandon says the eggs are deposited in a cluster of from 50 to 60 .

Valuable notices of the genera Nerita and Neritina by M. Récluz will be found in the 1st volume of the 'Journal de Conchyliologie;' and M. Pouchet has published an elaborate monograph on the Nerita fluviatilis, considered in an anatomical and physiological point of view. Neritina is very closely allied to Nerita, and probably only forms a section of the latter genus. There are marine, as well as freshwater, species of Neritina.

\section{NeritiNa Fluvia'Tilis*, Linné.}

Nerita fluviatilis, Linn. Syst. Nat. ed. xii. p. 1253. N. Auviatilis, F. \& H. iii. p. 3, pl. Ixxi. f. 1, 2, and (animal) pl. H. H. f. 1 .

BoDY of a clear yellowish-grey, speckled with black above, white below : head and snout black : mouth very large, furnished with cartilaginous jaws and a lingual plate or riband, which is very complicated: tentaclesclear greyish-white, darker at the sides, and more or less streaked with black transversely; they diverge widely from their base, and are very slender, ending in a fine point: eyes very large and black : foot obtusely rounded in front, and having its extremity or tail covered by the operculum when the animal is crawling.

SHeLL convex above, slightly compressed towards the spire,

$$
\text { * Inhabiting rivers. }
$$


and almost concave below, solid, moderately glossy, yellowish or brown, with often brown or white zigzag streaks, spots, or bands, which run lengthwise or in a spiral direction, and marked with fine but distinct transverse striæ or plaits, which are more conspicuous towards the suture: epidermis thin: whorls 3 , rather convex, the last or lowermost exceeding twothirds of the whole shell, increasing very rapidly and disproportionately in size: spire very short and oblique: suture rather deep: mouth, or aperture, semilunar: outer lip sharp: pillar-lip exceedingly broad, polished and flat, with a sharp and plain edge: operculum semilunar, glossy, of an orange or yellowish colour, marked spirally with two or three slight grooves, and transversely with numerous and flexuous striæ; its external edge is thin and has a border (sometimes two) of black or yellowish-red, both above and below; its internal edge is thick; the spire of the operculum is placed at the lower side, and formed of $1 \frac{1}{2}$ or 2 whorls ; attached to the under side of the opercular spire is a singular process, resembling a second but much smaller operculum, which has also a thickened edge on the inside, and projects obliquely so as to act as a bolt in fastening the operculum to the pillar-lip. L. $0 \cdot 35$. B. $0 \cdot 25$.

Habitat : Slow rivers, streams, and lakes through or into which water flows, or having a stony or gravelly bed, in all parts of the kingdom, from the Orkneys to Cornwall. It has been found in the peat-bed at Newbury; but this is not, I believe, recognized as belonging to the upper tertiary formation. This species ranges from Finmark to Algeria and Sicily, where the form or variety called by Lamarck $N$. Bcetica prevails. A dwarf variety has been described by Nilsson, which inhabits the shores of the Baltic Sea, adhering to seaweeds and stones, sometimes at a distance from the mouth of any river, and living in company with the common Mussel and a few other decidedly marine shells. He also noticed that these last are similarly dwarf forms. A variety in which the shell is quite black has been found by Mr. North in the Ouse. Many other varieties have been 
described by European authors as distinct species; but they appear only to differ from the typical kind in size and colour, as well as in the spire being more or less excentric. In adult specimens, the septa or internal walls of the spire are wanting, and appear to have been absorbed, as stated by Dr. Gray. This is also the case in Melampus or Conovulus.

\section{Family II. PALUDINID压.}

Bopy elongated, spiral, and having a prominent snout: eyes placed outside the tentacles at their base : gill inside the mantle : sexes separate.

SHELL having a long symmetrical spire and an oval mouth: operculum also oval, irregularly concentric or paucispiral.

These mollusks are, as well as those of the last family; herbivorous; but they differ in being ovoviviparous, instead of oviparous. Their habits are much more active than those of the Neritida. They sometimes, but rarely, float. The fry are furnished with opercula before they are excluded by the mother. According to BouchardChantereaux, the young remain in the ovary, to the number of 20 or 30, for two months, at the end of which time only 2,3 , or 4 are born, the period of accouchement extending over several days.

Genus I. PALUDI'NA *, Lamarck. Pl. III. f. 5, 6.

Eyes placed on short pedicles or footstalks: operculum horny, irregularly concentric, and having its nucleus on the inner side.

Lister and Cuvier have investigated, although at very distant intervals, the anatomy of these mollusks, which

* Inhabiting marshes. 
are the largest of our freshwater Pectinibranchs. Lister says he was indebted to Dr. Plot, the historian, for the discovery that they were viviparous; and he says that the males are smaller than the females and their shells have less-swollen whorls. They inhabit slow rivers, ponds and canals; and one species lives within the influx of the tide in the Thames. The epidermis of the last-formed whorl in the young shell, when it leaves its mother, has three transverse rows of recurved bristles, which in after-growth are replaced by the coloured bands that encircle adult shells, the formation of these bands, as well as of the bristles, being caused by different organs which are successively developed in the same part of the mantle. It has been stated in that useful periodical 'The Zoologist' (p. 7402) that our native Paludinoe are not always viviparous, and that a specimen of $P$. vivipara deposited in an aquarium some eggs from which the fry were subsequently excluded. This was in the winter, and after the Paludina had been kept for many months in a state of confinement. It is hoped that further observations will be made on this point, as the ovoviviparous character of this genus constitutes one of the grounds of distinction from the next genus, Bythinia.

\section{Paludina conted'ta*, Millet.}

Cyclostoma contectum, Millet, Moll. Maine et Loire (1813), p. 5. P. Listeri, F. \& H. iii. p. 8, pl. lxxi. f. 16.

BoDy dark grey or brown, with yellow specks: head small, but globular: snout prominent and bilobed: tentacleslong and widely spread out, blackish, with grey tips; the right tentacle of the male shorter and thicker at its point than the left: eyes round and black : foot cloven or bilobed in front, and rounded behind; its tail or extremity nearly covered by the operculum when the animal is crawling.

* Covered (i. e. by the operculum). 
SHELL conical, moderately solid and glossy, yellowish, with sometimes a green or brown tinge; the last whorl having 3 , and each of the two preceding whorls 2, spiral brown bands, the uppermost of which is usually the broadest; there are also numerous and very fine spiral striæ, besides faint and irregular lines of growth : epidermis iather thick : whorls 7, extremely convex ; the last being equal to about one-half of the shell ; they increase gradually in size, except the two first, which are disproportionately small and twisted, resembling those of Succinea: suture remarkably deep: mouth oval, or approaching to a circular shape: outerlip sharp and slightly reflected: inner lip separate from the columella; both lips forming a complete peristome: umbilicus small, oblique, but very distinctand deep, exposing part of the internal spire: operculum rather thin, compressed towards the nucleus, which causes the under side to project, like the boss of a shield ; it is marked with numerous concentric striæ and more distant lines of growth. L. 1.5. B. $1 \cdot 25$.

Habitat : Slow rivers, canals, and large pieces of standing water, throughout the greater part of England, as far north as Yorkshire. It is, however, rather local. This is a Finland species, and ranges south to the Pyrenees.

This mollusk, when at rest, adheres firmly to stones and wood; but on being touched, it immediately falls off. It sometimes attains to a large size, one of my specimens being more than 2 inches long and $1 \frac{3}{4}$ broad.

The Linnean description of Helix vivipara accords more properly with that of the next species, which has only an umbilical chink ("imperforata"), and is peculiarly "subovata" and "obtusa." The name given by Millet to the present species, which does not appear to have been known to the authors of the 'British Mollusca,' must of course be adopted in preference to the very modern one of "Listeri" which was proposed by them. Miiller considered this species to be that of Linné; and he described the other as Nerita fasciata. 


\section{P. VIVI'PARA*, Linné.}

Helix vivipara, Linn. Syst. Nat. ed. xii. p. 1247. P. vivipara, F. \& H. iii. p. 11, pl. lxxi. f. 14, 15, and (animal) pl. H. H. f. 2 .

BoDr of a darker colour than that of $P$. contecta: snout broad : tentacles bluish-black, with bright yellow spots; the difference of their size in the male being very perceptible: eyes rather large: foot very broad, and slightly truncate in front.

Shell oval, rather solid, but not so glossy as that of $P$. contecta, yellowish-green, with bands and striæ as in that species; the surface of the two last whorls is often irregularly indented or pitted : epidermis rather thin : whorls $6 \frac{1}{2}$, rather convex, the last exceeding one-half of the shell, gradually increasing in size, except the first, which is extremely small and twisted, but much less prominent than in the last species, making the point of the spire to appear blunt : suture rather deep: mouth oval, and less inclined to a circular shape than in $P$. contecta: outerlip rather thick and slightly reflected: inner lip united above to the columella, but both lips form a complete peristome : there is no umbilicus, but instead of it there is a small and narrow chink behind the inner lip : operculum rather thick, compressed transversely, and marked withstrong lines of increase and finer intermediate striæ. L. 1·5. B. 1·2.

Var. unicolor. Without bands.

Habitat : The same as that of the last species (with which it is often found living), except that the Rev. Dr. Gordon has found it at Findhorn in the Moray Firth district. Sir Charles Lyell has recorded its occurrence in the lacustrine deposit at Mundesley in Norfolk. Its northern range abroad is also the same; but it extends southwards to Naples, and (according to Philippi) probably also to Sicily. The variety has been found by Mr. Pickering in Hertfordshire, and by myself in the Thames at Richmond. I have also a monstrosity in which the last whorl has a keel occupying the place of the upper band.

This species differs from $P$. contecta in its shell being * Bringing forth its young alive and perfect. 
thicker and longer, the whorls being much less swollen, the suture not so deep, the apex or point of the spire more blunt, and the mouth being less circular. Its size is not quite equal to that of the other species, the largest British specimen which I have of this being $1 \frac{3}{4}$ inch long and $1 \frac{1}{4}$ broad.

The animal is rather active. M. Millet counted in a female 82 young ones of different sizes. Mr. Clark has remarked that, in all the specimens which he procured from the River Exe, the point of the spire is eroded. This is probably owing to the influx and admixture of sea-water in that part of the river, because there are few, if any, manufactories on the banks of the Exe. In the Paddington Canal and parts of the Thames near London, the erosion is evidently owing to the last-mentioned cause. Draparnaud named this species Cyclostoma achatinum.

\section{Genus II. BYTHI'NIA*, (Bithinia) Gray. Pl. III. f. 7, 8, 9.}

Eyes sessile: operculum testaceous and solid, irregularly concentric, and having its nucleus nearly in the middle.

This was first indicated by Dr. Gray as a subgenus of Paludina; and the name which he proposed has been adopted by almost all conchologists. The chief difference between this and Paludina consists in the animal of Bythinia being oviparous, instead of ovoviviparous,its eyes being sessile, instead of placed on stalks or tubercles as in the other genera of this family,-and in the operculum being testaceous and concentric, with its nucleus placed almost in the middle. The tentacles of the male are of equal size in the present genus. Although the derivation of the word Bythinia would imply that

$$
\text { * Inhabiting deep water. }
$$


these mollusks inhabit deeper water than others of the same family, such is not the case. They generally frequent small streams, canals, shallow ponds and ditches. They lay their eggs in three long rows on stones, as well as on the stalks and leaves of water-plants.

\section{Bythinia tentacula'ta*, Linné.}

Helix tentaculata, Linn. Syst. Nat. ed. xii. p. 1249. Bithinia tentaculata, F. \& H. iii. p. 14, pl. lxxi. f. 5, 6, and (animal) pl. H. H. f. 3.

BoDy dark brown or almost black above, dirty grey beneath, covered with small and irregular specks of yellow: head small and semioval : snout long and deeply cleft in front: tentacles very long and slender, greatly diverging : eyes large, oval, and black : foot much broader than the snout, rounded in front, with a blunt and rounded tail which is half concealed by the operculum when the animal is crawling.

SHELL subconical or oval, rather solid and glossy, nearly opaque, of an amber colour, with often more or less of a brownish tint, very finely and closely striate in a spiral direction and crossed transversely by the marks of growth ; the spiral striæ are sometimes confluent and form white lines: epidermis very thin : whorls 6, convex; the last exceeding one-half of the shell, and the rest diminishing in proportion and ending in rather a sharp point: suture rather oblique and deep: mouth oval, angular above : outer lip thick, and sometimes strengthened by a white, rather strong, internal rib, which when repeated gives the shell a slightly varicose appearance; this lip is very little reflected: inner lip united to the columella, but forming with the other lip a complete peristome: umbilical chink small and narrow : operculum obliquely oval, very thick, angular at the top, compressed or indented in the middle of the upper half; it is marked with exquisitely fine concentric striæ and a few coarser ridges, denoting the marks of periodical increase, which form raised platforms or layers, the smallest or first-formed being uppermost. L. 0.5. B. 0.25.

Var. 1. ventricosa. Shell white: whorls more swollen. Paludina ventricosa, Menke.

Var. 2. decollata. Upper whorls wanting in half-grown and * Having tentacles. 
adult specimens; their place being supplied by a nearly flat and semispiral plate, as in Bulimus decollatus.

Var 3. excavata. Whorls more rounded, and suture much deeper.

HaвiтAт: Slow rivers, ponds, and still waters everywhere in England, Wales, and Ireland, as well as at Frazerburg in Aberdecnshire; and it is perhaps the most abundant fossil in the lacustrine beds of our upper tertiaries. Var. 1. Devonshire (Mus. Turton); Bristol and Wandsworth (J. G. J.); Richmond, Surrey (Choules). Var. 2. Woolwich and Cardiff (J. G. J.); Co. Armagh (Waller). Var. 3. Cardiff (J. G. J.). This last variety seems to connect the present species with $B$. Leachii; but it differs from the last-mentioned species in its greater size, as well as the oval shape of the mouth. $B$. tentaculata ranges from Siberia to Sicily. The animal is sluggish, but irritable. It sometimes floats, or creeps on the under surface of the water. Draparnaud says that it feeds on animal as well as vegetable substances. The shell is often encrusted with a ferruginous or mineral deposit. From this circumstance Draparnaud derived the name of impura which he gave this species, having needlessly changed the prior one assigned to it by Linné. The epidermis in young specimens is slightly hispid and resembles a fine velvety pile.

This species was first made known and admirably described by our countryman, Lister.

\section{B. LEACH'II*, Sheppard.}

Turbo Leachii, Shepp. in Linn. Trans. xiv. p. 152. Bithinia Leachii, F. \& H. iii. p. 16, pl. lxxi. f. 7, 8, and (animal) pl. H. H. f. 4.

BoDy greyish-white, with black and yellow specks: tentacles very flexible : foot slender.

* Nạmed after Dr, Leach, a celebrated English zoologist, 
Shell conical, rather thin, glossy, and semitransparent, greyish horn-colour or amber, microscopically striate in a spiral direction, and irregularly marked by thelines of growth: epidermis extremely thin: whorls 5 , very convex and rounded, but narrow, the last occupying about one-half of the shell : spire rather abruptly pointed: suture nearly straight, extremely deep: mouth nearly round, very slightly angular above, where the outer lipmeets the columella : outer lip rather thick, and strengthened by a slight internal rib, scarcely reflected, except below : inner lip forming with the other lip a complete peristome : umbilicus small and narrow, but distinct: operculum almost circular and flat, otherwise like that of the last species. L. $0 \cdot 25$. B. $0 \cdot 2$.

Var. elongata. Shell smaller; spire more produced.

Habitat : Nearly the same as that of $B$. tentaculata; but the present species does not extend so far north, and it is more local and much less abundant. It is also equally rare as a tertiary fossil. The variety is from Woolwich marshes and Northampton. Malm has recorded this species as Swedish; and Morelet has noticed it as inhabiting Algeria.

This species is distinguishable from the last, in company with which it is sometimes found living, by its much smaller size, the whorls being more swollen and narrower (giving the shell a scalariform appearance), the very deep suture and distinct umbilicus, as well as by the shape of the mouth and operculum. It is sometimes known by the specific name of ventricosa, which was originally given to it by Dr. Gray, but without any description. The Cyclostoma simile of Draparnaud, to which the present species has been referred by some authors, is very different, as will be seen presently. Specimens in Dr. Turton's collection, named respectively "Paludina similis," "P. viridis," and " $P$. anatina," all belong to $B$. Leachii, being merely different stages of growth. The late M. D'Orbigny gave me, at Rochelle, in 1830 some 
shells which he had received from Draparnaud under the name of "Cyclostoma anatinum." These appear to be a small variety of the present species, and are probably the B. humilis of M. Boubée.

\section{Genus III. HYDRO'BIA*, Hartmann.}

H1. III. f. 10, 11, 12.

Eyes placed on tubercles: operculum horny and thin, paucispiral.

The little mollusks which are comprised in this genus, although very closely related to the true and marine Rissoce, appear to have as much right to be generically separated from the latter as Neritina has to form a distinct genus from Nerita. Nearly all the Hydrobiae are inhabitants of fresh and pure water; but one of them (H. ventrosa) frequents estuaries, as well as pools and ditches close to the sea-shore which are liable to be occasionally overflowed by the tide, and the water of which is more or less brackish. Those species which inhabit fresh water have been arranged by MoquinTandon in a subgenus of Bythinia, named by him Bythinella. With Bythinia, as well as with Rissoa, this genus has undoubted relations. It differs, however, from the former in the eyes not being sessile, but placed on short tubercles, and from the latter in wanting the caudal filament which is appended to the foot. The shell of Hydrobia has besides an umbilical cleft which does not exist in Rissoa; while its operculum is decidedly not Bythinian, but Rissoan, or rather Littorinan. It may therefore be considered as in many respects forming an intermediate link between those two genera, but having a greater affinity to Rissoa. The genus Hydrobia was

* Living in water. 
founded by Hartmann in 1821. An objection has been made to the name on the ground that it had been previously used for a genus of small water-beetles; but it does not seem that any confusion or inconvenience is likely to result from the use of the same name in such different departments of zoology, and precedents are not wanting for such a double application. We have only two species of Hydrobia; but on the Continent there are four or five times that number, including Hydrobia marginata which existed during the Glacial epoch in our eastern counties and Bedfordshire, but appears not to have survived that period.

The estuarine or brackish-water species of Hydrobia were formed by Professor D'Orbigny into another genus, which he called Paludestrina; and these also constitute the genus Paludinella of Pfeiffer and Lovén.

\section{Hydrobia símilis*, Draparnaud.}

Cyclostoma simile, Drap. Moll. Terr. et Fluv. Fr. p. 34, pl. i. f. 15. Rissoa anatina, F. \& H. iii. p. 134, pl. lxxxvii. f. 3,4 .

BoDy dark grey, with a yellow or brown tint and white flaky specks : head rather large and prominent : snout broad, long, and ridged transversely : tentacles long, slender, and diverging : eyes large and rather protuberant : foot short, very broad, and expanded on each side in front, rounded behind, and extending considerably beyond the operculum when the animal is crawling.

Shell subconical or oval, rather thin, glossy, semitransparent, yellowish horn-colour, or sometimes clear-white, obscurely and slightly marked by the lines of growth : epidermis a mere film : whorls 5-6, rounded, but compressed; the last exceeding one-half of the shell : spire rather pointed: suture somewhat oblique and deep, forming a narrow canal : mouth oval : outer lip thin, slightly reflected : inner lip united to the columella, but continuous with the outer lip : umbilical chink oblique, small, but distinct: operculum oval, obtusely angular

* Resembling another species, 
above, thin and flat, having a lateral and indistinct spire of only 2 whorls, and resembling that of the marine genus Littorina; it is marked with strong, but remote, irregular and flexuous lines of increase. L. 0-15. B. 0 1.

Habitat : Muddy ditches which are occasionally, but seldom, overflowed ly the tide, by the side of the Thames from Greenwich to below Woolwich. These ditches are separated from the river by a high and broad embankment, which is provided at distant intervals with sluices to drain off the surface water. It lives there in company with Bythinia tentaculata and other freshwater shells, as well as with the more marine and peculiar mollusk, Assiminia Grayana; and it is gregarious. Its food appears to consist of decaying vegetable matter; and its habits are rather active, creeping and floating with tolerable rapidity. Mr. Prestwich and Mr. Pickering found specimens of it in peat, in the main-drainage-cutting between Woolwich Arsenal and the exit to the Thames, through Plumstead Marshes; but it can scarcely be considered one of our upper tertiary fossils. This species is widely diffused in France, and extends south to Corsica. The Paludina meridionalis of Risso appears to be only a rather longer and stouter form of this species, judging from typical specimens in the Museum at the Jardin des Plantes.

No one can, I think, take the trouble of carefully comparing specimens of this shell with the description and figure given by Draparnaud of his Cyclostoma simile, without being satisfied of their specific identity; and the general consent of continental conchologists is in favour of this view. In France $H$. similis inhabits fresh water. Morelet states that in the South of Portugal it is found both in running water and marshes, and that the shells of the males have a longer spire than those of the other 
sex. British authors have referred this species to the Cyclostoma anatinum of Draparnaud, but, as I believe, erroneously. The Bulimus anatinus of Poiret, from which Draparnaud seems to have taken the specific name of his species, is in all probability the Turbo ulva of Pennant. That species is universally known in France by the name which Poiret gave. Michaud, in his Supplement to Draparnaud's last work, mentions Cyclostoma anatinum as inhabiting "les eaux saumâtres;" although Draparnaud gives a different habitat ("les eaux douces") for the same species. It is not impossible that the latter meant Bythinia Leachii. The contour of the shell of H. similis is not unlike that of a dwarf Bythinia Leachii; but the channeled suture, as well as the very different operculum, will readily serve to distinguish them, irrespectively of size.

\section{H. ventro'sA*, Montagu.}

Turbo ventrosus, Mont. Test. Brit. ii. p. 317, pl. 12. f. 13. Rissoa ventrosa, F. \& H. iii. p. 138, pl. lxxxvii. f. 1, 5, 6, 7.

BoDy dark grey, almost black in front: head rather protuberant : snout long and ridged transversely : tentacles filiform, with black and grey rings : eyes on very short stalks, placed a little behind the outer base of the tentacles: foot cleft in front and rounded behind.

Shell forming a lengthened cone, rather thin, glossy, semitransparent, yellowish horn-colour, obscurely but closely striate by the lines of growth: epidermis very delicate: whorls $6-7$, rounded and swollen; the last not being equal to half the length of the shell: spire pointed: suture rather oblique and deep: mouth oval: outer lip thin, slightly reflected: inner lipin adultspecimens separate from the columella and forming with the other lip a complete peristome: umbilical chink very small: operculum like that of $H$. similis, but having a smaller spire and closer lines of increase. L. 0.2. B. $0 \cdot 125$.

\footnotetext{
* Swollen.
} 
Var. 1. minor. Shell much smaller: spire shorter.

Var. 2. decollata. Shell slightly eroded: spire truncate.

Var. 3. ovata. Shell having a much shorter spire, consisting of only 4 whorls, which are more swollen than usual, and the last considerably exceeds one-half of the shell.

Var. 4. elongata. Shell having its spire proportionally longer, with sometimes as many as 8 whorls.

Var. 5. pellucida. Shell clear white, and nearly transparent.

HABITAT: Abundantly in many estuaries and in brackish water in which the admixture of fresh predominates over salt, throughout England and Wales; and I have also taken it in Larne Lough, Ireland. It occurs in the upper tertiary bed at Clacton, and elsewhere in the estuary of the Thames. Var. 1. Burry River, South Wales (J. G. J.). Var. 2. Burry River, but not in the same part of the estuary where the first variety is found, and Guernsey (J. G. J.). Var. 3. Oxwich marsh, near Swansea (J. G. J.). Var. 4. Arnold's pond, Guernsey (J.G. J.). Var. 5. Manorbeer, Pembrokeshire (J. G. J.); Scarborough (Bean): very rare. This species inhabits similar situations along the sea-coasts of Sweden, France, and Portugal, as well as of Algeria.

$H$. ventrosa is gregarious, and sometimes lives in company with $H$. ulvee, which however is more of a marine than a freshwater species. The latter is never found out of the reach of the tide, and inhabits the mud flats and ooze; while the present species usually lives in ponds and ditches into which the sea only flows at high water or in spring tides. The habits of this species are more active than those of $H$. ulvce; and I have observed that when they are found together the latter may be seen crawling slowly over the mud and Ulva at the bottom of shallow pools, while the other seems to disport itself by 
floating with tolerable rapidity along the under surface of the water. The shell is often encrusted with a mineral deposit or covered with an algoid or confervoid growth. The variety 5 resembles the Cyclostoma vitreum of Draparnaud and the Paludina diaphana of Michaud. Sometimes the shell is distorted by having the upper part of the spire twisted to one side, or by the last whorl having a few obscure spiral ridges.

This small, but abundant, species has received a great number of names from modern conchologists, in consequence of their referring it to ill-defined species of ancient authors. I do not believe that it is the Turbo stagnorum of Baster, because he describes the habitat to be "in aquis dulcibus," and the aperture or mouth to be margined. Nor can I identify it with the Helix octona of Linné, which is said to have eight whorls and a round aperture. Nor is it, in my opinion, the Turbo thermalis of Gmelin, because he gives an inland habitat (Pisa) and says that the shell is white and has only four whorls. There can, however, be no doubt of its being the $C y$ clostoma acutum of Draparnaud; and this specific name has been adopted by almost every continental naturalist. The Paludina muriatica of Lamarck is evidently $H$. ulvo.

This species differs from $H$. similis in its long spire, the suture not being channeled, and in the umbilical chink being very much smaller. From $H$. ulva it may be known by its being less than half the size of that species, its much deeper suture, the body or last whorl not being keeled (as is the case in $H$. ulva), as well as in the inner lip being disconnected from the columella.

The shells which Mr. Pickering found some years ago, about two miles below Gravesend, together with a specimen of Litiopa bombyx, and which Forbes and Hanley considered (but with some doubt) to be a variety of 
H. ventrosa, bear such a close and suspicious resemblance to a Cape of Good Hope species of Hydrobia, that I cannot venture to include it among the British Mollusca. It does not appear to have been described by any author; but Mr. G. B. Sowerby has named it Rissoa castanea, on my authority, in his 'Illustrations of British Conchology.' Both Mr. Pickering and myself have failed to rediscover this species in the spot where he originally found it, although we have at different times carefully searched for it. The fact of Litiopa bombyx, which is peculiar to the Gulf-weed, having been taken with it, leads to the supposition that both of these shells might have been accidentally brought into the Thames, attached to the keel, rudder, or anchor of an inwardbound vessel, and carried by the tide into the ditch where they were discovered by Mr. Pickering. Many other modes of introduction will doubtless occur to my readers. I received some years ago from the late Mr. G. B. Sowerby two specimens of Hydrobia Ferussina, which he said had been found in Hampshire. I do not propose to add this species to the British list on such slight and insufficient grounds; but as Helix obvoluta has only been found in the same county, as a British shell, and both these species inhabit the greater part of France, I merely call the attention of conchologists to the circumstance, it being not improbable that the $H$. Ferussina may also turn up in the South of England.

The Hydrobia marginata (Paludina marginata of Michaud) inhabited this country a long time ago, but appears to have become extinct as a British species. Sir Charles Lyell first, I believe, recorded it as occurring in the Mundesley bed, where I have since found it; it also occurs in the well-known upper tertiary strata at Grays, Stutton, Clacton, and Cropthorn; and I lately detected it 
among some shells collected by Mr. Wyatt from a similar deposit at Biddenham near Bedford. This species now inhabits the South and South-west of France, as well as the Jura and Switzerland; and it has been found in a fossil state in the lacustrine beds at Amiens.

The Natica Kingii of Forbes and Hanley (iii. p. 343, pl. ci. f. 1, 2) belongs to this family, and not to the Naticida. It is the Lithoglyphus Naticoides of Férussac, and inhabits the Danube. Professor King is said to have found the specimen (which is now in my collection) in the bottom of a fishing-boat at Cullercoats. How this Austrian and freshwater species could have got to the Northumberland coast, is very difficult to say. Professor King informs me that he never received any shells from the Danube, and that his statement as to the Northumbrian locality is perfectly correct. The question of the indigenousness and unaccountable habitat of this specimen must therefore remain a mystery.

\section{Family III. VAISATID E.}

Bopy elongated, spiral: eyes placed within the tentacles at their base: gill protruding beyond the edge of the mantle, the respiration being aided by a tentacular filament: sexes united, or common to each individual.

SHeLL having a short but symmetrical spire and a circular mouth: operculum regularly multispiral.

This family comprises only one genus (Valvata), which was founded by the Danish naturalist, Miiller. It is remarkable for its branchial apparatus, which is external or protruded when the animal is moving. In this position it resembles a feather, and caused Geoffroy to give to these elegant little creatures the expressive name of "porte-plumet." Besides this branchial plume, the ani- 
mal has another peculiar organ to facilitate its respiration, consisting of a filament or appendage to the mantle, which might be mistaken for a third tentacle or a parasitic worm, and is placed on the right side of the body. The form of the shell and operculum is very graceful, and is somewhat like that of Trochus or Margarita.

The members of this family and genus are vegetable feeders. They are very shy. Muiller relates that he was tantalized by watching them for several hours, in the hope that they would show themselves and enable his draughtsman to make a sketch of the animal and its curious plume, but that he was disappointed. $\mathrm{He}$ appears to have consoled himself by the idea that the little snails acted on the proverbial principle that you were not to put any trust in man! The reproductive system of these mollusks is peculiar, and resembles that of Ancylus, or the freshwater Limpet. Although each individual is of both sexes, it is at first only male or female, and afterwards changes its sex. They are gregarious, and inhabit slow rivers, streams, canals, and nearly stagnant water. The shells may often be seen attached to the cases of the Phryganea, or May-fly, and thus collected form a very pretty object.

The shells of some of the Valvatidce closely resemble in shape the cases made by the larvæ of certain insects; and their similarity is so great that Mr. Swainson proposed a new genus of Mollusca for these insect-cases, under the name of Thelidomus. Such instances of mimetic analogy occur in other branches of the animal kingdom. The valves of some Entomostraca, belonging to the genus Estheria, are not unlike those of a young Anodonta in appearance, although their structure and composition are very different. 


\section{VALVA'TA*, Müller. Pl. III. f. 13, 14, 15.}

Eyes nearly sessile: operculum horny and thin.

\section{Valvata Piscina'lis $\dagger$, Müller.}

Nerita piscinalis, Mull. Verm. Hist. pt. ii. p. 172. V.piscinalis, F.\&H. iii. p. 19, pl. Ixxi. f. 9, 10.

BODY of a clear yellowish grey, with small and indistinct milk-white specks: snout long, narrow, and transversely wrinkled: tentacles long, cylindrical, rather close together, and slightly recurved at the point: eyes large and round, but not prominent: foot separate from the snout and six times as broad, deeply cleft in front and rounded behind; its tail nearly covered by the operculum: branchial plume transparent, bearing on each side fourteen slender offsets, which are placed at right angles to the stalk: branchial appendage of the same size and length as the tentacles.

SHELL forming a depressed cone, subglobular, rather solid and opaque, brownish-yellow, closely and regularly striate transversely, and more or less distinctly ridged in a spiral direction, which often gives the surface an elegantly reticulated appearance: whorls 6 , rounded and convex, the last being rather less than one-half of the shell : spire compressed and blunt: suture nearly straight and very deep: mouth circular: outer lip rather thick and reflected: inner lip quite separate from the columella and continuous with the outer lip, so as to form a complete peristome: umbilicus round, not large, but very deep, exposing nearly all the interior of the spire: operculum circular, slightly compressed in the middle, forming a concentric spire of from 10 to 12 whorls, the outer edges of which are thickened and raised so as to project over and partly overlap the succeeding whorl of the operculum. L. $0 \cdot 25$. B. $0 \cdot 275$.

Var. 1. depressa. Shell having the spire more depressed and the umbilicus consequently larger. V. depressa, C. Pfeiffer, Deutsch. Moll. i. p. 100, pl. ii. f. 33.

Var. 2. subcylindrica. Shell having the spire more produced, and flattened at the top: umbilicus small.

* Closed by a valve, or operculum.

† Inhabiting fish-ponds. 
Var. 3. acuminata. Shell having the spire still more produced, and ending in rather a sharp point.

Habitat: Slow and still waters throughout the British Isles; common in our upper tertiary beds. Var. 1 occurs also in various parts of the kingdom; but it is more local, and not found with the typical form. The young of both these forms have invariably the spire proportionably more depressed than in the adult. Var. 2. Grassmere (J. G. J.). This somewhat resembles the wellknown form called "antiqua" by Professor Morris, from the upper tertiary deposit at Grays. Var. 3. Avon R., Bristol (J. G. J.); North of Ireland (Mrs. Puxley). Specimens of the typical form, which Mr. Bridgman procured and kindly sent me, from brackish water at Lynn, are much thicker and of a darker colour than usual, and have stronger striæ; and the opercula have fewer whorls and slighter ridges. In another variety which I have received from my valued friend and correspondent, $\mathrm{Mr}$. Waller, and which he found at Finnoe, Co. Tipperary, the shell is more conic and the spiral ridges form irregular white lines. A monstrosity has also occurred to me, in which the spire is twisted to one side. This species ranges from Siberia to Naples.

In May, June, July and August the eggs of this mollusk are deposited on various substances, and sometimes on the shell of a Planorbis. They are united in a gelatinous mass, and enclosed in a globular capsule having a short stalk, by which it is attached. The eggs contained in each capsule number, according to Bouchard-Chantereaux, from 60 to 80 ; but Moquin-Tandon, who appears to have observed many cases of such egg-laying and -hatching in an aquarium, states that out of 19 capsules the number of eggs in each varied from 4 to 24 only. When the eggs have come to maturity, which is about the 
twelfth day after they have been laid, the capsule, being distended, bursts, and about two-thirds of the fry emerge and enter on their career of life. The capsule then resumes its former shape, and retains the rest of the fry for four days longer, when they are, in their turn, hatched or emancipated.

Both Draparnaud and Montagu were aware that this species was furnished with the branchial plume; but the former included it in the heterogeneous assemblage of species which he called Cyclostoma, assigning the next species to Valvata; and our countryman referred one species to Helix and the other to Turbo. The present species is the Nerita obtusa of Studer; and Draparnaud adopted his specific name.

\section{V. CRISTA'TA*, Müller.}

V. cristata, Müll. Verm. Hist. pt. ii. p. 198 ; F. \& H. iii. p. 21, pl. lxxi. f. $11,12,13$.

BoDy dark grey or brown, with a few small black specks on the upper part, slate-colour underneath : snout prominent, rather narrow and curved, faintly wrinkled: tentacles long, slender, close together but recurved at their points: eyes small and round: foot quite separatefrom the snout, and resembling, in proportion to its size, that of the last species: branchial plume transparent, bearing about 15 offsets on each side of the stalk: branchial appendage rather shorter than the tentacles.

SHeLl forming a flat coil, concave beneath, rather solid, semitransparent, yellowish or greyish-horncolour, closely and regularly striate transversely: epidermis very thin: whorls 5, the last exceeding in breadth all the rest put together: spire flat, or slightly concave owing to the convexity of the whorls: mouth circular : outer lip thin and slightly reflected: inner lip separatefrom the columella and continuous with theouterlip: umbilicus very large and open, fully exposing the interior of the spire: operculum circular, concave like an inverted potlid, forming a concentric spire of about a dozen whorls, the

* Crested; so called from its branchial plume. 
outer edges of which are membranous and project in front so as to make slight ridges. L. 0.025 . B. $0 \cdot 125$.

Habitat : Lakes, canals, ponds and ditches, with the last species. It has an equally extensive range both here and abroad, except that the present species does not appear to have been found south of Corsica. It is also one of our upper tertiary fossils. A monstrosity is in my collection, which has the last whorl detached and coiled upwards, as is not unfrequently the case with several species of Planorbis.

The branchial plume is not always protruded, even when the animal is crawling.

Although the spire in some specimens is a trifle more depressed or sunk than usual, I am not aware that the Valvata spirorbis of Draparnaud (which Moquin-Tandon regards as a variety of the present species) has ever been found in this country. The $V$. minuta of that author is a totally different species, having a globular shell, with a produced spire, and resembling a miniature $V$. piscinalis. The present species is the $V$. planorbis of Draparnaud.

There is no difficulty in distinguishing $V$. cristata from the fry of $V$. piscinalis, much less from the adult, where the great difference of size affords a sufficient criterion. The shell of the present species in all stages of growth is quite flat, and resembles that of a Planorbis, constituting apparently a passage into that genus; while the other is trochoid or subglobose, and has a prominent spire. Their bodies, or the soft parts of the animal, do not present such a decided difference. The tentacles of $V$. piscinalis are, however, rather more slender, and the snout is proportionably larger than in this species. 


\section{Order II. PULMONOBRANCHIATA*.}

BoDy spiral: respiratory apparatus principally consisting of an internal cavity or sac, formed by a fold of the mantle, and lined with a network of vessels, which serves the purpose of lungs.

Shell usually external and spiral, but sometimes internal and rudimentary or wanting. In the two latter cases the mantle is external and forms a shield on the back.

With respect to the reproductive system of the Mollusca comprised in this Order, it may be observed that each individual of those kinds which do not possess an operculum has both sexes united in itself, but requires to be fertilized by another individual, while those which have an operculum are of different sexes. The former are androgynous, answering in some respects to the botanical term "monœcious;" and the latter are strictly "diœecious."

The Pulmonobranchs, Pulmobranchs, Pulmonifers, Pulmonates, or Pneumonobranchs, by all of which various names these mollusks have been called, on account of the analogy which their organ of breathing bears to the lungs of vertebrate animals, respire for the most part atmospheric air. The aquatic kinds obtain also some air from the water by means of auxiliary branchial organs. All the land mollusks, or Snails, belong to this Order. The other members of it are aquatic; but none of them inhabit the open sea, although a few, belonging to the genera Melampus or Conovulus and Otina, are amphibious. These last I propose to include in the marine Mollusca, as they live in the sea for many hours out of the twenty-four, and are only met with on dry land

$$
\text { * Having a lung-like gill. }
$$


when the tide has retired. One species of Melampus is found in brackish, but never in fresh, water.

In this country about three-fourths of the Pulmonobranchs are terrestrial; the remaining fourth live in fresh and shallow water, occasionally rising to the surface or crawling out of their native element to renew the supply of air. They are nearly all herbivorous; but the Testacella, or Shell-Slug, feeds exclusively on the earthworm, and the slugs and many kinds of Snail (both terrestrial and aquatic) eat animal as well as vegetable substances, and are occasionally cannibals. It has been proposed to call the tentacles of the aquatic kinds by another name (viz. vibracles), in consequence of their being contractile, instead of retractile like the tentacles or horns of land-snails, and also because they do not bear the eyes on their tips or extremities, as in the lastmentioned kinds. This distinction seems, however, to be unnecessary ; and much confusion might result from such an innovation, as the word 'tentacles' has been so long and universally applied to the feelers of all the Gasteropoda or univalve Mollusca.

They may be conveniently divided according to their different habitats; and the freshwater kinds will be described first, so as to complete this branch of the subject. These are all covered or protected by a shell, and are comprised in the undermentioned family.

\section{Family LIMN ÆID $Æ$.}

BoDy generally long and spirally coiled, but in one genus short and hood-shaped: mantle covering the upper part in front head short: tentacles 2, contractile: eyes placed on the inner base of the tentacles, a little towards the front: foot oval, used for crawling or floating.

Shell spiral, or hood-shaped. 
Genus I. PLANOR'BIS*, Guettard. Pl. IV. f. 1, 2, 3.

BODy long, twisted in a flat coil : tentacles very long and slender : foot short and narrow, attached to the upper part of the body by a stalk, which is shaped like the lower half of an hourglass.

Shell quoit-shaped, or flat: whorls cylindrical : spire dextral, or turning from left to right, and visible on each side.

This genus has some remarkable peculiarities. One of them consists in the habit of the animal emitting its purple-coloured blood, or a fluid like that which is secreted by the Aplysia, on being irritated, apparently as a means of defence against its enemies. Another is, having several of its vital organs placed on the left side of its body, instead of on the right (as is the case with nearly all the other Gasteropoda), while the spire of its body and shell is coiled the other way, viz. from left to right. And a third peculiar feature consists in the form of its shell, which is flat or concave on one or both of its sides, resembling that of an Ammonite. The body of these mollusks is too small for its shell; and when crawling, the animal leaves part of the shell empty, putting one in mind of loose and ill-fitting clothes. O. F. Müller, nearly a century ago, seems to have satisfactorily settled the question that was then raised as to whether the shells were right- or left-handed; but the discussion has lately been renewed. The shell being viewed in its natural position, there can be no doubt of its being dextral. Some of the smaller species of Planorbis, inhabiting marshes and very shallow water which are dried up in summer, close the mouth of their shell with an epiphragm, or filmy covering, like that of some land-snails. The animal then retires into the interior of its coil and 
awaits the return of moist and more congenial weather. All of them frequent stagnant or slowly-running water, and are herbivorous. Their eggs are enclosed in a globular bag, which is fixed to stones and the stalks or leaves of submerged water-plants. Owing to the sluggish habits of most of the species, as well as to the nature of their habitat, the surface of their shells is apt to become encrusted with a mineral or vegetable deposit. The genus seems to have been originally indicated by Petiver in his 'Gazophylacion.'

There being several species, it may be more convenient to divide them, as before, into sections.

A. Shell glossy ; last whorl very large in proportion to the rest, and partly covering the preceding one.

\section{Planorbis linea'tus*, Walker.}

Helix lineata, Walker, Test. Min. Rar. p. 8, pl. 1. f. 28. P. lacustris, F. \& H. iv. p. 162, pl. exxviii. f. 1-3.

BoDy reddish-brown, tinged with violet, dark purple in front with a few black specks: head strongly bilobed: tentacles filiform, diverging at their base : eyes small, but distinct, scarcely prominent: foot broad and rounded in front, gradually narrowing and pointed behind.

Shell quoit-shaped, the upper being rather more convex than the lower side, both sides depressed or almost concave in the middle, rather thin, very glossy, semitransparent, reddish or yellowish-horncolour, or grey, closely striate in a transversedirection, thestriæ becoming curved towards the mouth: epidermis very slight: periphery (or circumference of the outer whorl) bluntly keeled: whorls 4, compressed on all sides; the last exceeding in size the rest of the shell, and concealing nearly two-thirds of the preceding whorl in its clasp: suture distinct, but not deep : mouth obliquely heart-shaped : outer lip thin and flexuous, obtusely angulated above: umbilicus small and rather deep : inside the last whorl are from 
2 to 5 rows of curved plates, which are arranged on each side across the spire, opposite to each other and at nearly equidistant intervals. L. $0 \cdot 065$. B. $0 \cdot 2$.

Habitat : Slow streams and ditches in the home and eastern counties, as well as in Guernsey (Lukis), Notts (Lowe), and Co. Tipperary (Humphreys); but it is a local species. It is found in our upper tertiary strata. According to Malm it occurs in Sweden; and it appears to have a wide range over the more temperate parts of Europe, as far south as Toulouse.

This pretty and curious little mollusk is rather active, and is usually found on duck-weed and other aquatic plants. It lays only from 3 to 8 eggs, which come to maturity in ten or twelve days. The internal plates, which are observable outside the last whorl of the shell, form half-closed chambers; and the animal retreats into the front one for safety. These plates appear to answer the same purpose as the teeth or folds which barricade the apertures of many of the small land-snails. They are also only formed in adult individuals. The peculiarity of this structure induced one of its earliest discoverers, Lightfoot, to call the present shell a Nautilus; and the late Professor Fleming proposed for it on the same grounds a new genus (Segmentina), which has been adopted by Capt. Brown and Dr. Gray; but, even as a test of conchological distinction, this character does not seem to be of any value. Miiller noticed, in his description of the next species, that a few of the specimens which he had examined had two streaks, like ligaments, in the upper part of the last whorl, apparently indicating the marks of fracture and mending of the shell, by which he may possibly have meant this species; but he only described one species of this form, which still bears the name he gave it, Planorbis nitidus. The present species was first 
made known by Mr. Walker, an intelligent bookseller at Faversham in Kent, the description of it having been supplied to him by Mr. Jacob. The only share which Mr. Boys appears to have had in the discovery is his having sent parcels of shell-sand to Walker; but the credit of the publication entirely belongs to the latter. Two years afterwards Lightfoot described and published this species in the 'Philosophical Transactions,' under the name of Nautilus lacustris.

\section{P. NI'TIDUs*, Müller.}

P. nitidus, Müll. Verm. Hist. pt. ii. p. 163; F. \& H. iv. p. 161, pl. exxvii. f. 11, 12.

BoDy reddish-grey, with sometimes a yellowish tinge, and marked with extremely fine dark-grey specks : tentacles very long and slender : eyes rather large : font short, very broad in front, and slightly narrowing behind to an abrupt but not a fine point.

SHELL shaped like the last, but flatter and with much more of the spire visible above, in consequence of the last whorl not clasping such a large part of the preceding one, very thin, glossy and prismatic, light-yellowish-horncolour or grey, with sometimes a reddish tinge, faintly striate by thelines of growth, with occasionally a few spiral microscopical lines, which are more distinct on the under side, giving an appearance of the sculpture peculiar to the shells of Limnaea: epidermis extremely delicate: periphery rather sharply keeled: whorls 4-5, the last covering about one-half of the preceding whorl : suture rather deep: mouth and outer lip formed as in P. lineatus, but larger: umbilicus small, not deep. L. 0.06. B. 0·225.

Habitat: Ponds, marshes, and stagnant water throughout Great Britain, from the Moray Firth district southwards. It is also one of our upper tertiary fossils. Middendorff has included it in his list of Siberian shells ; and it is extensively distributed over the European continent, having apparently its most southern limit in 
Corsica. Although it is much less local than the last species, I am not aware of their having been found together. Its habits are slower and more timid than those of $P$. lineatus; and it is not so fertile, never laying more than 6 eggs. The shell is often infested by the minute egg-cases of a water-insect, or coated with the spores of Conferva.

The shell differs chiefly from that of the last species in being of a lighter colour, flatter, and thinner, in the whorls being more visible above, the keel being much sharper, and especially in the absence of the internal septa or partitions.

\section{B. Whorls few.}

\section{P. Nautíleus*, Linné.}

Turbo Nautileus, Linn. Syst. Nat. ed. xii. p. 1241. P. Nautileus, F. $\&$ H. iv. p. 152 , pl. exxvi، f. 6,7 .

BoDy greyish-brown, with sometimes a faint reddish tinge, minutely speckled with black: head very large and thick: tentacles long and cylindrical, greatly diverging: eyesdistinct, scarcely prominent: foot broad, rounded in front, and ending in a blunt point behind.

Shell quoit-shaped, having the upper side flat and the lower side rather convex, thin, not glossy, light-brown or grey, sometimes white, closely striate by the lines of growth, which atdistant but regular intervals form strong curved ridges and frequently rise into projections like the rowels of a spur on the outside: epidermis rather thick : periphery bluntly and indistinctly keeled : whorls 3, depressed above, the last exceeding in size the rest of the shell : suture rather deep : mouth oblique, and either oval or nearly circular, according to the greater or less depression of the whorls: outer lip thin, forming with the inner lip in the adult a complete peristome : umbilicus very large and exposing all the spire. L. 0.035. B. 0.1.

Var. cristata. Shell having the transverse ridges stronger, and the periphery deeply notched or crested by them. P.cristatus, Drap. Hist. Moll. p. 44, pl. ii. f. 1-3.

* Shaped like a Nautilus. 
Habitat : On aquatic plants in marshes, lakes, ponds, and ditches, from the northernmost extremity of Zetland to the Channel Isles. It is also one of our upper tertiary fossils. The variety is not uncommon, and merges insensibly into the ordinary form. The degree of sculpture appears to depend much on age, as it is usually stronger in half-grown individuals and disappears in the adult. A monstrosity also occurs in which the whorls are more or less twisted and separate from each other, sometimes being raised like a snake lying on its coil. The range of this species abroad extends from Finland to the Pyrenees and even to Algeria.

This pretty little mollusk is slow in its movements, and may be noticed feeding on the decaying leaves of the Iris pseudacorus and water-plants. According to Bouchard-Chantereaux, it lays only from 3 to 6 eggs, which leave the capsule in ten or twelve days. The sculpture of the shell is extremely elegant; and it is by far the smallest of its kind. The minuteness of its size, dull appearance, and comparatively large umbilicus will at once serve to distinguish it from either of the foregoing species. If the rings which encircle each whorl are marks of annual growth, it must attain a very respectable old age for a mollusk, as I have counted as many as 20 rings in one specimen. In all probability, however, these marks do not indicate the annual, but only the periodical growth, several of them being formed in the first year.

\section{P. AL'BUs* Müller.}

P. albus, Müll. Verm. Hist. pt.ii. p. 164 ; F. \& H. iv. p. 149, pl. exxvi. f. 1,2 .

BoDy grey or dirty-brown, sometimes inclined to a reddish hue, with fine but indistinctblack specks: head thick, rounded 
in front: tentacles widely spread at their base, long, slender, and pointed: eyes small and rather of an oval shape: foot narrow, rounded in front and narrowing gradually behind to a blunt point.

Shell flat above, with a depression in the centre, slightly concave below, rather thin, not glossy, greyish-white, closely striate in the line of growth, and more strongly striate or ridged spirally : epidermis thick, sometimes hispid or bristly periphery slightly compressed on each side, but not keeled: whorls 5, the last exceeding the rest in size: suture rather deep : mouth obliquely oval : outer lip slightly reflected; the upper part projecting considerably : inner lip spread on the columella, but continuous with the outer lip : umbilicus very large, but not deep. L. 0.08. B. $0 \cdot 275$.

Var. Draparnaldi. Shell more closely and sharply striate in the line of growth : periphery distinctly keeled : umbilicus deeper. $\quad P$. spirorbis, Drap. Hist. Moll. p. 45, pl. ii. f. 8-10. Helix Draparnaudi, Sheppard, in Linn. 'Tr. xiv. p. 158. $P$. Draparnaldi, Jeffr. in Linn. Tr. xvi. p. 386.

Habitat : Same as that of the last species, but more generally diffused. The most northern limit in these islands appears to be Aberdeenshire. It is also an upper tertiary fossil. The variety has been found at Holbrook in Suffolk (Sheppard); Cardiff, Bristol, and Church Stretton in Shropshire (J. G. J.). It has been referred by the authors of the 'British Mollusca' to the $P$. marginatus of Draparnaud. This common species ranges from Siberia to Portugal and Algeria.

The spire is often twisted or distorted in this, as well as in the other species of Planorbis. The spiral striæ are always visible, even in dead and water-worn specimens which have lost their epidermis. The finest specimens I have seen were kindly sent to me by my friend Mr. Norman, who found them at Kibworth, Co. Durham, their diameter being rather more than a third of an inch.

In all probability this was the Helix spirorbis of Linné. 
The description of its colour ("alba"), as well as all the other characters given of this species in the "Fauna Suecica,' are peculiarly appropriate to $P$. albus. The present species being common in Sweden, and not likely to be confounded with any other, could scarcely have escaped the keen observation of the great naturalist; and it was not otherwise noticed by him. However, as the confusion has already been too great in the specific names of this genus, I will not venture to increase it by restoring Linné's name.

\section{P. GLA'BER*, Jeffreys.}

P. glaber, Jeffr. in Linn. Tr. xvi. p. 387 ; F. \& H. iv. p. 150 , pl. exxvi. f. 8,9 .

BODY yellowish-grey: tentacles rather short, cylindrical, and ending in a blunt point: foot rather broad, especially in front, with a yellowish edge.

SHELL rather convex above and depressed in the centre, concave below, rather thin, glossy and sometimes iridescent, greyish-horncolour and occasionally marked with white curved streaks in the line of growth, finely but irregularly striate transversely, and very faintly and obscurely striate in the opposite or spiral direction; the spiral strix are only visible in some lights and by the aid of a strong magnifying power: epidermis thin and smooth: periphery rounded: whorls 5 , convex, but somewhat angular, the last scarcely exceeding onehalf of the shell: suture verydeep: mouth rather more circular than oval: outer lip slightly reflected, the upper edge projecting a little beyond the lower one: inner lip united to the columella, but continuous with the outer lip: umbilicus large and rather deep. L. 0005. B. 0-15.

Habitat: On aquatic plants in marshes, lakes, and ponds, from Burra fiord in Unst to Penzance; but it is not generally diffused. It is an upper tertiary fossil. I only know of about twenty localities. The largest specimens I have seen were found by Mr. Bridgman near

$$
\text { * Polished. }
$$


Norwich, and measure nearly a quarter of an inch in diameter. It is distributed throughout the greater part of the Continent, and ranges from Sweden to Corsica and Algeria. According to the Rev. R. T. Lowe, it also inhabits Madeira.

This species differs from $P$. albus in its smaller size and glossy aspect ; in the upper side being rather convex, instead of flat (owing to the rotundity of the whorls); in its deeper suture and umbilicus; in the upper part of the outer lip not projecting so much, in consequence of which the mouth appears to be more circular; and, especially, in not having the strong and regular spiral striæ which characterize the last species. The mouth is also not nearly so large; and the periphery is never keeled or compressed. The present species is equally abundant where it occurs; but I am not aware that both species have been found living together.

It is the $P$. laevis of Alder, and probably also the $P$. cornu of Ehrenberg from the Nile. The P. Rossmoessleri of Auerswald appears to be only a large variety of the same species, having the peristome thickened by an inner rib (as in the next species), judging from Rossmässler's description and figure, as well as from an examination of typical specimens in the Museum at the Jardin des Plantes. Von Martens has published, in the 'Malakozoologische Blätter' for 1859, some excellent dissertations on the synonymy of a few of the European land and freshwater shells, and is of opinion that this species is also the $P$. gyrorbis of v. Seckendorf and has five other aliases. 


\section{Whorls many, keeled.}

\section{P. SPIROR'BIs* Müller.}

P. spirorbis, Müll. Verm. Hist. pt. ii. p. 161 ; F. \& H. iv. p. 159, pl. cxxvii. f. 9, 10.

BoDY purplish-grey or reddish-brown, with minute black specks on the foot: tentacles rather long, slender and pointed : foot short and narrow, obtusely rounded in front and angular behind.

SHell slightly concave above and flat below, or vice versâ, slightly wider at the base, rather solid, glossy, brownish horncolour, closely striate in the line of growth, and marked spirally with very faint and minute striæ: epidermis thin: periphery angular, and sometimes bluntly keeled on the lower side : whorls 5-6, gradually increasing in size, the last not exceeding in diameter one-sixth of the whole spire; they are rounded, but angular : suture deep : mouth nearly circular, often thickened or strengthened inside by a rib: outer lip very slightly reflected: inner lip continuous with the other lip, but spread over the columella: umbilicus very large and shallow. L. 0·04. B. $0 \cdot 25$.

Var. ecarinata. Shell smaller, light grey, having one whorl less than usual and no trace of a keel. P. spirorbis, Moq.-Tand. Hist. Moll. Fr. p. 437, pl. xxxi. f. 1-5.

HABITAT: On plants and grass in shallow and stagnant water everywhere from the Moray Firth district to the Channel Isles. It is also a fossil of our upper tertiary beds. The variety appears to be very rare in this country. I have only found it once; and that was in Oxwich marsh, near Swansea. A monstrosity not unfrequently occurs, in which the whorls are more or less twisted and separated. Some specimens which my late friend Mr. Barlee found at Penzance resemble a minute corkscrew; and in another form of the same kind of distortion which I found in Bishopston Valley, near

* Round-spired. 
Swansea, the last whorl only is separated from the rest and curled upwards. In the last-mentioned locality there was a great deal of mud which had been brought down by a stream and deposited in the grassy pool where I found the shells. This mud must have inconvenienced the mollusk and prevented its completing the spire of its shell on the usual plane; so that it gave the last whorl an outward twist, apparently in order to get clear of the incumbrance. When the drains and splashy pools in which this kind of Planorbis lives are dried up by the heat of summer, it retires far within its shell and closes the mouth or opening with a yellowish-white and rather solid lid, patiently waiting for the next shower of rain and fasting in the mean time. This species inhabits Siberia, and ranges as far south as Algeria and Sicily.

It differs from $P$. glaber in the whorls being much narrower and consequently more compact, and in usually having a blunt keel on the periphery.

The typical or ordinary form is the $P$. rotundatus of Poiret, $P$. vortex var. $\beta$. of Draparnaud, and $P$. leucostoma of Michaud, besides having other specific names for several of the varieties.

\section{P. voR'TEX*, Linné.}

Helix vortex, Linn. Syst. Nat. ed. xii. p. $1243 . \quad P$. vortex, F. \& H. iv. p. 157, pl. exxvii. f. 6-8.

BoDy reddish-brown, with a slight tint of violet, rather distinctly marked with minute black specks : tentacles very long, slender and finely pointed: foot evenly rounded in front and keeled behind.

Shell much compressed, concave above and flat below, thin, glossy, yellowish or greyish-horncolour, finely and closely striate in the line of growth, and occasionally having a few obscure and extremely minute spiral striæ: epidermis 
thin : periphery slightly keeled towards the lower side, and always angular in consequence of the outward compression of the shell : whorls 6-8, gradually enlarging, the last not exceeding in diameter one-fifth of the whole spire, angular on both sides and sloping gently towards the outer edge: suture well defined, but not deep: mouth obliquely oval, ending above in rather an acute angle, and having the inside sometimes thickened by a slight rib : outer lip not reflected: inner lip much spread on the columella, but continuous with the outer lip : umbilicus very large and shallow. L. $0 \cdot 05$. B. $0 \cdot 3$.

Var. compressa. Shell thinner and much flatter, with the keel more distinct and sharp and placed nearly in the middle of the periphery. P. compressus, Mich. Compl. p. 81, pl. xvi. f. $6-8$.

Habitat : The same as that of $P$. spirorbis, and having a similar range at home and abroad as far southward as Algeria. It is, however, not so generally diffused as that species. They are sometimes found together. The present species is also one of our upper tertiary fossils. The variety is not uncommon. I have a distortion from Clumber lake, Notts, in which the spire is displaced on the lower side, and the first whorls are set at an acute angle to those which succeed.

This mollusk is sluggish, but fond of floating. It lays from 10 to 12 eggs. The epiphragm is thin and membranous.

The shell differs from that of $P$. spirorbis in being thinner, flatter, and rather longer, and in having a distinct and prominent keel. This species was first described and figured by Lister.

\section{P. CARINA'TUS*, Müller.}

P. carinatus, Müll. Verm. Hist. pt. ii. p. 175 ; F. \& H. iv. p. 153, pl. exxvii. f. 4, 5 .

BoDy deep-reddish brown with a yellowish tint, and of a * Keeled. 
lighter colour underneath, finely and rather distinctly marked with black specks : tentacles long, slender, bluntly pointed: foot acutely rounded in front and obtusely so behind.

SHell compressed, concave above and flat or very slightly convex below, rather thin and glossy, yellowish-horncolour, finely and closely striate in the line of growth, with a few slight spiral striæ : epidermis thin : periphery strongly keeled towards the middle: whorls 5-6, the diameter of the last being rather less than a third of the whole spire, moderately convex above, but much less so beneath, sloping gradually on both sides to the periphery: suture deep : mouth obliquely oval, sharply angulated above, the inside sometimes thickened : outer lip slightly reflected: inner lip continuous with it, much spread on the columella : umbilicus very indistinct, owing to the lower side being nearly flat. L. $0 \cdot 1$. B. $0 \cdot 5$.

Var. disciformis. Shell flatter and thinner, of a yellowish colour, having the last whorl larger in proportion to the others, and the keel more prominent and sharp and placed exactly in the middle. P. lutescens (afterwards altered to disciformis), Jeffr. in Linn. Tr. xvi. pp. 385 \& 521.

Habitat : Marshes and stagnant water in our home and eastern counties, as well as in those of Dorset, Somerset, Northampton, York, Glamorgan, and many parts of Ireland. Dr. Leach says that it also occurs near Edinburgh. It is, however, local, and never plentiful. It is an upper tertiary fossil. The variety is found in Bucks, Oxford, Cambridge, Glamorgan, Cork, and Tipperary, and is somewhat rare. This variety bears the same relation to the typical form as the $P$. compressus of Michaud does to $P$. vortex. The monstrosity, so common in this genus, in which the last whorl is disjoined from the rest, also occurs, but very seldom. It is a Swedish species, and ranges southward to Portugal and Corsica.

This mollusk is very slow in its movements, but appears to be fond of floating. It lays from 10 to 20 eggs, which quit the capsule in from ten to fifteen days. It is occasionally met with in company with the next species. 
This is in all probability the Helix planorbis of the 'Fauna Suecica,' which is described as "plana" and "margine prominulo;" but as the description and figure given by Lister, to which Linné there refers, apply to the Helix complanata of the latter, more confusion will be avoided by the adoption of Muiller's name.

\section{P. complana'tus *, Linné.}

Helix complanata, Linn. Syst. Nat. ed. x. p. 769. P. marginatus, F. \& H. iv. p. 155, pl. exxvii. f. 1-3.

BoDy of a deep violet-red, with very fine black specks, especially on the edges of the foot: tentacles very long and slender, bluntly pointed: foot rounded in front, convex behind, and ending in an obtuse tail.

Shell concave above and slightly convex below, rather solid and opaque, not glossy, yellowish-horncolour with sometimes a tinge of brown, closely but irregularly striate in the line of growth and more or less distinctly striate in a spiral direction: epidermis rather thick : periphery strongly keeled on the under side: whorls 6 , the diameter of the last being about one-fourth of the whole spire, convex above and slightly so beneath, sloping abruptly on the upper, and gradually on the lower side to the periphery : suture moderately deep : mouth roundish-oval, slightly angulated above by the keel, the inside being sometimes strengthened by a rib: outer lip a little reflected: inner lip continuous with it and affixed throughout to the columella : umbilicus broad and very shallow. L. $0 \cdot 125$. B. $0 \cdot 6$.

Var. 1. rhombea. Shell smaller, more solid, rather more convex above and deeply umbilicated below ; keel blunt and almost obsolete. Helix rhombea, Turton, Conch. Dict. p. 47.

Var. 2. albida. Shell whitish or colourless.

Habitat : Marshes, ponds, canals, ditches and standing water everywhere in England, Wales, and Ireland; but I am not aware of any Scotch locality. It is one of our upper tertiary fossils. The variety 1 . is from Dublin

* Flattened. 
and the South of Ireland; and the other variety has been found by Mr. Choules at Eltham in Surrey. A monstrosity, having the whorls dislocated and more or less separate from each other, sometimes corkscrewshape, has been found by Mr. Bean near Scarborough, and by myself on Crymlyn Burrows, near Swansea. It is the Helix Cochlea of Brown (Mem. Wern. Soc. pl. xxiv. f. 10) and H. terebra of Turton's 'Conchological Dictionary.' This common species is widely distributed in Europe from Finland (according to Nordenskiöld and $\mathrm{Ny}$ lander) to Algeria and Sicily.

It is a sluggish and slimy as well as a very irritable mollusk, and often indulges itself in floating lazily along the under surface of the water. It lays from 8 to 10 capsules, each of which contains from 6 to 21 eggs; so that it appears to be more prolific than many of its congeners.

Its shell may be distinguished from that of $P$. carinatus by its narrower and more rounded whorls, as well as by the keel being placed below, instead of in or towards the middle of, the periphery. It is usually larger and thicker than that species and is much more generally diffused and plentiful.

There can be no doubt that this is the Helix complanata of Linné, whose epithet "deorsum carinata" is peculiarly appropriate; but both Müller and Draparnaud have substituted other names (viz. umbilicatus and marginatus) on what I cannot help considering as very insufficient grounds. If Linné's name was prior to what is termed "the binomial epoch," and therefore inadmissible (which is a very questionable objection), still Gmelin's adoption of that name, as well as Muiller's, take precedence of the one proposed by Draparnaud. It must also be borne in mind that this species and $P$. carinatus 
are connected together through the $P$. submarginatus of Cristofori and Jan, alias the $P$. intermedius of Charpentier. Some of the aberrant forms are as difficult to separate as those of $P$. spirorbis and $P$. vortex. The present species was first made known by Lister.

The $P$. turgidus described by me in the 'Linnean Transactions' is not a British species; and I was misinformed as to the locality. Its nearest ally is, as I stated, $P$. corneus; but it has been erroneously referred by subsequent writers to the present species.

\section{Whorls rounded and not keeled. \\ 10. P. COR'NEUS* Linné.}

Helix cornea, Lynn. Syst. Nat. ed. xii. p. $1243 . \quad P$. corneus, F. \& H. iv. p. 147, pl. cxxvii. f. 1-3.

BoDY dark red or nearly black, of a greyish hue beneath, with black and grey specks on the upper part: tentacles long and curved, with rather blunt tips: eyes of a moderate size and not prominent : foot slightly tubercled, narrow and angulated in front, rounded and convex behind.

SHell rather deeply concave above and nearly flat below, somewhat solid and opaque, glossy, whitish-horncolour with a reddish-brown tinge, closely but irregularly striate by the curved lines of growth and marked with fine and close-set spiral strix, which are more perceptible in the first whorls; the upper surface is also sometimes pitted or impressed in an irregularly quadrangular form likecut-glass: epidermis rather thin : periphery rounded and quite destitute of any keel or angularity : whorls 5-6, more perceptible on the umbilical or lower side, in consequence of that part of the spire being intorted : diameter of the last whorl rather less than a third of the whole shell; they are very convex above and rather compressed beneath: suture deep: mouth forming a segment of two-thirds of a circle: outer lip a little reflected, the upper side not projecting much beyond the lower one: inner lip

* Horn-coloured. 
continuous, but closely attached to the columella and widely spread on it: umbilicus broad and shallow. L. 0.35. B. 1 .

Var. albina. Shell perfectly white.

Hавітат : Marshes, ponds, and ditches in many parts of England and Ireland; but although gregarious, it is very local. It occurs in a fossil state in the mammalian crag of Suffolk, as well as in the upper tertiary beds of Suffolk, Essex, and Worcestershire. The variety is found in Surrey. It is a Siberian species, and diffused over the Continent as far south as Corsica. M. Terver has found a thin variety of it in Algeria.

This far exceeds in size any other European species of Planorbis. Its anatomy, embryology, and habits were accurately described by Lister nearly two centuries ago ; and he seems to have made several experiments, but in vain, with the hope of being able to fix and render useful the purple dye which this mollusk so plentifully yields. It is a sluggish and extremely sensitive animal; and when irritated it emits the fluid or secretion in considerable quantity from a gland at the sides of its neck. It may often be seen floating on a warm and still summer day. It lays only two or three capsules, each containing from 20 to 40 eggs, which are excluded at the end of fifteen or sixteen days. The epidermis of the young shell is covered with fine down, its surface resembling velvet pile. In this state it is the $P$. similis of Muiller.

\section{P. contor'Tus*, Linné.}

Helix contorta, Lynn. Syst. Nat. ed. xii. p. 1244. P. contortus, F. \& H. iv. p. 160, pl. exxvi. f. 3.

BoDy black, with a slight tinge of red: tentacles remarkably slender: eyes very small: foot broad and rounded in front, narrowing behind to a blunt tail.

* Twisted. 
Shell flat above, with a deep depression or concavity in the middle, very concave below, rather solid for its size, and opaque, yellowish-brown or horn-colour, closely and deeply striate in the line of growth, but not otherwise sculptured: epidermis rather thick: periphery rounded: whorls 8, extremely compact and much compressed, angular above and slightly so beneath : suture deep : mouth semilunar, occasionally strengthened inside by a rib : outer lip not reflected, the upper side scarcely projecting beyond the lower one: inner lip thin, not continuous but attached to the columella: umbilicus large and deep. L. 0.075. B. 0.175.

Var. albida. Shell nearly white.

Habitat: On water-plants in lakes, ponds, and ditches throughout the greater part of Britain, and reaching as far north as the Shetland Isles; but it is local. It is also an upper tertiary fossil. The variety was found by me in a lake near Lerwick, with specimens of the ordinary colour. The usual monstrosity occurs in which the spire is dislocated. Abroad it ranges from Siberia to Portugal and Corsica.

This curious little mollusk is slow, irritable, and fond of floating. It is not very prolific ; for each capsule (of which it lays from 5 to 9 during the breeding-season) contains only from 6 to 8 eggs, giving an annual average of about 50 for an individual.

The shell of this, as well as of the last species, is so different from any other which I have described, that it is unnecessary to make any comparison. Their forms are, however, represented by many analogous species in North America.

\section{Genus II. PHY'SA*, Lamarck. Pl. IV. f. 4, 5, 6, 7.}

BoDY rather long, and twisted in a spiral coil : tentacles long and slender : foot rather long, rounded in front and 
pointed behind, attached to the upper part of the body by a very short and broad stalk or pedicle.

SHell conic-oval or oblong: spire produced, sinistral or turning from right to left.

This peculiar and characteristic genus has intermediate relations with Planorbis and Limnoca. It resembles the first in its long tentacles, as well as in some of the organs being placed on the left, instead of on the right side of the body; and it agrees with the latter in the form of its shell: but it differs from both in the spire being sinistral, although that is not a very important character. The shells of Physa have a remarkably polished appearance, caused in some cases by their being more or less enveloped by an expansion or lobe of the mantle, the lubricating friction of which always keeps the surface smooth and bright. These little mollusks frequent shallow, and generally clear water, and are gregarious. Their eggs are deposited in strips of a gelatinous consistency, which are fixed to submerged stones as well as to the stalks and leaves of aquatic plants.

A. Mantle having plain edges and not expanded over the shell, which is covered with an epidermis and has a long spire.

\section{Physa hypno'rum*, Linné.}

Bulla hypnorum, Linn. Syst. Nat. ed. xii. p. 1182. P. hypnorum, F. \& H. iv. p. 143, pl. cxxii. f. $6,7$.

BoDy lustrous, dark grey, dusky brown, or almost black, with sometimes a faint tint of blue, covered with very minute black or dark-grey specks: tentacles long, slender, and pointed, diverging considerably at their base : eyes very small and not very distinct : foot lance-shaped, narrow, blunt and truncate in front, compressed and rather pointed behind.

SHell oblong, spindle-shaped, thin, highly polished, semi-

* Frequenting the Hypnum, a kind of moss. 
transparent, yellowish or reddish-horncolour, faintly striate by the lines of growth, and marked spirally with a few very indistinct striæ, which are only perceptible by means of a high magnifying power: epidermis very thin: whorls 6-7, convex, but slightly compressed at the sides, the last exceeding in size all the rest put together: spire tapering, but blunt at its extremity: suture distinct, though not deep : mouth oval, contracted on the inner side by the periphery of the penultimate whorl, acutely angulated above and rounded below : outer lip thin and flexuous : inner lip spread on the columella, which has a strong and broad fold on its lower side. L. $0 \cdot 5$. B. $0 \cdot 2$.

Habitat : Ponds, ditches, and among grass in pools which are quite dried up in summer, throughout these isles from the Moray Firth district to Guernsey; but it is rather local. It is also an upper tertiary fossil. A variety occurs in which the shell is smaller and of a dark copper-colour; and I also possess a specimen in which the spire is eroded and truncate, the opening having been filled up by a shelly plate. Muiller recorded a specimen which had only the right eye, the other being wanting. It is a native of Siberia, and ranges southward to Nice and the Eastern Pyrenees. According to Gould and Philippi, it is the same species as the $P$. elongata of Say, which inhabits the northern and western parts of the United States.

This mollusk is rather active in its habits, and may be seen in fine weather floating with tolerable rapidity. It is rather prolific; and the young attain their full size at the end of the second year. The largest specimens I have ever seen of this species were found by me more than a quarter of a century ago, in fish-ponds at Fremington, in the north of Devon, some of which are three-quarters of an inch in length.

Gmelin supposed that the Bulla hypnorum of Linné might be a variety of the next species; and Miiller, for 
nearly the same reasons, called the present species Planorbis turritus. But the Linnean epithets "spira prominente" and "spira obsoleta" appear unmistakeably to distinguish the two species; and, at all events, it would now be very inconvenient to make any change of name by adopting that given by Muiller, instead of the one by which this species is so universally known. The late Dr. Fleming proposed to separate it generically from the next under the name of Aplexa; but this separation has only been adopted by a very few conchologists. A well-known European species, $P$. acuta, seems to connect the two British forms, both as regards the soft parts of the animal and the shell.

B. Mantle having lobes or digitated processes which expand over the shell ; the latter being destitute of an epidermis and having a short spire.

\section{P. Fontina'Lis*, Linné.}

Bulla fontinalis, Linn. Syst. Nat. ed. xii. p. 1185. P. fontinalis, F. \& H. iv. p. 140, pl. exxii. f. 8, 9.

Body lustrous, dark grey with sometimes a slight tint of yellow or violet: mantle fringed with about a dozen lobes or digitations of unequal size: tentacles rather slender, light grey : eyes conspicuous : foot obtusely rounded in front, and contracted behind to a somewhat fine point.

Shell oval, extremely thin, glossy, semitransparent, greyish-horncolour with a slight tinge of yellow or brown, faintly striate by the lines of growth and microscopically striate in a spiral direction: whorls 4-5, swollen, the last occupying considerably more than three-fourths of the shell: spire not much produced, blunt at its point : suture moderately deep : mouth nearly of the same form as that of the preceding species, but much larger and wider in proportion : outer lip very thin and flexuous: inner lip much spread on the columella, which has a slight and narrow fold on its lower side. L. $0 \cdot 35$. B. $0 \cdot 25$.

* Frequenting fountains. 
Var. 1. inflata. Shell half as large again as the usual size : whorls angular towards the suture, the middle one rather more prominent than the penultimate whorl, causing the summit of the spire to appear abruptly terminated.

Var. 2. curta. Spire extremely short. Bulla fluviatilis, Turt. Conch. Dict. p. 27.

Var. 3. oblonga. Spire considerably produced.

Var. 4. albina. Shell of a milk-white colour.

Habitat : On water-cresses and other aquatic plants in running brooks, as well as in slow rivers, canals, and ditches everywhere in Great Britain, as far north as Aberdeenshire. Var. 1. Dublin (Humphreys and Warren). Var. 2. Clonoony Barracks, Ireland (Brown); Bramerton, Norfolk (J. G. J.). Var. 3. Anglesea, on Chara aspera (J. de C. Sowerby); Naas, Ireland (Humphreys). Var. 4. Birkenhead (Webster). This species is widely diffused on the Continent, and ranges from Finland to Sicily.

This common and pretty little mollusk is rather lively, creeping and floating by jerks. A considerable portion of the shell (especially the back of the spire) in its living state is often covered with the spores of Confervæ or some of the freshwater Algæ, which shows that the mantle does not envelope all the surface. When the fry are excluded from their gelatinous case, they are about the size of a pin's head, and are very active. The jerking motion which this animal has, is said to be owing to its being infested by a small kind of parasitic worm which causes it some uneasiness. I should rather be inclined to attribute this motion to the length and narrowness of the foot, which has to support a comparatively bulky shell. According to Montagu, the $P$. fontinalis spins a filament by which it lets itself down to the bottom 
after floating, if there is no leaf or stalk near it. Leach says that when it is annoyed by the approach of wandering animals, it repulses them with repeated blows, inflicted by a rapid movernent of the shell ; the foot being the point of fixture. This species was first described and figured by Lister.

The shell is more ventricose than that of the last species; and it has a much shorter spire and a larger mouth.

The Bulla rivalis of Maton and Rackett, which was supposed to have been found in Hampshire, is a common West-Indian species, which now bears that name. It is the $P$. Sowerbyana of D'Orbigny.

Mr. Choules has described in the 'Zoologist' a species of Physa which he found in a water-tank in Kew Gardens, and which Mr. Norman (being misinformed as to the precise locality) has proposed to admit into our native Fauna. It appears to be a variety of the $P$. acuta of Draparnaud, but it is undistinguishable from specimens in the British Museum which were collected in Cuba, St. Thomas, and St. Croix; and it has probably been introduced with some aquatic tropical plant. Dr. Hooker informs me that many West-Indian plants have been imported and cultivated in the Gardens. P. acuta has never (so far as I am aware) been found in this country; and although it is abundant in the middle and South of France, it has not been recorded as inhabiting any of the northern Departments. The $P$. subopaca of Lamarck is a variety of that species.

The $P$. alba of Turton, who stated that he had received it from Capt. Blomer as a native of Towyn in North Wales, is the $P$. contorta of Michaud, and is only known to inhabit the Eastern Pyrenees, Corsica, Sicily, and Algeria. 
Genus III. LIMN $\mathbb{E}^{\prime} \mathrm{A}^{*}$, (Lymnea) Bruguière.

Pl. IV. f. 8, 9, 10.

Bopy rather long and twisted in a spiral coil : head prominent: tentacles short, triangular and flattened: foot oblong, bilobed or notched in front and obtusely rounded behind, attached to the upper part of the body as in Physa.

Shell conic-oval or elongated: spire usually produced, dextral or turning from the left to right.

As in Physa, some of the species of Limncea, which appear to form a transitional link between the two genera, have their shells enveloped by an outer fold or lobe of the mantle. These species have been generically separated by some authors under the several names of Amphipeplea, Lutea, and Myxas. The difference between such and the typical species is, however, not greater than between the two forms of Physa which I have above noticed. All the species of Limncea frequent shallow and still waters; and they are very prolific and gregarious. Their mode of propagation is very singular-three or more individuals being united in a chain for that purpose. Leach has remarked that, in consequence of the sexual parts being distant from each other, one individual is able, at the same time, to perform the function of each sex with two others, as was first observed by Geoffroy about the middle of the last century. The spawn resembles that of the last genus.

The generic name has been spelt by authors in no less than nine different ways; but the correct orthography is

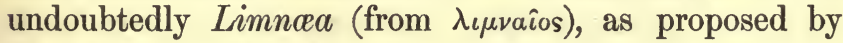
Rang. 
A. Shell extremely thin and fragile, and almost enveloped by an outer lobe or membranous expansion of the mantle : spire very short.

\section{Limnatea gutino'sA*, Muiller.}

Buccinum glutinosum, Müll. Verm. Hist. pt. ii. p. 129. Limnaeus glutinosus, F. \& H. iv. p. 182, pl. cxxiv. f. 6, 7.

BoDy dark grey, with a greenish-yellow tinge and brightyellow or whitish specks: tentacles very short, rather triangular, with blunt tips : eyes placed on tubercles on the inner side of the tentacles, very black and distinct: foot exceedingly large, broad in front and obtusely rounded before and behind.

Shell globosely-oval, so excessively thin as to be almost membranous, highly polished, transparent, yellowish or greyish-horncolour, with a few indistinct darker spiral zones, remotely and irregularly striate by the lines of growth, which are stronger towards the suture, and closely but microscopically striate in a spiral direction: epidermis extremely thin: whorls 3-4, globular, the last forming nearly the whole of the shell: spire slightly produced: suture rather deep: mouth oval, a little contracted above by the projection of the penultimate whorl: outer lip very thin: inner lip much spread on the columella and thickened at its edges : columellar fold (forming the lower part of the pillar of the spire) curved and sharp. L. 0:55. B. $0 \cdot 45$.

Var. mucronata. Shell not quite so globular: spire more produced.

HABITAT : Lakes and ponds in the home and eastern counties, as well as in a ditch near Dunster Castle in Somersetshire (Leach); Bala Lake (Gibbs) and a pond near Windermere (Bulwer); but it is a local species, although abundant where it occurs. Its periodical reappearance in the same spots has been remarked both by Mr. Bridgman and Mr. Whiteaves to be very uncertain and unaccountable. Specimens have been kindly sent to me by Mr. Bridgman, in which the spire is more 
or less intorted, resembling in this respect the form of $L$. involuta. The present species ranges from Finland, through Sweden, Germany, and France, as far south as the Pyrenees.

It is rather an active mollusk, and nearly always in motion. Bouchard-Chantereaux says that each of its capsules contains from 30 to 40 eggs. In the young the shell is entirely covered by the pallial fold.

\section{L. INVOLU'TA*, Thompson.}

Limneus involutus, (Harvey) Thomps. in Ann. Nat. Hist. v. p. 22. Limnceus involutus, F. \& H. iv. p. 184, pl. cxxii. f. 11.

BoDy unknown as to its external parts, except that the greater part of the shell is covered by the mantle.

Shell oval, rather glossy, semitransparent, yellowishhorncolour with a tinge of brown, closely but irregularly striate by the lines of growth, which are stronger towards the suture, often impressed and sometimes constricted by a few spiral grooves in different parts of the shell: epidermis thin : whorls 3-4, convex, the last covering all the rest except the point of the spire or nucleus : spire flat or slightly concave, with the point upraised and twisted: suture distinct, but not deep : mouth pear-shaped: outer lip thin, slightly reflected: inner lip much spread on the columella: fold narrow and sharp. L. $0 \cdot 4$. B. $0 \cdot 275$.

HaвiтAт : A small mountain-lake, and a stream which flows into it, at Cromaglaun near Killarney; not rare. In one of my specimens, which has the mouth somewhat contracted below, a tendency to an umbilical cleft is observable.

It is strange that no other locality but the one above mentioned has ever been discovered, here or abroad, for this remarkable species. It has some affinity to L. glutinosa, and may ultimately prove to be an aberrant form of that species, corresponding with the variety Burnetti

* Having the spire intorted or sunk. 
of $L$. peregra. Very little is known with respect to the external parts of the body; but Professor Goodsir has given some valuable details of its internal organization, which are published in an appendix to Mr. Thompson's paper in the 'Annals of Natural History.' He says, "In structure the Limnous involutus resembles the other species of the genus;" from which remark it might be inferred that the mantle has not the expanded lobe which is peculiar to the subgenus Amphipeplea. Dr. Percival Wright, however, informs me that the greater part of the shell in this species is covered by the mantle, as in L. glutinosa. The form and substance of the shell are also similar in both of these species.

B. Exterior of the shell never covered by the mantle : spire produced.

\section{L. PER'EGRA*, Müller.}

Buccinum peregrum, Müll. Verm. Hist. pt. ii. p. 130. Limnaeus pereger, F. \& H. iv. p. 168, pl. cxxiii. f. 3-7.

BoDy yellowish-grey, with a brown or olive-green tinge, mottled with black and covered with small yellow or milkwhite, and black specks : tentacles diverging from each other at nearly a right angle : eyes distinct: foot oblong, very broad, nearly truncate in front, and obtusely rounded behind.

Shell obliquely ovate, thin, moderately glossy, semitransparent, yellowish-horncolour, irregularly striate by the lines of growth, and closely and microscopically striate in a spiral direction, with occasionally a few indistinct spiral ridges and pitmarks : epidermis rather thin : whorls 5, convex, the last occupying three-fourths of the shell: spire produced and pointed: suture rather deep : mouth large, oval, very little contracted above by the projection of the penultimate whorl: outer lip thin, slightly reflected: inner lip folded on the columella and thickened, forming behind it a slight umbilical cleft : fold rather prominent and curved. L. 0·75. B. 0.425. 
Var. 1. Burnetti. Body a little broader than that of the typical form, dark olive, spotted with opaque yellow: mantle nearly black, with a few paler spots. Shell rather globular and solid, of a dull aspect, yellowish-brown, closely and strongly striate in the line of growth: epidermis rather thick: the last whorl nearly covering all the others: spire exceedingly short, nearly truncate and almost intorted. L. 0.725. B. 0.65. Limncea Burnetti, Alder in Ann. Nat. Hist. n.s. ii. p. 396, pl. ii., top figures. Limnceus Burnetti, F. \& H. iv. p. 172, pl. exxiii. f. 8, 9.

Var. 2. lacustris. Body of a darker colour than usual. Shell resembling that of the last variety; but it is much smaller and more glossy, and has strong and regular transverse grooves, and the spire is not quite so short nor inclined to be intorted. The shell is often eroded. Gulnaria lacustris, Leach, Moll. Brit. Syn. p. 107.

Var. 3. lutea. Shell remarkably solid, having a very short spire of from 3 to 4 whorls. Helix lutea, Mont. Test. Brit. p. 380 , tab. 16. f. 6 .

Var. 4. ovata. Body of a paler colour. Shell ampullaceous and rather thinner than usual: whorls exceedingly convex, the last being larger in proportion to the rest: spire very short: suture deep : mouth very large. Limneus ovatus, Drap. Hist. Moll. p. 50, pl. ii. f. 30, 31 .

Var. 5. acuminata. Shell resembling the last variety in all respects, except in having a more produced spire and a smaller mouth.

Var. 6. intermedia. Shell rather compressed towards the front margin and thinner than usual : spire more produced : mouth expanded. Limnea intermedia, Fér. in Lam. An. s. V. vi. pt. ii. p. 162.

Var. 7. oblonga. Shell oblong and compressed in front.

Var. 8. labiosa. Shell smaller, having the outer lip remarkably expanded and reflected. L. $0 \cdot 5$. B. $0 \cdot 35$.

Var. 9. picta. Shell rather smaller than the last, and beautifully marked by alternate bands of brown and white, which are sometimes confluent.

Var. 10. maritima. Shell dwarfed, rather solid: spire produced : suture deep. L. $0 \cdot 4$. B. $0 \cdot 225$. 
Var. 11. Succineceformis. Shell shaped like a Succinea, and very thin: whorls 4 : spire small and oblique.

Var. 12. decollata. Shell more or less eroded: spire truncate.

Var. 13. sinistrorsa. Shell resembling that of a Physa in having the spire sinistral or reversed, rather solid; the spiral ridges distinct and prominent. Limnceus lineatus, Bean, MS.; F. \& H. iv. p. 168, pl. cxxiii. f. 7.

Var. 14. scalariformis. Shell oblong, with deep and regular transverse striæ: whorls more or less disjoined: suture consequently very deep.

Habitat: Still and slowly running waters everywhere. Var. 1. Loch Shene, Dumfriesshire (Burnett); Breconshire (Moggridge). Var. 2. Mountain-lakes in Zetland, Scotland, Ireland, and the North of England. Var. 3. South Devon (Montagu); South Wales (J. G. J.): thrown up by the tide at the mouths of rivers. Var. 4 . Lakes, canals, and large ponds; attaining sometimes a considerable size. Var. 5. With the last. Var. 6. Ponds. Var. 7. Lewes, Suffolk; Church Stretton, Salop; Bearhaven, Co. Cork (J. G. J.). Var. 8. Appin, Argyleshire (Bedford). Var. 9. Ulva I., Hebrides (same). Var. 10. Marshes on the sea-coasts of Glamorganshire and North Devon (J. G. J.). Var. 11. Kensal Green (J. G. J.). Var. 12. Church Stretton; Oxwich, near Swansea (J. G. J.). Var. 13. Scarborough (Bean). Var. 14. Warminster (J. G. J.). This and the two last forms are rather monstrous than varietal. This species is frequently met with in our upper tertiary beds. The typical form and several of its varieties extend from Siberia to Sicily. It is a very ubiquitous species ; and Capt. Hutton found a variety of it in Afghanistan.

The variability of this common and abundant species is equal to the extent of its geographical distribution. I was at first inclined to consider that the Limneus ovatus 
of Draparnaud, and its allied forms, would legitimately constitute a distinct species; but, after a very careful and protracted comparison of many hundred specimens, I could not satisfactorily separate them from intermediate varieties. The difference in the colour of the body, as well as in the consistency and even the shape of the shell, appears to depend on the nature and quantity of the food, the chemical ingredients of the water, and the degree of stagnation or rapidity of its current. M. Morelet, in his description of the Portuguese land and freshwater Mollusca, says, with much naïvete, of the L. intermedia, "aussi reconnaissable que puisse l'être une espèce dont le caractère principal est de n'en point avoir." The difficulty of admitting or rejecting such forms as specific is quite as great as in the case of Anodonta. I have merely noticed some of the more peculiar varieties of the present species.

L. peregra is not very slow in its movements. It is nearly amphibious; and, as its name imports, it is fond of wandering and seeing a little of the world, being occasionally met with at some distance from its native element in a damp meadow or climbing up the trunk of a willow-tree. This habit reminds one of the inland travels of the Perca scandens. An interesting account of the floating voyages made by our molluscan traveller on an old canal near Inchbroom will be found in the Rev. Dr. Gordon's Contributions to the 'Zoologist.' He says that when the shoal of $L$. peregra had fairly started, they resembled a fleet of herring-boats in miniature. This mollusk is very prolific and lays about 1300 eggs in a season, contained in clusters of from 12 to 180 . It is zoophagous, as well as phytophagous; and a writer in the 'Zoologist' lately stated (p. 7400) that it ate minnows when they were confined together in an aquarium. 
I have seen these pond-snails attack and devour their own brothers and sisters under the same circumstances, when they had no other supply of food; and this was done by piercing the spire of the shell near its point, which was thinner and somewhat eroded by the action of the water. Their shells are often coated with mud.

It is probable that Linné considered this species to be a variety of his Helix auricularia. What his $H$. limosa was, it is now impossible to say with any certainty. His epithet "oblongiuscula" for that species appears to be more appropriate to L. palustris ; while the term "ovata" which he uses for "auricularia" is applicable both to this last species and L. peregra. In the first edition of the 'Fauna Suecica,' H. limosa is described as having an operculum like Paludina or Bythinia; but in the second edition this character is omitted. Nearly a century before Linne's time the present species had been distinguished by Lister, although not by any specific name. At least 30 species have been made by Continental authors out of some of its countless varieties.

\section{L. AURICULA'RIA ${ }^{*}$, Linné.}

Helix auricularia, Linn. Syst. Nat. ed. xii. p. 1249. Limnous auricularius, F. \& H. iv. p. 169, pl. cxxxiii. f. 1.

Bopy dull greenish-brown or yellow, mottled with black, and covered with very small bright-yellow or milk-white, and black specks : tentacles broad, flat and conic, diverging as in the last species : eyes small and indistinct : foot bordered with yellow, prominent and obtusely rounded in front, keeled and rounded behind.

SHell obliquely globose-oval, thin, glossy, semitransparent, yellowish-horncolour, deeply but irregularly striate by thelines of growth, with very much finer and closer intermediate striæ, which are arranged in rows, and regularly but indistinctly ridged in a spiral direction: epidermis thin: whorls 4-5,

* Ear-shaped. 
very much swollen and expanded in front, the last occupying at least five-sixths of the shell : spire oblique, exceedingly small, but produced and ending in a sharp point: suture very deep: mouth extremely large, roundish oval, a little contracted and nearly truncate on the inner side both by the penultimate whorl and the columellar fold: outer lip thin, considerably reflected : inner lip slightly thickened on the columella and forming behind it a slight umbilical cleft : fold prominent, strongly curved and sharp. L. 1-125. B. 0-825.

Var. 1. acuta. Body of a greyish colour and closely covered with black spots. Shell smaller than the typical form, more oblong, and having the last whorl and mouth proportionably narrower. Limneus acutus, Jeffr. in Linn. Tr. xvi. p. 373. Limnceus auricularius, var., F. \& H. iv. p. 171, pl. exxiii. f. 2.

Var. 2. albida. Shell smaller and thinner, white, with a shorter spire and less distinct striæ. L. $0 \cdot 675$. B. $0 \cdot 55$.

HABitat : Lakes, marshes, slow rivers, canals, deep ditches and large ponds in most parts of Great Britain; but it is local, and does not satisfactorily appear to have been found in Scotland. Var. 1. Marshes on the seacoast of Glamorganshire; Church Stretton, Salop ; Kent; Co. Tyrone (J. G. J.): Yoxford, Suffolk (Barlee). This variety is intermediate between $L$. peregra and the present species; but being found only with the former species, I am inclined to think it belongs to $L$. auricularia. A monstrosity of this form in my collection has a second or inner mouth formed by a plate on the columellar side. Var. 2. Bath (Clark); Blenheim lake (Mrs. Richard Smith). The variety acuta is one of our upper tertiary fossils. This species ranges from Siberia to Portugal.

Its habits are inactive; and when it crawls, only the front edge of its mantle and the tentacles are perceptible. It occasionally may be seen floating on the surface of the water. It is apt to be infested, as well as its congeners, by an annelid allied to the Nais vermicularis of Muiller, which usually takes up its abode between the 
neck and mantle and over the tentacles of the mollusk, incessantly vibrating, and apparently not parasitic but feeding on animalcules. Possibly, however, these worms may have the same truly parasitic propensities which are attributed to the Nereid, that often takes up its abode with the Hermit-crab in the same empty shell, and of which my friend Mr. Spence Bate has given in the 'Zoologist' (1859, p. 6687) an amusing account, as follows : "The soft and serpent-like Annelide smells the repast that the master of the house is enjoying, and, like a wily guest, takes care to be present at the meal, even though unbidden. See! beneath the Crab the beautiful head glides out. While the self-confident owner is devouring one piece, and in his full enjoyment looking round and, perhaps, admiring the submarine sconery, the worm attacks that which is in the other hand, and by little and little the Crab feels it going, and makes an effort to stop it on the way; but it evidently can be seen, by his manner, that he cannot believe that any one would be so rude as to steal his dinner out of his very mouth, and does not think much about the undevoured food, but which, nevertheless, is slowly, gradually and surely taken away."

Draparnaud noticed, besides the parasitic worms, four long and very minute filaments or tubes, which he thought were auxiliary organs of respiration; but subsequent naturalists have not confirmed this discovery. Muiller states that he kept a specimen of $L$. auricularia alive from June to October in the clearest water, which was never renewed, and that it appeared to have no other nourishment than Cryptogamia or Confervoid spores.

This species chiefly differs from some of the varieties of the last, with which it is connected by the form acuta, 
in the shell being much more swollen, and having the last whorl and mouth excessively large in proportion and the spire consequently smaller. The rows of very minute longitudinal striæ may also be regarded as another test of distinction. Young shells are more slender than those of $L$. peregra. The present species was first described by Lister.

\section{L. STAGNa'LIs*, Linné.}

Helix stagnalis, Linn. Syst. Nat. ed. xii. p. 1249. Limnaus stagnalis, F. \& H. iv. p. 174, pl. exxiv. f. 4, 5.

BoDy fawn-colour or yellowish-grey with a reddish tint, covered with very small brown and milk-white specks : tentacles rather long and pointed: foot having a narrow edge of yellow, very broad at its sides, swollen and keeled behind.

SHELL elongated, of a moderate thickness, semitransparent, yellowish-horncolour or greyish-white with sometimes a slight tinge of red, irregularly striate by the lines of growth, with extremely fine and close-set interstitial striæ, which are curved and arranged in rows, and regularly but indistinctly ridged in a spiral direction, so as to form, by intersecting the longitudinal striæ, quadrangular facets, resembling those of cut glass : epidermis thin: whorls 7-8, rather convex and bulging out in the middle, the last occupying nearly threefourths of the shell : spire oblique, much produced and tapering to a fine point : suture moderately deep, margined above by a narrow white line, which is formed by the upper edge of the preceding whorl: mouth oval, interrupted on its inner side by the periphery of the penultimate whorl and the columellar fold: outer lip rather thin and slightly reflected: inner lip spread on the columella and thickened in adult specimens: fold prominent and very strongly curved. L. 2. B. 1.

Var. 1. fragilis. Shell smaller, more slender and tapering. Helix fragilis, Linn. Fn. Suec. 2187; Mont. Test. Brit. p. 369, tab. 16. f. 7.

Var. 2. albida. Shell of the last-mentioned form, but of a white colour.

* Inhabiting ponds. 
Var. 3. labiata. Shell dwarfed and more solid, with the outer lip much reflected and thickened. L. 0.9. B. 0.55.

Var. 4. sinistrorsa. Spire reversed.

Habitat : Slow rivers, marshes, and standing water throughout the kingdom; but it is more local than $L$. peregra. Var. 1. Kennet and Avon Junction Canal, Wilts (Montagu) ; Surrey and Croydon Canal (Leach); R. Cam at Cambridge (Granger); Grand Canal, Dublin (Warren). This variety is the Stagnicola elegans of Leach. Var. 2. From the last-mentioned locality. Var. 3. Lough Neagh, Ireland (Moggridge). Var. 4. Kenn Moor, Somerset (Norman). This species is one of our upper tertiary fossils. It ranges from Siberia to Naples.

This mollusk is sluggish, but fond of floating. Before descending to the bottom it withdraws its body into the shell, and in so doing disengages the air from its pouch, which escapes with a perceptible noise. The shell is remarkably handsome; but it is often disfigured by a coating of vegetable or calcareous matter. The outer lip sometimes becomes thickened in consequence of a temporary cessation of growth ; and in such cases varicose marks are observable on the spire at intervals. Young shells are extremely slender, and the mouth is not expanded as in adult specimens. In this state they somewhat resemble $L$. glabra in form, and might be mistaken for a new species. Muller tried the experiment of outting off the heads of some of this kind of mollusk to see if they would be reproduced; but he tells us that the poor animals did not long survive the operation. Menke supposed that the shell of this species was the helmet of the Frogs in Homer's 'Batrachomyomachia'; but, in opposition to this ingenious idea, it may be remarked that the $L$. stagnalis does not appear to 
have ever existed in Greece. From the description of the armour of the Frogs, it does not appear that any species in particular was intended :-

"Form'd of the varied shells the waters yield, Their glossy helmets glisten'd o'er the field."

It is not likely that Homer was a conchologist, or distinguished one shell from another for poetical purposes. The kind of shell in question must have made cumbersome helmets for the valiant Frogs.

L. stagnalis is a large and favourite object for the aquarium; and Mr. Lloyd has recorded in the 'Zoologist' some interesting observations as to the mode of its respiration.

The shell is so much larger and longer than that of any other Limncea, that it is unnecessary to make any further comparison between them.

C. Spire of the shell much produced, and whorls gradually enlarging.

\section{L. PALUs'TRIS*, Müller.}

Buccinum palustre, Müll. Verm. Hist. pt. ii. p. 131. Limnceus palustris, F. \& H. iv. p. 180, pl. exxiv. f. 2.

BoDy dark grey, with a tinge of violet-brown, covered with fine black and yellowish-white specks : tentacles conic, curved and pointed: eyes placed on small tubercles: foot oblong, truncate and slightly notched in front, narrowing behind and ending in a blunt tail.

Shell oblong, rather solid, of a somewhat dull hue, yellowish-brown with sometimes a violet tint, sculptured as in $L$. stagnalis, but the spiral ridges are generally more prominent and numerous : epidermis rather thin: whorls 6-7, rounded and moderately convex, the last occupying about two-thirds of the shell: spire produced and tapering to a somewhat fine point: suture rather deep, often margined

$$
\text { * Inhabiting bogs. }
$$


above by a narrow white line, which is caused by the appearance through the shell of the upper edge of the preceding whorl : mouth obliquely oval, but contracted on the inner or columellar side : outer lip rather thick, scarcely reflected, but expanded below: inner lip spread on the columella; fold extremely prominent and sharp. L. 1. B. $0 \cdot 4$.

Var. 1. Corvus. Shell much larger and more swollen, of a purplish-brown colour. L. $1 \cdot 35$. B. ${ }_{0}^{* 0} 0 \cdot 65$. Helix Corvus, Gmel. Syst. Nat. p. 3665.

Var. 2. elongata. Spire elongated.

Var. 3. tincta. Shell shorter and broader, light brown with a purplish mouth. Limneus tinctus, Jeffr. in Linn. Tr. xvi. p. 378.

Var. 4. conica. Shell conic, greyish-white, with a deep suture and an umbilical cleft. L. 0.5. B. $0 \cdot 25$.

Var. 5. roseo-labiata. Mouth of the shell furnished inside with a rose-coloured or white rib.

Var. 6. decollata. Spire truncate.

Habitat : Marshes, ditches, and shallow pools everywhere from Aberdeenshire to the Channel Isles. Var. 1. Suffolk (Barlee). Var. 2. Falmouth (J. G. J.) Var. 3. Swansea and Dorsetshire (J. G. J.); Anglesea (Gibbs). This last variety resembles a Bulimus in form. Var. 4. Banks of the Thames from Hammersmith to Woolwich (J. G. J.); Cork (Humphreys). This is a peculiar variety; but as it is connected with the typical form by the variety tincta, and it is not found in company with any other form, I do not consider it to be specifically distinct. Some specimens have a longer spire and resemble $L$. truncatula. Var. 5. Belfast (Thompson); Cork (Humphreys). Var. 6. Preston (Gilbertson); Guernsey (Lukis); Ballinahinch, Co. Galway (J. G. J.). This species is also one of our upper tertiary fossils. Abroad it ranges from Siberia to Algeria and Sicily.

It has the character of being a slow, irritable, and very 
greedy animal-none of which are amiable qualities in our own species! Owing to the nature of its habitat, the shell is apt to have a coat of hardened mud. The whorls are sometimes more or less distorted or scalariform. Draparnaud says that the animal has only two aëriferous tubes, instead of four as in L. auricularia; but this remarkable and anomalous organization does not appear to have been observed by other naturalists.

This species differs from all the preceding in the shell being thicker and the whorls much more narrow. It was first (and well) described by Lister.

Mr. Bean was kind enough to give me specimens of L. cornea (a native of the North-American lakes) which his son was said to have collected in the West of Ireland. It is allied to the present species, through the variety tincta ; but I suspect there must have been some mistake as to the alleged Irish locality.

\section{L. TRUNCA'TULA*, Müller.}

Buccinum truncatulum, Müll. Verm. Hist. pt. ii. p. 130. Limncus truncatulus, F. \& H. iv. p. 177, pl. cxxiv. f. 3.

BoDy dark brown or grey, of a lighter colour on the lower side, covered with fine black specks: tentacles short, but slender, rounded at their tips: eyes nearly sessile: foot rather short, marked with milk-white spots, which are scattered and larger than the black specks, nearly truncate in front, gradually narrowing and abruptly rounded behind.

Shenc oblong-conic, turreted, rather solid for its size, glossy, yellowish-brown or horncolour ; sculpture the same as in the two last species : epidermis thin : whorls 5-6, rounded and convex, but compressed in the middle, so as to make the top of each appear somewhat truncate ; the last whorl occupying about three-fifths of the shell : spire abruptly tapering to a rather fine point: suture extremely deep : mouth oval, scarcely contracted on the inner side : outer lip sharp : inner lip continuous with it and reflected on the columella, behind

* Slightly truncate. 
which is a distinct umbilical chink : fold rather slight but thick. L. $0 \cdot 4$. B. $0 \cdot 2$.

Var. 1. major. Shell larger: whorls more swollen and the last considerably exceeding the usual proportion of size.

Var. 2. elegans. Shell much larger, more solid and slender, greyish-white, marked with coarse spiral ridges: spire much produced: suture oblique: outer lip thickened. L. $0 \cdot 6$. B. $0 \cdot 225$.

Var. 3. minor. Shell much smaller, thinner and semitransparent, dark horncolour, marked with stronger and closer longitudinal striæ. L. $0 \cdot 285$. B. $0 \cdot 165$.

Var. 4. albida. Shell smaller, milk-white.

Var. 5. scalariformis. Shell smaller: whorls nearly disunited.

Var. 6. microstoma. Shell smaller and narrower: whorls more swollen : mouth contracted.

Habitat: Banks of slow and muddy rivers and streams, marshes, ditches, grassy pools, waterfalls, and moist places everywhere from the northernmost point of Zetland to Jersey. Var. 1. Penzance (Millet and Barlee); Newton Nottage, Glamorganshire (J. G. J.). Var. 2. Hants (Mus. Loscombe). Var. 3. Mountainous tracts and sea-side marshes. Var. 4. Battersea (J. G. J.): Crymlin Burrows, Swansea, (Moggridge). Var. 5. Warminster (J. G. J.). Var. 6. Southampton (J. G. J.). Besides these varieties, my cabinet contains specimens in which the spire is more produced, or shorter with the whorls partly intorted, and some have interrupted spiral bands of white lines. This species occurs in our upper tertiary beds. Its foreign distribution extends from Siberia to Algeria and Sicily; and, according to Captain Hutton, it is a native of Afghanistan.

This abundant but pretty little mollusk is nearly amphibious, being more frequently met with out of the water than in it. It is also found in very elevated spots. 
Moquin-Tandon states that he had observed it in the Pyrenees at a height of 1200 mètres (nearly 4000 feet); and instances of its occurring at a tolerable elevation in this country might doubtless be also given, as I have found it living at the sides of all our mountain tarns, but no other animal in company with it. It deposits its spawn on the mud, which is its usual habitat, and not, like its congeners, on the stalks and underneath the leaves of water-plants.

The form of its shell somewhat resembles that of $L$. peregra, var. maritima; but its minute size and turriculated spire will serve to distinguish the present from any other species. This is the Limneus minutus of Draparnaud and Helix fossaria of Montagu. The name it now bears seems to have been derived, not from the truncature or decollation of the spire, but from the truncate or turreted form of the whorls.

\section{L. GLA'BRA*, Müller.}

Buccinum glabrum, Müll. Verm. Hist. pt. ii. p. 135. Limnaeus glaber, F. \& H. iv. p. 178, pl. cxxiv. f. 1 .

BoDy dusky-grey with a tinge of slate-colour, covered with minute, but distinct, black specks: tentacles rather long: eyes placed on prominent tubercles : foot truncate in front, from which it spreads a little towards the rear, ending in a thick and narrow tail.

SHell cylindrical, rather thin and glossy, greyish-horncolour or brownish, sculptured as in the three preceding species : epidermis very thin : whorls 7--8, rounded but not very convex, the last occupying not much more than half the shell: spire produced and ending in a somewhat blunt point : suture slight, but distinct, margined as in the two foregoing species: mouth pear-shaped, contracted above at an acute angle, and furnished inside with a thick broad white rib, which is placed at a little distance from the opening: outer lip thin, scarcely

$$
\text { * Smooth. }
$$


reflected : inner lip rather thick : fold somewhat prominent and sharp. L. $0 \cdot 6$. B. $0 \cdot 2$.

Var. elongata. Spire more produced, so as to alter the relative proportions of length and breadth.

Habitat : Ditches and shallow pools, but sparingly distributed in this country. It appears, however, to have been found in the following counties and places,-viz. Northumberland, Durham, York, Salop, Norfolk, Suffolk, Essex, Oxon, Wilts, Dorset, Cornwall, Guernsey, Jersey, Cork and Belfast. Although local, it is plentiful where it occurs. It ranges from Scandinavia to France as far south as the lower Pyrenees.

It is an exceedingly sluggish and timid mollusk, but ventures occasionally on a very short floating excursion. It often retires considerably within its shell, when it forms the inside lip or rib. The repetition at intervals of this lip, which is seen through the semitransparent shell, gives the latter a varicose appearance. The shell is also liable to lose its first or apical whorls, and consequently to become decollated.

This species is the Bulimus leucostoma of Poiret, Helix octanfracta of Montagu, and Limneus elongatus of Draparnaud.

\section{Genus IV. AN'CYLUS*, Geoffroy. \\ Pl. IV. f. 11, 12, 13, 14.}

Bopy oval, conic, slightly twisted behind: head very large: tentacles short, nearly cylindrical but thicker at their base: foot oval, or oblong, obtusely rounded in front and behind, closely attached to the upper part of the body: respiratory pouch or sac forming a short tube.

SHell hood-shaped, with an incomplete or rudimentary spire, which is in some species dextral and in others sinistral.

* Hooked. 
This is in some respects an anomalous genus, although undoubtedly related to Limncea. Menke and other conchologists have proposed to separateitfrom the Limnocidae and to make it a distinct family by itself. The resemblance of its shell to the marine Limpet, or Patella, has caused this to receive the not inappropriate name of the "freshwater Limpet,"-showing that the sea and land have their respective representatives or analogues in the system of Nature. It was for a long time supposed, even by the great Cuvier, that the Ancyli were branchiferous; but it has now been satisfactorily ascertained, by the careful investigations of Mr. Berkeley and other able physiologists, that they are truly pulmoniferous, although they are also capable (like other aquatic Pulmonobranchs) of extracting air from the water for the purpose of respiration. They inhabit both rapid and still waters, attached to stones and the leaves of plants. They are not inactive in their habits, but have never been observed in a floating position. One of our native species (A. fluviatilis) is nearly as amphibious as the Limnoca peregra and $L$. truncatula; and it may often be seen on rocks at the side of waterfalls, having no other moisture than the spray which occasionally falls on it. When it crawls, only the tips of its tentacles, and sometimes the front edge of its mantle, are visible. The only two British species of Ancylus are apt to be infested with a number of quasi-parasitic worms, as is also the case with many kinds of Limnara. The food of the Ancyli consists of freshwater Algæ or Confervæ, as well as of decayed vegetable matter. They are said also to eat or swallow a certain quantity of very fine gravel or sand, apparently to assist their digestion, which is very slow. They can live a long time without any nourishment. 


\section{A. Body sinistral. Shell dextral. \\ 1. Ancylus Fluvia'tilis*, Muiller.}

Ancylus fluviatilis, Müll. Verm. Hist. pt. ii. p. 201 ; F. \& H. iv. p. 186, pl. exxii. f. 4.

BODY slate-colour or dark grey, with fine black specks: tentacles somewhat triangular at the base, becoming slender towards their tips, which are blunt: eyes not very prominent, but distinct: foot oval, nearly equal in circumference to the mouth of the shell.

Shell semi-oval, incurved towards the front like a helmet of the ancients, rather thin, not glossy, yellowish-grey or horncolour, strongly and regularly striate longitudinally in a radiating direction from the crown to the margin or outer edge of the mouth (some of the striæ often forming remote ridges) and very finely striate transversely or in the line of growth: anterior margin somewhat narrower than the other: epidermis rather thin: spire forming the beak and being equal to about half a whorl, with a compressed and blunt top, which turns a little to the right, bending down towards and nearly reaching the posterior margin : mouth oval : outer lip membranous, slightly reflected. L. 0:3. B. 0:233.

Var. 1. Capuloides. Shell larger and higher, with the beak not placed so near the posterior margin. L. $0 \cdot 415$. B. 0.3. A. Capuloides, (Jan) Porro, Mal. Com. p. 87, pl. 1. f. 7.

Var. 2. gibbosa. Shell smaller, more swollen, with the beak reaching or overhanging the posterior margin. A. gibbosus, Bourguignat in Journ. de Conch. iii. (1853) p. 186.

Var. 3. albida. Shell milk-white and more finely striated.

Habitat : Abundantly on stones and rocks in shallow rivers and streams everywhere from Aberdeenshire to the Channel Isles. I once found it of a dwarf size on the leaves of the white water-lily in a stagnant pond near Swansea, into which no stream had flowed within the memory of man, living in company with A. lacustris, and coated with a confervoid growth. Var. 1. R. Corfe,

* Inhabiting rivers. 
Dorset : very rare (J. G. J.). Var. 2. Sark ; Osmington mills, near Ringstead, Dorset; Dunboy, near Bearhaven, Co. Cork (J. G. J.). This last variety is the A. deperditus of Ziegler and Dupuy; but (according to Bourguignat) not of Desmarest, who first used that name for another species. Intermediate forms in respect of the position of the beak incline me to consider this only a variety. Var. 3. Wokey hole, near Wells (Beevor); Scarborough (Bean); near Torquay (Norman); Arish mill, near Lulworth, Dorset (J. G. J.). Specimens from different places vary in colour from white to darkhorncolour or reddish-brown. This species is also one of our upper tertiary fossils. Abroad it ranges from Finland to Algeria and Sicily; and the Rev. R. T. Lowe has included it in his list of Madeiran land-shells.

M. Bouchard-Chantereaux published, nearly thirty years ago, an extremely interesting account of the embryogeny of A. fluviatilis, illustrated by a plate showing the successive development of the spawn into the fry. He says, each individual lays, in the course of the breeding-season, about 80 eggs, which are enclosed in from 7 to 10 capsules and arrive at maturity in from twentyfour to twenty-seven days, according to the temperature. The animal seems to be more fond of Fontinalis antipyretica than of any other plant.

Many species have been carved out of this variable kind by Continental authors. In very young shells may be detected faint traces of a more complete spire, which is intorted so as to cause a concavity in the beak, called by M. Bourguignat the "dépression apicale." This species was first made known by Lister, and described by him under the name of Patella fluviatilis, but accompanied by other epithets. It has by some authors been considered to be the Patella lacustris of Linné; 
but I will defer my remarks as to this name until I have to treat of the next species.

\section{B. Body dextral. Shell sinistral.}

\section{A. LACUS'TRIS*, Linné.}

Patella lacustris, Linn. Syst. Nat. ed. x. i. p. 783. A. oblongus, F. \& H. iv. p. 188, pl. exxii. f. 5.

Bopy yellowish-grey with a greenish tinge, covered with minute and indistinct dark specks : tentacles thick, pointed at the tips: eyes as in the last species: foot truncate in front and very round behind, having a few yellow specks interspersed among the black ones.

SHELL oblong, obliquely twisted to the left, thin, glossy greyish-horncolour, very finely but indistinctly striate as in A. fluviatilis, but without the intermediate ridges : anterior margin very little narrower than the other : epidermis thick: beak sharp and ridge-like, turning obliquely to the left, but placed close to the margin : mouth oblong : outer lip membranous, reflected. L. $0 \cdot 25$. B. $0 \cdot 1$.

Var. 1. compressa. Shell rather larger, and considerably broader and flatter, than usual.

Var. 2. albida. Shell milk-white, with a light-grey epidermis.

Habitat: On the under side of theleaves of water-lilies and other aquatic plants, as well as on fallen leaves of trees, in slow rivers, lakes, canals, marshes, and ponds throughout the greater part of the kingdom as far north as Aberdeenshire. It is, however, a local species. Var. 1. Dunstall, Staffordshire (J. G. J.). Var. 2. Grand Canal, Dublin (Warren). It is also one of our upper tertiary fossils. Its foreign distribution is the same as that of the last species.

Muiller states that this is not only a freshwater but a marine shell, having taken it alive and adhering to marine 
species of Conferva, in the Baltic Sea. According to Mr. Whiteaves, it hibernates between the sheathing leaves of Sparganium ramosum.

This species is easily recognizable from A. fluviatilis by its different habitat and the oblong shape of its shell, as well as by the form of the beak, which is twisted decidedly to the left, instead of being (as in the other species) nearly central or inclined to the right.

It has been called by some authors $A$. oblongus, being the specific name given to it by Lightfoot under the impression that this was not the Patella lacustris of Linné. There can, however, be scarcely any doubt that Linné meant this species, and not A. fluriatilis, because in his 'Fauna Suecica' he mentions its being rather common in lakes and attached to the submerged leaves of aquatic plants, especially of Stratiotes. His description of the shell is applicable to either species.

Nearly half a century ago, a curious instance of false analogy occurred with respect to an organism which Draparnaud described and figured (in his admirable History of the Land and Freshwater Mollusca of France) as "Ancylus spina-rosa," from specimens sent him by Férussac. These specimens were afterwards discovered not to be testaceous; and many conjectures were from time to time made as to their nature. It was supposed by some that they were parts of a small pod or capsule, by others that they were the bracts of a flower-stalk, and by not a few naturalists that they were scales of a fish. The puzzle, however, was at last solved by the discovery that these nondescripts were the valves of a Cypris, and therefore belonged to the Crustacea. 


\section{TERRESTRIAL.}

The Slugs and Land-Snails, which (as I before observed) constitute about three-fourths of the British Pulmonobranch Mollusca, may be conveniently divided into two sections. The first section agrees in all essential particulars, except that of having retractile (instead of contractile) tentacles, with the aquatic family of Limnceida, which have been above described. The second corresponds with the Pectinibranch Mollusca in having separate sexes, their eyes at the base of the tentacles, and univalve spiral shells which are furnished with opercula; and the main point in which it differs from that great Order consists in the organs of respiration, resulting from the nature of their respective habitats. All the land Pulmonobranchs are more slimy than their aquatic representatives; and they appear to be less inactive in their habits.

The first section comprises four families, viz., -

* Tentacles, almost in every case, 4 : eyes placed on the tips of the upper, or single, pair : shell rudimentary, shieldlike, or complete and spiral.

\section{LIMACID Ae. \\ II. Testacellid e. \\ III. HELICIDA.}

** Tentacles 2, besides rudiments of a second or lower pair : eyes placed at the internal base of the developed pair : shell spiral, elongated.

IV. Carychitda. 


\section{Family I. LIMACID $Æ$.}

BODY long, straight, and flexible: mantle covering only the upper part of the back, and forming a shield: headprominent: tentacles 4, cylindrical, arranged in pairs, the upper pair being the longest: eyes 2, placed on bulbs at the top of the upper tentacles: foot united to the body and coextensive with it.

SHell either rudimentary and of an indefinite form, or shield-shaped, placed underneath the mantle.

I do not propose to treat of this family and its component members to the same extent as my opportunities have enabled me to do with respect to the testaceous members of the same Order; and I must admit that I have not paid equal attention to this part of the subject. The aspect, and much less the handling, of these slimy. creatures cannot be considered as especially inviting; and as I believe the majority of my readers share in this opinion, I may with greater confidence ask their indulgence for any shortcomings on this point. At the same time I would observe that the subject offers, to those who are inclined to pursue it, a wide field of research and a greater prospect of novelty than can be expected from the study of the testaceous Mollusca. The anatomy, physiology, and habits of the Slugs were described nearly two centuries ago by our countryman, Dr. Lister, in his admirable treatises on British animals; and $\mathrm{Mr}$. Nunneley and the Rev. B. J. Clarke have lately done much to increase our knowledge of these mollusks. Some of their remains have been detected in our upper tertiary beds at Copford, as well as in similar deposits in the South-west of France. 


\section{Genus I. ARI'ON*, Férussac. Pl. V. f. 1, 2.}

BoDy nearly cylindrical, with a strongly wrinkled skin : shield oblong, shagreened: respiratory orifice placed near the front edge of the shield: foot furnished at its posterior extremity or tail with a mucus- or slime-gland.

SHELl amorphous, consisting of loose calcareous grains which are covered by the hinder part of the shield.

The Arions, or black slugs, frequent damp and shady woods, as well as hedge-banks and gardens. During the daytime they lurk under stones and logs of wood, or bury themselves in the earth, where they excavate a sort of tunnel; but at night and after rain, they sally forth to feed. They are great pests in gardens, generally selecting the best cabbages and most succulent vegetables. They are, however, not very particular about their food, and act the part of land-scavengers, devouring animal matter of all kinds in every state of decomposition, and even each other's slime. They may be frequently met with in garden-walks, after a shower, in search of food. During the season of reproduction they deposit their eggs, which are very numerous, separately underground. When at rest, they contract their bodies into a lump. In this state they offer a dainty prize to ducks. They differ from the Limaces, or common slugs, in their respiratory orifice being placed in front, instead of near the hinder part, of the shield, in having a slime-gland at the tail, and in the arrangement of the teeth.

* The name of an ancient musician and poet: scarcely appropriate to this genus. 


\section{Arion A'TER*, Linné.}

Limax ater, Linn. Syst. Nat. ed. x. p. 652. A. Empiricorum, F. \& H. iv. p. 7, pl. D. D. D. f. 4.

BoDY rather contracted and rounded in front, pointed behind, varying greatly in colour, from black to brown, red, yellow, greenish, and even white, with all the intermediate shades, covered with prominent and large tubercles : shield, or mantle, finely shagreened, of a lighter colour than the rest of the body: tentacles coarsely shagreened, much swollen at their tips, especially the lower pair : foot generally having a yellow border, which is crossed at the sides by close and curved dark lines: slime of a yellowish colour. L. 4. B. 0.5.

SHELL consisting of small separate calcareous grains of unequal size.

HABitat: Woods, hedges, fields, and all sorts of damp places in the country throughout these Isles. Abroad it ranges from Siberia to Portugal and Corsica, as well as to Madeira; and a variety of it was found as far north as Jan Mayens Isle by the naturalist who accompanied Prince Louis Napoleon's expedition.

This species has had an infinity of names given to it, on account of its extreme variability of colour. It is the A. Empiricorum of Férussac, so called from the calcareous substance which is found under the shield having been formerly used in the preparation of medicine.

The A. flavus of Férussac (Limaxflavus, Muiller), which has been found in the North of England by Mr. Alder and Mr. Blacklock, as well as by Mr. Norman and Mr. Whiteaves in Somersetshire and Oxfordshire, appears, according to Moquin-Tandon, to be a doubtful species. MM. Bouchard-Chantereaux and Normand state that this last-mentioned species or variety inhabits woods and moist places in the North of France.

* Black. 


\section{A. horten'sis* Férussac.}

A. hortensis, Fér. Hist. Moll. p. 65, pl. ii. f. 4-6 ; F. \& H. iv. p. 10, pl. F. F. F. f. 1.

BoDy longer than that of the last species in proportion to its size, and of nearly an equal breadth throughout, brown, red, yellow, grey, greenish, or black, usually more or less distinctly marked on the back and sides with stripes or longitudinal bands, and covered with coarse oblong tubercles : shield having usually a dark stripe down the middle and another on each side : tentacles not much swollen at their tips : foot narrowly bordered with grey, yellow, reddish, or orange : slime yellowish or whitish. L. $1 \cdot 5$. B. $0 \cdot 35$.

SHELL of an irregular shape, composed of grains like those in the last species, but cemented together by a calcareous matrix, so as to resemble tiny lumps of the conglomerate which is called by geologists "breccia."

Habitat : Under stones and dead leaves in gardens, fields, and damp spots everywhere. Its foreign distribution is also perhaps equally extensive with that of A. ater.

According to Bouchard-Chantereaux, the eggs of $A$. hortensis are phosphorescent during the first fifteen days after they have been laid. They take from twenty to forty days to arrive at maturity, and the young become adult towards the end of the first year.

This species differs from $A$. ater in being much smaller and more slender, as well as in usually having longitudinal lines or stripes. The substitute for a shell is also more compact, and making some approach to a definite form, in the present species. Dr. Gray describes the shell to be " distinct, oval, concave ;" but this description does not agree with the generic character of this part of the animal.

It is the A. fasciatus of Nilsson. Muiller described

* Frequenting gardens. 
two slugs (Limax cinctus and L. fuscus) as having longitudinal stripes; and although it is most probable that one or both of them may be identical with the present species, the name given by Férussac has been adopted to prevent confusion.

\section{Genus II. GEOMA'LACUS †. PI. V. f. 3.}

BoDy resembling that of Arion, but more extensile and keeled on the back, besides having the reproductive orifice placed near the base of the right lower tentacle, in which respect it differs both from that genus and Limax.

SHell unguiform, imbedded in the shield.

This genus, of which only one species is known, appears to be intermediate between Arion and Limax. I suspect that the Limax anguiformis of Morelet (Moll. Port. p. 36, pl. iii. f. 1) also belongs to the present genus, if indeed it is not the same species as ours.

\section{Geomalacus maculo'sus $\ddagger$, Allman.}

G. maculosus, Allm. in Ann. N. H., new series, xvii. p. 297, pl. 9; F. \& H. iv. p. 12, pl. F. F. F*. f. 5.

No detailed account of this curious slug has been published ; but it is described to be an exceedingly beautiful animal, measuring, when creeping about, two inches in length ; the colour of the shield and upper part of the body is black, elegantly spotted with yellow; the under surface of the foot light yellow, and divided into three nearly equal bands; the edge of the foot brown, with transverse sulci. A white-spotted variety also occurred. It can elongate itself, so as to assume the appearance of a worm and thus enter exceedingly small apertures. It was discovered by an active and indefatigable Irish naturalist, Mr. William Andrews of Dublin, during the † Earth-mollusk. $\mp$ Spotted. 
autumn of 1842, "on rocks around Lough Carrough, to the south of Castlemain Bay, Co. Kerry, in the West of Ireland." Mr. Andrews informs me that it is impossible to appreciate the extreme beauty of this slug without observing it in the living state. The surmise offered by the authors of the 'British Mollusca,' that this may be an Asturian, as well as an Irish, slug, is probably well founded. Morelet's description, in 1845, of his Limax anguiformis appears to have escaped their notice. He especially mentions the peculiar form of the slug and the position of the respiratory organ.

\section{Genus III. LI'MAX*, Linné. Pl. V. f. 4, 5.}

Bopy nearly cylindrical, with a wrinkled skin, and more or less keeled on the back: shield sometimes shagreened, but in most cases concentrically striate: respiratory orifice near the hinder edge of the shield: reproductive orifice close to and behind the right upper tentacle : foot not furnished with a mucus-gland.

Shell oval or shaped like a finger-nail, formed of concentric layers, and covered by the hinder part of the shield (Limacella, Brard).

The habits of this kind of slug are nearly the same as those of Arion; but some of them appear to like the company of man more than he desires, being often found in kitchens and domestic offices. They are, however, sometimes useful in eating that kind of fungus which causes dry rot, and another kind which infests cellars and makes choice Port wine what is termed "corked." Among themselves they are also sociable, and are often found clustered together in the same spot. Gardeners have great cause to complain of their voracity, and especially when they see the finest strawberries have been selected for their supper or early repast.

$$
\text { * Slug. }
$$




\section{A. Shield shagreened.}

\section{LimaX GaGA'tes *, Draparnaud.}

L. gagates, Drap. Hist. Moll. p. 122, tab. ix. f. 1 ; F. \& H. iv. p. 24, pl. D. D. D. f. 3.

BoDY very slightly contracted and nearly cylindrical in front, gradually tapering to a point behind, varying from slate-colour to dark-red or even black, covered with small oblong interlaced tubercles : shield oblong, somewhat truncate in front and rounded behind, apparently divided into two lobes, finely shagreened or grained: tentacles very short and thick, not much swollen at their tips: back sharply keeled its whole length, bordered with white or a lighter colour than the rest of the body: slime nearly colourless. L. $2 \cdot 5$. B. $0 \cdot 35$.

Shell oval, rather thick (especially in the middle), and slightly wrinkled.

Habitat: Hedges and at the roots of grass and the foot of old walls in many parts of Great Britain from the Clyde district to Guernsey ; but it appears to be a local species. It also occurs in the north, east, west, and south of France, ranging to Corsica and Algeria, and probably also to Naples. Mr. Norman has given an excellent description of this species in the 'Zoologist' for 1853, and remarked that when at rest this slug assumes a more rounded form than any other British kind, contracting and squeezing itself into so small a compass that its height is but little exceeded by its length. Its slime is thick and glutinous, resembling varnish. The apparent division of the shield into two lobes, as noticed by Draparnaud, is owing to its being indented behind by the keel.

$$
\text { * Jet. }
$$




\section{L. MARgina'TUS *, Müller.}

L. Marginatus, Müll. Verm. Hist. pt. ii. p. 10. L. Sowerbii, F. \& H. iv. p. 22 , pl. E. E. E. f. 3.

BODY nearly cylindrical, truncate and slightly tumid in front, gradually tapering to a point behind, yellowish or reddish-brown speckled with black, irregularly wrinkled: shield oblong, obtusely rounded at both ends, wider and slightly truncate behind, partly bordered with a dark band on each side and occasionally streaked down the middle, very irregularly granulated: tentacles thick, not much swollen at their tips: back having a prominent keel or ridge, which extends the whole length from the hinder edge of the shield to the tail, and is of a lighter colour than the rest of the body : foot pale-margined : slime colourless. Dimensions same as in the last species.

Shell oval, thickened, with conspicuous lines of growth: boss or nucleus near one end, rather prominent. L. $0 \cdot 2$. B. $0 \cdot 125$.

Habitat : Under stones, among dead leaves, and at the foot of old walls everywhere. The shell or Limacella has been found in our upper tertiary beds. Although this must be a widely diffused species, it does not appear to have been noticed by any Continental writers except Miuller, Moquin-Tandon, and the Abbé Stabile, according to whom it inhabits Denmark and the mountainous districts of France and Lugano.

This slug is inactive in its habits and secretes a thick and tenacious slime. Stabile says that it is much preyed upon by the Silphoe, Carabi, and other large carnivorous beetles. L. marginatus is said in its turn to attack and eat other animals, and especially live worms and smaller slugs.

Muiller's description seems to be sufficient for the identification of this species with that of Draparnaud and subsequent authors, who have adopted the name first

* Bordered. 
given to it. He particularly mentions its having a white keel, as well as marginal streaks on the shield,-although he says it inhabits the beech, which character is more applicable to L. arborum. Draparnaud doubted whether his species was that of Muiller because of this difference in the habitat. It is the L. Sowerbii of Férussac and L. carinatus of Risso and Leach. The shell is the Limacella unguiculus of Brard.

The shield in this species is much smaller in proportion to its body than in L. gagates; and the respiratory orifice is in the last-named species placed more towards the middle of the shield-area. The colouring is also different.

B. Shield concentrically wrinkled.

3. L. FLA'vUs * Linné.

L. flavus, Linn. Syst. Nat. ed. x. i. p. 652 ; F. \& H. iv. p. 19, pl. E. E. E. f. l.

BoDy slightly contracted in front, rather broad in the middle, and tapering gradually to a point behind, yellowish, speckled with white and black so as to form a kind of network, covered with coarse oval tubercles: head of a bluish colour: shield oblong, larger and more rounded behind, elegantly grooved by concentric and rather undulating lines: tentacles bluish; the upper pair rather short, the lower ones remarkably so: foot keeled towards the tail, margined with yellowish-white; sole milk-white: slime yellow. L.4. B. 0·75.

Shell obliquely oval or quadrangular, rather concave on the under side, thin, crystalline and nacreous, with distinct lines of growth: boss slightly projecting behind: margin membranous. L. $0 \cdot 3$. B. $0 \cdot 125$.

Habitat : Cellars, wells, sculleries, and other damp places, as well as in moist woods, everywhere. It is also common in the northern and central parts of Europe. 
This kind of slug is nocturnal, but very active. Its slime is abundant and stains linen of a yellow colour. It appears to be fond of bread, cooked vegetables, and all sorts of kitchen refuse.

It is probable that the L. flavus of Muiller may be a variety of Arion ater, because he describes the shield as not having any concentric wrinkles, although in the same description he also notices a yellow slug which seems to belong to the present species. This is the L. variegatus of Draparnaud; and its shell is probably the Limacella concava of Brard.

\section{L. AGRES'TIS *, Linné.}

L. agrestis, Linn. Syst. Nat. ed. x. i. p. 652 ; F. \&. H. iv. p. 13, pl. D. D. D. f. 3.

BoDr spindle-shaped, slender, ash-grey with a reddish or yellowish tinge and sometimes mottled, nearly smooth: shield rather large, more tumid behind, the concentric striæ more remote and indistinct than in any of the other species: tentacles dark grey: back obliquely, but not strongly, keeled towards the tail : foot having very pale sides: slime milky. L. $1 \cdot 5$. B. $0 \cdot 4$.

Shell obliquely oval or inclined to oblong, concave on the under side, rather thin, with indistinct lines of growth, and marked obliquely by exceedingly minute striæ which cross each other : boss very small, slightly projecting behind on one side : margin membranous, rather broad, and obliquely striate. L. $0 \cdot 2$. B. $0 \cdot 1$.

Habitat : Fields, gardens, and woods throughout the British Isles. The shell is also one of our upper tertiary fossils. Its foreign distribution extends from Siberia to Corsica and Algeria, and (according to Lowe) Madeira.

This slug is a great pest in the kitchen garden, and does not even spare succulent leaves and roots of flowerplants. Mr. Whiteaves says that it also feeds on earth-

* Inhabiting fields. 
worms. Its slime is abundant and viscous, feeling like a lump of sticky fat. . Muiller states that when it is touched it draws in its horns and remains all day as if it were dead, but in the evening it recovers itself. It is extremely prolific, producing several families, averaging fifty each, in the course of the breeding-season, viz. from April to November. According to Leuch, a German naturalist, a pair of these slugs have been known to lay 776 eggs. These eggs have retained their vitality and the young have been developed from them after having been dried eight times successively in a furnace. It has the same faculty as $L$. arborum of letting itself down from one branch of a tree to another or to the ground, by means of a slimy thread. Mr. Norman informs me that in the earlier part of the year this slug is usually creamy-white or light-drab; that as the summer passes away it assumes a darker hue, and brown flakes are more or less thickly scattered over the surface; and that during the autumn it is frequently of a rich brown colour. A monstrosity of L. agrestis was found by Mr. Gibbs, having the upper tentacles united into one.

Lister first distinguished the field-slug from other kinds by its smaller size and the nature of its slime; and he also described its shell by appropriate characters. This shell is the Limacella obliqua of Brard.

\section{L. AR'BORUM*, Bouchard-Chantereaux.}

L. arborum, Bouch.-Chant. Moll. Pas-de-Cal. p. 28 ; F. \& H. iv. p. 17, pl. E. E. E. f. 2 (as $L$. arboreus).

BoDy rather slender, gelatinous, sea-green or bluish-grey with irregular yellowish-white spots, indistinctly streaked with a darker colour down the sides, leaving a lighter stripe in the middle from the shield to the tail, finely wrinkled:

* Inhabiting trees. 
shield rounded in front and obtusely angulated behind, the concentric or transverse striæ rather fine, streaked lengthwise, the middle stripe being usually darker : tentacles short, yellowish-grey : back distinctly keeled towards the tail: foot having its edges nearly white : slime colourless. L. 3. B. 0·4.

Shell squarish-oval, nearly flat, very thin, glossy, and iridescent, with minute nacreous tubercles; lines of growth indistinct, obliquely striate as in the last species: boss nearly inconspicuous and subterminal : margin broad, thin and membranous. L. $0 \cdot 2$. B. $0 \cdot 125$.

Habitat: Trees(especially the beech), as wellas among rocks and under stones, both inland and on the sea-coast, in most parts of Great Britain, from the north of Zetland to the Channel Isles. According to Von Martens, it is the L. Livonicus of Schrenck, and inhabits Russia; it occurs in several parts of Norway; Bouchard-Chantereaux and Normand have instanced localities in the North of France, and I have found it in the Lower Harz: but it has not been noticed further south. It has been probably mistaken for the young of the next species.

M. Bouchard-Chantereaux, who first described the tree-slug, says that it prefers old trees, feeding on decayed wood and not touching the leaves; and he adds that it is not prolific. He has often seen the young (which he believes to be the L. filans or spinning-slug of Hoy and some other English authors of the last century) spin its slimy thread and descend from one branch to another, but not plunging into air (or taking what bathers would call "a header") without apparent fear and hesitation, the sole of its foot exhibiting during the descent a similar movement to that which is observable while it is crawling on the sides of a glass vessel. In a remote cluster of the Shetland Isles, called the OutSkerries, where I have taken this slug, with my friend Mr. Norman, no trees exist; but perhaps it found de- 
caying seaweed to be equally palatable. Its slime is abundant; and the animal, on being touched, yields a fluid like clear water. Professor E. Forbes found it plentifully, creeping on bare stones and rocks, at an elevation of above 1500 feet, near Connor Cliffs, above Dingle, in Kerry. Mr. Lowe observes that it prefers walnut-trees. Mr. Daniel informs me that he has seen this slug in couples during the pairing-season suspended by slimy threads from the branch of a tree.

\section{L. MaX'nuUs*, Linné.}

L. maximus, Linn. Syst. Nat. ed. xii. p. $108 . \quad$ L. cinereus, F. \& H. iv. p. 15 , pl. D. D. D. f. 1 .

BoDy rather slender, yellowish-grey, but varying in intensity of colour and being sometimes quite black, with occasionally streaks or spots of black or white covered with numerous and elongated tubercles, so as to appear strongly wrinkled : shield oblong, very tumid, somewhat contracted or even pointed behind, distinctly and regularly striate: tentacles (especially the upper pair) long in comparison with those of other species, yellowish-brown : back rounded, except close to the tail, where there is a slight keel : foot edged with white: slime whitish. L. 4.5. B. 0.75.

Shell squarish-oblong, rather convex above and nearly flat beneath, solid, irregularly crystalline, rather glossy and nacreous, with distinct lines of growth, obliquely striate as in the two last species : boss very small, placed near one end: margin thin and membranous. L. $0 \cdot 5$. B. $0 \cdot 325$.

HaвiтAт: Woods, gardens, hedges, under old logs of wood, and nearly everywhere in town and country. Its foreign range extends from Finland to Corsica and Algeria, and (according to Mr. Lowe) Madeira.

This is the largest species of Limax, and sometimes exceeds six inches in length. It is inactive in its habits, not very prolific, and exudes a thick and glutinous slime, 
which is iridescent when dried. Its eggs are deposited in a cluster and slightly attached to each other. When alarmed, or at rest, this slug merely draws its head within the shield, but does not otherwise contract its body. When irritated, it is said to expand its shield. It is liable to be infested, as well as some of the other slugs, by a white parasitic mite, called Philodromus (or Acarus) limacum, which swarms about its body and, according to Mr. Jenyns, dwells in its respiratory cavity, but which does not seem to cause the slug any harm or inconvenience, except perhaps in feeding on its slime and slightly lessening the secretion. Mr. Daniel informs me that these slugs suspend themselves in pairs during the breeding-season by threads of slime, and that they always feed by night, but that the variety cinereo-niger of Nilsson prefers terra firma to mid-air and keeps much more respectable hours. Like all other slugs and snails, it will soon eat its way out of a large pill-box, or even a stouter one made of cardboard, if confined in it. The shell or ossicle which is contained under the shield was known to Pliny; and it was used by the ancient physicians for the sake of its carbonate of lime. The substratum of this shell is membranous; and a layer of the same filmy material covers the upper surface, having the appearance and character rather of a periosteum than of a Molluscan epidermis.

The young of this species may be distinguished from L. arborum, among other respects, by its upper tentacles being proportionally much longer, as well as by the posterior margin of its shell being more pointed. The shell of $L$. maximus is also longer, more convex, and thicker.

Miiller gave this species the name of cinereus, on the supposition that the L. maximus of Linné might be a variety of Arion ater; but the diagnosis of the great 
Swedish naturalist is couched in the same terms as that of his predecessor, Lister, who accurately distinguished the present species from the black slug. It is the $L$. antiquorum of Ferussac; and the shell is the Limacella parma of Brard.

The L. brunneus of Bouchard-Chantereaux (F. \& H. iv. p. 20, pl. F. F. F. f. 4) is, according to Moquin-Tandon, a doubtful species; and it is probably only one of the numerous varieties of $L$. agrestis. It is rather local, but appears to be widely distributed in this country, from Zetland to Cornwall. In France its range extends from Boulogne to the Pyrenees. In Dr Gordon's excellent contributions to the 'Zoologist' it is stated that this little slug, which is not uncommon in the Moray Firth district, is the most lively and fearless of its tribe, and that when disturbed, instead of contracting itself into a lump, like most of its congeners, it makes bold and repeated efforts to escape from the annoyance and crawl away. The only essential difference that I can detect between it and $L$. agrestis is, that this slug is smaller (scarcely an inch in length when crawling), and of a uniform brown colour; and M. Bouchard-Chantereaux admits that it is closely allied to the latter species. The original L. brunneus of Draparnaud differs somewhat in colour. The British species so called appears to be the L. parvulus of Normand (Descr. Lim. Valenciennes, p. 8), judging from his description.

The $L$. tenellus of Forbes and Hanley (iv. p. 21, pl. F. F. F. f. 3), which they refer to Muiller's species of that name, can scarcely be considered as more than provisionally introduced into the list of British slugs. MoquinTandon reckons this also to be a doubtful species. Müller describes his L. tenellus as being ten inches long (although this is evidently a typographical error); and 
Nilsson describes his species of the same name as being equal in size to $L$. flavus; while the authors of the 'British Mollusca' state that the dimensions of their slug do not exceed an inch and a quarter in length. Muiller, Draparnaud, and Nilsson also mention its having a greenish hue, which the British slug does not appear to have possessed. M. Drouet says this species belongs to Arion. A single specimen was found by Mr. Blacklock in a wood at Allansford, near Shortly Bridge, in Northumberland, and by him communicated to Mr. Alder, who published the discovery in the "Transactions of the Northumberland and Newcastle-uponTyne Natural History Society.' It may possibly have been the young or a variety of L. flavus. As, however, this tribe is gregarious or at any rate individually numerous, it is to be hoped that further researches will be made, so as to settle the question as regards not only the specific distinction of this slug, but also the propriety of its admission into the British fauna.

\section{Family II. TESTACELLID $Æ$.}

BoDy cylindrical, exceedingly long and flexible: mantle rudimentary, but capable of being occasionally expanded, generally covered by the shell: other characters similar to those of Limacidae, except in a few anatomical particulars.

Shell ear-shaped, with a very small terminal spire, external, and occupying the same place as the mantle in the last family.

This family comprises only one genus, viz., -

\section{TESTACEL'LA*, Cuvier. Pl. V. f. 6-9.}

BoDy of a firm texture, with a nearly smooth skin: tentacles cylindrical : labial palps extensible : foot margined. * Diminutive shell. 
Shell solid : spire consisting of half a whorl : columellar fold internal, very broad.

This peculiar genus appears to form a natural family of itself, when viewed with respect to the British Mollusca only; but it is connected with the Slugs on the one hand through the genus Parmacella, which has no representative in this country, and on the other hand with the Snails through the Vitrina semilimax of Férussac (also a Continental mollusk), which Oken called a Testacella. The Testacellae partake in some degree of the nature both of a Slug and a Snail, having a long naked body and a small shell placed near its tail. The shell serves to protect the heart, liver, and other vital organs. The Snail-slug was first made known by the celebrated Réaumur in 1740 through the Academy of Sciences at Paris, in consequence of a communication made to him by M. Dugué from Dieppe, and which contains an excellent account of the shape, habits, and mode of reproduction of this curious mollusk. From that period down to 1800 , many observations were made and recorded in France on the same subject; but it was only in the last-mentioned year that Cuvier, being struck by the remarkable aspect of the shell, constituted for it, in his 'Lessons on Comparative Anatomy,' the genus Testacella. This name was adopted both by Lamarck and Draparnaud in 1801; but in the following year it was erroneously altered by Faure-Biguet to Testacellus. This slight history of the name is given to prevent a continuance of this mistake, which was adopted by Férussac, Sowerby, Gray, and other naturalists. By far the most complete and valuable account, considered in a conchological as well as a palæontological point of view, which has been given of this genus, is contained in a 
monograph by MM. Gassies and Fischer, published at Paris in 1856.

The Testacella appears to be the only land-mollusk which has truly predaceous habits ; its marine representatives in this respect being the Cuttle and the Whelk. It is scarcely inferior to the tiger, snake, or shark in its cunning and ferocity. Its prey chiefly consists of earthworms, which it hunts underground and pursues through their galleries, crouching occasionally and making a spring on its victim. It is said that when the poor worm has had the start of its pursuer, the Snail-slug intercepts it by tunnelling across the line of its retreat. It will devour a lob-worm much longer than itself, seizing it in the middle; and when the writhings have been succeeded by exhaustion, it detaches and swallows one half of the worm; and after that has been digested, it finishes its long meal with the other portion. For this purpose its mouth is furnished with an apparatus of sharp recurved teeth, which enables the Testacella to retain a firm hold of its victim and swallow it more easily. The worm is provided with some means of defence, in the rows of stiff bristles which encircle its rings; and by contracting its body a short respite is occasionally gained. But the chance of ultimate escape or safety is very slight. When the Testacella sees or scents its prey, it glides softly and cautiously towards it; and, apparently without taking any notice of the worm, it seems to feel its way, and usually succeeds in fastening itself on an unprotected part of the body between the rings. The attack, if unsuccessful at first, is renewed; but if the worm resists too long, the Testacella gets impatient, and by pressing or doubling its victim into the earth, by which means the rings are forced open, its purpose is effected and the meal secured. 
Although it also feeds on slugs and snails, and even on its own species (the shells of which have been found in its stomach), it will not eat dead animals, and even refuses pieces of a fresh worm which has been chopped up to feed it. It only sallies out at night in search of its prey, burying itself deep in the ground during the daytime. After having gorged itself with a worm, it rests many hours in a half-torpid state until the meal has been digested ; and it can remain fasting a long time (as much as fourteen or fifteen nights) until hunger impels it to make a fresh hunt. It does not fear the cold, or appear to suffer any inconvenience from it except when the ground is hardened by frost; and in this respect it resembles the Slugs, the Vitrince, and some of the Zonites, all of which are nearly as carnivorous and hardy as the Testacella.

Gassies and Fischer are of opinion that the holes which may be sometimes remarked in the shields of the Limax gagates and other Slugs have been made by the Testacella, for the sake of extracting the calcareous matter from the internal shells or Limacellae of the Slugs to form its own more complete shell ; and they have noticed that the Slugs which have been thus attacked soon die. If the Testacella is taken fresh from the ground and kept a short time in the hand, the warmth seems to revive it and induce it to crawl away; but if its retreat is opposed, it will violently bite the skin and oblige the experimentalist to let it go, from an instinctive feeling of disgust. During cold northerly and easterly winds these creatures enclose their bodies in a kind of cocoon, like that of the silkworm, which is secreted from their skin and often mixed with earthy and extraneous particles. Mr. Norman has informed me that in this state their mantle is expanded to such an extent as to cover all the upper part of the body. Férussac appears to have been 
mistaken in supposing that the whole of the body was enveloped by the mantle. If this slimy pellicle be suddenly removed, the Snail-slug is liable to be attacked by a disease which usually ends in its death. Heavy rains destroy a number of them. The average length of life in the Testacella appears to be five or six years. Their smell is like that of worms, but even more nauseous. They chiefly frequent gardens, where they are sure of finding their proper food; but they may occasionally be met with in woods near inhabited places as well as at the foot of old,walls. In winter they bury themselves very deep in the ground; and my gardener once brought me living specimens of $T$. Maugei which he had dug up in trenching some celery-roots at a depth of about two feet. The eggs are laid separately, and are very large in proportion to the size of the body. These somewhat resemble hen's eggs both in shape and consistency, and are covered with a rather thick and tough skin. If they are taken out of the earth and exposed to a cold air, they frequently crack and burst in pieces which fly off to some little distance. Faure-Biguet appears to have succeeded in preserving the eggs under such circumstances by plunging them as soon as taken into boiling water. It is believed that the Testacellae never come to the surface, except occasionally during the breeding-season, but that at all other times they live underground. Their eyes, however, are perfect; and their horns, or tentacles, are rather long and extremely sensitive. 


\section{Testacella Halioti'deA*, Draparnaud.}

T. haliotidea, Drap. Hist. Moll. p. 121, tab. ix. f. 12-14. T. haliotoidea, F. \& H. iv. p. 26, pl. G. G. G. f. 1.

BoDY contracted towards the front and somewhat pointed at the head, rather smaller in the middle, a little broader behind, capable of extending itself like a worm, with a thick and tough skin, which is smooth when the animal is crawling at its full length, but transversely wrinkled when it is at rest, yellowish-brown, sometimes mottled or speckled with black, red, or white: lips or labial lobes flexible and extensible, resembling a third (but much shorter and thicker) pair of tentacles: mantle very small and thin, not much larger than the shell: tentacles rather short, smooth, brown, very little swollen at their extremities: eyes placed on the upper side of the tentacular extremities, but not quite at the end: back convex, divided into three nearly equal parts by two longitudinal grooves which extend on each side of it from the front edge of the shell to within a very short distance of the tentacles; these grooves have parallel offsets above and below, which are finely ramified: foot bordered with distinct and prominent edges. L. 3. B. 0.4.

SHell oblong, compressed, especially in the middle and towards the front margin, solid, not glossy, closely striate by the lines of growth, and sometimes also marked by a few indistinct lines which radiate from the spiral point: epidermis rather thick: spire terminal, sharp, and very small : anterior margin rounded: posterior margin obliquely truncate: lateral margins obtusely curved: mouth exceedingly large: pillar lip thickened and slightly reflected: fold flat and sharp-edged. L. $0 \cdot 25$. B. $0 \cdot 15$.

Var. scutulum. Body yellowish, speckled with brown. Shell narrower: spire more produced and pointed. T'estacella scutulum, Sowerby, Gen. Sh. f. 3-6.

Habitat : Gardens at Norwich, Plymouth, Bideford, Youghal, and Bandon. The variety, which was first discovered by the late Mr. Sowerby in his garden at Lambeth, is not uncommon in many parts of the metropolitan

* Resembling a Haliotis or ear shell, 
district, as well as in Guernsey. This species has been noticed by Continental writers as occurring throughout a great part of France (principally in the South and South-west, but also, according to Collard des Cherres and De l'Hôpital, in the Department of Finisterre and at Cacn), Spain, Algeria, Corsica, Sicily, Madeira, and the Canary Isles. It has also been found in a fossil state near Clermont and in the South of France.

Whether this singular and somewhat anomalous mollusk is really indigenous to this country, or has been introduced and acclimatized, it is almost impossible to say. The means by which Mollusca become spread are various; and Man is one of the unconscious agents of such diffusion. A usual habitat of this kind of Testacella is at the roots of flower-plants, or under heaps of dead leaves in gardens ; and if a plant were imported into this country from the botanic garden at Montpellier with the native soil or a compost made of leaf-mould, either the Snailslug or its eggs would perhaps accompany it.

The European Snail-slug is by no means prolific, laying only 6 or 7 eggs from April to July. During this operation its head and tentacles are drawn in. The eggs, when new-laid, are pointed at each end. The young are excluded at the end of from twenty-five to thirty days. The slime is abundant and colourless.

Mr. Tapping described in the 'Zoologist' for 1856 (p. 5105) what he considered a new species of British Testacella, under the name of Medii-Templi. It was found in only one part of the Middle-Temple Gardens, under the shelter of a south-west wall. But his description scarcely differs from that of the variety scutulum; and Mr. Norman, who has examined typical specimens of the supposed species, informs me that they belong to that variety. The colour of the body, as well as the form 
of the shell, are exceedingly variable characters in this genus.

It is the Testacella Europcea of De Roissy, who proposed a change of name in consequence of Lamarck having, a few months previous to the publication of the 'Histoire ' of Draparnaud, described what was then supposed to be the same species under the somewhat similar name of Haliotoides; but it now appears that Lamarck's species is the one which I am next about to notice.

The T. Maugei of Férussac was observed by the late Mr. J. S. Miller, the Curator of the Philosophical Institution of Bristol, between forty and fifty years ago, in the nursery-gardens of Messrs. Miller and Sweet, near that city, where it is still to be found in considerable numbers. It has been since, to a certain extent, naturalized or acclimatized in this country, having been observed in other parts of Somersetshire, as well as at Plymouth and Cork. I may add to this list of localities my own garden at Norton near Swansea, which was occasionally supplied with plants from Miller and Sweet's nurseries. It was originally (in 1801) noticed as a native of Teneriffe; and it appears to be also indigenous to Madeira, the Canary Isles, Portugal, and the South-west of France. A variety of it (called T. Deshayesii or Altre-ripa) occurs in a fossil state at Haute-Rive in France. This species has a smaller head, as well as a much larger and more convex (almost semicylindrical) shell, than T. Haliotidea. The present species is more prolific and gregarious than its congeners. Mr. Norman has kept specimens of T. Mangei, as well as of T. Haliotidea and its variety scutulum, alive for some time, and has carefully watched their habits in a state of confinement. He says that the nest of earth which T. Mangei makes for itself in times of drought reminded him not a 
little of the cocoon of the Puss-moth. Within this cocoon the Testacella lies encysted until moisture, working its way through the walls of its dwelling, rouses it again into activity and sends it forth in quest of food. While in the encysted state, a thin white membrane (a development of the mantle) is extended from beneath the shell and stretched over the back and sides of the animal. An admirably-designed protective shield is thus formed, which checks evaporation from the surface of the body, and enables the flow of mucus, which is so essential to the life of the animal, still to course along the lateral canals and thence be distributed through the branching channels over the entire surface of the body. When T. Mauge $i$ is removed from its cyst and the body moistened with water, the extended membrane is gradually retracted until it is entirely withdrawn beneath the shell. Mr. Norman also remarks that the habits of this species resemble in many respects those of the earthworm, which (like the 'Testacella) may in times of drought be found coiled up in as compact a mass as possible within a chamber of the baked soil. The T. Maugei has also the power of greatly elongating and extending the body, which very much facilitates its passage through the earth. The Testacella and its prey are both nocturnal animals ; and those who wish to procure specimens should look for them at daybreak, especially after a warm dewy night in the months of July and August. Mr. Norman has had as many as five dozen living T. Maugei sent to him from Clifton, which were taken in this way. The eggs of this species are large, oval, opaque, and covered with a cream-coloured tough skin. The shell is developed upon the young, while still in the embryo state. 


\section{Family III. HELICID $\AA$.}

BoDx long and spirally coiled : mantle covering the front or anterior part: tentacles nearly always 4 (rarely 2 only), retractile: eyes placed on the tips of the upper or single pair : foot oblong, distinct from the rest of the body.

Shell spiral, and in almost every case capable of containing the whole body.

This family comprises the true Snails, and abounds in species as well as individuals. L. Pfeiffer described no less than 1149 species of the typical genus, Helix, in 1848, when his very serviceable Monograph on this family was published; and if we add to this list the result of subsequent discoveries or reputed novelties, as well as all the species of Bulimus and other allied genera (which scarcely differ from Helix, and are only considered distinct for the sake of more easy classification), we can form some idea how exceedingly numerous this family is. Strictly speaking, it only consists of one genus, like Testacellida; and there is rather a generic than a family resemblance amongst its members. The chief points of difference between the genera of the present family are, that in Succinea the body is ordinarily a trifle larger than the shell ; in Vertigo the two lower or smaller tentacles are wanting; in Clausilia the shell has a reversed spire, and is furnished inside with a small moveable process; in Bulimus, Pupa, and Balia the spire is longer, and in the last-mentioned genus reversed; while in Cochlicopa and Achatina the spire is more produced and the mouth of the shell is channeled or notched at its base. But without some artificial classification of this kind the genus Helix would be too unwieldy; and the division into subgenera is generally considered inconvenient, because it occasions additional and unnecessary nomen- 
clature. The genera into which this family may be divided, as regards the British species, are as follows :* Shell oval, usually not quite covered by the body. 1 . Succinea.

* Shell globular or round, glassy, sometimes covered in part by a lobe or expansion of the mantle. 2. Vitrina. 3. ZoNites.

*** Shell shaped like the last, but not glassy, nor any part of it covered by the mantle. 4. Helix.

**** Shell cylindrical : mouth often furnished inside with teeth, and in one genus also with a moveable plate. 5 . Bulimus. 6. Pupa. 7. Vertigo. 8. Balia. 9. Clau SILIA.

***** Shell shaped like the last: mouth more or less notched at the base, and sometimes also toothed. 10 . Cochlicopa. 11. Achatina.

\section{Genus I. SUCCI'NEA*, Draparnaud. Pl. VI. f. 1-3.}

: Bopy gelatinous, usually incapable of being quite contained within the shell : tentacles 4 ; upper pair conic, lower pair very short: foot large, oblong.

Shell oval or oblong, thin, amber-colour: spire short: mouth large.

The Amber Snails are allied to the Limnace in form and habits, as well as in some respects to the Slugs and the true Snails, or Helices-showing that the order of Nature is not like the steps of a ladder, but bears a greater resemblance to chain- or net-work, every link or mesh of which is connected with the other. These snails are in a great measure amphibious. Mr. Benson mentions his having found our common species (S. putris) creeping on stones under water in an Irish lough, in company with species of Planorbis, Bythinia, and Physa

* Amber-colour. 
although he had also observed that an Indian species of Succinea frequented dry places where no water ever lodged. Muiller says, however, that they are no more amphibious than Helix nemoralis, a variety of which he had seen living many days in a brook. Although the Succinece inhabit the banks of lakes and marshy places, and may even, after a flood of heavy or continued rain, be seen under water, I have noticed that they do not like remaining in it, but crawl out on comparatively dry land, or climb up the stalks of aquatic plants and willows. When they are under water they draw in their tentacles. They can float on the water in a reversed position; and in dry weather they withdraw themselves far into the shell, covering up the mouth with a membranous epiphragm like the Planorbis spirorbis, var. leucostoma. They are vegetable feeders. Their eggs are agglutinated together and deposited on the stalks and leaves of aquatic plants, as well as upon stones at the water's edge. Succinece are found in all parts of the world; and the extent of their variation is equally great. Their shells may be distinguished from those of Limncea by the absence of any fold on the columella or pillar.

\section{Succinea Pu'tris* ${ }^{*}$, Linné.}

Helix putris, Linn. Syst. Nat. ed. xii. p. 1249 . S. putris, F. \& H. iv. p. 132 , pl. exxxi. f. $4,5$.

BoDy rather thick, reddish-yellow, closely covered with small, flat and irregularly-shaped tubercles: tentacles short; upper pair not much swollen at their tips, and marked with minute and indistinct black specks : snout, or front of the head, large and very tumid : foot broad, nearly truncate in front, triangular and slightly pointed behind.

Shell oval, very thin, semitransparent, glossy, of an

* Frequenting putridity. 
amber-colour with often a greenish or reddish hue, finely but irregularly striate by the lines of growth, otherwise quite smooth: epidermis rather thick: whorls 3-4, convex, the last occupying at least four-fifths of the shell : spire short, abrupt and blunt at the point: suture rather oblique and deep : mouth oval: outer lip slightly thickened, contracted above, where it joins the columella : pillar lip sharp. L. 0*6. B. $0 \cdot 3$.

Var. 1. subglobosa. Shell shorter and broader in proportion to its length, usually much smaller and more solid.

Var. 2. vitrea. Shell extremely thin: spire smaller.

Var. 3. solidula. Shell much thicker, reddish-yellow.

Навітат: On water-plants and other herbage, as well as on mud, in all sorts of moist places, from the extreme north of Zetland to the Channel Isles. Var. 1. Marshes and by the side of lakes, on the sea-coast and in mountainous districts. Var. 2. Carmarthenshire (J. G. J.); Cork (Humphreys). Var. 3. Deptford, Wilts (J. G. J.). This species is one of our upper tertiary fossils. Abroad it ranges from Siberia to Naples; and Captain Hutton has found it in Afghanistan. Probably some exotic species are mere varieties of this widely-diffused shell.

It is a sluggish mollusk, and secretes a quantity of slime. The clusters of eggs are oblong. It hibernates early, and passes the winter attached to stones by means of its epiphragm, which resembles silver-paper. The shell sometimes attains the length of an inch.

According to the strict rules of priority, Klein's specific name of vetula ought to be adopted; but it is now obsolete. This name may possibly have been derived from an account which was given by Tulpius, an ancient and very learned physician, in his medical observations, of a wonderful cure performed on an old woman of eighty-nine by a dose of two of these snails pounded up alive! 
2. S. E'LEGANS*, Risso.

S. elegans, Risso, Moll. Alp. Marit. p. 59, no. 128. S. putris, var., F. \& H. iv. p. 135, pl. cxxxi. f. 1-3.

Bopy thick, yellowish-brown, sometimes nearly black, covered with minute round tubercles and clusters of black specks: tentacles very short, yellowish-white and transparent, streaked down the middle with lines of black specks; upper pair rounded at their tips: snout round and somewhat tumid: foot broad, rounded in front and behind, narrower at the tail.

SHell oblong, not very thin, glossy, scarcely semitransparent, amber-colour with a brownish or reddish hue, sculptured like thelast species: epidermis rather thin: whorls 3-4, moderately convex but compressed towards the suture, the last occupying about three-fourths of the shell : spire rather short and pointed: suture remarkably oblique, not very deep: mouth oval: outer lip slightly thickened and considerably inflected above: pillar lip sharp. L. 0-6. B. 0-25.

Var. 1. minor. Shell smaller and thinner, of a reddishbrown colour, with a shorter spire and more expanded mouth.

Var. 2. ochracea. Shell smaller and thicker, also reddishbrown, with a larger spire and smaller mouth.

Habitat : Similar situations and as extensively distributed as S. putris. Var. 1. Falmouth; Hammersmith (J. G. J.). Var. 2. Scarborough (Bean); Newcastle (Alder); Tenby; Tingwall lake, Zetland (J. G. J.). The last variety is often mistaken for S. oblonga. This species is also one of our upper tertiary fossils. Abroad it is found everywhere between Finland and Sicily. According to Deshayes, it inhabits the Morea ; and Captain Hutton notices it as an Afghanistan shell.

The present species sometimes occurs living with $S$. putris, of which, on account of the great variability of form which prevails in all the species of this genus, S. elegans has been considered by some authors as a variety. Each of these species has, however, its own

* Graceful. 
corresponding variety; and I am inclined to consider them distinct. The species now under consideration differs from $S$. putris in the darker colour of its body and the more slender shape of the shell, as well as in its longer and more pointed spire. It forms a passage through its second variety from the last to the next species.

It is the S. Pfeifferi of Rossmässler, as well as the $S$. gracilis of Alder, but not of Lea. M. Bourguignat has ascertained, by a recent examination of Risso's collection, that it is the present species which the celebrated naturalist of Nice described as $S$. elegans; and his description sufficiently corresponds with that of Rossmässler.

\section{S. oBLoN'GA*, Draparnaud.}

S. oblonga, Drap. Hist. Moll. p. 59, pl. iii. f. 24,25; F. \& H. iv. p. 137, pl. exxxi. f. 6, 7 .

Bopy short, brown or grey of different shades, with sometimes minute black spots, finely shagreened: tentacles rather short; upper pair scarcely inflated at their tips: foot short and rather broad, bluntly pointed behind.

SHeLLoblong-oval, rather solid, moderately glossy, brownish or reddish-yellow, with sometimes a greenish hue, rather strongly but irregularly striate by the lines of growth, but devoid of any other sculpture : epidermis thick : whorls 3-4, convex, the last occupying about two-thirds of the shell: spire prominent, but abrupt and blunt at the point: suture oblique and very deep : mouth roundish-oval: outer lip rather thick, considerably incurved on the columella: inner lip slightly reflected. L. $0 \cdot 25$. B. $0 \cdot 175$.

Habitat : Dry ditches, chiefly near the sea-coast. It is a very local species in this country. I have found it among the sand-hills on Crymlyn Burrows near Swansea, and in a similar situation on Braunton Burrows * Oblong. 
near Bideford in North Devon. Mr. Kenyon is said to have found it near Glasgow, Mr. M'Andrew at Baltimore, Mr. Wright and Mr. Carroll near Cork, and Mr. Waller discovered it among turf-bogs at Finnoe, Co. Tipperary. The last appears to be the only inland locality. It is not uncommon in our upper tertiaries. This species is widely diffused on the Continent from Sweden to Lugano; and the S. abbreviata of Morelet, from Braganza in Portugal, appears to be only a variety of it.

S. oblonga is unmistakeably different from either of the foregoing species, being invariably so very much smaller and having such a large spire in proportion to the size of the shell, with a deeper suture and a rounder mouth. I can scarcely regard the $S$. arenaria of Bouchard-Chantereaux as even a well-marked variety of this species. Most, if not all, of the British specimens belong to this form. The greater solidity of its shell and the comparatively shorter spire are probably owing to the nature of its habitat. According to Bouchard-Chantereaux this variety buries itself in the sand and makes a rather solid epiphragm. The shell is usually covered with a viscous slime or exudation from the animal, by which a slight coating of dirt is sometimes formed.

\section{Genus II. VITRI'NA*, Draparnaud. PI. VI. f. 4-6.}

BoDy short, usually incapable of being quite contained within the shell : mantle furnished with a supplementary lobe, which is extended over the front of the shell when the animal crawls : tentacles 4, cylindrical, the lower pair very short: foot rather narrow.

SHell somewhat globular, extremely thin and transparent: spire short: mouth obliquely semilunar: outer lip thin : no umbilicus.

* From vitrum, glass. 
These little Glass-Snails are allied to the Slugs in some of their habits, and to the true Snails in the form of their shells, leading to the former through Succinea and to the latter through Zonites. Their food is partly vegetable, consisting of Jungermannice and decayed leaves, and partly animal. They are said to attack earth-worms, although not in the same way as Testacelle. I once saw no less than seven individuals of $V$. pellucida busily engaged in feeding on a scarcely dead worm, which was faintly writhing about and endeavouring in vain to get rid of its tiny assailants. They have also been noticed eating horsedung. They live in moist and shady places, but are seldom met with until late in the autumn. Their eggs are deposited in small heaps and have a membranous covering. The whole of the body can be withdrawn into the shell. They are very hardy, and capable of enduring an extreme degree of cold. I have found a variety of the $V$. diaphana on the Rifelberg near Monte Rosa, at a height of between 7000 and 8000 feet above the level of the sea, living among perpetual snows and on ground that never thaws. Only one species now inhabits this country, although another ( $V$. diaphana) formerly did so, as is proved by its occurrence in our upper tertiary strata. This last species has a wide range over the Continent, and, according to Potiez and Michaud, inhabits the North of France. It has been observed on the Vosges Mountains at a height of upwards of 4000 feet. Several other species are found on the Continent.

\section{Vitrina Pellu'CidA*, Muiller.}

V. pellucida, Müll. Verm. Hist.pt. ii. p. 15; F. \& H.iv. p. 30, pl. exxxi. f. 8-10, and (animal) pl. I. I. I. f. 2.

BODY rather slender, grey with more or less of a reddish * Transparent. 
tinge, and having some minute black specks on the anterior part: foot yellowish underneath, pointed behind.

SHell convex above, rather depressed below, exceedingly thin and brittle, remarkably glossy and almost iridescent, nearly transparent, marked indistinctly by the lines of growth, as well as by close-set and very minute striæ in a spiral direction : epidermis thin: whorls 3-4, convex, the last occupying more than two-thirds of the shell: spire extremely short, rising gradually to a blunt point: suture very slight, forming a narrow groove, which is striate across: mouth nearly round, except where it is interrupted by the periphery of the penultimate whorl : outer lip not very thin, nor inflected above : pillar lip sharp. L. $0 \cdot 125$. B. $0 \cdot 25$.

Var. 1. depressiuscula. Shell rather oval and flatter on both sides: spire scarcely raised above the level of the last whorl. $V$. Draparnaldi and V. depressa, Jeffr. in Linn. Trans. xvi. pp. 326, 327.

Var. 2. Dillwynii. Shell nearly globular, with the last whorl very convex : spire more prominent. V. Dillwynii, Jeffr. l. c. p. 506.

Habitat: Under stones and logs of wood, as well as among moss and dead leaves, in woods and shady places throughout Great Britain. Var. 1. Neighbourhood of Swansea and Plymouth (J. G. J.). It approaches very near to $V$. major of the elder Férussac and $V$. Draparnaldi of Cuvier, with which I at one time considered it to be identical. Var. 2. Sand-hills near Swansea, at the roots of Rosa spinosissima. The foreign range of this common species extends from Siberia to Sicily.

This is an active and hardy creature, and, whether crawling or at rest, it seems always to keep the outer lobe of its mantle in motion, so as to polish the shell. Bouchard-Chantereaux says that it does not begin laying its eggs until September, October, or November, and that the young attain their full growth in from eight to ten months. He believes it does not live longer than from twelve to fifteen months, having always found a number 
of dead individuals in January, after the close of the breeding-season. Muiller has noticed that it is most lively during rain, and that it does not soon die if put in water. He added that while it was under water it extended all its body except the tentacles, which were drawn in, and feigned death; that after the lapse of some hours it crept out of the water cautiously and by degrees, and if it was not alarmed by the observer it stretched out its horns, and after crawling into some place of shelter withdrew its body into the shell. Mr. Daniel, having collected both of these species in Germany, informs me that $V$. pellucida is much more gregarious than $V$. diaphana.

\section{Genus III. ZONI'TES*, De Montfort. Pl. VI. f. 7-9.}

BoDy long, rather bulky, but always capable of being contained within the shell: mantle thick and slightly reflected: tentacles 4, cylindrical, swollen or bulbous at the tips : foot narrow.

Shell conical, usually depressed, thin and semitrans. parent, extremely glossy : spire composed of several whorls: mouth obliquely semilunar: outer lip thin : umbilicus more or less distinct.

These pretty little snails resemble the Vitrince in the bulkiness of their bodies and the glassy appearance of their shells, as well as in the structure and arrangement of their dental apparatus or lingual riband. The edge teeth are hooked in the present genus and Vitrina, but serrated or notched in Helix. Their habits also are nearly the same as those of the Vitrince, being rather zoophagous than phytophagous. They greedily devour all kinds of animal food, whether fresh or putrid; and

* From zona, a girdle. 
they are said even to attack the larger snails and to enter their shells for that purpose. They frequent dark and damp places, being generally met with under stones, old bricks, and logs of wood which are partly buried in the earth, as well as under and among dead leaves and moss in woods; and one kind inhabits cellars, vaults, and wells. Some of them give out when touched or disturbed a fetid smell like that of garlic, which may be perceived at a considerable distance. Their eggs are laid in the earth and joined together in small clusters.

\section{A. Spire depressed : umbilicus open. \\ 1. Zonites Celia'RIUS*, Müller.}

Helix cellaria, Müll. Verm. Hist. pt. ii. p. 38. Z. cellarius, F. \& H. iv. p. 33, pl. exx. f. 1-3, and (animal) pl. H. H. H. f. 3.

BoDy obtusely rounded in front and narrowing gradually behind, nearly covered with small and rounded but very flat tubercles, rather transparent, slate-colour or bluish-grey, with a faint tinge of yellow: tentacles long and slender, with very large bulbs surmounting the upper pair, bluish or yellowish-grey, finely speckled with black : foot very narrow, pointed and somewhat keeled behind.

Shell compressed, nearly as convex above as below, thin and brittle, very glossy, semitransparent, yellowish or brownish-horncolour above, and whitish with often a greenish tinge underneath, irregularly striate by the curved lines of growth, which are stronger near the suture and microscopically striate, like Vitrina, in a spiral direction: epidermis rather thick: whorls 5-6, dilated, regularly increasing in size, the last occupying about one-half of the shell : spire extremely short and nearly flat, almost central : suture slight, forming a narrow groove or channel : mouth obliquely and deeply semilunar : outer lip slightly reflected : umbilicus broad and deep, exposing nearly all the interior of the spire. L. $0 \cdot 2$. B. $0 \cdot 5$.

Var. 1. complanata. Shell rather smaller: spire very flat. * Frequenting cellars. 
Var. 2. albida. Shell white or colourless.

Var. 3. compacta. Shell not so white underneath : whorls more convex and compact, the last not being so much dilated: spire more prominent.

Habitat : Cellars, vaults, drains and sculleries, under stones, loose bricks, tiles and logs of wood about houses, as well as under stones and fallen trees which have lain long on the ground in woods, everywhere from Zetland to Guernsey. The varieties are occasionally found. Var. 3 approaches the next species in form. Z. cellarius occurs in a semifossil state at Copford, Clacton, and Maidstone. Its foreign distribution extends from Finland to Algeria and Sicily; and Mr. Lowe has recorded it from Madeira and the Canaries. Gould has described it as a North-American species, and says it is the Helix glaphyra of Say; but he adds that it was probably imported from Europe about water-casks or greenhouse plants.

Muiller has noticed the shy habits of this snail, and says that, when crawling, it alternately withdraws one of its horns half-way, although there is no obstacle in front of it, and immediately puts it out again. Mr. Sheppard remarked that it had a very fetid smell, much resembling that of the urine voided by the common snake se defendendo, and by which one might frequently be guided to the spot where it lies concealed. He also noticed that in some instances this odour was not perceptible until the snail had been immersed in boiling water. The organ of smell must be very acute in this, as well as all the other species of Zonites, judging from the size of their tentacular bulbs, in which this sense is supposed to be placed. Its slime is watery and abundant. The dark band which often encircles the suture in dead shells is owing to the dried remains of part of 
the body appearing through the shell. A specimen in my collection has the outer or last whorl marked by a rufous band between the suture and the periphery.

Linné does not appear to have known this common species. Much confusion has been caused by the posthumous editor of his 'Systema Naturæ' (Gmelin) carelessly changing the name which Muiller gave to a different species of Helix from nitida to nitens, and applying the latter name to the present species. This is the Helix lucida of Pulteney, but not of Draparnaud, and the $H$. nitida of the last-named author.

\section{Z. ALlia'nIUS*', Miller.}

Helix alliaria, Mill. in Ann. Phil. new ser. iii. p. 379. Z. alliarius, F. \& H. iv. p. 34, pl. exx. f. 5, 6.

BoDY resembling that of $Z$. cellarius; but it is of a much darker colour, and the tentacles are shorter in proportion.

Shell more convex above and less so below than in the last species, rather more solid and glossy, of a darker colour on the upper side and not so white underneath, sometimes marked with a few indistinct spiral lines: whorls 5, rather convex, often irregularly coiled, the last not so large in proportion to the others as in Z. cellarius: spire somewhat produced: suture moderately deep, but not channeled: mouth narrow: outer lip sharp, slightly reflected near the pillar: umbilicus open and deep. L. 0·1. B. 0.275.

Var. viridula. Shell greenish-white.

Habitat: Under stones on hills and open spots, as well as among sand-hills; having an equally wide distribution with the last species, but more local. The variety is from Northumberland (Alder); Kent (Smith); Somerset (Norman) ; Cork (Humphreys); Belfast (Thompson); Lincolnshire, Salop, Zetland, and Co. Tyrone (J. G. J.). This species is one of our upper tertiary 
fossils. It has been recorded by M. Grateloup as occurring at Dax in the Department of the Landes, and by M. Terver at Lyons ; but it has probably been passed over in other parts of Europe as a variety of Z. glaber, which is not uncommon in France, Germany, and Switzerland.

This snail has a very strong and pungent smell of garlic, especially when it is irritated; and I have perceived it at a distance of several feet from the spot. Having found living specimens under stones in a bed of wild garlic, I thought at first that they might have fed upon this herb and thus acquired the peculiar odour; but I afterwards observed that this scent was quite as powerful in specimens collected on an open down where there was no garlic. Mr. Norman informs me that the scent varies in intensity, and is sometimes scarcely perceptible, even after considerable irritation of the animal.

It differs from $Z$. cellarius, the young of which it resembles in the darker colour of its body and shorter tentacles, as well as in the spire of its shell being more produced, the mouth narrower, and the umbilicus more open. If the two shells are held sideways, with the mouth towards the observer, the last whorl of Z. cellarius will appear deeper than in the other shell.

There has been much controversy among Continental writers as to whether this species is distinct from the Helix glabra of Studer. I incline to the opinion of Schmidt, that they are different. One test mentioned by this author in support of his view is rather curious, viz., that $Z$. alliarius wants the bitter flavour of the other species! I much doubt if all conchologists would relish making such experiments. 


\section{Z. Nitínulus* ${ }^{*}$, Draparnaud.}

Helix nitidula, Drap. Hist. Moll. p. 117. Z. nitidulus, F. \& H. iv. p. 36, pl. exx. f. 8-10.

BoDy dark-grey or slate-colour, with a brownish tinge, covered with flat and irregularly-shaped tubercles of a darker hue, which give a speckled appearance: tentacles rather short and conical ; bulbs small : foot rather narrow in front, swollen and keeled behind.

Shell compressed, more convex above than below, thin, moderately glossy, scarcely semitransparent, brown or yellowish-horncolour above, whitish underneath, especially about the umbilicus; sculptured as in $Z$. cellarius, but having the spiral striæ more regular and distinct: epidermis rather thick: whorls 4-5, convex and rounded, the last occupying rather more than one-half of the shell : spire slightly raised, nearly central : suture rather deep: mouth round, except where it is interrupted by the periphery of the penultimate whorl: outer lip not so obliquely set as in the last species, nor reflected: umbilicus very broad and deep, fully exposing the interior of the spire. L. $0 \cdot 15$. B. $0 \cdot 33$.

Var. 1. nitens. Shell rather smaller and of a lighter colour, with a dull and waxy appearance ; last whorl somewhat larger in proportion to the others and laterally expanded. Helix nitens, Michaud, Compl. Drap. p. 44, pl. xv. f. 1-5.

Var. 2. Helmii. Shell resembling that of the abovementioned variety, but of a pearl-white colour. Helix Helmii, Gilbertson's MS.

Hавiтат: Under stones and among dead leaves, moss, and herbage in woods, hedge-banks, and elsewhere in this country, from the Moray Firth district to Guernsey. Var. 1. South Wales, West coast of Scotland, and many other places. This variety is more widely diffused than the typical form, which is not uncommon on the banks of the Thames near London and seems to prefer watery places, like Z. nitidus. Var. 2. Preston (Gilbertson); Sevenoaks, Kent (Smith). This species is one of our

* Rather glossy. 
upper tertiary fossils. On the Continent it ranges from Russia to the Pyrenees, and the variety nitens extends also to Sicily.

It is a shy animal and delights in dark places, being sometimes found underground at a depth of some inches where the earth is loose. Its flesh is of a rather firm consistency, and its slime is watery and abundant. It does not emit any offensive smell.

The shell differs from that of $Z$. cellarius in being smaller, and in having one whorl less, the spire more raised, and a much larger and deeper umbilicus. Its surface is also much less glossy.

I cannot recognize anything more than a varietal distinction between the Helix nitidula of Draparnaud and the $H$. nitens of Michaud, which are regarded by Continental authors as different species. This last is not the $H$. nitens of Gmelin or of Maton and Rackett. The variety Helmii is $H$. nitens, var. albina, of Moquin-Tandon, which I have found near Lausanne.

\section{Z. PU'RUs*, Alder.}

Helix pura, Ald. Cat. Northumb. Moll. p. 12. Z. purus, F. \& H. iv. p. 37, pl. exxi. f. 5, 6 .

BoDy yellowish-grey or whitish, with fine black specks and close-set tubercles, slightly transparent: tentacles very long and nearly cylindrical ; bulbs small : foot very narrow, slightly pointed in front and rounded behind.

SHeLl compressed, rather more convex above than below, very thin, not very glossy but semitransparent, light horncolour with a yellow or reddish tinge on the upper side, exquisitely sculptured transversely by numerous curved striæ, and spirally by still finer and almost microscopic lines, the intersection of which gives the surface a reticulated appearance: epidermis thin: whorls 4, convex, but dilated laterally, the 
last occupying scarcely one-half of the shell : spire slightly raised: suture moderately deep, puckered by the lines of growth : mouth nearly round and not much interrupted by the penultimate whorl: outer lip not very oblique : umbilicus rather narrow, but deep, disclosing all the internal spire. L. $0 \cdot 075$. B. $0 \cdot 15$.

Var. margaritacea. Shell pearl-white and nearly transparent.

Habitat: Among dead leaves and moss in woods throughout the greater part, if not the whole, of Great Britain from the Moray Firth district to Cornwall, as well as in Ireland, but more local and less common than the last species. The variety is equally diffused. This species is one of our upper tertiary fossils. Gerstfeldt, as well as Middendorff, has recorded its occurrence in East and West Siberia; and other writers have given Scandinavian, German, French, and Swiss localities for it. I found it in tolerable plenty at Alexisbad and elsewhere in the Lower Harz and also near Lausanne.

Its habits are almost subterranean, and in other respects resemble those of $Z$. nitidulus, with which it is often found, and from which it differs in its much smaller size, the delicate form and sculpture of its shell, and the umbilicus not being so large in proportion. According to L. Pfeiffer, it is the Helix Hammonis of Ström, which was found at Trondjhem and published in 1765 ; but Miiller has referred it to $Z$. nitidus. Judging from the description and figure given by Gould (in the 'Invertebrata of Massachusetts,' p. 183, f. 111) of his Helix electrina, I cannot agree with L. Pfeiffer in considering that species identical with the present, either as regards form or sculpture; and the habits of each species are quite different. 


\section{Z. RADIA'TULUS* Alder.}

Helix radiatula, Ald. Cat. Northumb. Moll. p. 13. Z. radiatulus, F. \& H. iv. p. 38, pl. cxxi. f. 1 .

BoDy dark horncolour : tentacles nearly black, the upper ones very slender and the lower pair short : foot exceedingly narrow, pointed behind, its sides marked with minute black specks.

SHELL compressed, equally convex on both sides, very thin, remarkably glossy, semitransparent, dark horncolour, distinctly and beautifully marked across the whorls on the upper side by strong curved and close-set striæ which reach the suture, the under side being also marked, but less distinctly, by similar striæ : epidermis thin : whorls $4 \frac{1}{2}$, convex, and very little dilated laterally, the last occupying rather less than one half of the shell : spire slightly raised: suture moderately deep : mouth nearly round, sometimes thickened inside by a broad but slight white rib: outer lip scarcely oblique: umbilicus narrow, but rather deep, disclosing all the internal spire. L. $0 \cdot 075$. B. $0 \cdot 15$.

Var. viridescenti-alba. Shell greenish-white.

Habitat : Under stones, logs of wood, dead leaves, and moss in woods, from the Moray Firth district to Dorset. The variety is from Shropshire, Co. Cork, and Co. Tyrone (J. G. J.); Belfast (Thompson). This species is one of our upper tertiary fossils. Malm has recorded it as a Swedish shell, Scholtz as Silesian, Moquin-Tandon and others from different parts of France, Stabile from Lugano, and myself from the Lower Harz and Switzerland.

This little mollusk is less shy and inactive than $Z$. purus, and usually frequents moister places. It resembles that species in the size and form of the shell; but the peculiar sculpture, more glossy appearance, and narrower umbilicus of the present species will easily serve to distinguish it from $Z$. purus.

* Slightly rayed. 
It is the Helix nitidula, var. $\beta$, of Draparnaud, as well as the $H$. nitidosa of Férussac and $H$. striatula of Gray ; but both these latter names were unaccompanied by descriptions. The H. striatula of Linné, Muiller, and Olivi are different from that of Dr. Gray and from each other.

\section{Z. NI'TIDUs*, Müller.}

Helix nitida, Müll. Verm. Hist. pt. ii. p. 32. Z. nitidus, F. \& H. iv. p. 39 , pl. cxx. f. 4,7 .

BoDY strongly truncate in front, bluish-black or darkbrown, covered with large round flat tubercles which are interspersed with a few minute milk-white specks: snout small, short, broad, and tumid: tentacles rather thick and short; bulbs globular: foot obtusely rounded in front, narrow and somewhat keeled behind.

Shell semiglobular, much more convex above than below, not very thin, but glossy and semitransparent, chocolatebrown, marked transversely by numerous curved striæ which are stronger and puckered towards the suture, and very finely granulated under the microscope: epidermis rather thin: whorls 5, convex, the last occupying about onehalf of the shell : spire somewhat prominent, with a blunt point : suture deep : mouth round, except where the penultimate whorl contracts it : outer lip rather obliquely set, thin, and reflected near the pillar: umbilicus narrow, but deep, exposing all the interior of the spire. L. $0 \cdot 1$. B. $0 \cdot 275$.

Var. albida. Shell white or colourless.

Habitat : Under loose stones and decayed wood, as well as at the roots of grass and on mud in bogs and moist places, from the North of Scotland to Guernsey. Specimens of the variety were found by Mr. Choules among the rejectamenta of the Thames at Richmond. Although dead shells, they have not become bleached by exposure to the sun. A monstrosity also sometimes occurs, in which the whorls are slightly disunited, as in 
Z. alliarius. This species is one of our upper tertiary fossils. Its foreign range extends from the North of Russia to Corsica and Algeria, through all the intermediate countries.

Nothing appears to be known as to the habits of this snail, except that it is, like its congeners, of an inactive or sluggish nature and that it forms a slight epiphragm during the heat of summer.

The shell differs from that of $Z$. radiatulus (which it somewhat resembles) in its much larger size, more prominent spire, the last whorl not being so large in proportion, and the striæ being very much slighter.

Gmelin made one of his usual blunders in changing the name which Muiller gave this species to nitens; and Draparnaud, apparently without any reason, substituted in his 'Histoire' a new name (lucida) for the correct one which he had previously given in his 'Tableau.'

\section{Z. EXCAVA'TUS*, Bean.}

Helix excavata, Bean, in Alder's Cat. North. Moll. p. 13. Z. excavatus, F. \& H. iv. p. 40, pl. exxi. f. 2-4.

Bopy lead-coloured (Alder).

Shell compressed, more convex on the upper than the lower side, glossy, semitransparent, light-brown or tawny, strongly and deeply striate in the line of growth: epidermis rather thin: whorls $5 \frac{1}{2}$, convex and nearly cylindrical, the last occupying not much more than one-third of the shell: spire slightly prominent: suture very deep: mouth round, except where it is interrupted by the penultimate whorl, somewhat compressed below : outer lip as in the last species: umbilicus broad and deep, exposing all the internal spire. L. $0 \cdot 085$. B. $0 \cdot 225$.

Var. vitrina. Shell greenish-white, transparent. Helix vitrina, Fér. Tabl. Syst. p. 45. H. viridula, Menke, Syn. Moll. p. 20. 
HaвiтAт: Under fallen trees and among dead leaves and moss in shady woods. The tract of country over which it is diffused comprises the South and South-west of Scotland, North of England, West and South of Ireland, North and South Wales, Isle of Wight, and Cornwall; but it is a local species. The variety is from South Wales, Cork, and Connemara.

This species has been considered peculiar to Great Britain, and to be the only land-shell which does not inhabit any other part of the world; but I have reason to believe that the greenish-white variety is the Helix vitrina of Férussac, as well as the $H$. viridula of Menke, $H$. petronella of Charpentier, and probably also the $H$. clara of Held. In the 'Malakozoologische Blätter' for 1858 will be found a critical dissertation by Von Wallenberg on the Helix viridula of Menke compared with Z. purus, in which the author showed that these were quite different species; and I can answer for the identity of $Z$. excavatus var. vitrina (or viridula) with the $H$. petronella of Charpentier, having found specimens of the latter on the Gorner glacier in Switzerland at a height of about 7000 feet above the sea-level, and afterwards compared them with the types in Charpentier's collection at Devens while I was on a visit to that eminent naturalist. In a letter which is now before me from the late M. Charpentier, dated 28th August, 1854, he says the H. vitrina of Férussac (but not that of Wagner, which is a Brazilian species) is identical with his own $H$. petronella, and that it is very different from $H$. radiatula, with which it has only a slight relation in respect of the striæ. Férussac did not give any description of his species. Instead therefore of the present species being exclusively British, it likewise appears to inhabit Lapland, Finland, Germany, and Switzerland. The publications of Alder and 
Menke having been made in the same year, I trust I may be pardoned in indulging a patriotic feeling and giving the precedence to my own countryman, especially as the name proposed by Menke designates a variety and not the species.

It differs from its nearest ally, $Z$. nitidus, in its less prominent spire, more compact whorls, much stronger striæ, deeper suture, and more open umbilicus.

\section{Z. CRYstal'Linus*, Müller.}

Helix crystallina, Müll. Verm. Hist. pt. ii. p. 23. Z. crystallinus, F. \& H. iv. p. 4l, pl. cxxii. f. $1,2$.

BoDy clear greyish-white, nearly transparent: tentacles rather short; upper pair ebony-black, coloured by the retractor nerve; lower pair grey : foot narrow, pointed behind, whitish.

Shell depressed, more convex below than above, thin, very glossy and iridescent, transparent, greenish-white or hyaline like glass, very finely and closely striate transversely, especially towards the suture: epidermis very thin: whorls $4 \frac{1}{2}-5$, rather convex, but compressed outwards, increasing gradually in size : spire not much raised: suture slight, but distinct: mouth semilunar, sometimes strengthened inside by a slight rib, which is seen through the shell: outer lip obliquely set, very thin: umbilicus narrow and only exposing a small part of the penultimate whorl. L. 0.065. B. 0·125.

Var. complanata. Shell nearly flat on both sides; the last whorl proportionally larger than the others.

Habitat : Under stones and decayed pieces of wood, as well as among dead leaves and moss, in woods and shady places, from the Moray Firth district to Guernsey. The variety was found by me in Leigh Woods near Bristol. This species is one of our upper tertiary fossils. Its foreign distribution is very extensive, and ranges from Finland to Algeria and Sicily, as well as to Madeira and the Azores.

* Like crystal. 
This exquisite little shell was first noticed as British by Dr. Gray in the 'Medical Repository' for 1821 .

B. Shell conical, having a slight depression and perforation instead of an umbilicus.

\section{Z. Fur'vUs*, Miuller.}

Helix fulva, Müll. Verm. Hist. pt. ii. p. 56 ; F. \& H. iv. p. 75, pl. exviii. f. 8, 9.

BODY dark-grey or slate-colour, with very fine black specks : tentacles very long; bulbs globular : foot rounded in front, pointed and keeled behind, having some scattered milk-white specks on the sole or under part.

Shell pyramidal, thin, glossy and semitransparent, horncolour or tawny, finely but irregularly striate in the line of growth, and marked spirally with close microscopical lines, which are more distinct and regular at the base: epidermis very thin: whorls $5 \frac{1}{2}$, cylindrical, increasing gradually in size : periphery obtusely keeled : spire very prominent, but blunt: suture deep: mouth semilunar, compressed and narrow : outer lip curved, but not oblique, reflected on the pillar : umbilicus consisting of a slight indentation, with sometimes a small hole. L. $0 \cdot 1$. B. $0 \cdot 1$.

Var. Mortoni. Shell of a paler colour, with the spire more depressed and peripheral keel sharper. Helix Mortoni, Jeffr. in Linn. Trans. xvi. p. 332.

HABITAT: Under decayed wood, leaves, and stones in shady woods and marshy places, from the Moray Firth district to the South of England, as well as all over Ireland. Specimens collected in dry situations are much larger than those which are found in wet moss. The variety is from Somerset and North Hants. This species is one of our upper tertiary fossils. Its foreign range extends from Siberia to Sicily, as well as to the Azores. According to Philippi, it is the same species as the Helix

* Tawny. 
Chersina of Say, which inhabits Georgia and a considerable tract of North America.

It is the Helix Trochiformis of Montagu. In all probability the adult specimen from which Müller described his Helix fulva was the H.edentula of Draparnaud or the H. bidens of Chemnitz, both of which have a white keel and lip, as noticed by Muiller in his description. The last-mentioned species is Scandinavian as well as French, and is closely allied to $H$. edentula. In the present species neither the keel nor lip is white.

This species forms a passage to the next genus, Helix.

\section{Genus IV. HE'LIX*, Linné. Pl. VI. f. 10, 11.}

Bopy rather long, always capable of being contained within the shell : mantle thick, slightly cloven on the under side: tentacles 4 , cylindrical, more or less swollen or bulbous at the tips : foot in most species broad.

Shell conical, not very glossy: spire usually produced, rarely depressed or flat: mouth forming an oblique segment of a circle, which differs in size according to the degree in which it is intersected by the penultimate whorl : outer lip sometimes thin, but more frequently strengthened by an internal rib or reflected, in some cases furnished with toothlike tubercles which contract the mouth : umbilicus usually distinct and more or less open, but in a few species quite closed or wanting, except in the young state.

This genus comprises all the true Snails. They are for the most part vegetarians; but they occasionally show a preference to animal food, both raw and cooked-being, like Man, omnivorous. Every wood, hedge-bank, old wall, field, and garden yields some kinds; while others frequent mountains, water-sides, open plains, and sanddowns near the sea. Most of them prefer shade and 
moisture; but some delight to bask in the sun's rays, and protect their soft and tender bodies from the heat by forming an epiphragm or film that covers the mouth of the shell. They would soon perish if the secretion of slime were checked. Their habits are nocturnal or crepuscular; and they are seldom met with crawling about in the daytime, unless in wet weather or after a heavy shower of rain. Before the sun has fully risen they retire to their lurking-places and hasten to conceal themselves under stones or logs of wood, among dead leaves, at the roots of grass, in the bark of trees, or in the chinks and crevices of rocks and walls. Some of them, which have no such place of shelter to resort to, attach themselves to the stalks of grass or leaves of trees and other herbage, by means of a secretion like that of which the epiphragm is formed. During the pairingseason they are furnished with crystalline darts which they shoot at each other, after preliminary coquettings, increasing this mutual excitement by long-continued caresses with their horns. These curious love-weapons have been observed sticking in the bodies of snails after such conflicts. They are contained in a special pouch or receptacle ready for use, and are peculiar to the present genus. Their shape varies according to the species. In some species each individual has only one of these missiles, in others two; and a few species have none at all. The eggs of the Helices, which are usually round and united in a cluster, are laid underground in short and slanting galleries which the mother snail excavates in the moist or loose earth with her foot. The tentacles of these, as well as of all other land-snails, are withdrawn in the same manner as the fingers of a glove turned inside out.

The present genus, as restricted by some conchologists, 
only comprises those species which are more or less globular and have usually a semilunar mouth. But the line of demarcation seems to have been drawn close enough when it excluded those species having turreted shells, such as the Bulimi, which only differ from some of the Helices in the spire being a little more produced. The number of British Helices is not sufficiently large to justify the artificial separation, by some conchologists, of a few species which have a depressed spire and a more or less complete peristome, under the generic titles of Carocolla or Chilotrema, and Zurama or Amplexus otherwise Vallonia.

Three species of Helix appear to have lived in this country during the glacial era; but they have since become extinct, or at any rate have not been noticed by any writer on British Conchology, although they are all of a tolerably large size. Their shells are found in the upper tertiary beds of our Eastern counties. They have survived and still exist in the northern and temperate parts of Europe. One of these species is the H. ruderata of Studer, which ranges from Siberia and Lapland to the alpine districts of France and Switzerland. Another is the $H$. incarnata of Muiller, which does not seem to extend quite so far north, but inhabits Sweden, Germany, France, Switzerland, and Lugano. Mr. Daniel informs me that he has found it in the Loess at Baden. The third species is the $H$. fruticum of Muiller, which is found living in every part of the European continent between Finland and Switzerland, and (according to Gerstfeldt) also inhabits Siberia and the Amoor territory. Mr. Searles Wood has recorded this last species as a pliocene fossil in consequence of his having found an imperfect specimen at Stutton; and I lately detected it in the lacustrine bed at Mundesley. 
A. Shell globosely conic : outer lip sometimes thickened: umbilicus small or indistinct.

\section{Helix lamelia'ta*, Jeffreys.}

H. lamellata, Jeffr. in Linn. Trans. xvi. p. 333 ; F. \& H. iv. p. 73, pl. exvii. f. 8, 9.

BoDy whitish ; back and head bluish-grey (A. Müller).

SHeLl pyramidal, thin, of a silky appearance and lustre, yellowish-horncolour or tawny, closely and regularly striate or plaited in the line of growth, with similar but much finer striæ in the interstices: epidermis rather thick: whorls 6, cylindrical and compact, increasing gradually in size : spire rather compressed and blunt: suture deep: mouth semilunar: outer lip thin, slightly reflected on the pillar : umbilicus narrow, but very deep. L. 0.08. B. 0.09.

Habitat : Among dead leaves (especially those of the holly) in woods in the northern counties of England, Anglesea, the North and West of Scotland, and throughout the greater part of Ireland. It also occurs as a fossil in our upper tertiary beds at Copford. Dr. A. Muiller has found it near Kiel and on the Isle of Rugen in Holstein, and Lilljeborg afterwards discovered it in Sweden; but it does not appear to have been noticed elsewhere on the Continent.

The plaits on the surface of the shell are membranous and form part of the epidermis. Further particulars of the animal are desirable. I unfortunately neglected the opportunity of making a note of it.

This species is the $H$. Scarburgensis of Alder (from Bean's MS.) and the $H$. seminulum of Rossmässler.

* Covered with small plates. 


\section{H. ACUleA'TA*, Müller.}

H. aculeata, Müll. Verm. Hist. pt. ii. p. 81 ; F. \& H. iv. p 74, pl. exvii. f. 5, 6.

Bopx rounded in front and gradually narrowing behind, greyish-slatecolour or light-brown : tentacles long, thick, and nearly cylindrical; upper ones covered with minute black specks : foot slender.

Shell globosely pyramidal, rather thin, not glossy, horncolour or light-brown, marked transversely by about 30 plaits of the epidermis, which rise in the middle of each whorl to a sharp thorn-like point, as well as by smaller intermediate folds, and striate spirally by close-set microscopic lines: epidermis thick: whorls $4-4 \frac{1}{2}$, convex, gradually increasing in size : periphery slightly and obtusely keeled : spire somewhat compressed and blunt: suture deep: mouth rather large and forming a deep arch : outer lip thickened with a white rib and reflected in adult specimens: umbilicus narrow and small. L. $0 \cdot 1$. B. $0 \cdot 1$.

Var. albida. Shell of a whitish colour.

Habitat : Among dead leaves and moss in woods, from Aberdeenshire to the Channel Isles. Variety from Bath (Clark). This species is one of our upper tertiary fossils. Its foreign distribution extends from Finland to Italy, and even to the Azores.

The animal walks with its shell erect, carrying it in the most graceful manner. I have observed it feeding on the Jungermannia platyphylla. Mr. Daniel informs me that in Germany it travels high up into trees, particularly the alder, and that in the autumn it uses the falling leaves as a locomotive to reach the ground. The shell is an exquisitely beautiful object, especially when it is fresh and encircled with its coronet of spines. This character alone will serve to distinguish it from any other British species of Helix.

It is the $H$. spinulosa of Montagu.

* Prickly. 


\section{H. POMA'TIA*, Linné.}

H. pomatia,Linn. Syst. Nat. ed. xij.p. 1244;F.\&H.iv. p. 46, pl. cxvi.f.2.

BoDY obtusely rounded in front, and narrowing behind to a rather fine point, yellowish-grey, with sometimes a brownish tinge, covered all over with large or a? cubercles or granulations, which are of a yellow colour with greyish interstices: mantle furnished on its upper part with three fleshy and prominent lobes : tentacles very long and nearly cylindrical ; terminal bulbs on the upper pair small and globular : foot large and broad, rounded in front and obtusely pointed behind.

SHell globular, thick and strong, opaque, of rather a dull aspect, yellowish-white, with spiral bands of brown, which latter colour is more or less diffused over the surface; these bands are four or five in number on the last or body whorl, and are sometimes confluent, and there are generally two or three(but occasionally only one) on the penultimate whorl ; the surface is also marked by numerous but irregular lines of growth and very fine spiral or longitudinal striæ : epidermis rather thick : whorls $4 \frac{1}{2}$ or 5, extremely convex, the last occupying about two-thirds of the shell: spire short and ending in a rather blunt point: suture not very deep, but distinct : mouth nearly round, slightly contracted and angulated above by the projection of the penultimate whorl : outer lip thick, reflected over the umbilicus, margined inside with reddish-brown: inner lip spread over the columella and scarcely distinguishable: umbilicus narrow and small. L. 1·75. B. 1·75.

Var. albida. Shell whitish or colourless.

Habitat: Woods, hedgebanks, and uncultivated places in Surrey, Hertford, Kent, Oxon, Wilts, and Gloucestershire. The variety has been found by Mr. Brewer near Reigate. There was at one time a popular notion that it had been introduced into this country by the Romans, because it is found near several ancient encampments; but there does not appear to be any other foundation for this idea. The $H$. pomatia has not been found at Wroxeter or York, or in many other parts of England 
and Wales where the Romans built cities or had ims portant military stations; and in all probability this kind of snail was not known to them, as another species (H. lucorum) takes its place in Central Italy. There is no better reason for the rumour which is mentioned by Montagu, that it was imported from Italy about the middle of the 16th century, either as an article of food or for medicinal purposes, and turned out in Surrey by a Mr. Howard at Albury. It was well known to Lister, who wrote in 1678 , as the largest of our native snails; and in all probability it is equally indigenous with $H$. aspersa or the common garden-snail. Neither of these species has been found in any recognised stratum of the upper tertiary formation in this country. The foreign distribution of $H$. pomatia extends from Finland (Nordenskiöld and Nylander) to Lombardy (Villa); but it does not appear to have been found in the South of France.

This large snail makes a common and rather a favourite dish in the North of France and some parts of Switzerland; and Lister gave a recipe for dressing and cooking it in this country. It is furnished with a peculiar mouth-piece, by means of which it effectually keeps out the cold and wet while it is hibernating. This covering is not like an operculum, forming part of the animal, but consists of a solid, calcareous and slightly convex plate, which exactly fits the aperture of the shell. It is secreted and formed by the mantle; and after it has served the purpose for which it was made it is thrust aside, and may be found lying on the ground on the return of spring and genial weather. The snail repairs its shell, when broken, in a more substantial manner than other kinds, on account of the superabundance of its calcareous secretion; and it can for that purpose withdraw its mantle far into the interior of the spire, so as to 
reach almost the summit. Owing to its large size and the consistency of its body, it has been from an early period a favourite study of comparative anatomists. Lister, Cuvier, and others have published full details of its internal organization. But the most interesting account of its physiology and habits is contained in a memoir by M. Gaspard, which will be found in the 'Annales des Sciences Naturelles ;' and an excellent abstract of it, with notes by Professor Bell, appeared in the 1st volume of the 'Zoological Journal.' Space will not admit of its being reproduced here; but I will briefly mention the more salient points of this excellent memoir. M. Gaspard says that when the period of hibernating has arrived these snails become indolent, lose their appetite, and associate together. Each snail then excavates with its large and muscular foot a hole in the ground, just large enough to contain the shell; this it roofs in and lines with earth and dead leaves, making with its slime a kind of mortar, and smoothing over the inner surface of its winter domicile. Having accomplished this, it closes the mouth of the shell with a thick calcareous lid, the substance of which, when first poured out from the edges of the mantle, resembles liquid plaster of Paris. It then withdraws its body far into the interior of the shell, covering, as it retires, the empty space with several layers in succession of a fine membrane or film, in order the more completely to exclude the cold air. In this snug receptacle it remains in a torpid state until the return of spring, all animal functions being in the mean time suspended. It then loosens and casts aside its winter bands and resumes its former life. In the genial month of May, these snails unite for propagation, and in June they commence laying their eggs, usually producing only a single brood in the year. The eggs are about the size 
of a small pea, and much resemble in colour and consistency the berries of the mistletoe. They are laid in a kind of nest, which the mother snail makes in the loose earth, in order to protect them from wet and the heat of the sun. No incubation is necessary, and they are left to the care of nature. The young are developed at the end of from twenty-one to forty-five days, according to the season and state of the temperature. The little snail, when it is first excluded, lives only on the pellicle of the egg, the whole of which is eaten by it. This provision is similar or analogous to that which is appropriated to the young of land vertebrate animals. The experiments made by M. Gaspard with respect to the function of those organs in snails which are called "eyes," led him to conclude that these mollusks are totally devoid of sight and are quite insensible to light, that they do not perceive an obstacle placed in their way until they touch it, and that, after being deprived of their horns which support the so-called eyes, they guide themselves as surely as before. It may be observed that this absence of sight and apparent insensibility to light are quite consistent with the nocturnal habits of snails. Perhaps the deficiency of this sense is supplied by the excessive susceptibility of the skin to outward impressions. M. Gaspard remarks that he found in these pretended optical bodies, or "eyes," nothing more than the organs of an exquisite sense of touch, arising from a large nerve which runs through the tentacles and is expanded over their extremities. He also denies the existence of any sense of hearing or smell in these mollusks; but this latter statement does not appear to agree with the observation of subsequent writers.

This is sometimes called the "Apple-snail," which is an appropriate name as regards its shape; but the word 
"pomatia" is derived from $\pi \hat{\omega} \mu \alpha$ an operculum, and not from pomum an apple. Pliny and Dioscorides applied the same name to it, and for a similar reason.

B. Shell globose: outer lip reflected: umbilicus wanting, except in the young.

\section{H. ASPER'SA*, Müller.}

H. aspersa, Müll. Verm. Hist. pt.ii.p. 59; F. \&H.iv. p. 44, pl. cxvi.f. l.

BoDy oblong, narrow and rounded in front, pointed behind, dark-brown or dirty-grey, mottled with milk-white specks, coarsely and strongly granulated: tentacles long and slender, considerably diverging from each other, brown; bulbs small : foot broad, rounded in front and finely pointed behind, having a narrowish border of yellow, and transversely wrinkled.

Shell globular, rather solid, opaque, not glossy, yellowish, with spiral dark-reddish-brown bands; these bands are often five in number on the last whorl and three on the preceding one, but some of them are frequently confluent, and they are always more or less interrupted by transverse and zigzag streaks of white: the sculpture consists of numerous pitmarks, which probably correspond with the tubercles of the mantle, as well as of very fine, but indistinct, spiral striæ, giving the surface a shagreened appearance: epidermis rather thick: whorls $4 \frac{1}{2}$, convex, the last occupying about two-thirds of the shell : spire short and ending in a blunt point: suture rather oblique, well defined but not deep : mouth obliquely roundish-oval, obtusely angulated above: outer lip rather thin, white and considerably reflected, much incurved towards the columella: inner lip extremely thin and spread on the columella: umbilicus slightly perceptible in the young, but afterwards covered by a fold and thickening of the pillar lip. L. 1*4. B. $1 \cdot 4$.

Var. 1. albo-fasciata. Shell reddish-brown, with a single white band.

Var. 2. exalbida, Menke. Shell yellowish or whitish.

Var. 3. conoidea, Picard. Shell smaller, more conical, and thinner: mouth smaller. 
Var. 4. tenuis. Shell dwarfed, extremely thin, and nearly transparent; bands reddish-brown.

Habitat : Woods and gardens (especially the latter), from the Moray Firth district to the Channel Isles. I have not found it so far north as Zetland. Vars. 1 and 2 are rather local, but not uncommon. Mr. Bridgman has found the latter under hornbeam hedges near Norwich. Var. 3. Sand-hills and cliffs on the sea-side. Var. 4. Downs on the south coast of Guernsey. The dwarf size and extremely thin texture of this last variety are probably owing to the absence of calcareous material in the soil where it is found. Monstrosities sometimes, but rarely, occur in which the spire is reversed, or the whorls are more or less disjoined, in some cases so much so that the shell resembles a ram's-horn. The late M. D'Orbigny showed me a colony of the reversed monstrosity in his garden at Rochelle. Mr. Bridgman succeeded in rearing a young specimen of the same monstrosity and bringing it to maturity by feeding it on cabbage and lettuce leaves. This species has been found in the peat-bed at Newbury, but has not been noticed as an upper tertiary fossil. It does not appear to inhabit the North of Europe nor Germany (although C. Pfeiffer has noticed it as found in gardens there); but its range extends southward from France to Sicily, as well as to Spain, Algeria, and the Azores. It seems to take the place of $H$. pomatia in some parts of Europe.

Lister says that, having put one of these snails and a Limax ater together in the same vessel, he found the next day that the slug had been killed and half-eaten by its companion; and he also remarked that the fluid, which exudes so copiously from the body of $H$. aspersa when it is pricked, was used in his time in bleaching wax for artistic purposes, as well as in making a firm 
cement mixed with the white of egg. The latter economical use might now be repeated with success, but by a less cruel operation, viz. killing and pounding, instead of pricking the snail, and straining the fluid. The garden-snail is much more prolific than many of its congeners. Bouchard-Chantereaux mentions that he has often counted from 100 to 110 eggs which had been laid by a single individual. Brard noticed that they are very sensible of cold, and hibernate early, clustering together in the crevices of old walls and trunks of trees, and attached to each other by their membranous epiphragms or winter coverings. They make great havoc in kitchen-gardens and spoil the best wall-fruit. There is, however, some compensation for this mischief: a kind of broth is made from them and used as a remedy for pulmonary complaints. This kind of snail is occasionally eaten by the French; but it is not held by them in the same estimation as the Apple-snail. Dr. Gray says that the glassmen at Newcastle once a year have a snail-feast, and that they generally collect the snails themselves in the fields and hedges the Sunday before the feast-day. They are supposed to have the power of excavating holes in limestone rocks to form their winter quarters. The late Dr. Buckland first called the attention of geologists to this circumstance; and M. Bouchind-Chantereaux has lately published, in the 'Annales des Sciances Naturelles' (4 $4^{\mathrm{e}}$ série, p. 197-218), an article entitled "Observations sur les Hélices saxicaves du Boulonnais," which will well repay the trouble of a perusal.

By way of further illustrating the habits of our common garden-snail, I trust I may be excused in transferring to these pages a short poem by Cowper, which ought to be known to all conchologists. It is called "The Snail," and is as follows :- 
" To grass, or leaf, or fruit, or wall, The Snail sticks close, nor fears to fall, As if he grew there, house and all Together :

"Within that house secure he hides, When danger imminent betides Of storm, or other harm besides Of weather.

"Give but his horns the slightest touch, His self-collecting power is such He shrinks into his house with much

Displeasure.

“Where'er he dwells, he dwells alone; Except himself has chattels none, Well satisfied to be his own

Whole treasure.

"Thus, hermit-like, his life he leads, Nor partner of his banquet needs, And, if he meets one, only feeds

The faster.

"Who seeks him must be worse than blind, (He and his house are so combined,) If, finding it, he fails to find

Its master."

This common species received from Pennant in 1766 the appropriate name of Helix hortensis; but in consequence of that name having been applied by Muiller, although nearly eight years afterwards, to a different species or a supposed species, the present name has been adopted by nearly all conchologists. The $H$. grisea of Linné, to which this species has been referred by some authors, is stated to inhabit Sweden, which is not the case with $H$. aspersa.

The $H$. aperta of Born can hardly be considered a British shell,- - the sole ground for supposing it to be a native of this country being the discovery by the late Professor E. Forbes in 1839 of a dead specimen in a 
cart-track in Guernsey. Dr. Lukis, who was at that time and is still a resident there, informs me that he has frequently searched in vain for this remarkable shell; and I have accompanied him in one of these excursions. Its shape is not much unlike that of the variety tenuis of $H$. aspersa, which is common in Guernsey, and is frequently bandless and without coloured markings. $H$. aperta is not found anywhere in France, except in the extreme South; it is also a native of Italy. It is the $H$. Naticoides of Draparnaud. This snail is said to feed on vine-leaves; and it ranks with the ortolan in gastronomic celebrity. Forbes's specimen might possibly have been imported and dropped by some French sailor, who had feasted on its contents. This specimen, however, is not to be found in the British Museum, where it was said to have been deposited by the discoverer; and Dr. Baird (who has the charge of this department) informs me that he has never seen it, although he has made inquiries and searched more than once for it.

\section{H. NEMORA'LIS*, Linné.}

H. nemoralis, Linn. Syst. Nat. ed. xii. p. 1247 ; F. \& H. iv. p. 53, pl. cxv. f. 1-4.

Bopx dark brown, tinged with yellow, and covered with very small and close-set round tubercles: mantle of a greenish 'ne, marked with yellowish specks: tentacles of a darker colour, very long and rather slender; bulbs globular: foot angular in front, gradually narrowing and pointed behind.

SHell globular, depressed below, rather solid and nearly opaque, moderately glossy, yellow, brown, pink, white, and of various other colours and shades, with from 1 to 5 spiral bands, which are usually brown, rarely white, and occasionally confluent or interrupted ; the sculpture consists of close, but irregular, lines of growth and minute spiral undulating

* Inhabiting groves. 
striæ: epidermis rather thin: whorls $5 \frac{1}{2}$, convex, the last occupying about three-fifths of the shell: spire short and ending in a blunt point: suture slight: mouth obliquely and deeply crescent-shaped: outer lip thick, reflected and strengthened by a strong internal rib, much inflected above, slightly angular beneath, where it makes an abrupt bend towards the columella; colour of the lip, rib, and columella reddishbrown: inner lip consisting of a slight reddish-brown layer: umbilicus open and narrow in the young, but afterwards covered and quite closed. L. $0 \cdot 65$. B. 0.9.

Var. 1. hortensis. Shell smaller and more globular : mouth white-lipped, and rib of the same colour : inner lip excessively thin and coloured or banded like the rest of the shell. H. hortensis, Müll. Verm. Hist. pt. ii. p. 52.

Var. 2. hybrida. Shell of the same size as the first variety, but not quite so globular: mouth and rib of a pink or livercolour. H. hybrida, Poiret, Coq. Aisne, p. 71.

Var. 3. major, Férussac. Shell much larger and rather more depressed than usual.

Var. 4. minor. Shell dwarfed, of the same shape and colour as the first variety.

HABIтAт: Woods, hedges, gardens, and similar situations everywhere ; and it is one of our upper tertiary fossils. Var. 1. Nearly equally diffused and common. Var. 2. More local, but not rare. Var. 3. Sand-hills and downs; remarkably large on the rocky Isle of Arran, Co. Galway (Barlee). Var. 4. Zetland (Barlee); Loch Carron, Ross-shire (J. G. J.). This last is analogous to the dwarf variety alpestris of $\mathrm{H}$. arbustorum. A reversed, as well as a scalariform, monstrosity sometimes occurs; but they are very rare. This abundant, but pretty, shell ranges from Norway to Sicily; and the variety hortensis is described by Gould as North American, although he was strongly of opinion that it had been imported and become to a certain extent acclimatized.

This kind of snail is said to be eaten in France; but I believe such an experiment has not been tried in this 
country. Lister says that thrushes are very fond of them, and, in order to eat them, pierce the upper part of the shells with their beaks. He also remarks that they are more hardy than other snails and are the first to make their appearance when spring returns. Mr. Whiteaves has observed that they are often destroyed by ants. Muiller relates that he had detected a young lizard, which he had confined together with a live $H$. nemoralis in a box, entering the shell and eating the snail. They appear to be fond, in their turn, of animal food. Mr. James Sowerby mentioned in the 'Zoological Journal,' the case of a pet specimen of this kind of snail which preferred roast mutton to lettuce-leaves. All the snails are omnivorous; but they seldom have the opportunity of feasting upon cooked meat.

The variety of colour, as well as the number and arrangement of the bands and markings in this common shell are almost infinite. Albin Gras has enumerated no less than 198 varieties of the typical form alone, and Moquin-Tandon has distinguished 46 more of the form called hortensis. The colour of the animal also varies nearly as much as that of the shell.

A great controversy has long raged between conchologists, as to whether the two forms called nemoralis and hortensis are distinct species. Linné united them; Muïier separated them. In modern times, Forbes and Hanley agree with the former, and Dr. Gray with the latter. Mr. Norman contends stoutly that they are not the same species; and his principal reason is that $H$. nemoralis invariably, but $H$. hortensis never, has a calcareous, and frequently coloured, deposit on the columella. He has referred, in the 'Zoologist,' to " a schoolboy's amusement in Southey's days," in backing his "black-mouths" (nemoralis) against any number of 
"white-mouths" (hortensis); and he offered to give odds of ten to one in favour of the former. The variety hybrida seems, however, to connect the two above-mentioned forms, so far as concerns their conchological distinction; and the only malacological character of importance, upon which a difference between them can be founded, consists in a slight variation of shape in their love-darts. With great deference therefore to the opinion of those who rank these forms as separate species, I cannot help regarding $H$. nemoralis as the type, and $H$. hortensis and H. hybrida as local or casual varieties of one and the same species. I have never found any two of these forms living together; and M. Bouchard-Chantereaux and others have made the same remark.

\section{H. ARbusto'rum*, Linné.}

H. arbustorum, Linn. Syst. Nat. ed. xii. p. 1245 ; F. \& H. iv. p. 48, pl. exv. f. 5, 6.

BoDy lustrous, dark grey or almost black above, and of a light slate-colour below, covered with round tubercles: mantle marked with a few indistinct milk-white specks : tentacles slender, much diverging, glossy and black; bulbs very globular : foot narrow and slightly keeled at the tail, with the sides transversely grooved.

SHELr globular, somew hat compressed below, usually rather solid and nearlyopaque, glossy, yellowish mottled with brown, mostly having a single brown spiral band round the middle of each whorl, or a little above it, closely but coarsely and irregularly ridged in the line of growth, and very finely striate in a spiral direction : epidermis rather thin : whorls 5-6, convex, the last occupying about three-fifths of the shell : spire varying in length, but usually depressed, and always ending in a blunt point : suture rather deep : mouth forming a segment of two-thirds of a circle : outer lip thick, white and reflected, sometimes strengthened by an internal, but not well-defined rib, much inflected above and rounded beneath: inner lip con- 
sisting of a mere film which is spread on the columella: $u m b i$ licus very small and oblique, nearly concealed by a fold of the outer lip. L. 0:5. B. 0:8.

Var. 1. flavescens. Shell yellowish-white, generally without any band.

Var. 2. major. Shell larger : spire more depressed. L. 0.7. B. 1 .

Var. 3. alpestris, Ziegler. Shell smaller: spire more raised. L. 0.5 . B. $0 \cdot 65$.

Var. 4. fusca, Férussac. Shell dark-brown, with or without the band, very thin and semitransparent.

Habitat : Among alders and in moist and shady woods and hedges, as well as occasionally in meadows by the side of rivers, from Zetland to Cornwall. It is rather a local species, and does not appear to have been found in the Channel Isles, probably because the conditions there are not suitable to it. Vars. 1 \& 2 are not very uncommon. Var. 3. Hoddesden, Herts, on the marshes by the side of the River Lea, the specimens being numerous and all of the same form and size (Pickering). Such a locality is very remarkable for this dwarf variety, which I have taken on the Swiss Alps, in the region of perpetual snow. The same variety occurs in the upper tertiary beds at Copford. Var. 4. Lunna, East Zetland, where there is no limestone or other calsaraous rock. This probably accounts for the extreme thinness of the shell. It appears to be the $H$. picea of Ziegler. My cabinet contains a distortion, from Oxfordshire, in which the spire is exceedingly raised. This species is distributed over the greater part of Europe. Von Wallenberg has recorded it from Lapland; and Aradas and Maggiore found it in Sicily. Mr. Lowe has included it in his list of Madeiran land-shells.

Bouchard-Chantereaux says that this snail lays its eggs from July to September, and that the young attain 
their full growth in fifteen or sixteen months after they are excluded. Moquin-Tandon enumerates this as one of the eatable kinds, but he adds that it is not much esteemed. The shell varies considerably in size. The epiphragm is exceedingly thin and like silver-paper.

It was known to Lister, who appropriately called it "Cochlea maculata." Whether it is the species which Linné described as $H$. arbustorum is questionable, as his diagnosis ("Testa umbilicata, convexa, acuminata, apertura suborbiculari bimarginata, antice elongata") is scarcely applicable to this species. It is, however, a Swedish shell; and the present name has been adopted by every author.

C. Shell conical : mouth furnished with an internal rib : umbilicus distinct.

\section{H. Cantia'na*, Montagu.}

H. Cantiana, Mont. Test. Brit. p. 422, and Suppl. p. 145, pl. 23. f. 1; F. \& H. iv. p. 50, pl. exvi. f. $8,9$.

Bopy yellowish, with a rosy or blush-colour tint in front, covered with small and numerous greyish tubercles : mantle marked with close-set milk-white specks: tentacles greyishbrown, widely diverging; upper pair rather thick at the base, but becoming slender towards the point; bulbs nearly spherical : foot somewhat truncate in front, ending in a triangular, swollen and keeled tail, with close transverse grooves at its sides.

SHELL subglobular, somewhat compressed both above and below, rather thin and semitransparent, slightly glossy, yellowish-white, with often a tint of reddish-brown or fawn-colour, especially on the last whorl towards the mouth and on the under side, and often marked with a white, but indistinct, spiral band, which is placed a little above the periphery and does not extend much beyond the last half of the body whorl; sculpture consisting of rather close, butirregular, curved transverse striæ: epidermis thin, covered in young and half-grown

* Kentish. 
specimens with short hairs, which are easily rubbed off and disappear in the adult: whorls 6-7, convex, the last occupying rather more than one-half of the shell: spire short and ending in a blunt point: suture rather deep: mouth oblique, forming a segment of about three-fifths of a circle, furnished inside with a rather thick white rib, which is placed at a little distance from the edge : outer lip thin and slightly reflected, not much inflected above, rounded beneath, and folding over at its junction with the columella: umbilicus small and narrow, but rather deep, exposing the whole of the spire. L. $0 \cdot 4$. B. 0.7 .

Habitat : Hedges, wooded banks, and walls, in the home and many of the southern counties of England, as well as in Northumberland, Yorkshire, Gloucestershire, Somersetshire, Monmouthshire, and Glamorganshire. In the appendix to Welsh and Whitelaw's 'History of Dublin,' it is stated to inhabit that neighbourhood; but this locality seems to be doubtful, as subsequent writers on Irish Conchology have not confirmed the correctness of such statement. It does not appear to range north of England; but it is found in France, Illyria, Italy, and Sicily.

Bouchard-Chantereaux mentions its breeding at so early an age that the mouth of its then tender shell is often broken at the edge in the course of propagation. The eggs are laid in a damp spot. It hibernates from November to February, and forms an epiphragm like a film of the finest blown glass.

Lister appears to have indicated $H$. Cantiana as a large variety of $H$.rufescens, or a distinct species, which he says is found in Kent. It is the $H$. Carthusiana of Draparnaud, but not the $H$. Cartusiana of Muiller; and Donovan described it under the name of $H$. pallida, which is much more appropriate than the one it now bears. The present species is very unlike any of those which $I$ have above described. 
The $H$. limbata of Draparnaud has been introduced into the list of our Mollusca on the authority of the late Mr. G. B. Sowerby, in consequence of several specimens having been once found on hedges near Hampstead. It is about half the size of the last species, of a reddishbrown colour, more conical and strongly striate, and it has a very conspicuous white band encircling the periphery. It inhabits the centre and South of France; and Terver has found it as far north as Rouen. Possibly it may be rediscovered in this country and have its claim to admission as a British species recognized.

\section{H. Cartusia'na*, Müller.}

H. Cartusiana, Müll. Verm. Hist. pt. ii. p. 15. H. Carthusiana, F. \& H. iv. p. 5l, pl. exvi. f. 5, 6 .

BoDy rather narrow and much rounded in front, yellow or saffron-colour, with a faint tinge of red; tubercles close-set and finely, butindistinctly, speckled with brown; neck marked with a short longitudinal black line which commences at the base of the upper tentacles: mantle covered with minute milkwhite specks: tentacles long; upper pair very slender; bulbs very small and nearly globular: foot somewhat rounded in front and narrowing behind.

SHELL subconic, depressed above, rather more globular below, somewhat solid and nearly opaque, not very glossy, yellowishwhite, with a tint of fawn-colour or light-brown, and generally marked with a white spiral band, which is placed a little above the periphery and does not extend much beyond the last half of the body whorl ; sculpture consisting of irregular striæ in the line of growth, which are stronger towards the suture and on the upper whorls, as well as of faint and indistinct spiral strix, which are only perceptible on the umbilical region and by the aid of a strong magnifying power; besides this striation, the surface of the lower or body whorl is indented by crowded and indistinct pit-marks, giving it a shagreened appearance : epidermis rather thin : whorls 6-7, compressed above and convex beneath, so as to make the

* From its having been first discovered near a Carthusian Monastery. 
periphery appear slightly keeled; the last occupying about half the shell : spire short, but somewhat pointed: suture rather deep : mouth of the same shape as in the last species, and similarlystrengthened inside by a broad white rib, which is visible on the outside and placed near the opening: outer lip thin and verylittle reflected, except towards the umbilicus, not much inflected above : umbilicus very small and narrow, having more the character of a perforation, and partly covered by the reflexion of the outer lip. L. 0.275 . B. 0.5 .

Var. rufilabris. Shell smaller, with the inside rib of a reddish-brown colour. H. rufilabris, Jeffr. in Linn. Trans. xvi. p. 509.

HABItAT: On grass and herbage in the hollows of downs on the Kentish and Sussex coasts; common. The variety is found at Lewes and Littlehampton. Gerstfeldt, as well as Middendorff, has recorded this as a Siberian species; but it does not apjear to have been noticed in the North of Europe. It inhabits the whole of France, the Rhine district, South Germany, Switzerland, Dalmatia, Italy and Greece. Miluller, who first described this species, says that he received French specimens from Geoffroy.

This mollusk is hardy, and during the heat of the day remains attached to stalks of grass and leaves of plants by means of a film, of the same nature as the epiphragm, which it secretes for that purpose. The edges of the mouth or outer lip are thus agglutinated. The animal has a singular habit of protruding the whole of its foot before any other part of the body when it issues from the shell to commence its walk. Its eggs are nearly as large as those of $H$. Cantiana, which has nearly three times the bulk of the present species. I have never observed any appearance of hairs on the shell; but perhaps none of my specimens are sufficiently young to show this character. 
Dr. Leach says that Mr. Gibbs first discovered this species to be an inhabitant of Britain, in 1814, and communicated it to Col. Montagu, who named it in his MS. "Helix Gibbsii." It is the H. Carthusianella of Draparnaud, who mistook Müller's species for $H$. Cantiana. It differs from the last-mentioned species in the shell being of a much less size, more solid and nearly opaque, and in the spire being more depressed and the umbilicus much smaller and more contracted.

All authors subsequent to Muiller (with the exception of Gmelin and Poiret) have written the specific name with an "h," i. e. Carthusiana. The name of the religious Order is said to have been derived from Cartuse or Chartreuse, a hamlet near the famous Monastery; and in Ducange's Glossary the monks are called "Cartusienses, a Cartusiensibus montibus." I therefore think the original spelling of Cartusiana ought to be retained.

\section{H. Rufes'cens* ${ }^{*}$, Pennant.}

H. rufescens, Penn. Brit. Zool. iv. p. 134, pl. lxxxv. f. 127 ; F. \& H. iv. p. 66, pl. exviii. f. 4, 7 .

BoDy yellowish, grey, or brown, of various degrees of intensity, with dark-brown stripes running along the neck and on to the tentacles, rather strongly tubercled: tentacles of the same colour as the rest of the body; upper pair long and slender, lower ones very short; foot of a lighter colour, somewhat narrow and slender, but short.

SHell subconic, compressed above and angularly rounded below, rather solid and nearly opaque, scarcely glossy, light ash-grey with generally a reddish-brown hue, sometimes transversely streaked with the last colour, and often marked with a white spiral band which encircles the last whorl, finely and closely but irregularly striate transversely : periphery obtusely keeled: epidermis not very thin : whorls 6-7, depressed above and convex beneath, the last occupying rather more than half

$$
\text { * Of a reddish colour. }
$$


the shell : spire short and blunt: suture rather deep: mouth obliquely semilunar, higher than broad, furnished inside with a broad white rib, which is distinctly visible outside and placed at a little distance from the opening : outer lip not very thin, slightly reflected, especially towards the umbilicus, sharply but not much inflected above: umbilicus narrow, but distinct, exposing all the interior of the spire. L. 0*3. B. $0 \cdot 5$.

Var. 1. albida. Shell white or colourless.

Var. 2. minor. Shell smaller: spire more raised.

HABiтAт: Hedges, gardens, shrubberies and suburban woods, among nettles, under stones and logs of wood, and in strawberry- and violet-beds, in most parts of England from Westmoreland southwards, as well as in South Wales and Ireland. The two varieties are not uncommon; and I have a scalariform distortion. It is one of our upper tertiary fossils. This species does not appear to be known in the North of Europe; but it is common in the North of France and at Heidelberg, and (according to Morelet) it inhabits Algeria. Mr. Lowe has enumerated it as a Madeiran species. If Férussac is right in referring to it the $H$. Altenana of Kickx, the present species is a native of other parts of Germany.

$H$. rufescens was accurately described by Lister, who said it was a favourite food of thrushes. Little heaps of empty shells, with the spire broken, may often be seen in our gardens; so that the safety of a strawberry crop may be partly ensured by encouraging these favourite songsters. This little snail never goes out in the daytime, unless after a shower of rain. According to BouchardChantereaux, it lays from 40 to 50 eggs, between the months of August and October, and the young are excluded at the end of from twenty to twenty-five days. The shells of these young ones, and even of such as have as many as four whorls, are really hispid. This was first 
noticed by Montagu; but as he evidently confounded $H$. hispida with the present species in this stage of growth, his statement that the young of $H$. rufescens was covered with hairs was discredited. Capt. Bruce Hutton has quite satisfied me on this point; and the hairs are very easily discerned with a lens of moderate power. They are very short and caducous; but the sockets of the hairs, or the impressions which are caused by their insertion into the epidermis, remain on the surface of full-grown specimens, and may be seen under a microscope. M. Drouet has lately confirmed this fact of the young shells being hispid. In some specimens from Clifden, Co. Galway, the shell is finely striate in a spiral direction.

Having had an opportunity of observing in their native habitats the H. circinnata, montana, and ccelata of Studer, which appear to belong to one and the same species, I am not inclined to consider them as varieties of $\mathrm{H}$. rufescens. Their spire is much more depressed and the suture deeper than in the present species. I have, however, no doubt that the $H$. glabella of Draparnaud, and probably also the $H$. clandestina of Hartmann, are the same as our shell. The $H$. rufescens of Gmelin and Grateloup are very different from this, the former being a river shell and the latter an exotic species.

\section{H. CoNCIn'NA*, Jeffreys.}

H. concinna, Jeffr. in Linn. Trans. xvi. p. 336. H. hispida, var. concinna, F. \& H. iv. p. 70, pl. cxviii. f. 2, 3.

BoDy lustrous, reddish-brown, minutely tubercled or granulated: tentacles of a lighter colour; upper pair larger and more slender than in the next species (H. hispida); lower ones very short: foot narrow, of a greyish colour on its sides and sole. 
SHeLl subconic, compressed on both sides, rather solid for its size, but semitransparent, somewhat glossy, light ash-grey, with occasionally faint streaks of reddish-brown, giving the shell a prettily mottled appearance; there is also frequently on the last whorl a white spiral band like that in H. rufescens; the surface also is transversely striate as in that species: peripheryobtusely and indistinctly keeled: epidermis rather thick, sparsely covered with short white hairs, which are easily rubbed off : whorls 6-7, compact, rather depressed above and slightly convex beneath, the last scarcely occupying one-third of the shell : spire short and blunt: suture deep : mouth obliquely semilunar, considerably higher than broad, furnished inside with a sharp white rib, which becomes thicker towards the umbilicus and is placed near the opening: outer lip not very thin in adult specimens and somewhat reflected: umbilicus rather broad, open and deep. L. 0.2. B. 0.4.

Var. 1. albida. Shell white.

Var. 2. minor. Shell smaller and also white: spire more depressed than usual.

Habitat : Under stones among nettles and the Arum maculatum, as well as at the roots of grass in moist places; generally distributed. Var. 1. With specimens of the usual colour. Var. 2. South of Ireland (Dillwyn); Bath (Clark); Dover (J. G. J.). The typical form occurs not unfrequently in our upper tertiary beds. It is not uncommon in many parts of the Continent, but it has been probably overlooked and considered a variety of $H$. hispida. The second variety I found at Calais, as well as at Dover.

Between two and three years after I had described this species in the 'Transactions' of the Linnean Society, I had some misgivings as to its being distinct from some of the numerous varieties of $H$. hispida, and I expressed this doubt in a Supplement to my Monograph; but as the species I had proposed is adopted by Continental naturalists, and there is a fair probability that this has quite as good a claim to specific distinction as many 
others, I have now ventured to restore it. The shell is never globose, like that of $H$. hispida, and it is more glossy; the umbilicus is considerably more open; and the hairs are more scattered and easily shed. Besides these differences in the shell, Mr. Smith has pointed out in the 'Zoologist' (1854, p. 4333) that the animal is darker-coloured, and the foot narrower and far less fleshy than in $H$. hispida, which has a thick yellowishwhite foot. From $H$.rufescens, with which the present species seems to connect $H$. hispida, it differs in the shell being much smaller, and in the whorls being more rounded and compact, though equally numerous. All these three species are found together. Sometimes the shell of $H$. concinna exhibits several formations in succession of the labial rib.

Beck has referred the $H$. umbrosa of Partsch to the variety minor of the present species; but, judging from Rossmässler's figure, the Austrian shell is much more globular. Neither can this be the $H$. depilata of $\mathrm{C}$. Pfeiffer, which he describes as subglobose and having a narrow umbilicus. He compares it with $H$. sericea, and not with $H$. hispida.

\section{H. HIs'PIDA* Linné.}

H. hispida, Linn. Syst. Nat. ed. xii. p. 1244 ; F. \& H. iv. p. 68, pl. exviii. f. 1, and (animal) pl. G. G. G. f. 1.

Bopy greyish-brown or slate-colour, mottled with black; tubercles speckled with milk-white: tentacles rather thick, of a somewhat darker colour than the rest of the body : foot rounded in front, marked with fine black specks, gradually narrowing behind to a rather blunt, convex and keeled tail.

SHeLt subconic, more convex above than below, rather thin and semitransparent, very little glossy; colour, markings, and sculpture the same as in $H$. concinna, but the colour of the 
present species is usually much darker and of a uniform yellowish-brown: periphery rounded, and seldom keeled or angulated: epidermis thick, closely covered with short recurved white hairs, which are persistent and not easily rubbed off: whorls 6-7, rounded and moderately convex on both sides, the last occupying about one-third of the shell: spire somewhat raised, but blunt: suture deep: mouth obliquely semilunar, rather broader than high, sometimes (especially in the adult) furnished with an interior rib, as in the last species: outer lip thin, not reflected, and very little inflected above : umbilicus small and narrow, but deep. L. $0 \cdot 185$. B. $0 \cdot 3$.

Var. 1. subrufa. Shell reddish-brown and more solid, with a strong labial rib.

Var. 2. albida. Shell thinner, white or colourless.

Var. 3. conica. Shell smaller: spire more raised.

Var. 4. nana. Shell much smaller, but with a strong labial rib : spire depressed. L. 0-1. $\quad$ B. 0.2.

Var. 5. subglobosa. Shell more globular and much thinner, horncolour or white: umbilicus very small. H. sericea, Alder, Suppl. Cat. Northumb. Moll. p. 4.

HABiтAT: Everywhere under stones and logs of wood, as well as among moss and herbage in woods, gardens, hedges and all sorts of rural spots. Var. 1. Not uncommon in dry situations. Var. 2. In osier-beds, as well as on the limestone at Kendal. Var. 3. At the roots of Rosa spinosissima on the sand-hills near Swansea. Var. 4. Freshwater, Isle of Wight (Metcalfe). Var. 5. Northumberland and Durham (Alder): Hammersmith; Plymouth; Brocklesby, Lincolnshire (J. G. J.). I have noticed this variety in Continental collections as $H$. sericea ; but it is certainly not Muiller's species of that name, although forming a passage to it. Distortions of the spire are sometimes met with. This species is common in our upper tertiary strata. It has a wide range, extending from Siberia to Sicily, from which latter place Philippi has recorded it under the name of 
$H$. sericea. Mr. Lowe has noticed it as inhabiting Madeira. In all probability it derives its origin from a preglacial epoch.

This little snail does some mischief in our gardens by nibbling before the dawn of day the leaves of some of the more succulent plants. The Rev. Revett Sheppard remarked that it was an amphibious species, being "frequently found some feet below the surface of water on stakes and piles, upon which it ascends and descends at pleasure ;" and he added that the eggs resemble those of birds and retain their form without shrinking. According to M. Bouchard-Chantereaux, the $H$. hispida lays, between the months of April and September, 40 eggs, which are globular, white and opaque; the fry are born at the end of the twentieth to the twenty-fifth day, and emerge from the egg with nearly one whorl of their shell formed; and more than half of this embryonic shell is then covered with minute red and straight hairs of a tolerably strong consistence. The summit of the spire is quite smooth and polished. The black spots on the mantle are sometimes visible through the semitransparent shell, even in dried specimens. The first-formed whorls are often whitish, in consequence of their not being occupied by the animal.

The $H$. plebeia of Draparnaud seems to be one of the numerous varieties of this species, judging from his description and a comparison of specimens thus named which I received from his friend M. D'Orbigny at Rochelle. According to Moquin-Tandon, the umbilicus of this variety is very narrow. Several other species have been carved out of this variable and ubiquitous form by Continental conchologists. 


\section{H. SERI'CEA*, Miuller.}

H. sericea, Mull. Verm. Hist. pt. ii. p. 62; F. \& H. iv. p. 71, pl. cxviii. f. 5,6 .

BoDr yellowish-grey, closely tubercled: mantle reddishbrown, with milk-white specks : tentacles rather long, of an iron-grey colour : foot rather broad and slightly raised at its sides.

Shell conical, subglobular, thin, but (by reason of its colour) not usually semitransparent, scarcely glossy, greyishwhite, with sometimes a few slight transverse streaks of reddish-brown, very finely but indistinctly striate in the line of growth: periphery rounded, and never keeled or angulated: epidermis rather thick, closely covered with rather long and very fine, white, downy hairs, which are persistent, and, when rubbed off, leave their sockets very perceptible, giving the surface in that case a finely granulated appearance: whorls 6 , extremely convex, the last occupying nearly one-half of the shell : spire considerably raised, but blunt : suture not very deep : mouth semilunar, much broader than high, sometimes (in adult specimens) furnished with a slight internal white rib, which is much stronger towards the umbilicus: outer lip thin, a little reflected, scarcely at all inflected above : umbilicus exceedingly small, but deep, having more the character of a perforation. L. 0.2. B. $0 \cdot 3$.

Var. cornea. Shell horncolour, very thin, glossy and semitransparent; the labial rib perceptible on the outside.

HaBitat : Mossy banks and hedges in various parts of the country, from the Moray Firth district to Cornwall, as well as at Tenby and Manorbeer in Pembrokeshire. I am not aware of any Irish locality. The variety was found by me at Lulworth. This species occurs in our upper tertiary beds. It inhabits the more temperate parts of Europe ; but according to Krynicki it is found in the Caucasus, and Gerstfeldt has recorded it as occurring in the province of Irkutsk in Siberia. It, however, seems to be local both here and abroad. It is 
difficult to ascertain its exact distribution, because of a variety of $H$. hispida being often mistaken for it.

It seems to affect elevated as well as moist situations. Puton found it on the Vosges mountains at a height of about 3772 English feet.

This shell is easily distinguishable from $H$. hispida by the globoseness of its form and greater height of the spire, by being much more thin and of a lighter colour, by the want of any keel or angularity, and by the thicker and downy covering of hair.

It is the $H$. hispida of Montagu, whose description of the shell is, as usual, most accurate. He says " it is so remarkably light and so covered with hairs, that when let fall upon a hard body it is scarce heard." Beck is of opinion that the $H$. sericea of Muiller is the young of $H$. incarnata; but the surface of immature shells of that species is not hairy, but scaly or like seal-skin. The present species appears to be the $H$. revelata of Férussac; and it is also the H. granulata of Alder, and my $H$. globularis.

\section{H. Revela'tA*, Michaud.}

H. revelata, Mich. Compl. p. 27, pl. xv. f. 6-8; F. \& H. iv. p. 70, pl. cxix. f. 1-3.

BoDy pale yellowish-grey, sometimes having a reddish or dusky hue, closely tubercled: mantle yellowish-brown, minutely speckled with brown and milk-white: tentacles rather thick and long, of a dirty-grey colour faintly tinged with violet or brown; the upper ones finely granulated, with globular bulbs : foot rounded in front, triangular and keeled behind; sides marked with transverse furrows.

Shell subglobular, somewhat compressed above and rounded below, very thin and semitransparent, rather glossy, yellowish-green, marked with irregular wrinkles in the line of

* Discovered. 
growth, which are stronger towards the suture and base of the shell, making the former appear slightly puckered; the surface is also very finely granulated: periphery rounded and prominent : epidermis rather thick, covered with short white hairs, which are easily rubbed off: whorls $4 \frac{1}{2}$, very convex and swollen, the last occupying two-thirds of the shell: spire very little raised and blunt : suture remarkably deep : mouth forming a segment of about three-fifths of a circle, contracted inside by the prominence of the periphery, not furnished with a rib: outer lip thin, a little reflected and considerably so near the umbilicus, sharply inflected above: umbilicus small, narrow and not deep. L. $0 \cdot 185$. B. $0 \cdot 285$.

Habitat : Downs on the sea-coast of our Southern counties and the Channel Isles, as well as (according to Mr. E. J. Lowe) in Nottinghamshire. The British localities are so few that I will particularize them, in the hope that the known range of this comparatively rare species may be extended by further observation. They are-Torquay (Hanley); Plymouth (Norman); Devon (Bellamy); Megavissey (Couch); Pendennis (Cocks, Benson); Land's End (Millet) and Scilly Isles (Barlee),-_all the last four being Cornish localities; Guernsey (Forbes and others); Sark (Lukis and J. G. J.); Stanton-on-the-Wolds, Notts, in woods during October (Lowe). It is found in the South-west of France and in Portugal, as well as (according to Michaud) in the alpine valleys of the former country.

In winter and dry weather it buries itself rather deep in the earth, and must be looked for by pulling up tufts of grass and large stones which are sunk in the ground, as well as by searching among the roots of shrubs and furze-bushes. It has a different kind of epiphragm for summer and winter. The former kind is filmy, transparent and iridescent, and it has a small round hole corresponding with the position of the respiratory orifice, thus enabling the animal to procure a continual supply 
of air from the atmosphere. The winter covering is thicker, opaque, and nearly white.

This is another instance of rather conspicuous landshells having been overlooked in places where observant naturalists had long searched and obtained much smaller species. Col. Montagu especially investigated the Testacea of our Southern counties; and these have always been a favourite haunt of our field or outdoor conchologists. The $H$. revelata was for the first time noticed as a British species by Dr. Gray in 1840, in consequence of the late Professor Edward Forbes having found it in Guernsey and presented specimens to our National Museum.

The $H$. revelata of Férussac, who first used this name, is (as I have before observed) the $H$. sericea of Muiller; but Michaud afterwards described and figured the present species under the same name, supposing it to be Férussac's species. It therefore appears unnecessary to adopt the name either of Ponentina or occidentalis, which were subsequently (in 1845) applied to this species by Morelet and Récluz. The $H$. revelata of BouchardChantereaux is our H. fusca, of which I had an opportunity of satisfying him soon after the publication of his excellent Memoir on the Land and Freshwater Mollusca of the Pas-de-Calais. Some shells which I noticed in the collection of M. D'Orbigny at Rochelle, in 1830, as having been received by him from Draparnaud, under the name of $H$. sericea (two of which he kindly presented to me and are now in my possession), belong to the present species, and occasioned the remark which I made in the Supplement to my paper in the 'Linnean Transactions' (vol. xvi. p. 507) as to the $H$. sericea of the last-named author. Michaud's work was not published until 1831. 


\section{H. FUs'CA*, Montagu.}

H. fusca, Mont. Test. Brit. p. 424, pl. xiii. f. 1; F. \& H. iv. p. 77, pl. cxix. f. 4, 5, and (animal) pl. G. G. G. f. 4.

Bopy long, yellowish-white or grey, with two longitudinal streaks of brown leading to the tentacles, irregularly but rather finely tubercled: mantle covered with faint and minute specks of brown and milk-white: tentacles long, bluish-grey with a slight tinge of violet; bulbs short: foot very long and narrow, pointed behind, with a bluish tint on the sides near the sole.

SHeLl subconical, slightly compressed above and below, extremely thin and transparent, glossy, yellowish-brown, marked transversely with strong but irregular wrinkles; the surface of young shells is also very finely striate in the same direction like hair-cloth : periphery rounded, but encircled by a slight keel : epidermis tolerably thick: whorls $5 \frac{1}{2}$, convex, the last occupying rather more than one-half of the shell : spire somewhat raised, but not pointed: suture distinct, though not deep : mouth oblique, semilunar, considerably broader than high, not furnished with a rib: outer lip very thin, reflected over the umbilicus and sharply inflected above : umbilicus extremely small and narrow, reduced to a little more than a perforation. L. $0 \cdot 225$. B. $0 \cdot 35$.

HaвiтAт: Woods, on young trees, and among nettles and dog-mercury, in many parts of these isles from Aberdeenshire to Devon, but not everywhere. It is one of our upper tertiary fossils. Montagu mentions, in his Supplement (p. 148), having received through Mr. Boys from Scotland a shell which would seem from the description to be a white variety of this species; but the source is rather suspicious, as Mr. Boys was the means of introducing many exotic shells into our Fauna. The finest specimens in my collection were kindly sent to me by the late Mr. Thompson of Belfast, from that neighbourhood. H. fusca occurs in the North and South-

* Dark-brown. 
west of France, but it does not appear to have been noticed elsewhere on the Continent.

M. Bouchard-Chantereaux, who was the first to discover this species in France, but who mistook it for $H$. revelata, says that it inhabits young alders (the foliage of which constitutes its food) in the woods near Boulogne, and protects itself from the heat of the day by clinging to the underside of the leaves, falling with them in September and October; and that it then occupies itself in the work of reproduction, for which the dead leaves offer a convenient'place of retreat. Its eggs number from 40 to 50, and are globular and of an opaline lustre. The young are excluded about the twentieth day after the eggs are laid, and become adult at the end of from ten to twelve months. These pretty little snails are tolerably active, and appear to be nearly always moving their horns about. They secrete a good deal of slime. According to Moquin-Tandon they are gregarious and sociable, and have been observed each mutually polishing its neighbour's shell with its foot.

The shell differs from that of any other kind of British Helix in its peculiar sculpture, which resembles that of a Continental species, $H$. incarnata. In shape and the narrowness of its umbilicus it somewhat resembles $H$. sericea; but in the present species the spire is more depressed, the last or body whorl is proportionally larger than the others, and the epidermis is never hairy like that of the last-named species, or $H$. revelata. The texture of this shell is also far more fragile than in either of those species, and its colour is uniformly of a light yellowish-brown, instead of whitish or dark greenish-brown.

This is not the $H$. fusca of Poiret (whose work preceded that of Montagu by two years); but as that shell is only a variety of $H$. nemoralis and allied to the one 
called hybrida, there does not appear to be any greater reason for changing Montagu's name than there was in the similar case of $H$. revelata.

D. Shell subconical or depressed, and banded: outer lip strengthened by an internal rib : umbilicus large or distinct.

\section{H. Pisa'NA*, Müller.}

H. Pisana, Müll. Verm. Hist. pt. ii. p. 60; F. \& H. iv. p. 56, pl. cxv. f. 7, 8.

BoDY yellowish-grey with a tinge of red in front, rather strongly tubercled: mantle often dark-brown, tinged with yellow and marked with very small and numerous milk-white specks : tentacles rather broad at their base, but slender, finely shagreened; the so-called optic nerves continue along the neck, so as to form two dark lines; bulbs very globular and of a reddish colour, indistinctly speckled with brown: foot long, somewhat truncate in front, gradually narrowing and pointed behind, but not keeled.

SHELL subglobular, slightly compressed above, convex below, rather solid and opaque, moderately glossy, yellowishwhite, beautifully marked with brown spiral bands, which vary greatly in number (there being sometimes as many as fifteen or sixteen on the last whorl, but usually only one underneath), and more or less marked tranversely with short oblique streaks of the same colour, causing the upper part of the shell to appear speckled; sculpture consisting of irregular striæ in the line of growth and of fine, close, spiral striæ, which intersect the transverse striæ on the upper whorls and give to the surface a delicately reticulated appearance : periphery rounded: epidermis extremely thin and only perceptible under a microscope: whorls $5 \frac{1}{2}$, very convex, but compressed towards the suture, the last occupying considerably more than one-half of the shell : spire somewhat raised, but having a blunt point, which is of a purplish-brown colour : suture rather slight: mouth forming a segment of two-thirds of a circle ; interior sometimes pink or blush-colour and furnished with a slight rib, which is either pale yellowish, white, or pink : outer lip sharp but thickened, reflected in the direction of the umbilicus and especially over it, rather

* First found at Pisa. 
abruptly inflected above : umbilicus extremely small, narrow and oblique. L. 0.5. B. 0.75.

Var. alba. Shell pale yellowish-white or snow-white, with or without translucent markings. H. Pisana, var. alba, Shuttleworth, Moll. Cors. p. 15.

Habitat : On a hill and sand-banks, as well as in gardens facing the sea, at Tenby in Pembrokeshire, to the south and south-west of that charming wateringplace (Montagu and others); Manorbeer in the same county (J. G. J.); St. Ives and Whitsand Bay, Cornwall (Montagu); Jersey (Lukis); and also (according to Dr. Turton) Balbriggan strand in Dublin Bay. Although local, it is most abundant at Tenby, and is said to be equally so in Jersey and near Dublin. Its foreign distribution seems also to be limited. The centre and South of France, Spain, Portugal, Italy, Judæa, Dalmatia, Illyria, Algeria, Madeira, the Canary Isles, and Azores are the only extra-British localities that I have seen recorded.

The limited range of this species in Great Britain is unaccountable. I have endeavoured twice, with an interval of nearly three years between each attempt, to colonize this beautifully marked and peculiar shell on the sand-hills near Swansea, by bringing a basketful of live specimens from Tenby, a distance of only about thirty miles ; and they were spread over different parts of the Burrows, in order to ensure a better chance of success. But, although they seemed at first to thrive tolerably well in the new locality, they did not multiply, and the birds soon ate up the immigrants. These experiments were made at different times of the year; and the soil and herbage on the Swansea sand-hills were the same as at Tenby, the only difference being the aspect, which at Swansea was more easterly. The colouring of the man- 
tle corresponds with the markings of the shell. The pink hue of the mouth appears to be deeper and brighter in specimens which are exposed to the sun. Draparnand says that this colour is more preceptible in the shells of those individuals which have been kept a long time without food, or after their death. These snails adhere in the daytime to the stalks and leaves of grass, as well as to shrubs, by means of a rather thick calcareous secretion, which lines the outer lip of the mouth. My late friend Mr. Barlee informed me that at St. Ives he procured live specimens by digging some inches in the sand-hills, at the roots of the Carex arenaria, where the snails had buried themselves, the weather being then very hot and the herbage not affording much shelter from the sun's rays. Both in summer and winter they close the mouths of their shells with an epiphragm, which in the former case is filmy, very transparent and iridescent, and in the latter opaque and like thin paper. Mr. Millet says that they feed on the Eryngium maritimum. According to St. Simon they are omnivorous. One of them greedily devoured a globule of slime which he had taken from a slug. In Jersey the thistles are covered with them. It seems only to be found on the coast-line, and never inland, in this country.

This and the three following species constitute a subsection, of which Risso made the genus Theba, from Leach's MS.; but $H$. Cantiana and other different forms were associated with it both by Risso and Leach.

The present species was first described by Petiver, and received from him the name of Pisana, but accompanied by other characters which preclude his authority being recognized for the name under the rules of the binomial system. It is the $H$. zonaria of Pennant, H. rhodostoma of Draparnaud, and $H$. cingenda of Montagu. 


\section{H. virgA'TA*, Da Costa.}

H. virgata, Da Costa, Brit. Conch. p. 79, pl. iv. f. 7 ; F. \&. H. iv. p. 57, pl. exvii. f. 10.

BoDy yellowish-white or ash-grey, coarsely tubercled: mantle often dark-violet, indistinctly speckled with milk-white and brown: tentacles rather thick, cylindrico-conic, greyish with a dusky tinge; bulbs globular and reddish, speckled with brown at their base: foot broad and rounded in front, gradually narrowing behind and ending in a blunt but not keeled tail.

SHeLl conical, with a broad and convex base, rather solid and opaque, moderately glossy, white or cream-colour, with a single broad purplish-brown or chestnut band immediately above the periphery and two or three other bands (sometimes as many as six or seven) below it; the colour, however, is very variable, being occasionally plain yellowish, white, or dark brown with white bands, or the dark bands are streaked or interrupted so as to make the surface appear spotted; sculpture consisting only of striæ in the line of growth, which are closer on the upper whorls: periphery rounded, except in young shells, which have a short but rather sharp keel : epidermis scarcely perceptible : whorls 6 , convex but slightly compressed towards the suture, the last occupying more than one-half of the shell: spire raised, purplish-brown at the point: suture moderately deep: mouth forming a segment of three-fourths of a circle, inside purplish-brown with a strong rib of the same colour, or white in the albino variety: outer lip sharp, reflected towards and over the umbilicus, rather abruptly inflected above: umbilicus narrow, but deep, and exposing nearly all the interior of the spire. L. $0 \cdot 4$. B. $0 \cdot 55$.

Var. 1. subaperta. Shell of a whiter hue: spire more depressed : umbilicus wider.

Var. 2. subglobosa. Shell smaller, with a double band above the periphery, last whorl larger in proportion to the others: umbilicus wider.

Var. 3. submaritima, Des Moulins. Shell much smaller and more deeply coloured, often with a violet tinge: spire raised. L. $0 \cdot 25$. B. $0 \cdot 325$.

Var. 4. carinata. Shell yellowish-white, compressed above: periphery strongly keeled.

Habitat : Sandy downs and heaths in most parts of * Banded. 
England, Wales, and Ireland, from Yorkshire to the Channel Isles. It is generally found on the sea-coast, where the conditions are probably more favourable to its existence; but it also inhabits inland districts, such as Oxfordshire, Wilts, and Bath, and it is by no means confined to calcareous soils. Var. 1. Bath (Clark). This variety is allied to the $H$. neglecta of Draparnaud. Var. 2. Bantry Bay and St. Mawes near Falmouth (J.G.J.). Var.3. Braunton burrows in North Devon, and Swansea burrows (J. G. J.); Isle of Wight (Pickering). This resembles the $H$. lineata (H.maritima, Draparnaud). Var. 4. Wingfrith near Wareham, about five miles from the sea (Daniel). This is a remarkable variety, and resembles the $H$. submaritima of Rossmässler from Oran. Mr. Norman found at Clevedon a specimen of the ordinary form which has the spire reversed. The foreign distribution of this species appears to be confined to France, Portugal,' Italy, Greece, and the sea-board of North Africa. In the North of Europe, Germany, and Switzerland its place is taken by the $H$. unifasciata of Poiret (H. candidula, Studer); but both that and the present species are found together in the North of France.

This is one of the species which has given rise to the popular notion that it sometimes rains snails. $H$. virgata is extremely abundant and gregarious ; and in suitable weather myriads of them may be seen clinging to the stalks of grass and leaves of shrubs. When the season is very dry, however, they ensconce themselves among the herbage; but immediately on a shower of rain falling they emerge suddenly from their lurkingplaces and appear before the astonished rustic like Roderick Dhu's warriors at the sound of their chieftain's horn. The idea of their descending in showers may also have originated in a whirlwind having caught up a num- 
ber of them by sweeping along a grassy plain and dropping its contents in a limited area. Draparnaud mentions this snail as eatable; but it must be small game for those who like that kind of food. It is, however, supposed to impart a nice flavour to our South-country mutton. Borlase, in his 'Natural History of Cornwall' (1758), says:-

"The sweetest mutton is reckoned to be that of the smallest sheep, which usually feed on the commons where the sands are scarce covered with the green-sod, and the grass exceedingly short; such are the towens or sandhillocks in Piran-sand, Gwythian, Philne, and SenanGreen near the Lands-End, and elsewhere in like situations. From these sands come forth snails of the turbinated kind, but of different species, and all sizes from the adult to the smallest just from the egg; these spread themselves over the plains early in the morning, and whilst they are in quest of their own food among the dews, yield a most fatning nourishment to the sheep."

In Montagu's time also it appears to have been the prevailing opinion in the South of Devon that the $H$. virgata contributed not a little to fattening sheep; and in a recent number of the 'Field' newspaper a correspondent says that this kind of food is supposed to give Dartmoor mutton its admitted superiority. Bouchard-Chantereaux remarks that $H$. virgata does not seem to mind the cold, and never hibernates; that during frost, or when the grass is covered with snow, it covers the mouth of its shell with the same kind of epiphragm that it makes in summer as a protection against the rays of the sun; and that when a thaw takes place it is again active and in search of food. It usually lays its eggs from September to November, but sometimes as late as January. He also observed that when the she 
was of a light colour the animal was black, and that the clear transparent band which often accompanies the white variety appeared to be black when the animal occupied the shell. The largest specimens of $H$. virgata that I have ever seen were collected by Mr. William Thompson near Weymouth; they were four-fifths of an inch in breadth. Sometimes the mouth has two ribs, which are placed at a little distance from each other. Lady Elizabeth Finch presented me with a very prettilymarked variety from Sandgate.

This species differs from $H$. Pisana in its much smaller size, more prominent spire, having only one band on the body whorl, and in the larger and deep umbilicus. It is very variable in the shape and markings of the shell. Moquin-Tandon has particularized seventeen varieties, besides eleven more of $H$. lineata, which very closely approaches the present species. Several of these varieties have been described by Continental authors as distinct species. The typical form is the H. variabilis of Draparnaud; but the name given by Da Costa was long anterior.

\section{H. CAPERA'TA*, Montagu.}

H. caperata, Mont. Test. Brit. p. 430, pl. 11. f. 11 ; F. \& H. iv. p. 59, pl. cxvii. f. 7 .

BoDy pale or yellowish-grey, streaked with brown; tubercles rather large and close-set, with fine black points: mantle greyish-brown, minutely speckled with black and milkwhite: tentacles long and rather slender, having a dusky hue; bulbs somewhat globular: foot nearly truncate in front, ending in a short and blunt tail, which is, as well as the sides of the foot, of a lighter colour.

SHell subconical, compressed both above and below, solid and opaque, not glossy, greyish-white, with usually a

$$
\text { * Wrinkled. }
$$


rather narrow yellowish-brown or chestnut band immediately above the periphery, and from two to seven smaller bands of the same colour below it; the colour is equally variable in this species as in $H$. virgata, being also occasionally plain yellowish-white, or dark brown with a single white band, or the dark bands are streaked or interrupted, so as to make the surface appear mottled or spotted; sculpture consisting only of striæ in the line of growth, which are exceedingly strong and close together, resembling ribs: periphery obtusely keeled : epidermis very slight: whorls 6, compressed towards the periphery, but rather convex below ; the last occupying about two-fifths of the shell; top whorls minutely granulated: spire slightly raised, often chestnut-brown at the summit: suture rather deep: mouth shaped as in $H$. virgata but more oblique, inside furnished with a strong white rib which is sometimes double: outer lip sharp, slightly reflected towards (and considerably so over) the umbilicus, somewhat inflected above: umbilicus moderately open and exposing all the inner spire. L. $0 \cdot 225$. B. $0 \cdot 375$.

Var. 1. major. Shell larger. L. $0 \cdot 25$. B. $0 \cdot 5$.

Var. 2. ornata, Picard. Shell smaller, with broader and darker bands. L. $0 \cdot 15$. B. $0 \cdot 3$.

Var. 3. subscalaris. Shell conical : whorls more convex.

Var. 4. Gigaxii. Shell rather smaller: spire more depressed: umbilicus consequently larger. H. Gigaxii, Charpentier, MS. in sched. and mus. Cuming!

Habitat : Under stones and on the stalks of grass and shrubs in dry and sandy soils in most parts of Great Britain, both inland and maritime, from the Moray Firth district to the Channel Isles. Var. 1. Norwich (Bridgman); Surrey (Choules). Var. 2. Sandy coasts of North and South Wales, South Devon, and Cork (J. G. J.). Var. 3. Cork (Humphreys); Swansea (J. G. J.). Var. 4. Sandwich and Falmouth. This species has not been noticed as an upper tertiary fossil, or as inhabiting the North of Europe; but it is widely diffused over a great part of the Continent and ranges 
through Germany, France, Portugal, Spain, and Italy to Algeria, Greece, and Palestine.

This is a sluggish mollusk and never leaves its retreat or place of attachment, except after rain. It is often found in gardens and corn-fields near the sea. BouchardChantereaux says that between the months of August and October it lays from 35 to $\mathbf{4 0} \mathrm{eggs}$, which are quite white and opaque, and that the young are excluded at the end of from fifteen to twenty days, becoming adult at the end of the next year. Brard hazarded a singular conjecture, that the tinge of violet-brown which is observable in the shells of this and a few other allied species, and which fades away soon after death, may be owing to an exudation or secretion by the animal of oxide of manganese.

H. caperata differs from $H$. virgata in its much smaller size, its depressed spire and larger umbilicus, and especially in the numerous rib-like striæ which hoop round each whorl. This appears to be the $H$. striatula of Muiller, but not that of Linné. It is also in all probability the $H$. fasciolata and $H$. intersecta of Poiret, and certainly the last-named species of Michaud; but Poiret's descriptions are much too brief and obscure for the purpose of identification. Draparnaud also described and figured the present species under the name of $H$. striata ; but although the work which contains this description and figure (the 'Tableau') bears date and was published before that of Montagu, Draparnaud's name cannot be adopted, because Müller had previously described another species of Helix under the same name. The present species is allied to $H$. conspurcata of Draparnaud, which, however, has a hispid shell and belongs to the last section of Helix.

A specimen of the H. terrestris of Pennant (H. elegans, 
Drap.) is in Dr. Turton's collection of British shells, marked "Cornwall" (the birthplace of many spurious or exotic shells); but although it has not at present any well-founded claim to British parentage, it is remarkable that this characteristic species, which had been so long considered as peculiar to the shores of the Mediterranean, has been lately found by M. l'Abbé Maillard at Beauvais in the North of France; and I have seen the specimens and been satisfied as to the correctness of this discovery.

\section{H. ERICETo'RUM* Müller.}

H. ericetorum, Müll. Verm. Hist. pt. ii. p. 33 ; F. \& H. iv. p. 61, pl. exvii. f. 4.

BoDy greyish-white or yellowish, with sometimes a tinge of reddish-brown; tubercles very close-set ; mantle marked with rather small and irregular, but distinct, milk-white specks: tentacles rather long and thick, distinctly granulated, of a yellowish-grey colour; bulbs globular: foot slightly angulated in front, its sides having a narrow whitish border, and the tail tapering to a blunt point.

SHeLL nearly circular, much compressed above, but not quite so much below, rather thin, but nearly opaque, glossy, whitish or cream-colour, with usually a rather broad chestnut band a littleabove the periphery, and from two to six narrow bands of the same colour below it, but all these bands (or some of them) are often interrupted or altogether wanting ; sculpture consisting of faint striæ in the line of growth, and often of irregular pit-marks or indentations, which are thickly scattered over the surface: periphery round, and not in the least keeled or angular: epidermis very thin: whorls 6, cylindrical, the lastoccupyingabout three-fifths of theshell: spire very slightly raised, chestnut-brown at the summit : suture deep : mouth nearly round, forming a segment of about four-fifths of a circle, somewhat oblique, in consequence of the greater prominence of the upper lip, and occasionally strengthened by a slight internal rib : outer lip rather thick, slightly reflected and especially towards the columella, very abruptly inflected

* Frequenting heaths. 
above: umbilicus extremely large and open, exposing a considerable part of the penultimate and preceding whorls and all the interior of the spire. L. 0.25. B. 0.675.

Var. 1. alba, Charpentier. Shell milk-white.

Var. 2. minor. Shell smaller. L. 0.2. B. 0.5.

Var. 3. instabilis. Shell smaller, of a darker colour, and sometimes streaked or spotted: spire more raised: umbilicus narrower. $H$. instabilis, (Ziegler) var. $\beta, \mathrm{L}$. Pfeiffer, Mon. Hel. i. p. 165 .

Var. 4. sinistrorsa. Shell having the spire reversed.

Haвiтat: Dry heaths, downs, and sand-hills, on thistles and other plants, in various parts of Great Britain, but apparently not ranging further north than the Hebrides. Var. 1 is also not uncommon, and is (according to Gray) the $H$. obliterata of Hartmann, besides having five other names. Var. 2. Kendal (J. G. J.). Var. 3. Iona (Lowe); Mull (Bedford); Connemara (J. G. J.). Var. 4. Bridlington (Strickland). The shell is also inclined to be occasionally scalariform. This species and several of its varieties are widely diffused over the Continent from Cassel to Sicily; but it does not seem to inhabit the extreme North of Europe, unless it is the same species as that which Nilsson has described under the name of $H$. ericetorum. The Swedish species has been considered by many conchologists to be distinct, and it has been named $H$. Nilssoniana by Beck, Malm, and other writers. With the above exception, all the species comprised in the present section appear to belong to what may be termed a South-European type.

This is a shy and inactive mollusk, withdrawing itself into the shell on the slightest touch. The specific name now borne by this very elegant shell was first given to it by Lister, who observed that continued rains kill a great number of them-a fact which I can corroborate. It 
commences egg-laying in August, and retires into winterquarters in November, when it shuts itself up by means of its epiphragm and remains concealed at the roots of grass or under the shelter of a stone until spring.

The flat shape of this shell, its exceedingly large umbilicus, and nearly circular mouth will easily serve to distinguish it from any other of our banded Helices.

Linné was supposed by some to have given the name of Itala to this species; but L. Pfeiffer considers it a synonym of $H$. cespitum. The Linnean description, however, is "convexa," and the size that of a hazel-nutboth of which characters are more appropriate to $H$. virgata than to the present species. The original types in the collection of the illustrious Swede appear to have been so disarranged and confused by the late possessor (Sir James Smith) and others, that I fear they are now of little value as a means of identifying any of the species described either in the 'Fauna Suecica' or the 'Systema Naturæ,' except in a very few instances where the handwriting of Linné has been preserved on or with the specimens; and this unfortunately is very seldom the case.

E. Shell depressed : outer lip usually thin and destitute of a rib : umbilicus very large.

\section{H. RоTUNDA'TA*, Müller.}

H. rotundata, Müll. Verm. Hist. pt. ii. p. 29; F. \& H. iv. p. 80, pl. cxix. f. 6, 7, and (animal) pl. G. G. G. f. 2.

Body small in comparison with the shell and very slender, rounded in front and ending in a blunt point, slate-colour or light-grey with a faint tinge of blue, very finely speckled with black on the front and sides: tubercles rather large, flat, round and thick, but notvery distinct: mantle reddish yellow, marked with very close and distinct milk-white dots: tentacles

* Rounded. 
dark-grey with black specks; upper pair rather close together and nearly cylindrical; bulbs short, thick, and subglobular: foot rather narrow, rounded in front, thickened at its sides, and ending in a very slender but blunt tail.

SHell nearly circular, more compressed below than above, rather thin but nearly opaque, moderately glossy and slightly iridescent, yellowish-brown or horncolour, and marked transversely with equidistant reddish-brown streaks or blotches; sculpture consisting of numerous curved transverse ribs, which are equally strong on both sides and sometimes anastomose, as well as of minute intermediate striæ, and of a slight granulation on the first whorl, which is destitute of ribs: periphery bluntly keeled: epidermis not very thin: whorls 6-7, subcylindrical, convex below, the last occupying about one-third of the shell and the rest gradually diminishing in size : spire slightly raised; summit glossy and semitransparent: suture very deep: mouth obliquely quadrangular, strengthened in adult specimens by a narrow, but strong, white internal rib : outer lip thickened in the adult, but usually sharp and thin, very slightly reflected, and not much inflected above: umbilicus extremely large, open, and deep, exposing a considerable part of all the whorls, as well as the whole of the internal spire. L. $0 \cdot 1$. B. $0 \cdot 275$.

Var. 1. minor. Shell smaller.

Var. 2. pyramidalis. Shell subconical : spire more raised.

Var. 3. Turtoni. Shell greatly depressed above and below: spire nearly flat. H. Turtoni, Fleming, Brit. Anim. p. 269.

Var. 4. alba, Moquin-Tandon. Shell pale yellowish-white or with a greenish tinge.

HaвiтAт : Under stones, logs of wood, and bark of old trees, as well as in decayed wood and moss, and among dead leaves, everywhere from the most northern extremity of Great Britain to the Channel Isles. Var. 1 appears to be an alpine form. I have found it not only in Zetland, and on the Jura and Swiss Alps, but also in Guernsey. This form occurs also in our upper tertiary beds, probably indicating their northern origin. Var. 2. Swansea and other places (J. G. J.). Var. 3. Dublin 
(Turton); Bath (Clark); Bristol, and Dunboy in Bantry Bay (J. G. J.). This variety is the $H$. rotundata of Turton's 'Conchological Dictionary.' Var. 4. Bucks, Surrey, Kent, Essex, Oxon, Gloucester, Somerset, Salop, York, Northumberland, Aberdeen, Glamorgan, and most probably other counties; but it is rare. This common species ranges from Russia and Finland to Sicily and the Azores.

This pretty little shell reminds one of a Solarium or of the Trochus perspectivus. The animal is exceedingly shy; and Muiller relates that he spent two hours in watching one of them, before it made its appearance, although he took every precaution not to alarm the little creature. It appears not to be prolific. According to Bouchard-Chantereaux, it only lays from 20 to 30 eggs in the course of the breeding-season, viz. from May to September. It secretes a very thin and transparent epiphragm.

It is the $H$. radiata of Da Costa and Montagu. Some authors have erroneously placed this and the two following species in the genus Zonites; but the texture and aspect of the shells, as well as the arrangement of the teeth, show that they belong to the present genus, and not to Zonites.

\section{H. RUPES'TRIS *, Studer.}

H. mupestris, Draparnaud, Tabl. Moll. p. 71. H. umbilicata, F. \& H. iv. p. 81, pl. exxi. f. 7,8 .

BODY dark slate-colour, with sometimes a reddish tinge, covered with minute depressed tubercles: mantle dusky brown, indistinctly speckled with black : tentacles diverging, dark-grey; upper pair thick and almost cylindrical, with nearly oval bulbs, which are about a fourth of the size of those tentacles ; lower pair almost rudimentary and nearly black, not more than a twelfth of the size of the other pair : foot

* Inhabiting rocks. 
rounded in front, obtusely pointed behind; sides marked with minute and numerous black specks, which are arranged in squares and form rather large spots.

SHell subconical, more compressed below than above, rather solid but semitransparent, slightly glossy, dark-brown or horncolour, marked transversely with close-setcurved striæ, which are equally strong on both sides : periphery rounded, but obtusely keeled in young specimens: epidermis rather thin: whorls 5, cylindrical, compressed on the upper part and towards the periphery, rather convex underneath, first whorl slightly granulated: spire somewhat raised; summit rather glossy and transparent: suture remarkably deep: mouth horseshoe-shaped, but compressed above, destitute of an internal rib : outer lip thin, very slightly reflected in adult specimens, considerably inflected above and below : umbilicus large, open, and deep, exposing part of the whorls, as well as all the interior of the spire. L. $0 \cdot 075$. B. $0 \cdot 115$.

Var. viridescenti-alba. Shell greenish-white.

Habitat: On rocks, walls, and ruins of castles, as well as under stones on hill-sides, throughout the greater part of this country. Fleming noticed it in his 'British Animals' as a Scotch species, and Leach states that he had observed it near the summit of mountains in Arran, N. B. ; its English range extends from Westmoreland to South Devon. It is also not uncommon in South Wales and Ireland. The variety has been found by Mr. Norman at Clevedon in Somersetshire, and by Mr. Webster at Clifton, near Bristol. The spire is often more or less raised, and not unfrequently distorted. This species does not appear to be a pliocene fossil or to inhabit the North of Europe ; but Dr. Zittel has taken it near Baden. It is diffused throughout Central and Southern Europe, as far as Algeria, Sicily, and Greece, and even (according to Lowe) ranges to Madeira.

Montagu observed, with respect to this species, that it always affects lofty and exposed situations, braving equally the scorching beams of the sun in summer and 
the frigid winds of winter, without attempting to descend. It forms, however, a thin membranous epiphragm for its protection against such extremes of heat and cold, and shelters itself in clefts of rocks and crevices of walls. This little snail, in crawling, usually carries its shell quite upright, and not inclined to one side like most of its congeners. The upper whorls of the shell are generally bleached by exposure of that part to the sun. The animal is ovoviviparous, as well as that of Pupa umbilicata; and in specimens which I collected at Kendal in the month of August, the fry in the interior of the shell had a whorl and a half completely formed. Moquin-Tandon counted in the matrix of several specimens which he had received from Marseilles, from three to seven young ones in each. It mostly frequents calcareous strata; but in Germany it has been found on felspathic rocks. It sometimes occurs in unusual places. A specimen in my collection was taken by the trawl at a depth of between twenty and thirty fathoms several miles seaward of Plymouth, having been probably washed down by a river or freshwater stream and transported a long way before it sunk to the bottom.

This is the H. umbilicata of Montagu; but as his excellent work was published two years after Draparnaud's 'Tableau des Mollusques terrestres et fluviatiles de la France,' my patriotic inclinations, however strong, will not justify me in preferring the name given by my countryman to the more ancient one of the French conchologist. The above-mentioned work of Draparnaud does not appear to have been known to Dr. Gray when he published an improved edition of Dr. Turton's 'Manual of British Land and Freshwater Shells.' The work in question was published in 1801, Montagu's 'Testacea Britannica' in 1803, and Draparnaud's 'Histoire natu- 
relle des Mollusques terrestres et fluviatiles de la France' was edited by his widow and appeared in 1805 . Studer first gave this species the name of "rupestris" in Coxe's 'Travels through Switzerland' (1789), but did not describe it.

\section{H. PYGM $\mathbb{A}^{\prime} \mathrm{A}^{*}$, Draparnaud.}

H. pygmoza, Drap. Tabl. p. 93, and Hist. p. 114, pl. viii. f. 8-10;

F. \& H. iv. p. 83, pl. exxi. f. 9, 10.

BoDy greyish-brown or slate-colour, minutely speckled with black; tubercles round and much depressed: mantle brown, with a slight tinge of red: tentacles rather close together, nearly cylindrical, abruptly thickened at their base ; bulbs indistinct: foot narrow and ending in a thick and keeled tail.

ShELL nearly circular, depressed above and below, thin, semitransparent, rather glossy and having a silky lustre, light-brown or tawny, marked transversely with extremely fine and close-set curved striæ and spirally (especially round the umbilicus) with a few delicate lines, which are only perceptible with a high magnifier : periphery rounded and not keeled: epidermis rather thin: whorls 4, convex and cylindrical, gradually increasing in size : spire not much raised; summit glossy and transparent: suture deep : mouth shaped as in $H$. rupestris and not margined : outer lip thin, somewhat inflected on both sides: umbilicus moderately large, but deep and fully exposing the interior of the spire, as well as part of the penultimate whorl. L. 0003. B. $0 \cdot 06$.

Habitat: Woods and moist places under stones and among dead leaves, as well as at the roots of grass and rushes, from Oban to Guernsey. It is widely diffused, although difficult to find on account of its minute size. Saint-Simon seems to have been successful in taking it several times and in considerable numbers by sweeping the wet grass and herbage after rain with an entomologists' gauze net; and Dr. Turton told me that he pro- 
cured many specimens by collecting a bagful of dead and rather moist leaves and afterwards spreading them on paper to dry, when the refuse yielded a good harvest. This species has a wide range on the European continent and has been met with in every country between Siberia and Sicily, and is said also to inhabit the Azores.

Moquin-Tandon says that this tiny snail is extremely timid and irritable, avoiding the garish light of day and shutting itself up in its shell at the slightest touch, and that when it is about to move it protrudes from the shell the tail of its foot before any other part of the body. Like the last species, it carries its shell erect when crawling. It forms an excessively thin and delicate epiphragm.

This beautiful little testaceous gem differs from $H$. rupestris in its much smaller size, finer texture and sculpture, lighter colour, fewer whorls, more depressed spire, slighter suture, and more open umbilicus. Leach and Fleming, however, regarded it as the young of the last species, and M. D'Orbigny of Rochelle made the same mistake. It was first noticed as a British shell by Dr. Gray in the 'Medical Repository' for 1821.

It is the H. minuta of Studer in Coxe's 'Travels,' and H. Kirbii of Sheppard.

F. Shell depressed : outer lip thickened and reflected, sometimes forming a complete peristome.

\section{H. PULChEL'LA*, Müller.}

H. pulchella, Müll. Verm. Hist. pt. ii. p. 30 ; F. \& H. iv. p. 78, pl. cxix. f. 9, 10.

BoDy gelatinous, milk-white with a faint tinge of grey or yellow, nearly transparent, very slightly tubercled: mantle * Pretty. 
thick, yellowish, minutely speckled with white: tentacles (upper pair) hyaline, thick, nearly cylindrical, with very thick bulbs, which are half the length of those tentacles and nearly round ; lower pair extremely small : foot short, broad, strongly truncate and slightly bilobed in front, having a faint yellowish border on the sides, and ending in a rather short and somewhat rounded tail.

Shell depressed but slightly convex above and below, rather solid although transparent and glossy, light-grey or white, striate transversely by numerous and very fine, but somewhatirregular and faint, curved lines, which are stronger in the umbilical region, and occasionally marked with a few indistinct spiral lines on the lower part: periphery rounded in the adult, but slightly and obtusely keeled in the young: epidermis rather thick: whorls $3 \frac{1}{2}$, compressed towards the periphery, the last exceeding in size the rest of the shell and considerably dilated towards the mouth: spire very little raised : suture rather deep : mouth almost circular and trumpet-shaped, but very slightly oblique: outer lip very thick and strongly reflected, forming in the adult a complete peristome, much inflected on both sides : umbilicus rather large, exposing a considerable portion of the whorls and all the internal spire. L. $0 \cdot 04$. B. $0 \cdot 09$.

Var. costata. Shell much less glossy, and marked transversely with curved membranaceous ridges (of which there are about forty on the last whorl), besides numerous intermediate striæ. H. costata, Müll. Verm. Hist. pt. ii. p. 31 ; F. \& H. iv. pl. cxix. f. 8.

HАвітAт: Under stones and logs of wood, as well as in moss and at the roots of grass, in moist situations, from the Moray Firth district to the Channel Isles. The variety is equally diffused, but not so common; and it frequents dry and sandy places, often under loose stones or bricks on old walls. Montagu says that he had often found this variety with the typical form, and he described the former, but with considerable doubt, as a different species, under the name of $H$. crenella; Maton and Rackett have made the same remark; the authors of the 'British Mollusca' state that "both 
varieties inhabit wet and dry localities indifferently;" and Malm has confirmed these observations and added that, out of 100 specimens which he had collected in one spot, twenty of them belonged to the variety. I have not been so fortunate as to find them living together. Muiller describes the present species as common in wet moss, and the variety as very rare in an elevated spot at some distance from any water. Some specimens, however, of the variety are more strongly ridged than others; and there is an evident transition from the smooth to the ridged form. I cannot detect any difference between the shells, except in respect of the membranaceous ridges, which form part of the epidermis and are easily rubbed off, leaving the surface of the shell quite smooth. This species is common in our upper tertiary deposits. Abroad it ranges from Siberia (according to Gerstfeldt) to Lugano (according to Stabile), as well as to Corsica and even to Madeira and the Azores. Gould says that the typical form is rather common near Boston, and that it has been noticed on the Ohio, and on the banks of the Missouri, as high up as Council Bluffs. With reference to the opinion of some that it had been introduced into America from Europe, Dr. Binney remarks that "it does not seem possible that so small an animal, if naturalized since the arrival of Europeans, could have been able to penetrate to the remote points in the interior of the Continent where it is now found." Without quite concurring with the American conchologist in this remark, I do not see how this little snail is likely to have been transported across the Atlantic from the one hemisphere to the other. It only inhabits waste and uncultivated spots ; and a flower- or kitchen-garden would be the last place to look for it. But the modes of transport are various ; and it would be rash to assert positively 
that $H$. pulchella has never crossed the Atlantic. If I may be permitted to offer a suggestion on this knotty point, I would remark that, being a comparatively northern species, it is much more probable that it has spread from the Arctic regions through Canada. This is one of the European species which Dr. Thompson found in Cashmir and Thibet, according to the identification of Mr. Woodward.

This little creature is very shy and difficult to observe. Its eyes appear remarkably black, in consequence of the two upper tentacles being so transparent. The liver is saffron-coloured; and the upper part of the spire in dead shells often shows it. The epiphragm is like tissuepaper, and iridescent. Bouchard-Chantereaux says that H. pulchella lays, in August and September, from 12 to 20 globular and opaline eggs, which are united in a cluster two or three times the size of the shell. It seems to be hardy, and has been found at rather considerable heights. Von Martens noticed its occurrence on the Dovre fjelds at an elevation of more than 2000 feet.

This species is the $H$. paludosa of Da Costa and Montagu, and the Turbo Helicinus of Lightfoot; but the name given by Müller is anterior to both of these.

\section{H. LAPICI'DA* Linné.}

H. lapicida, Linn. Syst. Nat. ed. xii. p. 124l ; F. \& H. iv. p. 65, pl. cxvi. f. 3, 4.

BoDy yellowish-brown above, with a slight tinge of red in front, and of grey behind and underneath, covered with minute close-set, unequal-sized tubercles, which are of a darker colour and arranged in indistinct lines corresponding with those of the tubercles or granulations on the surface of the shell: mantle extended round and lining the mouth of the shell, concentrically wrinkled and tumid, reddish-brown 
or dusky, speckled with milk-white: tentacles very long, darkgrey with a slight tinge of yellow; bulbs very short and globular : foot narrow and rounded in front, broader and keeled behind, its sides having a whitish border.

Shell depressed above and below, rather solid, nearly opaque, not glossy, yellowish tinted with reddish-brown, and irregularly streaked across the whorls with the latter colour, marked with indistinct lines of growth, and finely shagreened, like seal-skin : periphery strongly and sharply keeled: epidermis rather thick: whorls 5, greatly compressed towards the periphery, the last exceeding in size the rest of the shell and somewhat dilated towards the mouth : spire very little raised, point blunt : suture rather slight but distinct : mouth obliquely oval, angulated above and below, with rather a deep notch in the line of the keeled periphery: outer lip white, thickened and reflected, forming a complete peristome, abruptly and considerably inflected on both sides : umbilicus rather large, exposing a great part of the whorls and all the internal spire. L. $0 \cdot 25$. B. $0 \cdot 65$.

Var. minor. Shell smaller and more deeply coloured.

Habi'ite : Moist rocks, woods, and other places in many parts of England, from Went Vale, Yorkshire, to Portland Island. This species does not appear to be found in Wales, Scotland, or Ireland. It has been supposed to be restricted to calcareous districts; but Mr. Reece has found it close to Worcester, and Capt. Bruce Hutton at Linton in North Devon, in neither of which places is there any limestone, chalk, or oolite. In a specimen now before me the whorls are twisted, like the scalariform distortion of some kinds of Planorbis. This is one of our upper tertiary fossils. Its foreign range extends from Finland to Portugal ; and Aradas and Maggiore are said to have found a single specimen in Catania.

This is a rather hardy, but inactive, snail. During the daytime it lies concealed in the crevices of rocks or old walls and under the bark of trees; but in the dusk of the evening, or after a shower of rain, it sallies forth 
in search of food, and may in the latter case be met with in cousiderable numbers. The coloured streaks on the shell somewhat resemble those on $H$. rotundata. Lister first made the present species known, and says he had often found it in woods in Lincolushire. Linné gave it the inappropriate name it now bears, from an erroneous idea that it ate or excavated calcareous rocks, as the Teredo does wood. This notion probably originated in the surface of the shell being rough and like a file. His $H$. albella appears to be the immature or younger state of the variety called by Menke albina. This white variety has not been noticed as British; but it is found in Sweden and many other parts of the Continent. I have taken it in Switzerland and the Lower Harz, with specimens of the usual colour. The H. albella of Fleming (Brit. Anim. p. 260) may also be the same state of this variety. He found a single dead specimen on the shore at St. Andrews in 1810. It is not at all likely that Draparnaud's species of that name (the $H$. explanata of Miiller) would have found its way so far north; and Dr. Fleming says that his shell differs from Draparnaud's description. The $H$. Somershamiensis of Sheppard (Linn. Trans. xiv. p. 159) is probably the young of the present species.

G. Shell flat or slightly concave above : outer lip thick and furnished with a tooth-like tubercle: umbilicus rather large.

\section{H. oвvold'TA*, Müller.}

H. obvoluta, Müll. Verm. Hist. pt. ii. p. 27 ; F. \& H. iv. p. 63, pl. exvii. f. 1-3.

Bopy narrow and somewhat truncate in front, brown with a slight reddish tinge, and speckled with milk-white 
in several parts; tubercles oblong and arranged in close lines, smaller in front: mantle tumid, forming a narrow collar and leaving a slight space empty round the neck: tentacles very long and slender, dark-brown, shagreened; bulbs very globular: foot delicately edged with milk-white, ending in a long, narrow, triangular and keeled tail.

SHELL nearly circular, shaped somewhat like one of the men in a backgammon board, except that this is spiral, flat above, with a slight depression in the middle, and compressed below, rather solid, opaque and of a lurid aspect, reddish-brown, finely and closely striate in the line of growth: periphery rounded, but compressed: epidermis very thick, closely covered with stiff reddish-brown hairs : whorls $6 \frac{1}{2}$, cylindrical, but compressed at the sides, gradually increasing in size, the first (being the nucleus of the shell) nearly smooth and polished, and the last slightly dilated towards the mouth : spire sunk below the level of the last whorl : suture rather deep : mouth obliquely triangular, in consequence of a tooth-like protuberance at the peripheral edge: outer lip reddish-white, very thick and reflected, its upper margin abruptly and considerably inflected : umbilicus rather large, exposing part of the whorls (especially the last but one) and all the internal spire. L. 0.2. B. $0 \cdot 5$.

HABiтAт: On stumpsand at the roots of trees in woods at Ditcham and Stoner Hill near Buriton, in Hampshire, where it is rather common. It is a native of France, Germany, Switzerland, and Lombardy ; but it does not seem to inhabit the extreme North or South of Europe.

This curiously-shaped snail is rather active, and secretes a good deal of clear slime. Its epiphragm is chalky-white and remarkably thick.

Considerable doubt has been raised by many British conchologists (myself included) as to $H$. obvoluta being really indigenous to this country. It was first noticed by Dr. Lindsay (in 1831) as occurring in Ditcham Wood. He found with it Zonites cellarius and Helix rufescens. Mr. Hawker says, in the 'Zoologist' for 1853 (p. 3764), "The two ridges (Stoner Hill and Ditcham 
Wood) are quite distinct, and the intervening country is low and flat: therefore I do not think it possible that $H$. obvoluta could have spread or wandered from the Ashford Woods to Ditcham." Stoner Hill appears to be six miles distant from Ditcham Wood. This species inhabits the North of France, having been found by Dr. Baudon at Morainval Wood near Mouy ; and if H. Cartusiana is British, the present species has quite as good a claim to the same privilege.

\section{Genus V. BU'LIMUS*, Scopoli. Pl. VII. f. 1, 2.}

Bodx long, always containable within the shell : tentacles 4 : foot rather long and narrow.

SHeLl cylindrically-conic or oblong, not thin or very glossy: whorls drawn-out: spire long: mouth oval: outer lip usually reflected, and sometimes (but not in British species) furnished with tooth-like tubercles: umbilicus exceedingly small and narrow.

I will not inflict upon my readers a repetition of the stale and uninteresting controversy which formerly vexed the conchological world as to the origin and meaning of the name of this genus. A few words will suffice to give its history. The celebrated French naturalist, Adanson, proposed, in 1757, for a small freshwater mollusk of Senegal, a new genus, which he called Bulin, being a local word. This name was capriciously or inadvertently changed by Scopoli into Bulimus; and it was used by him, and subsequently adopted by Bruguière, to receive a heterogeneous assemblage of land and freshwater shells, having no affinity with Adanson's species, or with any of those to which the genus is now restricted. Draparnaud in 1801 was the first to apply the generic word to its present and generally recognized signification.

* A corruption of Bulin, an African word. 
The difference between this genus and Helix is very trifling. The tentacles in the present genus are rather shorter, and there are also some minor points of anatomical distinction. The shell of Bulimus has a longer spire; but this is a comparative character, and the degree of difference between the length of the spire in Helix conica and the young of Bulimus ventricosus (Helix Bulimoides of Moquin-Tandon) is scarcely appreciable. It is not from the limited means of observation which are afforded by a collection of the Mollusca in this or any other particular country that a safe conclusion can be arrived at with respect to the line of generic distinction ; and this is especially the case with the genus now under consideration. There are only three British species of Bulimus; and one of them, which is by far the most common of all (B. acutus), has been restored by MoquinTandon to the genus Helix. This species is included in a section from which Leach constructed his genus Elisma; and it will be here described first, as forming a passage from Helix to the present genus.

The habits of the Bulimi are nearly the same as those of the Helices. Our native species of Bulimus appear to be exclusively herbivorous. They frequent open downs and woods, and are rarely met with in the haunts of men, though $B$. acutus infests gardens near the sea-coast, being probably tempted by the more succulent pasture. Their manner of oviposition, as well as the shape and arrangement of the eggs, are similar to what has been observed with respect to the typical genus, Helix. A peculiarity of this genus is the tendency which some exotic species have to a reversal of the spire, attended with a change of position in some of the principal organs of the body. In other land-shells this phenomenon is more usual in genera or species than in varieties. 


\section{A. Shell cylindrically conic : spire long and pointed : outer lip thin and plain.}

\section{Bulimus ACU'TUs*, Müller.}

Helix acuta, Müll. Verm. Hist. pt. ii. p. 100. B. acutus, F. \& H. iv. p. 86, pl. exxviii. f. 5, and (animal) pl. G. G. G. f. 6.

BoDy rather thick, slightly narrowed and nearly truncate in front, slender and pointed behind, semitransparent, yellowish-grey of different shades of intensity, covered with very close and flattened tubercles: mantle touching the outer lip of the shell, tumid, marked with milk-white and brown specks: tentacles greyish, of a darker hue on the upper part, nearly smooth; upper pair very slightly conic, with their bulbs dilated but rather globular; lower pair very short: foot nearly truncate in front, the sides transversely and very closely grooved, tail blunt and keeled.

Shell turreted, opaque, white with a faint tinge of yellow, transversely streaked with light-brown, sometimes having one or two dark-reddish-brown or almost black bands encircling the lower whorl, one of which (where there are two) is continued on the upper whorls; the shell is occasionally white or colourless; sculpture consisting of rather close but irregular striæ in the line of growth, which are stronger in some parts than in others, and there are occasionally a few indistinct spiral lines which intersect the striæ and give the latter an appearance of being disposed in curved rows; the surface is also sometimes wrinkled or faintly pitted: periphery rounded: epidermis rather thin: whorls 8-9, convex, gradually increasing in size, the upper one smooth, polished and horncolour: spire tapering, but blunt at its extremity: suture deep : mouth oval, not much encroached upon by the penultimate whorl: outer lip reflected on the pillar and slightly inflected at its upper angle: umbilicus almost covered by the reflexion of the lip in that part, but rather deep. L. $0 \cdot 6$. B. 0.2 .

Var. 1. bizona. Shell smaller and having two dark bands on the body whorl.

Var. 2. inflata. Shell rather more ventricose, streaked with brown or marked with a single dark band: spire shorter: whorls proportionally broader.

* Pointed. 
Habitat : Downs and sand-hills on the sea-coast, from Durness in Sutherlandshire (where it has been found by the Rev. Walter Grigor) to the Channel Isles, as well as throughout Wales and Ireland. The variety bizona is remarkably pretty, and has been found in Iona by Messrs. Lowe and Berkeley; at Abergelly, near Conway, by Mr. Gibbs; near Cork by Mr. J. D. Humphreys; and at Tenby, and Portmarnock in Dublin Bay, by myself. The variety inflata occurs with the typical form, but merges insensibly into it through intermediate gradations. It somewhat resembles the $B$. ventricosus of Draparnaud. The present species is common in the granitic, as well as calcareous districts; but the only authority for its being found anywhere except on the sea-coast is that of the late Mr. Thompson of Belfast, who says it "occasionally occurs inland." It is a very doubtful member of our upper tertiary list, Mr. Pickering having only found a fragment of a shell, which he believed was this species, in the deposit at Copford. The circumstance of this not being a northern form makes the identification more questionable. Abroad it seems also to be confined to the coast-line, and ranges from France to Algeria and Sicily. Hartmann is said, however, to have found it near Romanshorn in Switzerland.

It is rather an active, but irritable creature, and withdraws itself into its shell on the slightest touch. These snails may be seen in the daytime clinging to the stalks of grass and other herbage in countless numbers; and this attachment is effected by means of a pellicle secreted in the same way as the epiphragm. The popular idea that sheep feed on and are fattened by snails relates to this kind as well as to Helix virgata; and, as Montagu very justly observes, "it is, indeed, impossible that those animals should browse on such short grass as clothes 
the hills above Whitsand Bay in Cornwall, without devouring a prodigious quantity of snails, especially in the night, or after rain, when they ascend the stunted blades." The summer epiphragm is very thin, transparent, and iridescent; and it has a small hole in it, which corresponds with the position of the respiratory orifice, thus enabling the snail to procure fresh air without exposing its body to the heat of the sun. The winter epiphragm is thicker, opaque, and yellowish, like paper. Geologists can have some idea of the way in which landshells are accumulated and form tolerably thick strata, from the fact recorded by Montagu, that the drifted sand at Bigberry Bay in the South of Devon is full of dead shells of the present species, to the depth of four feet.

This is the Turbo fasciatus of Pennant and Montagu.

The $B$. articulatus of Turton (the typical specimen of which is in my collection) is an exotic shell, and not Lamarck's species of that name, which is only a variety of $B$. acutus.

B. Shell oblong: spire blunt: outer lip thickened and reflected.

\section{B. MONTA'NUS*, Draparnaud.}

B. montanus, Drap. Tabl. Moll. p. 65. B. Lackhamensis, F. \&. H. iv. p. 89 , pl. cxxviii. f. 6 .

BoDY rather thick, rounded in front, narrowing gradually and pointed behind, dark-red or greyish-brown; tubercles flattened, with very fine black points: mantle indistinctly and minutely speckled with milk-white and brown: tentacles somewhat thick and conical; upper pair coarsely shagreened, with thick and rather globular bulbs; lower pair nearly smooth, of a somewhat darker colour than the others: foot truncate in front and ending in a long but blunt tail.

SHELL conic-oblong, nearly semitransparent, rather glossy,

* Inhabiting mountains. 
light-brown with a yellowish tint, but varying in intensity of colour, faintly and irregularly striate in the line of growth, and marked spirally with fine and close-set but undulating lines, which, being intersected by the transverse striæ, give the surface a slightly shagreened appearance: periphery rounded, but compressed : epidermis rather thick : whorls $7 \frac{1}{2}$, somewhat compressed, the last forming nearly one-half of the shell : spire tapering, but somewhat abruptly, blunt at its extremity : suture rather slight and oblique: mouth oval, a little contracted on the inner side by the penultimate whorl: outer lip white, reflected and considerably thickened within, where it is of a reddish-brown colour: umbilicus nearly covered by the reflexion of the pillar lip, rather oblique, and deep. L. 0.65. B. $0 \cdot 225$.

Haвitat: On trunks of trees, chiefly of beech, ash, and hornbeam, in the woods of our southern and western counties. It is local, although tolerably plentiful where it occurs. At Buriton in Hampshire it is found with Helix obvoluta and Clausilia Rolphii. The locality given in the Appendix to Welch and Whitelaw's 'History of Dublin " (viz. "neighbourhood of Dublin ") is very questionable, as the occurrence of this shell in Ireland has not been noticed by Mr. Thompson or Mr. Waller. As a tertiary shell it has only been discovered in the Clacton deposit. Its foreign distribution appears to be limited to the North and East of France, as well as the Pyrenees, Germany, Switzerland, and Silesia, in all of which countries it is only known to inhabit elevated situations.

The colour both of the body and shell varies in intensity. In immature specimens the periphery is keeled. The young are sometimes encrusted with earth in the same manner as B. obscurus.

It is the Helix Lackhamensis of Montagu; but his name is subsequent to that of Draparnaud and is, besides, objectionable on account of its being derived from a very obscure locality, which was not the first recorded for the discovery of this species. 


\section{B. oBscu'Rus *, Müller.}

Helix obscura, Müll. Verm. Hist. pt. ii. p. 103. B. obscurus, F. \& H. iv. p. 90 , pl. cxxviii. f. 7 .

BoDy of a lighter colour than that of $B$. montanus, with the tubercles comparatively more prominent: mantle larger and more tumid in proportion to its size : tentacles less thick and conical; upper pair finely, but distinctly, graulated, with globular bulbs, which are dilated at the top; lower pair minutely speckled with black : foot very delicately and slightly fringed, narrow and angular in front, very broad behind, and ending in a rather slender and pointed tail.

Shell much resembling that of the last species, except in size; but differing also in the following particulars:-this is shorter in proportion and more glossy ; it has no spiral lines, but instead of them the transverse striæ are divided by very minute intermediate lines, and the surface consequently has not the slightest appearance of being shagreened: whorls only $6 \frac{1}{2}$ and more convex: spire more abrupt: suture deeper: mouth proportionally larger: outer lip more reflected and not so thick, plain white, and much more inflected above : umbilicus a little more contracted. L. 0-35. B. 0-15.

Var. alba. Shell white or colourless.

Habitat: On the trunks of trees and among dead leaves in woods, on hedge-banks and old walls, under stones in rocky places, and sometimes in gardens, from the Moray Firth district to South Devon, as well as in South Wales and Ireland. It is much more generally diffused than the last species. The variety has been found by Mr. Smith at Sevenoaks in Kent; and I have observed it at Lulworth in Dorsetshire. My collection contains a monstrosity, in which the mouth had been broken and renewed in such a manner as to be much stronger than it was before the fracture. This species is in Mr. Brown's list of upper tertiary shells from Copford. It ranges from Siberia, through Finland, Sweden,

* Concealed. 
France, Germany, Switzerland, Portugal, and Lugano, to Sicily.

Bouchard-Chantereaux says that the eggs of this species, which are laid from May to September, are not numerous, but very large in proportion to the size of the animal. It hibernates early and makes a glassy or papery epiphragm. It loves shade and moisture. It has a remarkable habit, which it shares with the young of Pupa secale, of covering its shell, or rather of causing it to be covered, with a crust of fine earthy particles or other extraneous matter, by means of its slime, or an exudation from the epidermis. Adult as well as young specimens are sometimes thus coated, but more frequently the latter. It is perhaps an involuntary measure of natural defence, with which many animals are provided, in order to escape or delude their enemies; and even the sharp eyes of a bird might be deceived by the disguise which these little creatures put on. The Rev. Revett Sheppard, in his interesting account of the Land and Freshwater Shells of Suffolk, observes with respect to the present species, "These shells, particularly in their young state, show great sagacity and ingenuity by covering themselves with an epidermis adapted to the different situations in which they are found; and when so covered, it is almost impossible for any other than a conchological eye to detect them. If its abode be upon the trunk of a tree covered with Lichens, then is the epidermis so constructed as to cause the shell to resemble a little knot on the bark covered with such substances. If on a smooth tree, from whose bark issue small sessile buds, as is frequently the case, it will pass off very well for one of them; and on a dry bank, or the lower part of the body of a tree splashed with mud, its appearance will be that of a little misshapen pointed piece of dirt." 
The first of these curious resemblances may be caused by the adhesion of Lichen spores, which would grow as well upon a shell as upon the bark of a tree; and the other cases I have endeavoured to explain. B. obscurus is sometimes found at considerable heights, probably indicating its Arctic origin. M. Puton observed it on the Vosges mountains, at an elevation of 2624 feet above the level of the sea. It occasionally occurs on granite and gneiss, but more commonly on calcareous strata.

The difference, which is slight, between this species and $B$. montanus will appear from the description. The simplest character is that the latter is at least four times the size of the other in cubical contents. Lister seems to have been acquainted with the present species; but his notice of it is not satisfactory. In its young state it is in all probability the Helix trochulus of Muiller.

The Helix detrita of Montagu (judging from a specimen received from him by Mr. Dillwyn and now in my collection) is exotic, and apparently a variety of the Bulimus Guadaloupensis of Bruguière.

The $B$. tuberculatus of Turton (the typical specimen of which I also have) is the Helix pupa of Linné. It is a native of the extreme South of Europe, and is not at all likely to have been found in Worcestershire, whence Dr. Turton is said to have received it. Capt. Blomer, who gave this specimen to Turton, told me that he had been in Sicily; and he admitted that he might have made a mistake as to the locality.

The Helix Goodallii of Miller is a West-Indian species, and appears to have been introduced into this country with pine-plants. It is still very common on the tan in the pineries at Garraway and Co's. nursery-gardens near Bristol, where the late Mr. Miller first observed this little shell about forty years ago. It has not been 
noticed elsewhere in this country. It is the Bulimus clavulus of Turton.

The $B$. decollatus was recorded by Dr. Turton as having been once found living in a greenhouse at Watton in the South of Devon, where it was observed to breed for many years in succession; but, in consequence of some alterations being made in the greenhouse, the colony was destroyed and became extinct. It is common in the South of Europe, as well as on the opposite shores of the Mediterranean; but its most northern locality appears to be Agen, in the Department of Lot-etGaronne.

\section{Genus VI. PU'PA*, Lamarck. Pl. VII. f. 3, 4, 5.}

BoDy slender, but generally short, always containable within the shell: tentacles 4, short, especially the lower ones: foot narrow.

Shell cylindrical, not very thin or glossy: whorls compact, the last not broader, or very little more so, than the penultimate or preceding one : spire long : mouth horseshoeshaped or semilunar, mostly furnished with one or more teeth; sometimes there are also spiral plates and incomplete septa in the interior: umbilicus oblique, very small, and contracted by an upward twist of the last whorl at its base.

The Pupce are all of a small size and gregarious. They live in moss or in the crevices of rocks and,walls, as well as on exposed hill-sides under stones or at the roots of grass. They are vegetable feeders, and appear to live on small plants, Cryptogamia, and decaying leaves. Some species are ovoviviparous. The mouth is parallel to the columella or axis of the shell ; and this, combined with the last whorl being of nearly the same breadth as the preceding one, causes the shell to assume some-

* Like the chrysalis of an insect. 
what of an ellipsoid form. The whorls are also more compact than in Bulimus; and the mouth is usually furnished in the present genus with transverse plates or teeth, instead of the outer lip being merely thickened by tooth-like tubercles, or of their being a similar protuberance on the columella, as is sometimes the case in the former genus. The main characters of both these genera, however, are nearly the same, as regards their habits as well as the body and shell.

The curious processes, called "teeth," which fence in and contract the mouth of the shell in Pupa, are of different kinds. In $P$. secale they form plate-like ridges, which extend some way into the interior. In $P$. umbilicata and $P$. ringens the adult have either a simple tooth on the columella and a spiral plate on the pillar lip, or else several plate-like ridges as in $P$. secale, although shorter and more curved; but, in $P$. umbilicata and $P$. ringens, the young have a much more complicated apparatus. This consists of two long spiral ridges like the worm of a corkscrew, one on the pillar lip and the other on the pillar itself, besides a short transverse plate or septum on the outer lip, which is reproduced at intervals. In P. marginata the mouth is often furnished with a denticle or small tubercular tooth on the pillar, and sometimes also with a similar process inside the outer lip; but it never has the plate-like ridges which are found in the other species. All these various processes appear to be formed in the same way, viz. by folds of the mantle secreting the testaceous matter in excess and applying it to particular parts of the shell.

Two species of Pupa (viz. tridens and doliolum) have lately been found in the North of France; and it is therefore not unlikely that they may be found in this country. 
A. Spire long and pointed: mouth horseshoe-shaped, narrow, and furnished with several teeth and folds: outer lip slightly expanded and reflected.

\section{Pupa Seca'le*, Draparnaud.}

P. secale, Drap. Tabl. Moll. p. 59; F. \& H. iv. p. 101, pl. exxix. f. 5.

BoDy brownish-grey or slate-colour, with a reddish tint, slightly and irregularly tubercled; mantle minutely speckled with black: tentacles short and thick; bulbs oblong: foot usually fringed, broader behind than in front, and ending in a triangular and somewhat pointed tail.

Sheld conic-oblong, rather solid, opaque, somewhat glossy, light-brown or yellowish-horncolour, marked transversely or in the line of growth with numerous obliquely curved striæ : periphery rounded, but compressed : epidermis rather thin: whorls 8-9, slightly convex and gradually increasing in size, the four or five first whorls smaller in proportion to the others, the last somewhat dilated and twisted at its base upwards to form the mouth: spire, although long, rather abrupt and blunt at the point: suture moderately deep : mouth longer than broad, somewhat angular, and contracted by the teeth or inside folds, which are as follows - two or three on the pillar (the middle one when there are three being in front of the others), two on the pillar lip, and four inside the outer lip; the front tooth on the pillar lip is often accompanied by a smaller tubercle or denticle, and it is placed so near the point of insertion of the outer lip as often to appear a continuation or inflection of that lip; the tooth-like plates or folds inside the outer lip extend a considerable way into the interior and are visible outside, resembling white lines: outer lip thickened and slightly reflected: umbilicus extremely small and oblique, forming a narrow chink. L. 0.3. B. 0-125.

Var. alba. Shell white or colourless.

HABITAT : Rocks, woods, and hill-sides in many parts of England, from Westmoreland to the South of Devon, as well as (according to Dr. Gibbon) near Crickhowell in Breconshire, South Wales. Dr. Lukis informs me that he has not found it in the Channel Isles, although his 
brother believed that he had once taken $P$. avenacea (or avena) in Guernsey. It is a local species, but plentiful wherever it occurs. It is not confined to calcareous districts. Mr. Eyton found it in abundance on the triassic sandstone near Shrewsbury, where there was no limestone (nor, of course, chalk or oolite) within some miles of the place; and I observed it in equal plenty on the Molasse in Switzerland. I am also credibly informed that it has been found at Sudbury, near Harrow, on the lower tertiary strata. The variety was found by me at Lulworth in Dorsetshire ; but it is rare. This species is widely diffused throughout Central Europe, ranging south to Corsica; but it does not appear to inhabit the North or extreme South of Europe.

The young have their shells encrusted with earth or the spores of lichens and mosses, in the same way as Bulimus obscurus; and even adult specimens have occasionally a similar covering. From this latter circumstance I am confirmed in the opinion I ventured to suggest with respect to that species, that the coat is not purposely made by the animal, but is involuntarily caused by the accidental adhesion of extraneous matter to the outer surface of the shell, by means of the slime or a glutinous film which exudes from or invests the epidermis. Full-grown specimens have not the same need of disguise for their protection as those which are young and unprovided with teeth. In the daytime the shells are attached by a thin pellicle to the under side of stones and crevices of rocks.

This is the Turbo juniperi of Montagu; and the immature state is probably the Helix ventricosa of Muiller. There is a great similarity of form between the young of Pupa and Helix. 
B. Spire short and blunt: mouth horseshoe-shaped, rather oblique, furnished with one or more teeth or folds, and in the young with transverse plates and spiral screwlike ridges : outer lip thickened and reflected.

\section{P. RIN'GEns* Jeffreys.}

P. ringens, Jeffr. in Linn. Trans. xvi. p. 356. $P$. Anglica, F. \& H. iv. p. 99, pl. exxix. f. 6.

BoDY yellowish-grey or slate-colour, with several dark lines or streaks along the sides, leaving a clear space in the middle, underneath milk-white : mantle thick, projecting a little beyond the mouth of the shell : tentacles short, of a lighter shade than the upper part of the body; larger pair cylindrical and stumpy, rather close together, the bulbs scarcely distinguishable: lower pair more like tubercles: foot rounded in front and obtusely pointed behind.

Shell subcylindrical, inclined to oval, rather solid, nearly opaque, glossy and slightly iridescent, light-brown or yellowish-horncolour, closely but slightly striate transversely: periphery rounded, but compressed : epidermis thin : whorls 6 or $6 \frac{1}{2}$, convex, the last being equal to more than one-third of the shell and having its base sharply twisted upwards to form the mouth, the two or three top whorls much smaller in proportion to the rest: spire short, abruptly and bluntly pointed: suture well defined, but not deep : mouth triangular, rounded below, much contracted by the teeth or folds, which are as follows - two on the pillar (the outside one being larger than the other and extending far into the interior of the mouth in the form of a spiral screw), two on the pillar lip (the outermost being much the larger and more prominent), and one fold, with from one to three smaller denticles, inside the outer lip and rather deeply seated, the larger one being visible outside; besides these, there is a short curved side process or fold, which connects the lip at its outer base with the larger and more prominent tooth on the pillar, so as to resemble one of the lower fronds of a trefoil leaf; the mouth in unformed or immature specimens isfurnished not only with two main spiral ridges (viz. one on the pillar and the other on the pillar lip), but also with a transverse plate, like those in Planorbis lineatus, which lies at a right angle to the position of the 
folds within the outer lip of adult specimens and is repeated at short intervals; these transverse plates or septa are distinctly visible outside the base of young shells : outer lip and pillar lip light reddish-brown, much thickened and slightly reflected: umbilicus small, narrow and oblique, but distinct. L. $0 \cdot 133$. B. $0 \cdot 65$.

Var. pallida. Shell of a lighter colour, sometimes whitish.

Habitat : Among dead leaves and moss, and at the roots of grass, in moist places throughout the northern counties of England, the West of Scotland, and all Ireland, as well as in Guernsey. It occurs in a subfossil state at Copford. Its foreign range appears to be limited, so far as is at present known,-it having only been found once in the rejectamenta of a river near Toulouse (Moquin-Tandon), Cintra and the neighbourhood of Oporto (Morelet and Pring), and Algeria (Morelet and Dupuy). This southern distribution would seem to bear out the conjecture made by the authors of the 'British Mollusca' that the present species "is probably a member of our Atlantic fauna and of Southern or South-western origin;" but at the same time its occurrence as an upper tertiary fossil, with Helix lamellata and many other decidedly Northern forms, is a fact that must not be overlooked in considering the geographical distribution of the Mollusca.

This is a shy little creature, although tolerably active when inclined to make its appearance. It has a singular habit of withdrawing slowly one of its eyes, which rolls backwards like a little ball until it reaches the neck, while the tentacle which supports it remains extended to its full length. This I have observed being done when there was no obstacle in the way. It also retracts occasionally, and apparently without any reason, one of its horns and not the other. It does not appear to be ovoviviparous, like the next species ( $P$. umbilicata): at 
least I have not succeeded in finding any perfect embryo inside a full-grown specimen, although the shells thus examined were collected at the same period of the year and in the same spot with specimens of $P$. umbilicata which contained young ones completely formed. In a living specimen of $P$. ringens which I have just received with others from Dr. Lukis, the top whorls have been accidentally broken off and replaced by an imperfect septum, showing that these whorls are not occupied by the animal after it has attained its maturity. The shell varies considerably in the length of the spire; and in the young it resembles that of a small conical Helix. The internal structure of the shell was first noticed and described by Mr. Alder in his excellent Memoir on the Land and Freshwater Shells of Northumberland.

This species was first discovered by Mr. Bean, the venerable, but still active, conchologist of Scarborough. It is the Vertigo Anglica of Férussac; but although that specific name is prior to the one which $I$ have ventured to adopt, it was unaccompanied by any description; and the Supplement to Wood's 'Index Testaceologicus' only contains a figure of the shell, although referring to the same name. The Pupa ringens of Michaud's Supplement to Draparnaud's 'Histoire,' which bears a subsequent date to that of my Monograph in the 'Linnean Transactions,' is a different species from this, and is allied to $P$. secale.

\section{P. UMBILICA'TA*, Draparnaud.}

P. umbilicata, Drap. Tabl. Moll. p. 58, and Hist. Moll. p. 62, pl. iii. f. 39,40 ; F. \& H. iv. p. 95 , pl. cxxix. f. 7.

BoDy decidedly truncate in front and blunt behind, greyish* Having an umbilicus or navel. 
brown with a dusky shade above, and of a paler hue on the sides and rear, as well as underneath; head and neck marked with black specks, which are arranged in confused rows: mantle annular or circular, minutely speckled with black and milk-white: tentacles slightly transparent; upper pair close together and nearly cylindrical, with large pearshaped bulbs, forming one-fourth of these tentacles; lower pair widely separate from each other, very thick and slightly conical : foot not fringed, rather broad, rounded in front and behind.

Shell subcylindrical or inclined to oval, rather thin and semitransparent, glossy and slightly iridescent, yellowishbrown or horncolour, closely but slightly and irregularly striate in the line of growth: periphery rounded, or sometimes very slightly and obtusely keeled: epidermis thin : whorls 6-7, convex, the last equal to about two-fifths of the shell and sharply twisted upwards towards the mouth, the two firstformed whorls much smaller in proportion to the rest: spire short, abruptly and bluntly pointed : suture rather oblique, well defined, but not deep: mouth subtriangular, contracted or channeled below in the adult, furnished with a small and short tooth-like ridge on the pillar near the insertion of the outer lip (where it bends to form a junction with the lip), as well as with a short and oblique ridge-like tooth on the pillar lip ; young shells have a spiral screw on the pillar and another on the pillar lip, the position of which nearly corresponds with that of the ridge and tooth in the adult, and they have also transverse plates like those in the last species: outer lip white, with sometimes a slight tinge of reddish-brown, much thickened and considerably reflected : pillar lip also white and thickened, almost straight: inner lip spread on the pillar: umbilicus very small and oblique, contracted by a ridge or crest at the base of the shell, which arises from the abrupt and upward twist of the lower part of the body whorl. L. $0 \cdot 15$. B. $0 \cdot 075$.

Var. 1. edentula. Columellar tooth wanting.

Var. 2. alba. Shell white or colourless.

Habitat: On old walls and rocks, under stones, among dead leaves and beneath the bark of trees everywhere, from Zetland to the Channel Isles. It inhabits high as well as low situations. The first variety is not 
uncommon. The second has been found by Mr. Norman at Plymouth and in Somersetshire, and by myself at Grassmere, Church Stretton, Cardiff, and Tenby. This species belongs to our upper tertiaries. It ranges from Finland to Algeria, as well as to the Archipelago. Von Martens considers it is a southern form, because it retires early into winter quarters; and he remarked that he could not find it in September in a place near Bergen, where he had in the previous summer noticed it in abundance and living in company with $P$. marginata.

Mr. Alder first indicated that this species is ovoviviparous, and recorded the fact in the Supplement to his Catalogue of Land and Freshwater Shells found in the vicinity of Newcastle. Adolf Schmidt published the same discovery in the 'Zeitschrift für Malakozoologie' for February 1853; and I can confirm the fact from my own observation. Moquin-Tandon has more than once seen two or three young ones attached to the shell of their mother near the umbilicus and carried about by her-a kind of marsupial arrangement. P. umbilicata reproduces in July and August; but it does not appear to be prolific, as no more than 5 eggs have been found in the womb at the same time. The epiphragm is very thin and iridescent. Young shells are Trochiform and obtusely keeled, and have a central and rather deep umbilicus. The spire varies greatly in length. A dwarfed, toothless and thin variety is the P. Sempronii of Charpentier.

This species differs from $P$. ringens in being more cylindrical and less barrel-shaped, as well as in the form of the mouth and number of the teeth.

The observant Lister first made known this little land-shell, and the young is probably his Trochus sylvaticus. The present species is the Helix muscorum of 
Montagu; and it may also be that of Linné, as his description in the 'Fauna Suecica' of the form of the mouth ("ovato-acuminata, mucrone obtuso") agrees better with this species than with $P$. marginata, to which so many conchologists have attached the specific name of muscorum. According to the strict rules of scientific nomenclature, the present species (if it is not the Helix muscorum of Linné) ought to bear the name of cylindracea, which was given to it by Da Costa in 1778, long before either of Draparnaud's publications; but I fear justice must in the present instance cede to convenience, as the name of umbilicata is so universally used. Da Costa's name appears to have shared the same fate as the early leaf,-

" Ut silvæ foliis pronos mutantur in annos,

Prima cadunt; ita verborum vetus interit ætas,

Et juvenum ritu florent modo nata vigentque."

C. Shell short, cylindrical: spive blunt: mouth semioval, sometimes furnished with one or two tubercular teeth: outer lip strengthened by a thick exterior rib.

\section{P. margina'ta*, Draparnaud.}

P. marginata, Drap. Tabl. Moll. p. 58, and Hist. Moll. p. 62, pl. iii. f. 36-38. P. muscorum, F. \& H. iv. p. 97, pl. cxxix. f. 8,9 .

BoDY narrow and somewhat rounded in front, more slender behind, lustrous, dark-grey with a brownish tint, finely speckled with black, and of a much lighter shade on the under part; slightly butclosely tubercled: mantleas in thelast species, but the milk-white specks are larger: tentacles thick, opaque, dusky, rounded at their points; upper pair similar to those in $P$. umbilicata, with subglobular bulbs; lower pair somewhat diverging from each other, conical, smooth, rather opaque, and nearly black : foot not fringed, narrow but somewhat rounded in front, broader behind, and ending in a triangular tail.

SHell subcylindrical, rather solid for its size, nearly opaque, not very glossy, pale yellowish-brown or horncolour, 
faintly and irregularly, but closely, striate, in the line of growth: periphery rounded: epidermis thin: whorls 6-7, convex, but a little compressed, the last equal to about one-third of the shell, the two first whorls much smaller in proportion to the rest: spire short, abruptly and bluntly pointed: suture rather deep: mouth forming an oblique segment of about two-thirds of a circle, furnished sometimes with a small tubercular tooth on the columella, which is placed nearly in the middle: inside slightly tinged with reddish-brown : outer lip sharp, strengthened by a thick, white, exterior rib, which is placed at a little distance from the margin; outer edge slightly reflected: inner lip spread on the pillar: umbilicus small and shallow, contracted by a slight ridge or crest at the base of the shell. L. 0·133. B. 0.6.

Var. 1. bigranata. Shell rather smaller and thicker, and having a tubercular tooth or denticle considerably within the outer lip, as well as that on the columella. P. bigranata, Rossmässler, Iconogr. ix, x. p. 27, f. 645.

Var. 2. albina, Menke. Shell white.

Habitat : Under stones, at the roots of grass, and among dead leaves, everywhere from the Moray Firth district to Guernsey, especially on the sea-coast. Var. 1. Bath (Clark); Lulworth, Dorsetshire (J. G. J.); Oxfordshire (Whiteaves); Weston-super-Mare (Norman). Var. 2. Somersetshire (Clark, Norman, and J. G. J.); Oxfordshire (Whiteaves). I have also found a monstrosity in which the lower whorl is furrowed, and another which has the periphery keeled,- - the former having been apparently caused by a grain of sand adhering to the mantle while the shell was in course of formation, and the latter by an accidentalfracture of the last whorl, which obliged the animal to make a new mouth and to shorten the base. As an upper tertiary fossil it is very common, and often indicates the former presence of littoral conditions, as this species not only peculiarly affects sandy shores and maritime places, but is also washed down in great numbers by estuarine rivers and thrown up on 
the beach by the reflux of the tide. I have often found it under such circumstances mixed with recent sea-shells on a flat sandy coast. The Rev. Revett Sheppard says that it occurs "in profusion in Essex, near Wrabness Point, on the upper part of the marsh-a situation which at high tides is covered with water." The foreign range of this species is very extensive. Middendorf, as well as Gerstfeldt, has recorded it as Siberian; Von Martens has noticed it as inhabiting Iceland and Lapland; it is common in Scandinavia; and southwards it has found its way to Central Europe, Spain, Corsica, and Sicily.

This is a hardy and fearless little animal, and crawls rapidly for its size, compared with the movements of $P$. ringens. According to Moquin-Tandon this species is ovoviviparous, as well as $P$. umbilicata, and the young are sometimes attached to the shell of the mother and carried about by her. The work of reproduction takes place in the months of July and August. The number of eggs varies from 3 to 7 . In some specimens the spire is much longer or shorter, and the shell is consequently narrower or broader than usual. The epiphragm is like that of the last species, but is seldom complete.

This differs from $P$. umbilicata in the shell being more cylindrical and mostly of a smaller size, as well as in the mouth being semioval instead of triangular, but more especially in having a strong back rib instead of a reflected lip. The present species seems to connect Pupa with Vertigo.

In consequence of the hopelessly inextricable confusion which has so long existed as to the identity of Linne's Helix muscorum with this or the last species, or the Pupa minutissima of Hartmann (and which confusion seems to be increased by every new writer on the subject), there scarcely seems to be any alternative but to 
adopt Draparnaud's specific and significant name of marginata. It is more than probable that Linné knew both this species and $P$. umbilicata, but did not distinguish one from the other. The present species appears, however, to be the Helix muscorum of Muiller, who pointed out the difference between his and Linne's species of the same name. This is the Turbo chrysalis of Turton.

\section{Genus VII. VERTI'GO*, Müller. Pl. VII. f. 6, 7, 8.}

Body rather short, always containable within the shell: tentacles 2 only, scarcely at all inflated at their extremities: foot short.

SHeLl subcylindrical or fusiform, thin and glossy : whorls compact, the last considerably exceeding the others in size : spire short, sometimes reversed: mouth semioval or semicircular, usually furnished with several teeth, in which case the outer lip is contracted: umbilicus scarcely perceptible, or consisting of an oblique and narrow chink.

The members of this genus are miniature forms of Pupa; and their habits are the same, except that these are more retired and avoid the sun's rays more than some species of Pupa. But the difference between them does not consist in size alone. The animal of Vertigo, instead of having, like that of Pupa, four tentacles, has only two, and is quite destitute of the lower pair. I have satisfied myself, by a careful examination of many living specimens, that not the slightest rudiment or vestige exists of a second pair of tentacles in several species of Vertigo, although in $V$. pygmexa and $V$. pusilla lines or dark spots are discernible in the places which would be occupied by these tentacles if they were present. Muiller was the first to discover the fact of these Mollusks being bitentaculate, and founded on it the present genus. Several 
Continental naturalists of repute have also made independent observations and arrived at the same conclusion. An exotic species (V. rupestris) is half as large again as Pupa marginata ; and yet, according to MoquinTandon, not a trace can be detected in this species of Vertigo of the lower tentacles which are possessed by all the species of Pupa. The shell of Vertigo differs also in a corresponding degree from that of $P$ upa. The spire is shorter; and when the mouth is furnished with teeth (as is commonly the case) the outer lip is contracted. It would therefore seem to be quite as reasonable that Vertigo should be separated from Pupa, as Bulimus from Helix. The line of demarcation in either case is confessedly slight. The value of such generic distinctions will probably not be admitted by all naturalists; and unfortunately there is no Court of Science to which an appeal can be made for an adjudication of the point.

The typical and original species ( $V$. pusilla) has the spire reversed or sinistral, from which character the name now borne by the genus was derived.

A. Shell dextral, barrel-shaped: mouth furnished with teeth.

\section{Vertigo antivertígo *, Draparnaud.}

Pupa antivertigo, Drap. Tabl. Moll. p. 57, and Hist. Moll. p. 60, pl. iii. f. 32,33 ; F. \& H. iv. p. 109 , pl. exxx. f. 7 .

BoDy thick, lustrous and dusky, greyish-black with a tinge of slate-colour or brown, covered with exceedingly minute black or dark tubercles: snout short, but somewhat produced: tentacles rather close together, subcylindric; bulbs forming one-third of them, oval and obtusely pointed : foot oblong and narrow; edges very light grey and finely speckled with black; tail rather blunt.

SHell oval, thin, semitransparent, very glossy and of an opaline lustre, dark yellowish-brown with a reddish tinge, very 
faintly and closely striate in the line of growth, and microscopically striate in a spiral direction : periphery rounded : epidermis very thin: whorls $4 \frac{1}{2}$, tumid and more prominent in the middle, the last being equal to about half the shell, and the first whorl and a half very small in proportion to the others: spire short, very abrupt and blunt at the point: suture deep: mouth small, semioval, contracted in the middle of the outer edge, and furnished with teeth as follows-three on the pillar (the inner one of which is only a small tubercle, or denticle), one on the pillar lip, and three or four (besides one or two denticles) inside the outer lip and placed at some distance from the opening; the teeth are of a reddish-brown colour; the principal ones are strong and arched, and the labial or palatal teeth extend a little way in the form of ridges and are visible outside; all of them are of an irregular shape and unequal in size and length: outer lip sharp, whitish, flexuous or constricted in the middle of the front margin, slightly reflected, and strengthened by an exterior rib of nearly the same colour as the rest of the shell, which is placed at some little distance from the margin; outer edge much inflected: inner lip spread on the pillar and tolerably thick in adult specimens, so as almost to form a complete peristome : umbilicus moderately open, but somewhat contracted by a blunt and wrinkled crest at the base of the shell. L. $0 \cdot 065$. B. $0 \cdot 04$.

Habitat : Under stones and logs of wood, as well as at the roots of grass, and on moss, flags, and waterplants, in marshy places and at the sides of streams and canals, generally throughout these isles, from the Moray Firth district to Guernsey. It is also one of our upper tertiary fossils. Abroad it is distributed from Sweden, through the whole of Central Europe, to Portugal on the west and Lugano on the east; and Aradas and Maggiore have recorded a small variety (the Pupa pusilla of Bivona) as Sicilian.

This little mollusk carries its shell nearly straight on its back, and balances it from right to left (as if it were topheavy) when crawling. It inhabits elevated as well as moist places. The late Dr. Johnston of Berwick in- 
formed me that he found it with V.pygmcea and $V$. substriata at Fastcastle on Sparkleton Mountain, in East Lothian, at a height of 1200 feet. Such localities appear to have an obvious relation to the preglacial origin of many of our Mollusca. The epiphragm of the present species is filmy and iridescent, like that of the smaller Pupce. Half-grown specimens have only two teeth, viz. one on the pillar and the other on the pillar lip. The number of teeth in adult specimens varies from six to ten. The shell does not differ much in size.

It is the Turbo sexdentatus of Montagu, the V. septemdentata of Férussac, Charpentier, and others, the $V$. octodentata of Studer, and the V. palustris of Leach. The Pupa ovata of Say (a North-American shell) is closely allied to this species.

\section{V. Moulinsia'na *, Dupuy.}

Pupa Moulinsiana, Dup. Cat. Gall. Test. no. 284, and Moll. Fr. p. 415 , pl. 20. f. 11 .

BODY rather slender, dark-grey above and of a paler colour below: tentacles rather thick, short, clavate and obtuse at their extremities : foot narrow.

ShELL oval, very thin and nearly transparent, exceedingly glossy, light yellowish-horncolour, very faintly striate in the line of growth and microscopically striate in a spiral direction: periphery rounded: epidermis very slight: whorls $4 \frac{1}{2}$, extremely tumid, the last being larger than the rest of the shell, and the first whorl and a half very small in proportion : spire short, remarkably abrupt and blunt at the point: suture very deep: mouth semioval or forming an arch equal to nearly two-thirds of a circle; teeth four, as follows-one on the middle of the pillar, one on the pillar-lip, and two inside the outer lip; these teeth are of the same size, and placed at about equal distances from each other and a little within the mouth: outer lip rather thin, whitish and reflected, strengthened by a slight

* Named after M. des Moulins, the author of several excellent papers on the French Mollusca. 
exterior rib, which is of the same colour as the rest of the shell and situate near the opening of the mouth ; outer edge considerably inflected: inner lip scarcely perceptible and consisting of a merefilm: umbilicus ratheropen. L. 0.08. B.0006.

Var. bidentata. Labial or palatal teeth wanting.

Haвitat : Under stones by the side of a small lake at Ballinahinch near Roundstone, Co. Galway, where I made this acquisition to the British Mollusca in 1845. $V$. antivertigo and a variety of $V$. pygmcea were also found by me at the same place and time; but I had not examined my specimens until I commenced describing the species of Vertigo for this work. The mouth and lip in the variety are completely formed. On the Continent the present species occurs in the North, South, and West of France, the Cantons of Vaud and Valais in Switzerland, and near Heidelberg. It is a local and rare shell.

The description of the animal is taken from my "Notes on Swiss Mollusca," which appeared in the "Annals and Magazine of Natural History' for January 1855 ; and I there stated that the body is more slender and of a lighter colour than that of $V$. antivertigo, and that the tentacles are more decidedly clavate. There is no trace of a second or lower pair of tentacles. I observed it in Switzerland feeding on Confervce. The situations in which I found it in Switzerland were like that of the Irish habitat; and I have no doubt that it will be rediscovered in this country by attention being thus drawn to it. The fen districts of our Eastern counties, as well as the wilds of Connemara, require to be more thoroughly searched. I did not keep one of my Swiss specimens, from a desire to confine my collection exclusively to our own Mollusca; but I have fortunately had, through the kindness of Mr. Daniel, an opportunity of comparing 
the Connemara specimens with some from Germany. The latter are the largest.

This species differs from $V$. antivertigo in being larger, more ventricose, and of a much lighter colour, in the mouth and outer lip not being contracted, and especially in the number and position of the teeth, which never exceed four, instead of being from six to ten as in that species. From V. pygmaea it may be distinguished by being twice the size and very much more ventricose, and also of a lighter colour. The difference is equally great between all the three species. V. Moulinsiana resembles $V$. antivertigo in form and V. pygmaea in the number of teeth. It is among the largest of our native species of Vertigo.

It is the Pupa Anglica of Moquin-Tandon's 'Catalogue of the Mollusca of Toulouse,' but not that of Alder or of Potiez and Michaud; and it is the P. Charpentieri of Mr. Shuttleworth in Kiister's edition of Martini and Chemnitz, and my $P$. Desmoulinsiana. The P. arctica of Von Wallenberg (Mal. Bl. 1858, p. 99, pl. i. f. 3 , and $a, b, 4)$ from Lapland is perhaps a variety of the present species, differing in not having the second and smaller tooth on the outer lip.

\section{V. PYGMAE'A*, Draparnaud}

Pupa pygmrea, Drap. Hist. Moll. p. 60, pl. iii. f. 30, 31 ; F. \& H. iv. p. 106, pl. cxxx. f. 4-6.

Bopyslender, expanded and rounded in front, very gradually narrowing and pointed behind, of a dark greyish-slatecolour, closely but indistinctly tubercled : mantle of a reddish hue, finely speckled with black: tentacles very close together at the base, but considerably diverging, with oblong bulbs; in the place of the lower tentacles two black spots are perceptible with a high magnifying power: foot truncate in front, speckled

* Dwarf. 
with black like the mantle, as well as with milk-white dots on the sole; tail very narrow, slightly rounded at the extremity

SHELL oval or inclined to cylindrical, rather solid for its size, semitransparent, glossy, reddish-brown or yellowish-horncolour, very faintly striate in the line of growth, andalso marked with a few obscure spiral striæ: periphery rounded: epidermis slight: whorls $4 \frac{1}{2}$, convex, but not very tumid, the last being nearly as large as the rest of the shell, and the first whorl and a half verysmall in proportion: spireshort, abruptand bluntly pointed: suture moderately deep: mouth semioval, rather higher than broad; teeth four or five, arranged as followsone sharp and prominent tooth on the middle of thepillar, one strong and thick tooth on thepillar lip, and two or three platelike teeth (more frequently the latter number)inside the outer lip; these last or labial teeth are seated considerably within the mouth and appear to spring from a kind of rib, which is formed inside this part of the lip and corresponds in position with an outer rib of greater breadth and thickness; the third labial tooth is the smallest : outer lip rather thin, very little reflected, strengthened by the outer rib above noticed, which is sometimes reddish-brown like the rest of the shell, but occasionally of a lighter colour; outer, edge abruptly inflected: inner lip thickened in adult specimens: umbilicus small and narrow, but rather deep. L. 0.065. B. 0.04 .

Var. pallida. Shell thinner and of a lighter colour.

Hавітат: Under stones and logs of wood, and at the roots of grass, on hills and almost everywhere in this country, from the Moray Firth district to Guernsey. The variety inhabits marshy places, and has been found by Mr. Daniel at Wool in Dorsetshire, and by myself in the North of Devon as well as in Connemara with $V$. Moulinsiana. This variety has probably been mistaken by collectors for $V$. alpestris. The present species is not uncommon in our upper tertiary strata. It is widely distributed abroad from Siberia and Finland to Algeria and Sicily; and it even reaches the Azores. This is a tolerably active and lively little creature, crawling by jerks and carrying its shell nearly upright. 
It makes, like its congeners, a filmy epiphragm, but which is not iridescent. It may be in some degree considered a subalpine form, as it occurs at considerable heights. Dr. Johnston found it at the top of a mountain in East Lothian at an elevation of 1200 feet, and M. Puton on the Vosges at a height of 1640 feet. The teeth do not appear to be formed in any of the whorls except the last. They project into the mouth at right angles, so as to present a chevaux de frise against all intruders.

This species may at once be known from $V$. antivertigo, as well as from $V$. Moulinsiana, by its more cylindrical or narrower shape, and from the former by its having only a single tooth on the pillar, instead of two or three as in that species. The outer lip is also not contracted and angulated as in $V$. antivertigo. The other points of difference between the present species and V. Moulinsiana have already been noticed in the account of that species.

Montagu was evidently acquainted with the present species, but confounded it with $V$. antivertigo (his Turbo sexdentatus), in describing which he says, "younger shells have only four teeth." I may observe that the fifth or smaller tooth, which is placed within the outer lip and close to the pillar lip, is seldom wanting, although not so conspicuous as the others, and that five is the usual, and four the exceptional number of teeth.

\section{V. ALPES'TRIS *, Alder.}

V. alpestris, Alder, Trans. Nat. Hist. Soc. Newc. ii. p. 340. Pupa pygmax, var. alpestris, F. \& H. iv. p. 107, pl. cxxx. f. 6.

Bopy light-strawcolour: tentacles and foot longer than in $V$. pygmica.

* Inhabiting high land. 
SHeLl subcylindrical, thin and semitransparent, very glossy, pale yellowish-horncolour, closely and rather strongly striate in the line of growth: periphery rounded: epidermis thin: whorls $4 \frac{1}{2}$, convex, but slightly compressed : spire short, abrupt and bluntly pointed: suture excessively deep : mouth semioval and subangular, owing to the outward compression of the periphery; teeth four, viz. one sharp and prominent tooth on the middle of the pillar, one strong and also prominent and thick tooth on the pillar lip, and two lamellæ or plate-like teeth which are placed at some little distance within the outer lip, but not on any rib or callous fold as in V. pygmaea; the labial teeth are visible on the outside, owing to the thinness and transparency of the shell : outer lip rather thick, very slightly reflected, not strengthened by any rib either outside or inside ; outer edge abruptly inflected : inner lip somewhat thickened in adult specimens: umbilicus small and narrow, but rather deep. L. 0.07. B. 0.04.

Habitat : Under stones and among dead leaves near Clithero in Lancashire (Gilbertson); Lipwood, near Haydon Bridge, Northumberland (J. Thompson); near Ambleside, on slate (Miss Sarah Bolton); Grassmere (J. G. J.). It is one of our most local species; and it does not appear to be extensively distributed abroad. Maack has recorded it as Russian; Von Wallenberg found it in Lulea-Lapland; Charpentier and myself in several parts of Switzerland; and I have also taken it in the Lower Harz. It is in Mr. Brown's list of Copford shells; but as a variety of $V$. pygmoea has been often mistaken for this species, I cannot satisfactorily recognize it as one of our upper tertiary fossils.

In my notice of the Harz Mollusca in the 'Annals and Magazine of Natural History' for November 1860 (p. 349) I stated that "this is a true Vertigo, and has not the slightest vestige of the lower pair of tentacles." The epiphragm is iridescent. The "Malakozoologische Blätter' for 1858 (Taf. 1. f. 5. $a-d$ ) contains an admirable representation of the shell. 
This species differs from $V$. pygmaea in being more cylindrical, of a paler colour and nearly transparent, and especially in the numerous and sharp transverse striæ, as well as in not having any rib either outside or inside the mouth.

It is questionable whether the $V$. alpestris of Férussac is the same as our shell, because he gave no description; and his original specimens appeared to me, from two careful examinations which I made in 1860 and 1861 , to be the marsh variety (pallida) of $V$. pygmcea, and not Alder's species. I have, however, no doubt of the present species being the Pupa Shuttleworthiana of Charpentier (Zeitschr. f. Malak. 1847, p. 148), having compared with that naturalist the specimens I collected in Switzerland. The Pupa borealis of Morelet from Kamtschatka appears also to belong to this species.

\section{V. SUBSTRIA'TA*, Jeffreys.}

Aloea substriata, Jeffr. in Linn. Trans. xvi. p. 515. Pupa substriata, F. \& H. iv. p. 108, pl. exxx. f. 3.

Bopy grey of different shades : snout short, bilobed : tentacles slender, cylindrical or club-shaped, and divergent : bulbs equal to about one-fourth of their length : foot of a lighter colour, thick, short, narrow and keeled at the tail.

SHeLl oval or subfusiform, rather thin and semitransparent, glossy, pale yellowish-horncolour, very strongly and obliquely striate and almost ribbed in the line of growth, but less so on the body whorl, which is faintly striate spirally : periphery rounded : epidermis rather thick : whorls $4 \frac{1}{2}$, very convex or cylindrical, and suddenly increasing in bulk, the penultimate whorl slightly exceeding in breadth the last, which occupies about one-half of the shell: spire short, very abrupt and bluntly pointed: suture remarkably deep: mouth semioval, contracted or sinuous in the middle of the outer edge; teeth from four to six, viz. from one to three (usually two) on the

$$
\text { * Slightly striate. }
$$


pillar, one on the pillar lip, and two or three on the inside of the outer lip, the last springing from a white rib; in halfgrown specimens the pillar lip has a spiral or longitudinal fold : outer lip thin and slightly reflected, strengthened by a strong rib, which is placed very near the opening of the mouth; outer edge abruptly inflected: inner lip thickened in the adult: umbilicus small and narrow, contracted by a keel or ridge at the base of the shell. L. 0.065. B. $0 \cdot 04$.

Habitat: Under stones, among dead and decaying leaves, and at the roots of grass in woods and moist places, in many parts of Great Britain from Skye to Devon, as well as throughout Ireland. Mr. Brown has enumerated it in his list of upper tertiary shells from Copford. Abroad it has been noticed by Nordenskiöld and Nylander as inhabiting Finland, by Malm as Swedish, and by Held as Bavarian. It does not appear to have been found in France.

This exquisite little snail is tolerably active, though timid, and carries its shell nearly upright. The epiphragm is like that of its congeners. There is no rudiment or trace of lower tentacles; and my first description of the animal (in 1830) is incorrect in that respect. I have since very carefully examined a great many living specimens, and could not detect with a Coddington lens even a speck in the place usually occupied by these tentacles. Dr. Johnston found this species in East Lothian at a height of 1200 feet.

The form of the shell, and the strong transverse striæ, as well as the number and arrangement of the teeth, will at once serve to distinguish this from any of the foregoing species.

It is the $V$. curta of Held ; and it closely resembles, and may be specifically identical with, the Pupa milium of Gould, which is a native of the United States. 
B. Shell sinistral, fusiform: mouth furnished with teeth and contracted.

\section{V. PUSIL'LA*, Müller.}

V. pusilla, Müll. Verm. Hist. pt. ii. p. 124. Pupa pusilla, F. \& H. iv. p. 111, pl. exxx. f. 8.

BoDY oblong, slightly contracted and rounded in front and insensibly narrowing behind, brown or greyish-slatecolour above, and whitish with a faint tinge of blue on the sides and underneath, minutely tubercled: mantle yellowish-brown: tentacles very close together at their base, but widely diverging, thick, nearly cylindrical, dusky-grey with a slight tinge of brown; bulbs long, but not very prominent: foot broad and rounded in front, very tumid, keeled and a little pointed behind.

SHELl subfusiform, with somewhat of a quadrangular outline, thin and semitransparent, very glossy, horncolour with a faint tinge of yellow, very slightly and remotely striate in the line of growth: periphery rounded, with a tendency to angularity: epidermis thin: whorls $4 \frac{1}{2}$ or 5, very convex and cylindrical, gradually increasing in size; the penultimate whorl as broad as the last, which occupies about two-fifths of the shell: spire shortish, but rather tapering, and blunt at the point: suture very deep: mouth semioval, contracted or sinuous in the middle of the outer edge; teeth six or seven, viz. two on the pillar, two on the pillar lip (the inner one of which is always larger, and the outside one tubercular and placed in the angle where the outer lip joins), and two or three within the outer lip (the third, when it is present, placed near the pillar lip and being a mere tubercle) : outer lip rather thick and slightly reflected, strengthened by a strong rib both outside and inside, which is situate near the opening of the mouth and is yellowish-white; outer edge rather abruptly inflected: inner lipslightly thickened in full-grown specimens: umbilicus small and narrow, contracted by a rather sharp and gibbous crest or ridge at the base of the shell. L. 0.07. B. 0.045 .

HaвiтAт: Under stones and among dead leaves and moss in woods, in various parts of Great Britain from Westmoreland to Devon, as well as in the North and * Little. 
West of Ireland; but it does not appear to have been detected in Scotland. Although diffused, it is local and rare. It occurs in our upper tertiary strata. On the Continent it ranges from Finland to the North of Italy,viz. Lugano (Stabile); Como (Porro); Lombardy (Villa); and Aradas and Maggiore are said to have found a specimen on the sea-shore at Catania.

This is a very shy little snail and slow in its movements. When it is about to crawl and emerges from the shell, it puts its foot foremost. Its slime is rather abundant. The shell is carried perpendicularly. The epiphragm is membranous and plaited. Muiller says that under the microscope a small black line can with great difficulty be detected in the place which is occupied in the animal of Pupa by each of the lower tentacles.

The reversed direction of the spire is an easy mark of distinction between this and all the foregoing species of Vertigo. The present species is not a sinistral form or variety of any other kind, as I have satisfied myself by comparing this in a mirror (which of course makes the spire appear dextral) with $V$. antivertigo and $V$. substriata, in which the teeth are somewhat similarly arranged. The shape of the present species, if it were dextral, would be intermediate between that of the lastnamed species and $V$. edentula.

Leach is the only conchologist who has proposed to change the original name; and he has rechristened this species $V$. heterostropha. It must be recollected that Müller was the founder of the genus, as well as the discoverer of the present species, which was at that time the only one known; so that, if any alteration were necessary on account of the contrary direction of the spire, this species ought at all events to retain the name first given to it by its discoverer. I had long previously 
proposed the institution of another genus (Alcea) for the reception of those species which have a dextrorsal spire; but I now consider this generic addition to be quite useless and untenable.

\section{V. ANGUS'TIOR*, Jeffreys.}

V. angustior, Jeffr. in Linn. Trans. xvi. p. 361. Pupa Venetzii, F. \& H. iv. p. 112, pl. exxx. f. 9.

Bopy short and stumpy, blackish in front and greyish on the sides and underneath; tubercles indistinct: mantleyellowish-grey : tentacles thick, somewhat cylindrical, dusky-grey, considerably diverging from each other; bulbs scarcely distinct : foot thick and narrow, pale-grey.

SHELL subfusiform or barrel-shaped, narrower in proportion than V.pusilla, rather solid, but semitransparent, glossy, light horncolour, strongly, obliquely and rather closely striate in the line of growth: periphery compressed and somewhat angular: epidermis thin: whorls $4 \frac{1}{2}$, rather convex, but compressed, gradually increasing in size, the penultimate one a trifle broader than the last, which occupies about two-fifths of the shell, the first or upper whorl smooth and shining: spire rather short, abrupt and blunt at the point: suture rather deep: mouth subtriangular, and very narrow in consequence of the great contraction or sinuosity of the outer edge in the middle as well as towards the base; teeth four or five, viz. two on the pillar (the outer one of which is a little in advance of the other), one on the pillar lip, which is sunk deep within the mouth and resembles a strong curved plate more than a tooth, and one thick and prominent tooth inside the outer lip, with rarely a small tubercle by the side of it: outer lip exceedingly thick and scarcely inflected, strengthened outside and inside by a strong rib, which is situate near the rim and is yellowish-white; the inside rib remarkably thick and increasing the contraction of the mouth: inner lip consisting of a slight deposit on the columella: umbilicus very small, narrow and indistinct, being much contracted by a sharp and gibbous keel or crest at the base of the shell. L. 0006. B. $0 \cdot 035$.

Habitat: At the roots of grass in marshy ground, * Narrower. 
but only hitherto noticed in a few localities. These are as follows:- Singleton near Swansea, and the rejectamenta of the Avon River at Bristol (J. G. J.); Tenby (Webster); Battersea fields (Stephens); Co. Clare (Humphreys); and Connemara, Co. Galway (Warren). Mr. Brown has noticed it among the shells in the upper tertiary deposit at Copford. Abroad it has been found in the North, East, and South of France, as well as in Germany, Switzerland, and Lugano. Near Villeneuve, in the upper Valley of the Rhone, I observed it to be tolerably plentiful in a wet meadow or piece of land by the side of the road leading from Vevay to St. Maurice, as well as in similar situations near Lausanne and at Chable in the Valley of Bagne. The first-mentioned piece of land had lately been mown; and consequently these tiny shells were more easily detected. I have thus specially noticed these foreign localities, to indicate the kind of station in which this rare shell may be sought for in this country.

The animal is rather slow in its movements and carries the shell upright on its back.

The shell differs from $V$. pusilla in its much smaller size and being proportionally narrower, in the distinct and strong transverse striæ, and especially in the shape of the mouth, which is triangular and very narrow, instead of being subquadrate and open (which is the case in V. pusilla), as well as in the number, shape, and position of the teeth. The single labial tooth in the present species is situate opposite to the space between the two teeth in the columella, and would lock into them if the two sides were in contact, like the hinge teeth of many bivalve shells. An excellent and enlarged figure of the shell is given in 'Wiegmann's Archiv' for 1838, pl. iv. f. 6 . 
I hope I may be excused saying a few words here about the correct name of this species, as regards myself. It is an invidious and unpleasant task to vindicate one's own supposed discoveries; but it is at the same time useful to the cause of Science, and in some respects resembles the duty of a parent in defending his children. As our Continental neighbours and friends would say, "il faut faire une réclamation."

In the 'Linnean Transactions' for 1830 I proposed the present species and gave it the name of "angustior," accompanied by a full description, in Latin, of its specific characters. I also noticed particularly the contour of the shell, the shape of the aperture or mouth, and the position of the teeth, in comparison with those characters in V. pusilla. In the following year Michaud described and figured the same species in his Supplement to Draparnaud's posthumous work, under the name of $V$. nana. In the 'Isis' for 1837, Held also described the shell and gave it the name of $V$. hamata. In 1838 Professor A. Miuller again described and figured it in 'Wiegmann's Archiv' as V.plicata. And, in order that this mite of a shell should have as many names as any Spanish Hidalgo, Rossmässler in 1839 redescribed and figured it in his 'Iconographie,' and adopted Charpentier's MS. name of $V$. Venetzii. This last name has been used by the authors of the 'British Mollusca'; and Held's name of plicata has been adopted by Moquin-Tandon, under an erroneous impression (originating apparently in a typographical error in Rossmässler's work) that the number of the 'Isis' which contained the latter name was published in 1828, and not in 1838 . I have ascertained, by an examination of Michaud's and Charpentier's types, that their species are the same as mine. I have also no doubt of the Turbo vertigo of Montagu, 
as first described by him, being specifically identical with it, and his name is consequently prior to all those which I have enumerated; but the reduplication of the same name, both in a specific and generic sense, would be objectionable. V.pusilla, as well as the present species, were confounded by Montagu in the subsequent part of his description. I fear that this little episode will interest none but bibliographical naturalists.

\section{Shell dextral, cylindrical : mouth seldom furnished with teeth.}

\section{V. EDEN'TULA*, Draparnaud.}

Pupa edentula, Drap. Hist. Moll. p. 52, pl. iii. f. 28, 29 ; F. \& H. iv. p. 103, pl. exxx. f. 1 .

BoDy rather slender, ash-grey, of a darker hue above, and much paler behind as well as on the sides and underneath; tubercles extremely small, reduced to blackish or greyish dots: mantle very pale reddish-grey: tentacles thick, nearly smooth, blackish-grey ; bulbs forming about one-third of their length, oval, and very blunt; there is no sign of any lower tentacles and not even a spot to indicate their place: foot oblong and narrow, slightly pointed behind.

SHELL oblong, nearly cylindrical, thin, semitransparent and glossy, light yellowish-brown or horncolour, marked with slight, but numerous, oblique and somewhat curved striæ in the line of growth: periphery rounded, although having a slight tendency to angularity : epidermis thin : whorls $5 \frac{1}{2}-6 \frac{1}{2}$, moderately convex, gradually increasing in size, the penultimate whorl rather broader than the last, which occupies about two-fifths of the shell : spire long, abrupt and blunt at the point: suture deep: mouth forming an arch or segment of two-thirds of a circle, destitute of teeth : outer lip thin, very slightly reflected, except towards the umbilicus, over which it folds on the side next to the mouth : pillar lip nearly straight in adult specimens; umbilicus narrow and contracted by the pillar, but rather deep. L. $0 \cdot 1$. B. $0 \cdot 05$. 
Var. columella. Shell somewhat longer, and having the last whorl a little broader than the next. Pupa columella, (V. Martens) Benz, Ueber Würtenburg. Faun. p. 49.

Habitat : Woods, among dead leaves, at the roots of grass and in herbage, as well as on the trunks of trees, in most parts of the kingdom, from the Moray Firth district to Guernsey. This species, however, is local. The variety has been found by Mr. Waller at Finnoe, Co. Tipperary. It inhabits moister places than the typical form and is the Pupa inornata of Michaud. The present species is one of our upper tertiary fossils. Its foreign range extends from the Amoor territory and Lapland to Lombardy.

This elegant little mollusk is timid, and retires within its shell at the slightest touch. When crawling, it usually carries the shell in a slanting position. Its slime is watery. Mr. Sheppard noticed that his Essex specimens were uniformly darker than those which he found in Suffolk. It inhabits considerable heights. Puton found it on the Vosges Mountains at an elevation of 1150 mètres, or 3773 feet. Young shells resemble those of a conical Helix, and have a sharply keeled periphery and a small umbilical perforation. Mr. E. J. Lowe says that Professor Babington once observed this species in great abundance on the under surface of the fronds of Aspidia in autumn. They may be found in winter, together with Carychium minimum and other minute shells, concealed in the decayed stalks of the larger umbelliferous plants.

Although this species is peculiar and by no means uncommon, it seems to have escaped the notice of Montagu and the older writers on British Conchology. It is the V.nitida of Férussac, Turbo Offtonensis of Sheppard, and my Alaea revoluta. 


\section{V. Minutis'Sima*, Hartmann.}

Pupa minutissima, Hartm. in Neue Alp. i. p. 220 , pl. ii. f. 5 ; F. \& H. iv. p. 104, pl. exxx. f. 2.

BoDy slightly narrow and rounded in front, very gradually attenuated and somewhat blunt behind, finely shagreened, greyish-slatecolour, streaked or dotted with black: mantle greyish-brown and of a lighter hue than the upper part of the body: tentacles greatly diverging, separated by a narrow groove, very tumid at their base, broadly edged with black; bulbs slightly globular: foot of a paler colour (sometimes milk-white) at the sides and underneath, with a faint tinge of yellow towards the middle of the sole, ending in a triangular and blunt tail.

SHELL oblong, nearly cylindrical, rather solid, semitransparent and glossy, yellowish-brown or horncolour of different shades, marked with strong, close-set, obliquely transverse and rib-like striæ: periphery rounded, but slightly compressed, with a tendency to angularity: epidermis thin: whorls $5 \frac{1}{2}$, moderately convex, gradually increasing in size, the last but two being somewhat the broadest of all, the body whorl occupying about two-fifths of the shell: spire long, very abrupt and blunt at the point: suture deep: mouth shaped as in $V$. edentula, and (in British specimens) equally destitute of teeth : outer lip thin, white, and reflected: umbilicus small, narrow and oblique. L. 0.07. B. 0.035.

Habitat: Under stones on hills in a few scattered places in Great Britain, and which are as follows:Skye (Macaskill); Balmerino, Fifeshire (Chalmers); Arthur's Seat, Edinburgh (E. Forbes); Sunderland, South Hylton on the Wear, and Pontefract on magnesian limestone (Howse); Went Vale, Yorkshire (Ashford); Durdham Downs near Bristol, and Lulworth in Dorsetshire (J. G. J.); Undercliff, Isle of Wight (More). As an upper tertiary fossil it has been found at Clacton and Copford in our eastern counties. It is widely diffused on the Continent from Finland to Lombardy and

* Exceedingly minute. 
Corsica; and (assuming the Pupa Callicratis of Scacchi to be the same species) it ranges to Sicily. According to Roth it has been found at Athens.

This exquisitely beautiful but tiny creature is slow in its movements, and carries its shell nearly upright when it crawls. Puton is said to have found it at a height of 1352 feet on granite in the Vosges Mountains. The epiphragm is very thin and glistening. The length of the spire varies considerably in this, as well as the last species. Our native examples are toothless; but foreign specimens have frequently a tooth on the pillar and another within the outer lip; and I found a specimen in Switzerland which had three teeth, arranged triangularly as in the Pupa triplicata of Studer.

This species is the Pupa minuta of Studer, P. muscorum of Draparnaud, Vertigo cylindrica of Férussac, Pupa obtusa of Fleming (but not of Draparnaud), and it is probably also the $P$. costulata of Nilsson.

\section{Genus VIII. BA'LIA*, (Balea) Prideaux. Pl. VII. f. 9, 10, 11.}

BoDy long and slender, always containable within the shell : tentacles 4, proportionally short: foot rather broad.

SHell sinistral, turriculate, thin, delicately striate and streaked with white in the line of growth: spire reversed, long and pointed: mouth squarish, sometimes furnished with a small tubercular tooth on the columella: umbilicus narrow and oblique.

This generic group has only a single species which is indigenous to this country. A few others are exotic. In the reversed turn of the spire and general aspect, as well as in the shape of the mouth and the straight pillar

$$
\text { * Bay-coloured. }
$$


lip, it closely resembles a young or incomplete Clausilia, and might lead to the supposition that its growth or development had been suddenly arrested. It wants, however, the clausilium or twisted internal plate which is characteristic of the adult Clausilia, as well as the oblique teeth or folds which contract the aperture of that shell. In the small tubercular tooth which is occasionally formed on the pillar, Balia has some affinity to the genus Vertigo; but the mouth of the shell in the present genus is of a different shape, and the spire is more elongated or drawn out. The shell of Balia, when viewed in a mirror (so as to make the spire appear dextral), is not unlike that of a wide-mouthed Pupa. The soft parts of the animal do not present any peculiarity, or appear to be different from those of the other genera above mentioned. The members of this genus are inactive in their habits, and are fond of shade and moisture, but not of excessive wet. They are usually found in the crevices of rocks and walls and under the bark of old trees; and they probably feed on the spores of mosses and other Cryptogamous plants, as I have observed them after a shower of rain apparently thus occupied, while slowly crawling over the trunk of a sycamore. They may be called the "Tree-snail."

The present genus was first made known by Dr. Gray in the 'Zoological Journal' (vol. i. p. 61) under the name of Balea, from MS. information furnished by Mr. Prideaux, an assiduous conchologist and friend of Dr. Leach. In a posthumous work of the latter author, entitled 'A Synopsis of the Mollusca of Great Britain,' which was edited by Dr. Gray and published in 1852, the same genus appears as Balcea. The word is probably taken from balius (pro badius), and not, as M. Bourguignat supposed, from $\beta a \lambda$ ı̀s (maculosus), as the shell is 
not spotted. Balea and Balaca may therefore be typographical errors. M. Ch. D'Orbigny, in the 'Dictionnaire d'Histoire Naturelle,' thought the name might be an obsolete Latin word (balea) signifying a bark or vessel ; but this meaning is not applicable to either the shape or habits of our little snail, which rather dreads than courts the water. Swainson substituted Balia for the original name; and his emendation has been adopted by Stabile as well as Bourguignat, the latter of whom has published, in his 'Aménités Malacologiques,' an elaborate and valuable article on the species comprised in this genus.

\section{Balia Perver'sA*, Linné.}

Turbo perversus, Linn. Syst. Nat. ed. xii. p. 1240. Balea fragilis, F. \& H. iv. p. 114, pl. exxviii. f. 8, 9.

BoDY rounded in front, slender and tapering behind, darkbrown with a shade of grey, covered with minute black tubercles and specks: snout prominent and rather tumid: tentacles short, rather thick; upper pair close together, cylindro-conical and broad at the base, with bulbs about one-sixth of their length; lower pair very small in proportion, and conical : foot somewhat rounded in front and gradually narrowing to a tumid and slightly keeled tail.

Shell club-shaped, thin, semitransparent, glossy, yellowishbrown, with transverse and oblique streaks of white, closely but irregularly striate in the line of growth, and also marked with a few remote and indistinct spiral lines: periphery rounded, with a tendency to angularity: epidermis rather thin: whorls 7-8, convex, but slightly compressed, regularly increasing in size, the last being equal to about one-third of the shell and much broader than the others, the first or top whorl quite smooth, semiglobular, and shining: spire tapering to a somewhat blunt point : suture deep: mouth squarishoval, higher than broad, sometimes furnished with a tubercular tooth, which is placed nearly on the middle of the columella : outer lip rather thin, white and reflected, especially over the umbilicus, sinuous outside and sharply inflected above: pillar

* Awry, or twisted the wrong way. 
lip nearly straight: umbilicus forming a narrow and oblique slit. L. $0 \cdot 275$. B. $0 \cdot 1$.

Var. viridula. Shell greenish-white and transparent.

Haвitat: On the trunks of trees (chiefly of beech, ash, sycamore, and apple), as well as on mossy rocks and walls, in various parts of Great Britain and Ireland from the Moray Firth district to Guernsey. The variety was found near Cork by Mr. Humphreys. Professor Morris has noticed this species as fossil in the upper tertiary deposit at Grays. It ranges from Finland to Sicily, and even to Madeira and the Azores. It is widely diffused in Europe.

The Tree-snails are gregarious, and are found of different ages in the same spot, as if forming a sociable family party. It is difficult to discover them in dry weather, as they lie concealed in crevices of rocks or under the bark of trees; but after rain they come out from their hiding-places and feed on the moistened vegetation. They are not particularly sensitive, and do not withdraw into their shells on being touched or disturbed; nor are they afraid of cold, having been observed crawling about when the temperature was very little above zero. Puton found specimens on the Vosges Mountains at a height of nearly 2300 feet. Bouchard-Chantereaux says that $B$. perversa lays, in the beginning of autumn, from 12 to 15 whitish and globular eggs, which are of a large size compared with those of most other snails, and that the young are excluded or hatched on the fifteenth or sixteenth day afterwards and become adult at the end of their first year. Lister stated that the sexes were distinct in this species, and that there was a difference of size between the male and female, the latter being more bulky; but Dr. Gray very properly remarks that this 
cannot be the case, because in these mollusks each individual is both male and female.

The shell of this species differs from the young of Clausilia rugosa (which it somewhat resembles in form) in being thinner and of a much lighter colour, in the whorls being much more convex, and especially in the periphery or basal edge being rounded, instead of sharply angular as in the young shell of that species.

It is the Pupa fragilis of Draparnaud ; and MoquinTandon has retained it in that genus. The Balia Sarsii of Philippi appears to be only a variety of the present species, judging from his description in the 'Zeitschrift für Malakozoologie' for June 1847, p. 84.

\section{Genus IX. CLAUSI'LIA*, Draparnaud. Pl. VII. f. 12, 13, 14.}

BoDy long and slender, always containable within the shell : tentacles 4 ; upper pair rather long and prominent; lower pair very short and resembling conical nipples : foot long and narrow.

SHELL sinistral, spindle-shaped, rather solid, usually ribbed transversely, and always more strongly, or wrinkled, towards the mouth : spive reversed, long and pointed: mouth small, pear-shaped, and twisted on the body whorl, having a deep sinus or groove at its upper angle, furnished with two spiral plates and sometimes also with intermediate ridges or teeth on the columella, as well as with a flexuous plate or fold behind the pillar lip and curved plates or folds within the outer lip; besides these various processes there is a peculiar and complicated apparatus lying deep within the throat or cavity of the mouth and consisting of a moveable and elastic nacreous-white plate or ossicle, which is twisted and somewhat resembles a flattened ram's-horn, serving the purpose of an operculum: outer lip continuous and forming a complete peristome: basal crest (which is formed by an upward and abrupt twist and contraction of the last whorl) more or less

* Furnished with a clausilium or operculum-like process. 
prominent: umbilicus very slight, and consisting of a narrow and oblique slit behind the pillar lip.

The Clausiliae are herbivorous. Some species inhabit rocks, stony places, and old walls, while others seem to prefer woods and shady spots, and are to be met with on trunks of trees and under stones among herbage. They bury their bodies and three-fourths of their shells in the earth, and excavate a small oblique tunnel, for the purpose of depositing their eggs.

The malacological relations of this genus are with Bulimus and Pupa. In the form of the shell it is allied to both of those genera, setting aside the circumstance of the spire in the present genus being reversed; but the spire in Bulimus and Pupa is shorter than in Clausilia. As in most of the species of Pupa, the laminar teeth in Clausilia are never formed until the last whorl has been commenced.

A peculiar and characteristic feature of the present genus is that the animal is provided with an internal process called the "clausilium." It is analogous to the testaceous appendages of Teredo, called "pallets;" although they are not homologous organs, nor is the clausilium attached to the body of the snail, like the pallets to that of the Ship-worm. This remarkable process acts as a valve or spring-door in closing the shell against all intruders, and has been well described by Mr. J. S. Miller, in the 'Annals of Philosophy' for 1822 (vol. iii. p. 378), in the following words:-

"Independently of the various contrivances which Nature has resorted to for the protection of the otherwise vulnerable Mollusca, it has taken peculiar care to guard the apertures of many univalves from the intrusion of enemies; hence the apertures are sometimes peculiarly contracted and provided with numerous folds and teeth. 
Other Mollusca have a calcareous operculum permanently formed, which increases in thickness, and enlarges on a depressed spiral plane, as the opening of the shell extends with the growth of the animal, thus continually assimilating to its size, and when the animal retreats, excluding it completely from all external intrusion. In the Clausilia, Naturehas continued the protection afforded by means of contractions and folds, and also added an opercular appendage. The inhabitant of the Clausilia, when nearly full-grown, secretes a thread-like elastic calcareous filament, one of whose ends is affixed to the columella. This filament makes half a spiral turn round the columella, insinuating between its folds. When the animal finishes its shell and completes the aperture, it secretes, at the unattached end of the filament, a spoonshaped calcareous lamina conforming at its margin to the contour of the aperture. The lamina is somewhat smaller than this, and its margin is rounded. Its adhesion to an elastic filament enables the animal to push it, when it comes out of its shell, against the columella; and the same elasticity closes it on the inhabitant retreating, thus securing it from intruding enemies. Thus, then, this valve may be compared to a door provided with an elastic spring. The elasticity of the filament may be restored to its full power (in the empty shell) by sometimes immersing it in water, as $I$ have ascertained in a section made with a view to this inquiry."

Müller had, nearly half a century before, accurately described this singular piece of mechanism and called it an ossiculum. He quaintly remarks that when the snail has opened the door of its house, "Veneri et Cereri otiosus vivit." The 'Journal de Conchyliologie' for 1853 contains an excellent article by M. Cailliaud on the subject, which is illustrated by admirably executed figures, 
showing the position and shape of the clausilium or ossicle in several species.

The Clausilice would seem to be more at home in the South of Europe and Asia Minor than in any other part of the world, judging from the statistics given by Charpentier in his Monograph on the genus, which was inserted in the 'Journal de Conchyliologie' for 1852. He enumerated 235 species; and this number has since been added to by M. Schmidt, who has lately published an exhaustive essay on the same subject. None of them have been discovered in North America. Three species are dextral and inhabit Transylvania. Some of our native Clausilice occur in the upper tertiary strata of Essex, Suffolk, and Norfolk ; and their origin, as inhabitants of Northern Europe, must therefore be very remote.

A. Shell ribbed or striate transversely: clausilium having its margin entire.

\section{Claudilia Rugo'sa*, Draparnaud.}

C. rugosa, Drap. Tabl. Moll. p. 63. C. nigricans, F. \& H. iv. p. 121, pl. exxix. f. 1, 2.

BoDy dark-grey or slatecolour, with a tinge of reddishbrown, paler at the sides and underneath, indistinctly tubercled in such a way as to appear wrinkled: tentacles thick, minutely speckled with black ; upper pair rather close together, with bluntly rounded bulbs which are darker than the tentacles; lower pair decidedly conical, and darker than the upper ones : foot of a rather clear greyish colour, narrowing gradually towards the tail, which is tumid and pointed.

SHELL shaped like a long club, but somewhat attenuated at the broader end, not thin and scarcely semitransparent, rather glossy, light-brown or horncolour, with a few transverse streaks and lines of white, marked with numerous and close-set but somewhat irregular striæ in the line of growth, which are curved on the upper and flexuous on the lower

* Wrinkled. 
whorls, as well as with a few indistinct spiral striæ, the intersection of which gives the surface a slightly granular appearance : periphery angular or ridged : epidermis rather thin: whorls 12-13, compressed, regularly increasing in size, the last being equal in bulk to about one-third of the shell, but somewhat narrower than the two or three preceding whorls; the first whorl nipple-shaped and quite smooth: spire tapering to an obtuse point: suture rather oblique, slight but distinct: mouth almost funnel-shaped, compressed on the outer side, and having an effuse base, like the lip of a water-jug; teeth or folds as follows:- two on the pillar, the upper one of which is prominent and oblique and forms one of the sides of a channel at the outer angle, and the lower one is smaller and more sunk or deeply seated, being also oblique and sometimes bifurcate, and between these are occasionally from one to three smaller folds or ribs ; one strong but deep-seated and not very distinct crescent-shaped fold (or lunella) on the pillar lip; one still more sunken and very slight spiral fold near the last; and occasionally one or two teeth (like those in Pupa) within the outer lip: the outer lip is thick, white, and reflected: basal crest sharp and angular, transversely ridged: umbilicus much contracted by the intortion of the mouth : clausilium ovaloblong, regularly curved, slightly dilated above. L. $0 \cdot 5$. B. $0 \cdot 1$.

Var. 1. albida. Shell greenish-white, with a few white transverse lines.

Var. 2. Everetti, Miller. Shell smaller.

Var. 3. gracilior. Shell longer and more slender.

Var. 4. tumidula. Shell smaller, shorter, and more ventricose.

Var. 5. dubia. Shell larger and more ventricose. $C^{\prime}$. dubia, Drap. Hist. Moll. p. 70, pl. iv. f. 10.

Var. 6. dextrorsa. Shell resembling a Pupa in shape: spire dextral.

Habitat : On old walls and rocks, as well as under stones and on the truuks of trees, throughout these isles, from Zetland to Guernsey. Var. 1. Dinton Hall, Bucks (Goodall). Var. 2. Bristol (Miller); Whalsey Skerries, Zetland; Giant's Causeway and Co. Tyrone (J. G. J.). Var. 3. Battersea marshes (J. G. J.). This last variety appears to be the $C$. rugulos $a$ of Ziegler. Var. 4. Brockley 
Combe near Bristol, and Connemara (J. G. J.). Var. 5. Northumberland and Durham (Alder); Oxfordshire (Whiteaves). Var. 6. Sevenoaks, Kent (Smith). This species occurs in our upper tertiaries. Its Continental range extends from Finland to Portugal and Lombardy.

The shells of different individuals of this species vary considerably in the length of the spire and their comparative solidity, as well as in the degree of sculpture. Sometimes a great part of the surface is quite smooth, as if filed and polished; and this is the case with living specimens. How this effect is produced it is not easy to say. Perhaps they lived in a sandy soil, and the continual friction of the shells, when trailed along by the animal, might account for the abrasion. Such specimens were in the collection of Dr. Turton and were considered by him (as well as at one time by myself) to be the C. parvula of Studer; but the smooth and sleek appearance of the last-mentioned shell is very different from that of the above specimens. Some curious monstrosities occur, in some of which the spire is distorted, or a faint keel or impressed lines encircle the whorls, or the mouth is renewed in such a way as to show the columellar folds in their incipient state. Lister was the first to notice this shell; and his communication to the Royal Society "On the odd turn of some Shell-snails" is one of the earliest on their records.

It is (partly) the Helix perversa of Miiller, Turbo bidens of Montagu (but not of Linné), T. nigricans of Maton and Rackett, and Clausilia obtusa of C. Pfeiffer. Many other names have been given by Continental authors to different forms of this extremely variable species.

C. parvula differs from the present species in being smaller and quite smooth, with the exception of some very faint transverse lines, which are only observable 
with a lens, or of a few striæ near the mouth. It inhabits the North of France, as well as every other part of the Continent, and may be expected also to be found in Great Britain.

\section{C. Rolph'I*, Gray.}

C. Rolphii, Gray in Turt. Man. L. \& F.W. Sh. p. 71, f. 54. C. plicatula, F. \& H. iv. p. 120, pl. cxxix. f. 3.

BoDy dark-brown or dusky, with a reddish hue above, greyish-brown on the sides and underneath; tubercles blackish, arranged in very close lines: mantle thick, yellowish-white, with small specks of pure white: tentacles greyish-brown; upper pair rather short and stout, nearly cylindrical as far as the bulbs, slightly shagreened and covered with black dots, which are so minute as scarcely to be visible with a lens of ordinary power, the bulbs thick and nearly spherical; lower pair exceedingly short and of a paler hue than the others: foot very long, narrower in front, ending in a slightly rounded tail : sole greyish-white.

Shell fusiform, rather thinner than the last species but scarcely semitransparent, slightly glossy, reddish- or yellowish-brown, with occasionally a few white lines dispersed here and there over the surface, marked with strong, sharp and somewhat regular transverse strix, of which there are from sixty to seventy on the body of the last whorl; these striæ are curved on the upper and somewhat flexuous on the lower part of the shell, becoming fewer and consequently more remote but stronger towards the outer lip; spiral striæ very indistinct and scarcely perceptible: periphery angular: epidermis rather thick: whorls 9-10, tumid, but somewhat compressed, the last being rather less than onethird of the shell and a little narrower than the two preceding whorls; the two or three first whorls are nearly of the same breadth and form a short cylinder: spire abruptly tapering and obtuse at the point: suture rather oblique, not very deep : mouth subquadrangular, sinuous on the outer side and effuse below; teeth as in C. rugosa, but in the present species there are often two or three small teeth or ridges between the columellar folds, and the lower of these

* Named after Mr. Rolph, an English conchologist. 
folds is less prominent but often cruciate: outer lip thick and rather broad, white or cream-coloured and inflected: basal crest short and curved: umbilicus indistinct: clausilium oblong, regularly curved, slightly contracted above. L. 0.5 . B. $0 \cdot 15$.

HABITAT: Under stones, in the bark of trees, and among dead leaves, in Kent, Sussex, and Hants, as well as in Gloucestershire, but hitherto found only in a few places. This species is one of our upper tertiary fossils. It is not uncommon in the North and South of France, Belgium, and parts of Germany. Probably it is also a member of the Scandinavian fauna, assuming Nilsson's variety $\beta$ of $C$. plicatula to belong to the present species. His diagnosis, although too short and indefinite for satisfactory identification, appears to agree with the main characters of our shell.

This species differs from C. plicatula (for which it has been mistaken) in being more than twice the size, much more ventricose and of a paler colour, in the spire being more abrupt, and especially in the striæ being closer and more numerous in proportion to the size of the shell. From $C$. rugosa and its variety dubia this differs in being also more ventricose and of a lighter colour, as well as in having much coarser striæ and in being destitute of the distinct spiral striæ, which impart to the last-mentioned shell a decussated or slightly granular appearance. The mouth of the shell in C. Rolphii is, besides, larger and broader. The shell in this as well as the other species varies considerably in respect of the length of its spire and the development of its teeth and basal crest. C. Mortilleti of Dumont is, according to Schmidt, only a synonym of the present species ; although Mr. Benson at one time considered that they were distinct, and pointed out the difference between them in the 'Annals of Natural History' for July 1856. 


\section{C. BIPLICA'TA*, Montagu.}

Turbo biplicatus, Mont. Test. Brit. p. 361, tab. ii. f. 5. C. biplicata, F. \& H. iv. p. 118, pl. cxxix. f. 4 .

BoDy reddish-grey, dusky or almost black above and paler on the sides and underneath; tubercles rather large, but irregular: mantle minutely speckled with white: tentacles dirty reddish-grey ; upper pair subcylindrical and finely shagreened, with slightly tumid bulbs; lower pair conical : foot long and rather narrow; tail depressed and bluntly rounded.

SHell subfusiform and slender, rather thin, but scarcely semitransparent, having somewhat of a silky lustre, reddishor yellowish-brown, irregularly streaked with white lines, which colour some of the striæ and are often more conspicuous near the suture, imparting a greyish hue to the shell, strongly and closely striate in the line of growth, as in $C$. Rolphii; but the striæ in the present species are straighter, although slightly flexuous on the last whorl: periphery obtusely angular: epidermis rather thick: whorls 12-13, compressed, the last being very little more than one-fourth of the shell and slightly narrower than the preceding whorl; the first whorl and a half are quite smooth and glossy, and the second whorl is broader than the first: spire slender and gradually tapering, obtuse at the point: suture rather oblique, not very deep: mouth oval, angular, contracted below, where a narrow but deep channel is formed; outer margin compressed and nearly straight; teeth as in all the foregoing species, but the interlamellar denticles on the pillar seldom occur or are very slight: outer lip white, expanded, prominent and detached, not so thick, as in the last species: basal crest strong, nearly straight: umbilicus broader than usual in this genus: clausilium nearly oval, slightly curved, attenuated below. L. 0.65. B. $0 \cdot 166$.

HaBitat : At the roots and in the bark of old willowtrees; Easton Grey, Wilts (Montagu); Clarendon, near Salisbury (Bridgman); and banks of the Thames near London, where this species is not uncommon. These appear to be the only localities hitherto recorded or known in this country. It has been found in a semifossil state at Clacton and Grays in Essex. Its foreign

* Having two folds. 
distribution is not very extensive; but it occurs in many parts of France, Germany, and Switzerland. If (as I suspect) this is the same species as that which Malm has referred to the C. lineolata of Held, it ranges northward to Sweden.

This is an inactive mollusk, and seems to drag its shell along with difficulty, as if it were an incumbrance. In its natural state the shell has often a slight covering of mud or dirt.

It differs from $C$. Rolphii in its shell being twice as large and much more slender, in the constant presence of white lines or streaks, and in seldom having any interlamellar teeth, but chiefly in the form of the aperture and the distinct channel at its base. In the latter respect it also differs from the $C$. ventricosa of Draparnaud.

It is the $C$. similis of Charpentier. Another of its synonyms is the $C$. vivipara of Held; but I am not aware that the organization of the animal warrants this last specific name.

B. Shell nearly smooth, glossy : clausilium having its margin on the lower side notched.

\section{C. LAMinA'TA*, Montagu.}

Turbo laminatus, Mont. Test. Brit. p. 359, tab. ii. f. 4. C. laminata, F. \& H. iv. p. 116, pl. exxviii. f. 10.

BoDy slightly narrowed and nearly truncate in front, gradually attenuated and rather pointed behind, reddish-black or greyish-brown, with a yellow tinge on the upper part, lightgrey on the sides and underneath ; tubercles somewhat large and prominent, more or less deeply coloured: mantle not reaching the mouth of the shell, annular and narrow, covered with minute and indistinct black dots: tentacles rather short, thick and diverging, reddish-brown; upper pair very finely

* Having plates. 
granular, with rather tumid bulbs; lower pair more conical and deeply coloured than the upper ones, and nearly smooth : foot broad and rounded in front, transversely grooved at its sides, and ending in a slender but blunt tail.

SHell of the same shape as C. biplicata, but semitransparent and glossy, yellowish-brown with a faint tinge of red, smooth to the naked eye, but under a magnifier delicately striate in the line of growth, these striæ being more perceptible near the suture; there are also a few coarse wrinkles near the mouth and umbilicus, besides irregular pit-marks dispersed over thesurface : periphery much more rounded than in any of the foregoing species : epidermis thin: whorls 12, compressed, the last scarcely exceeding one-fourth of the shell and a little narrower than the preceding whorl ; the first two or three whorls are nearly of the same size and form a short cylinder: spire slender and gradually tapering, obtuse at the point: suture rather oblique and slight: mouth oval or inclined to quadrangular, broad, rounded and effuseat the base, and not acutely angled above ; columellar teeth more strong and prominent than in any of the other species which have been above described; there are three or four labial or palatal folds, which are conspicuous outside, owing to the shell being nearly transparent; but there are no intermediate denticles between the columellar folds, nor any lunella: outer lip white, expanded and thick : basal crest slight : umbilicus very small: clausilium squarish-oblong, flexuous, with a deep notch on its side near the base. L. $0 \cdot 7$. B. $0 \cdot 15$.

Var. 1. pellucida. Shell thinner, more transparent, and very glossy.

Var. 2. albida. Shell greenish-white.

Habitat : On the trunks and at the roots of trees (especially the beech and ash), as well as among dead leaves, and occasionally on mossy rocks, in woods throughout a considerable part of these islands, from Northumberland to Devon, and also in South Wales and Ireland, but not everywhere. Var. 1. Penrice, Glamorganshire (J. G. J.). It is rather difficult to account for the thinness of these shells, as they were found in a limestone district, and calcareous material was therefore 
not wanting. Var. 2. Box Wood, near Bath (Clark); Darnwood, Kent (Stephens); Clevedon, Somersetshire, and Watlington, Oxfordshire (Norman); Surrey (Choules); Newmarket (Wright). This last variety has also been noticed by Malm as occurring in Sweden. $C$. laminata has been found in the upper tertiary strata at Copford. Its extra-British range extends from Finland to Italy, and (according to Roth) it inhabits Smyrna.

This pretty land-shell is by no means common, although it seems to be gregarious in some places. Bouchard-Chantereaux says that its eggs are enormous in comparison with the size of the animal, being wider than the mouth of the shell, and that their number seldom exceeds from 10 to 12. They are laid in August and September; and the young are excluded on the twentieth day, but do not become adult until the end of their second year's growth. According to DesMoulins, these snails regularly leave their lurking-places at nightfall and climb the trees in search of food, descending at sunrise. In wet weather, however, they may be found crawling freely on the trunks of trees in the daytime.

This is the Helix bidens of Muiller (but not of Linné) and the Clausilia bidens of Draparnaud, Nilsson, and other writers, as well as the $C$. derugata of Férussac.

C. labiata was introduced by Da Costa and Montagu into the British fauna on the authority of Mr. Swainson; but both of the localities mentioned by the latter (viz. "an osier-ground in Battersea fields" and "Hyde Park near the banks of the Serpentine") are more applicable to $C$. biplicata than to the species in question, which inhabits dry situations. It is a native of the extreme South of Europe.

The $C$. solida of Draparnaud, which has been referred by Férussac and all subsequent writers to $C$. labiata, is 
very different, and is more like $C$. papillaris or the Helix bidens of Linné. C. solida has been found by BouchardChantereaux near Boulogne, and may therefore be discovered in this country. Possibly this may have been Pulteney's species, which was said to be found in Dorsetshire and has been referred to $C$. papillaris. The lastnamed species has been recorded by Nilsson as Swedish. It is very common in the South of France and in Italy.

\section{Genus X. COCHLI'COPA *, Férussac. \\ Pl. VII. f. 15, 16, 17.}

BODY rather long, gelatinous and lustrous, always containable within the shell : tentacles 4 ; upper pair long and nearly cylindrical; lower pair short and conical : foot rather long and narrow.

SHELL oblong, rather solid, smooth, glossy and transparent: epidermis resembling a coat of thin varnish : whorls rapidly increasing in size, the last being much larger in proportion to the others: spire long: mouth small, obliquely pear-shaped, sometimes furnished with teeth and folds as in Clausilia, and having the base more or less distinctly notched (especially in the young) : outer lip thickened by an internal rib, but not reflected, sometimes channeled at its upper angle: umbilicus wanting in the adult.

The position of the few European species which are comprised in this genus has for a long time been debateable ground. In 1817 Schumacher instituted the genus Glandina for some species of Lamarck's much older genus Achatina, as well as for other species which will be presently referred to, the type of Schumacher's genus being the Bulimus glans of Bruguière. Montfort's genus Polyphemus, which had been previously founded on the same type or species, was considered inadmissible, because that name had been appropriated to a genus of

* Having a notch in the shell. 
Crustacea. In 1819 the elder Baron Férussac, in his great work (or rather Prodromus to a work) on the Land and Freshwater Mollusca, which was continued, edited, and published after his death by his son, adopted the genus Polyphemus of Montfort, in the synoptical table which preceded this part of his work, for the species comprised in the present genus, but added other species which have no relation to those now under consideration. Férussac, however, in a subsequent part of the same work, modified this view, and proposed to include this miscellaneous assortment of species in a tenth subgenus of Helix, which he called Cochlicopa. This subgenus he divided into two groups, one to contain the species of Polyphemus, and the other (Styloïdes) to contain certain species of Achatina, as well as the Helix lubrica of Muiller. In 1826 Risso republished Cochlicopa as a separate genus, and restricted it to the above-named species of Muiller; but the generic characters given by him are very insufficient and in many respects incorrect. In 1830 I proposed the genus Cionella, not being at that time aware of Risso's publication ; and in my "Synopsis of the Pulmonobranchous Mollusca of Great Britain," which appeared in the "Transactions of the Linnean Society' (vol. xvi. p. 347), I gave the following description of this genus :

"Animal glutinosum. Tentacula inferiora brevissima.

"TESTA oblonga, seu elongata; anfractu ultimo majore. Apex acutiusculus. Columella subinterrupta. Apertura canaliculata, ad basin subeffusa, marginibus inæqualissimis. Umbilicus nullus."

I also remarked that in this genus the columella forms a sinus or channel in the aperture, though it does not appear to be accompanied by any corresponding peculiarity in the animal. The species which I referred to it 
were the Helix lubrica of Muiller, the Buccinum acicula of the same author, the Bulimus octonus of Bruguière, and (subsequently) the Turbo tridens of Pulteney. I see no reason for altering the opinion which $\mathrm{I}$ then formed, so far as regards the first and last of these species: but as the name of Cochlicopa is prior to mine, I have no hesitation in substituting it for Cionella; and I propose to restore the Buccinum acicula of Muiller to the genus Achatina. The Bulimus octonus of Bruguière belongs also to the last-mentioned genus. The Helix lubrica of Muiller and Turbo tridens of Pulteney agree in all essential particulars, except in the latter being furnished with teeth; but it has been shown that in the genus Vertigo some species are toothed and others toothless, and that even an undoubted species of Helix (H. obvoluta) is provided with similar processes. Bulimus tridens, quadridens, and other allied species may also be cited in illustration of this view, although they do not occur in this country. Cochlicopa tridens forms a passage from Clausilia to Achatina; and it is connected with $C$. lubrica through the Achatina dentiens of Rossmässler. Leach proposed the genus Azeca for $C$. tridens, and the genus $Z u a$ for $C$. lubrica; but these generic names are of recent manufacture.

The tongue or lingual plate of Cochlicopa resembles that of Bulimus; and the members of the present genus would therefore seem to be also herbivorous. They inhabit wet and shady situations.

Two British species of this genus form two artificial sections, which I propose to define, as in other genera, from characters furnished by the shell. These correspond with the genera Azeca and Zua of Leach. 
A. Mouth furnished with teeth and folds: outer lip sinuous or notched: inner lip thickened.

\section{Cochlicopa trídens*, Pulteney.}

Turbo tridens, Pult. Cat. Dors. Sh. p. 46, pl. xix. f. 12. Azeca tridens, F. \& H. iv. p. 128, pl. exxv. f. 9.

Body greyish-slatecolour with a faint tinge of yellow, closely covered with small black specks, which impart a dusky or sooty hue, strongly wrinkled: mantle rather thick, milk-white or greyish: tentacles somewhat transparent; upper pair very slender, with bulbs occupying about onefifth; lower pair rounded at their extremities : foot long, rounded in front and slightly projecting beyond the mouth of the shell ; sides edged with white, and minutely speckled with milk-white; tail very pointed.

Shell subcylindrical or shaped like a chrysalis, nearly transparent, very shining and of almost an opaline lustre, light yellowish-brown with a tinge of red, faintly and indistinctly wrinkled in the line of growth and marked with extremely minute spiral lines, which are only perceptible by the aid of a powerful lens : periphery rounded in the adult, but sharply and strongly keeled in young specimens: epidermis very thin : whorls 7, rather tumid, the last and preceding whorl being nearly of equal breadth, and much larger in proportion than the others, which form a blunt cone : spire produced, rounded at the point: suture slight, with a transversely wrinkled border: mouth narrow, angularly curved or channeled at the base and subtruncate in the young, and also channeled at the upper angle; it is still further contracted by the teeth or plate-like folds which are as follows:- one principal fold on the pillar, which is twisted round the inner lip, its crest sometimes notched, and extends like a screw far into the interior, and there is usually also a second small tooth or denticle close to the principal fold and nearer the outer lip; a strong fold winding round the pillar lip, the end of which appears like a sharp and prominent tooth ; and a sharp tooth-like tubercle on the middle of the outer lip and placed on the inside edge of this lip; besides this last, there are occasionally two small and scarcely perceptible denticles placed below it: outer lip sinuous and (as well as the inner lip) encircled by a narrow 
rib, which is often reddish-brown or flesh-colour,-a nearly complete peristome being thus formed, the interruption being caused by the narrow channel at the upper angle of the mouth. L. $0 \cdot 25$. B. $0 \cdot 1$.

Var. crystallina, Dupuy. Shell greenish-white and transparent, like glass.

Habitat: Among herbageand on damp mossin woods, but sparingly distributed, in many of the English counties from Northumberland to Devon. I am not aware of its having been found in the eastern counties, Wales, or Ireland. According to Dr. Fleming it inhabits Scotland, but only on the authority of Capt. Laskey, who is said to have found it in Carline Park near Leith. The variety is from Wheeley Castle, Worcestershire (Clark); on Mercurialis perennis near Stansted, Kent(Smith); Tawstock Woods, near Barnstaple; and Brockley Combe, Somersetshire (J. G. J.). This species is one of our upper tertiary fossils. It does not appear to have an extensive range abroad-Germany and France being the only countries in which I can find any notice of its occurrence. A variety of it (the Azeca Nouletiana of Dupuy) has been found by Boissy in the Pyrenees; and the variety crystallina is also recorded as inhabiting the South of France.

Scarcely anything is known as to the habits of this curious snail. It appears to be gregarious and to love shade and moisture. Mr. Alder justly observes that it "seems to form a link between Bulimus and Clausilia, resembling the former in shape and general appearance, but approaching more nearly to the latter in having the margin completely surrounding the aperture, and also more particularly in having a longitudinal plate on the columella considerably within the aperture, similar in situation and making a slight approach in form to the 
clausium of the genus Clausilia, though attached through its whole length and inflexible."

This species has been placed by different writers in no less than eight genera, and has received six specific names. On the Continent it is more generally known as Bulimus Menkeanus, in consequence of there being another $B$. tridens; but if the present species is not to be placed in that genus, there can be no objection to retain the original name given to it by Dr. Pulteney.

B. Mouth destitute of teeth or folds : outer lip entire : inner lip thin.

\section{C. LU'BRICA*, Müller.}

Helix lubrica, Müll. Verm. Hist. pt. ii. p. 104. Zua lubrica,

F. \& H. iv. p. 125, pl. exxv. f. 8, and (animal) pl. G. G. G. f. 5.

Bopy broad and rounded in front, gradually narrowing and very pointed behind, black or dark greyish-slatecolour above, of a paler grey on the sides and underneath, slightly tubercled: mantle greyish-brown, closely speckled with milk-white: tentacles broad at their base and slightly transparent; upper pair slender, finely and distinctly granulated, with very globular bulbs; lower pair of the same length as these bulbs and rather thick: foot somewhat angular in front, not extending beyond the neck; sides very delicately edged with a dusky line and distinctly speckled with milkwhite; tail pointed and rather flat.

SHell subcylindrical, with an approach to a turreted shape in consequence of the base being wider than the top, nearly transparent, very shining andlustrous, lightyellowish-brown, quite smooth and polished to the naked eye, but under a lens marked with slight and curved transverse striæ, especially near the suture, and under a microscope very closely and faintly striate in a spiral direction: periphery rounded in the adult, very slightly angular in young specimens: epidermis exceedingly thin: whorls 5 or $5 \frac{1}{2}$, tumid, gradually increasing in size, the last occupying about one-half of the shell: spire produced, but rounded at the point: suture 
moderately deep, with a transversely wrinkled border: mouth placed obliquely, proportionally much larger than in the other species: outer lip very thick and strengthened by a broad inside rib, which is usually reddish-brown or fleshcolour: pillar-lip apparently furnished with a blunt tooth which forms the notch: inner lip consisting of a slight deposit of shelly matter, which is spread on the pillar. L. $0 \cdot 25$. B. $0 \cdot 085$.

Var. 1. hyalina. Shell greenish-white.

Var. 2. lubricoides, Fér. Shell smaller and more slender.

Var. 3. viridula. Shell shaped like the last variety, but greenish-white.

Var. 4. fusca. Shell smaller and thinner, reddish-brown. Var. 5. ovata. Shell much smaller and oval: spire shorter.

Habitat : Woods, hedges, fields, gardens, and everywhere in the country, under stones and logs of wood (especially when sunk deep in the ground or decayed), as well as among moss and dead leaves, and at the roots of grass in meadows (frequently after being irrigated), from Unst to Guernsey. Var. 1. Tawstock, near Barnstaple (J. G. J.). Var. 2. Bath (Clark); Church Stretton, Salop ; Clifton-Hampden, near Oxford ; Rawleigh, near Barnstaple; Minlough Castle, Co. Galway; Dunboy, Co. Cork (J. G. J.). Var. 3. Dunboy (J. G. J.). This and the last variety appear to be the variety $\beta$ of Nilsson. It has much the aspect of a distinct species, if placed by the side of the typical form ; but they are connected by intermediate gradations. Var. 4. Guernsey (Lukis). Var. 5. Cardiff (J. G. J.). This species is very common in our upper tertiary deposits. It has almost a world-wide range (or is what has been erroneously termed " cosmopolitan"), being found in Kamtschatka and on the steppes of Siberia, in the South of Italy, Algeria, Madeira and the Azores, North America, Cashmere and Thibet, and probably in every other part of Europe, Asia, Africa, and America. 
This is a hardy but sluggish and impassive little mollusk, and lives on the highest mountains as well as in the lowest plains. These habits and the capability of enduring different conditions of climate and temperature may account for the great extent of time and space which it has enjoyed as a species. It is also in some degree amphibious. In consequence of Geoffroy having stated that it was killed by being put in water, and that by this means the animal could be removed from the shell, Miiller tried some experiments, which convinced him that the French naturalist was more imaginative than accurate. One of these snails, which Miiller had forced to withdraw into its shell, was plunged into a cold bath, and it immediately thrust out its body; but, perhaps catching sight of the philosophical experimentalist, and apparently as if resigned to its fate, it staid three hours in the water, when it crawled out and (seemingly pleased at reaching dry land) put out its horns and walked off. However, although they do not mind an occasional soaking, they are often washed down by heavy floods of rain or the overflow of rivers, and their shells occur in great numbers in alluvial deposits. This circumstance will perhaps explain how certain kinds of land-shells so frequently occur in fluviatile, estuarine, or even lacustrine strata. Young shells of C. lubrica are oval or almost globular, and have a slight umbilical perforation. Full-grown specimens vary considerably in size and the length of the spire. The epiphragm is very thin, glistening and iridescent. That made in summer has a small respiratory hole. In France this shell bears the appropriate name of "la brillante."

This species differs from $C$. tridens in being turreted, instead of spindle-shaped, in the whorls being more convex and the suture consequently deeper, but especially 
in the mouth being much larger and never furnished with teeth or folds.

It seems not to have escaped the keen notice of Lister. Whether Linné was also acquainted with the present species is another question. Some writers consider it to be the Helix subcylindrica of his 'Systema Naturæ ;' but that shell is described as inhabiting fresh water and having the inside lip or margin of the aperture reflected, neither of which characters is applicable to $C$. lubrica. It is, however, the Turbo glaber of Da Costa.

\section{Genus XI. ACHA'TINA*, Lamarck. Pl. VII. f. 18, 19, 20, 21.}

BODY long and slender, always containable within the shell: tentacles 4; upper pair having small bulbs; lower pair exceedingly short: foot narrow.

SHeLr long and cylindrical, thin, glossy, and smooth: whorls rapidly increasing in size: spire long: mouth oval or oblong, without teeth or folds, but notched and nearly truncate at the base : outer lip thin and plain : umbilicus wanting.

L. Pfeiffer described, fourteen years ago, no less than 157 species of Achatina; and in these days of speciesmaking and foreign enterprise, we may fairly assume that this number has since been considerably increased. In our own country we have only a solitary representative of this numerous genus, and that scarcely exceeding in length one-sixth of an inch. Risso constituted out of this minute species a new genus, which he named Acicula. Beck proposed another genus (Cacilioïdes) for its reception; and Bourguignat has, in his 'Aménités Malacologiques,' given another generic name (Cacilianella), as well as divided our species into several. One of these species he has called "Anglica," and distin- 
guished the French shell from it under the name of Liesvillei. Whatever difference of opinion may, howe er, exist as to the scientific value of the species which this last-named author has so prodigally described, his bibliographical learning and laborious research cannot fail to command our admiration. The two generic names of Cacilioïdes and Cacilianella are founded on a peculiarity which does not appear to be shared by any other British land or freshwater snail; although in the famous caves of Adelsberg many of such instances occur. It is, that this snail is eyeless. This remarkable fact, with respect to the Achatina acicula (which will be presently described), was first noticed by Nilsson, and it has been fully confirmed by subsequent observation. The $A$. acicula always lives underground; and the conditions of its habitat are therefore similar to those of the several species of Zospeum, living in the inmost recesses of the Illyrian caverns, into which the light of day never penetrates. It is true that Testacella, which is also a subterranean mollusk, is not deficient in those organs which are called eyes; but this animal passes some of its time (especially in the pairing-season) above ground, while our little Achatina has never been observed on the surface in a living state. Similar exceptions of eyeless species, belonging to genera the animals of which are usually ocellated, occur (although very rarely) among our marine Cephalic Mollusca - as, for instance, Eulima stenostoma and Mangelia nivalis; but these are deepwater species, and very little is known as to the extent to which light penetrates into the abysses of the ocean, or as to its action on the sensorial organs of invertebrate animals. In all probability the $A$. acicula lives upon animal matter; for, in the spots where it has been found living, no underground fungus or other vegetation 
appears to exist, and the form of the shell would induce a belief that this snail is not only zoophagous but predaceous. The shells of all the true species of Glandina, which are carnivorous, have the same kind of notch or truncature at the base as the present species of Achatina. The structure of the lingual plate or tongue of Glandina is similar to that of Buccinum and other marine Proboscidiferous Mollusca, which also have a notch or canal in the mouth of their shells and are exclusively predaceous. The present genus is closely allied to $\mathrm{Co}^{-}$ chlicopa through $C$. lubrica, the habits of which are partly subterranean; but the notch in that shell is not so strong or well marked as in this.

\section{Achatina ACi'cUla*, Müller.}

Buccinum acicula, Müll. Verm. Hist. pt. ii. p. 150. A. acicula, F. \& H. iv. p. 130, pl. exxviii. f. 4.

BoDY quite white and nearly transparent, tubercled or granulated in lines: mantle rather thick, marked with a raised longitudinal line in the middle : tentacles cylindrical; upper pair destitute of eyes or black specks; lower pair forming almost imperceptible bulbs: foot compressed, pointed behind, and ending at the penultimate whorl of the shell when the animal is crawling.

SHELl turreted and slender, transparent, very thin, highly polished and iridescent, ivory-white, with a yellowish tinge on the upper part in fresh specimens (owing to the colour of the liver), perfectly smooth and polished when examined with a lens of ordinary power, except a few faint and irregular wrinkles in the line of growth, but under a microscope exhibiting delicate and close-set spiral striæ: periphery rounded: epidermis exceedingly thin and forming a mere film : whorls $5 \frac{1}{2}$, not convex, but compressed and drawn out, rapidly increasing in size; the last occupying about onehalf of the shell: spire very obtuse and rounded at the point: suture moderately deep and oblique, apparently margined on the under side by reason of the upper part of the succeeding

* A hair-pin, used by Roman women. 
whorl being seen through the pellucid shell : mouth oblong, contracted by the penultimate whorl, narrowing above into an acute angle, slightly widened and rounded below, but interrupted by a deep notch at the base of the pillar lip: outer lip thin and flexuous: pillar lip thick and curved: inner lip consisting of a slight deposit of shelly matter, which is spread on the pillar. L. 0.175. B. $0 \cdot 04$.

Habitat : Under stones and at the roots of bushes and grass, but usually some inches beneath the surface, in various parts of the country from Yorkshire to Guernsey, as well as in Wales and Ireland. It occurs in our upper tertiary strata. On the Continent it ranges from Sweden to the South of Italy; and it has been also noticed in Greece, Algeria, and Madeira. It is widely diffused, but rather local, and difficult to find in a living state.

Nilsson has given a good description of this curious little mollusk, and has noticed that, in consequence of the transparency of the shell, the irregular motion of its breathing could be easily observed under a microscope, and that, when the respiratory cavity was shut, the motion ceased, but was resumed on the chamber being again opened; and he likened this alternate expansion and contraction of the breathing-organ in this snail to the pulmonary action of vertebrate animals. He supposed that the $A$. acicula fed on the tender and juicy fibrils of the roots of grass. Mr. Pickering informed me that a considerable number of live specimens were once procured by a gentleman in Hertfordshire, while digging up potatoes. His friend, not being a conchologist, thought at first that they were little white maggots. It has been stated that this species is only found in calcareous soils; but, besides the last instance, its occurrence has been noticed by Mr. Bridgman at Norwich, "on a sunny bank near the Thorpe toll-bar, adhering to the roots of 
grass, in the loose earth between the stones." The epiphragm is very thin and glistening. The eggs are said to be large in comparison with the size of the shell.

This is the Buccinum terrestre of Montagu; but it can scarcely be the Helix octona of Linné (as some authors have supposed), because that shell is described as having eight whorls and a roundish mouth. The last species is common in the West Indies, but in former times found its way into collections of British shells, owing to Dr. Pulteney having mistaken it for the Limncea glabra, or Helix octona of Pennant.

\section{Family IV. CARYCHIID $\approx$.}

BODY long and spirally coiled : mantle covering the front or anterior part: snout prominent: tentacles 2 (besides rudiments of a second or lower pair), contractile; eyes at the base of the developed tentacles and somewhat in their rear: foot oblong, distinct from the rest of the body.

Shell spiral, oval-oblong, enveloping the whole body: mouth somewhat ear-shaped, furnished with columellar folds and a tooth-like tubercle on the outer lip : umbilicus narrow and indistinct.

This family forms part of an incongruous assemblage of Mollusca, which Lamarck called Auricula or Auriculacea, the type of which is the Bulimus fibratus or AurisMidce. As, however, Muiller had long previously indicated the characters of the present family by his description of the genus Carychium, it would seem to be an act of common justice to the memory of that great naturalist that the patronymic or family name should be taken from that of his original genus, and not from Auricula, which was subsequently founded. A few amphibious Mollusca which belong to this family, and to the genera Melampus (or Conovulus) and Otina, being 
excluded from the category of land-shells and placed with those having a marine habitat*, there only remains a single genus, containing a solitary species, for present consideration. This is one of our smallest terrestrial Mollusca.

There are several points of resemblance between this family and the Limnaida. The contractility of their tentacles and the position of the eyes and reproductive organs are nearly the same in each of these families; and the only British member of the Carychiidoe is semiaquatic in its habits and can live a long time under water. Every individual of both families is male as well as female.

\section{Genus CARY'CHIUM †, Miuller. Pl. VIII. f. 1, 2, 3, 4.}

The characters of the body and shell are given in the above definition of the family.

\section{Carychiom mínimum}

C. minimum, Müll. Verm. Hist. pt. ii. p. 125 ; F. \& H. iv. p. 198, pl. exxv. f. 6.

BoDr bilobed in front and rounded behind, transparent, yellowish-white: snout as long as the tentacles and triangular: tentacles very close together, thick and conical, with somewhat rounded extremities : eyes rather prominent, exceedingly black and distinct: foot rounded in front, very finely speckled with black and milk-white, terminating in a blunt and thick tail.

Sheld subfusiform, transparent, but not very thin, glossy, whitish, finely and closely striate in the line of growth, with a few obsolete or indistinct spiral lines; the transverse striæ are flexuous and stronger towards the suture, and they are sometimes partly decussated by the spiral lines in such a

* I accidentally omitted to notice, in my account of the slugs, that one of them also (Onchidium Celticum) is marine.

† From its resemblance to a Murex or kind of whelk. ‡ \$ Smallest. 
manner as to give the surface an appearance similar to that which is observable on the shells of several species of Limnoea (showing the conchological relation between that and the present genus): periphery rounded: epidermis not very thin : whorls $5 \frac{1}{2}$, convex; the last occupying nearly one-half of the shell, and the penultimate whorl fully equalling (if not exceeding) it in breadth: spire moderately pointed: suture deep : mouth obliquely oval, contracted below into a narrow channel, furnished with a strong spiral fold or plait on the middle of the pillar, and with another on the pillar lip : outer lip exceedingly thick and reflected, having on the middle of its inside edge a strong tooth or tubercle which projects into the mouth : upper edge considerably inflected : inner lip thickened in adult specimens and forming with the outer lip a complete peristome: umbilicus consisting of an oblique slit. L. 0.07 . B. 0.035.

HAвгтAт : Under stones and logs of wood, at the roots of grass, and among moss and dead leaves, in woods and damp places, everywhere from the Moray Firth district to the Channel Isles, as well as throughout Wales and Ireland. It is a member of our upper tertiaries. Gerstfeldt has recorded it as a Siberian species, Philippi as Sicilian, Morelet as inhabiting Algeria ; and it seems to be universally distributed over every part of the Continent.

This is an exquisitely beautiful creature, both alive and dead; and Muiller did scant justice to it in calling it a "bestiola," when he was apparently provoked by its shyness. Its eyes are so exceedingly black and piercing that they are visible through the shell, when the animal is not disposed to venture out of doors. It inhabits mountainous tracts as well as plains, but seems to prefer the vicinity of water. Dr Lukis informs me that it makes its winter domicile in the hollow stems of the larger marsh umbelliferous plants. The plaits or folds are in course of formation at a very early period of growth; and young shells have the columella notched 
at the base, as in Cochlicopa and Achatina. The epiphragm is extremely thin and glistening. The spire is complete; and in this respect it differs from that of the shells belonging to species which British conchologists place in the genus Conovulus. The Rev. M. G. Berkeley supposed that $C$. minimum might have the sexes distinct; but the anatomical details of its structure given by Moquin-Tandon prove that such is not the case, and that this animal agrees in its mode of reproduction with all the other members of the inoperculated Pulmonobranchs.

The second section of the British Pulmonobranch Mollusca comprises only the following-

\section{Family V. CYCLOSTOMATID无.}

BoDy long and spirally coiled: mantle covering the front or anterior part, and encircling the neck with an extremely thin fold: snout strong and elongated : tentacles 2 only, contractile: eyes at the external base of the tentacles: foot long, distinct from the rest of the body.

Shell spiral, oval or cylindrical, and enveloping the whole body: mouth round or oval: umbilicus small and narrow : operculum paucispiral, testaceous or horny.

This extremely numerous family has its home in the tropics. Only two members of it inhabit this country; and each of these is included in a separate genus. As I have before observed, many characters of organization are common to the present family and the Pectinibranch Mollusca. They are diœcious: their tentacles are two in number and contractile: their eyes are placed at the base of these tentacles: and their shells are furnished with opercula. But their respiratory system is very different, and corresponds with that of other families of Pulmonobranch Mollusca. 
Our Continental neighbours are richer than ourselves in genera as well as species belonging to this family. Of the typical genus, Cyclostoma, two well-marked species are common in France, although one of them $(C$. sulcatum) is confined to the South. As to Acme they boast of having four species to our one; but none of the three which we want are found in the North of France. Of a third genus, Pomatias, no less than six species are French, while we have no representative of the genus. Two of these last species (viz. P. septemspiralis or maculatus and $P$. obscurus) have been lately detected in the extreme North of France ; and it is therefore not impossible that they may be also met with in the South of England. Their operculum is horny, instead of shelly as in Cyclostoma; and the genus to which they belong appears to bear nearly the same analogy to Cyclostoma as Hydrobia does to Bythinia among the Pectinibranch Mollusca.

The British genera comprised in this family may be thus divided.

* Shell oval : operculum testaceous. Cyclostoma.

** Shell cylindrical : operculum horny. AcMe.

The position of the male organ of reproduction is also different in these genera.

\section{Genus I. CYCLO'STOMA*, Draparnaud. Pl. VIII. f. 5, 6, 7, 8.}

BoDy oblong, always containable within the shell: tentacles cylindrical, with slightly swollen tips: foot small and broadish.

Shell oval, rather solid: whorls rapidly increasing in size: spire short: mouth round: umbilicus oblique: operculum roundish, testaceous and solid, with a nearly central spire.

${ }^{*}$ Round-mouth. 
More than a century ago, Guettard made known, through the Academy of Sciences at Paris, the apparently anomalous fact that a land snail was furnished with an operculum. The genus Cyclostome was founded by Lamarck in 1789 and reproduced in 1801, for the reception of certain marine Gasteropoda which are now referred to the genera Scalaria and Delphinula. But it is to Draparnaud that science is indebted for the establishment of the genus Cyclostoma on a more correct basis, although he comprised in it, besides the true members of this genus, many freshwater species belonging to the genera Paludina, Bythinia, and Hydrobia, and even a species of Truncatella which is exclusively marine. The present genus is restricted to those land-shells which have a round mouth and a solid operculum; and the structure of the animal is in strict accordance with that of the shell.

\section{Crclostoma élegans*, Müller.}

Nerita elegans, Müll. Verm. Hist. pt. ii. p. 177. C. elegans, F. \& H. iv. p. 201, pl. exxii. f. 3 .

BODY very thick, blunt and strongly bilobed in front, rounded behind, dusky greyish-brown or almost black above, of a paler hue underneath, coarsely wrinkled in front and finely tubercled behind : mantle semiannular, rather tumid and smooth, speckled with milk-white except at the sides: snout projecting beyond the rest of the body, strongly bilobed in front, divided transversely by distinct wrinkles, which are finely streaked with grey : tentacles dark-coloured, strongly wrinkled across, with nearly hemispherical bulbs, which are more transparent and clear than the tentacles: eyes placed on reddish or whitish tubercles, a little behind the tentacles: foot rounded in front and divided into two equal parts by a longitudinal groove, very dusky, especially on the sides; tail rounded, and to a great extent covered by the operculum. 
SHeLl globose-oval, rather solid and opaque, scarcely glossy (owing to the strong sculpture), yellowish-brown with moreor less of a reddish tinge and often marked with irregular streaks or spots of reddish-brown or purple, sometimes plain yellow or fawn-colour; the spots sometimes form three or more indistinct and interrupted rows on the body whorl ; sculpture consisting of strong spiral ribs, of which there are about forty on the last whorl, and of much finer but more numerous transverse ribs, which do not cross the main ribs but intersect the interstices, giving that part of the surface a somewhat reticulated appearance: periphery rounded: epidermis thin: whorls $4 \frac{1}{2}$, exceedingly tumid, the last occupying considerably more than two-thirds of the shell; upper whorls purple or yellowish-brown and quite smooth: spire bluntly pointed: suture very deep: mouth circular, with the exception of a slight angle at the upper part: outer lip and inner lip rather thick, very slightly reflected, and forming a complete peristome: umbilicus twisted, but rather deep:operculum flat, composed of about five whorls, strongly and closely marked with oblique and flexuous strix; nucleus depressed, smooth, and of a darker colour, like the nucleus or apex of the shell. L. $0 \cdot 6$. B. $0 \cdot 4$.

HaBitat : Under stones and at the roots of fern and furze in many parts of England, Wales, and Ireland, from Yorkshire to Alderney. It appears to frequent chiefly the sea-coast and calcareous soils; but it occurs in Northamptonshire and Oxfordshire (inland counties), as well as in parts of Norfolk where there is no chalk. It has not been recognized with any degree of certainty as a fossil of our upper tertiaries. Its foreign range is southern, and includes Central Germany, France, Italy, and Portugal ; and it extends to the Canaries. Donegal Bay appears to be its most northern limit.

Lister gave, nearly two centuries ago, some excellent details of the physiology of this mollusk; and in 1828 another of our countrymen (the Rev. M. G. Berkeley) published, in the 'Zoological Journal' (vol.iv.p. 278-284), further particulars of its anatomy. According to MoquinTandon it is a vegetable feeder; and the structure of its 
tongue is the same as that of other phytophagous Mollusca. The bulbs or points of the tentacles are supposed to be olfactory organs. This species does not make its appearance until the first warm days of spring ; and in dry weather it buries itself in the earth. It is an exceedingly timid animal. Montagu says that its strong and muscular proboscis is of considerable service in removing obstacles, and especially the earth when the animal retires to its hibernaculum; and he adds that it is also used in crawling, to hold by, in order to bring forward the body. Dr. Gray has described a remarkable peculiarity in its mode of walking, as follows:- "The foot is formed of two longitudinal portions: as the animal walks, the portion on one side is first advanced, while the animal holds on by the other; and then holds on with the advanced portion as the other side is gradually advanced before it." This alternate action of the two sides of the foot is nearly similar to that which was observed by Adanson as to his genus Pedipes, of which we have a representative in Melampus; but in that case the foot is divided into two transverse instead of longitudinal sections, and the action is more like that of a caterpillar, or what is called "looping." Villa has noticed that great numbers of $C$. elegans are devoured by predaceous beetles, especially by those belonging to species of Cychrus, which contrive to get into the shell in spite of the solid and close-fitting operculum. This curious lip or mouth-piece is as hard as a stone, and covered on both sides with a thick and tenacious epidermis, a double fringe of which completely encircles it and causes the operculum to appear laminated. This is one of our handsomest land-shells, and, if it were rare, would be highly prized-like many other too familiar objects of equal beauty. 
The "Cyclostoma marmorea" of Capt. Brown appears, from the description and figure in the 'Edinburgh Journal of Natural and Geographical Science' for October 1829, to be a specimen of $C$. elegans which had been worn smooth by attrition.

The $C$. ferrugineum of Lamarck was erroneously introduced by Dr. Turton into the British fauna. It is a native of the extreme South of Europe, and has not even been found in France.

\section{Genus II. $\mathrm{AC}^{\prime} \mathrm{ME} *$, Hartmann.$$
\text { Pl. VIII. f. 9, 10, 11, 12, } 13 .
$$

Bopy elongated, always containable within the shell : tentacles awl-shaped, without bulbs or swollen extremities: foot narrow.

SHell cylindrical, rather thin : whorls gradually increasing in size : spire long, but ending in a blunt point : mouth oval: umbilicus straight: operculum oblong, horny and thin, with an excentric spire.

This singular genus of minute operculated land-shells was first distinguished by Hartmann, and described by him in the 'Neue Alpina' of Steinmiuller for 1821 under the name of Acicula. However, for some reason or other which does not appear, Hartmann changed this name for Acme, and redescribed the genus at considerable length in the sixth volume of Sturm's 'Deutschlands Fauna,' which was published also in 1821. Risso having, as before stated, in 1826 used the name Acicula for another genus with Achatina acicula as its type, and the original founder having discarded it, there seems to be no alternative but to adopt the second name given by Hartmann to the present genus. It takes precedence of

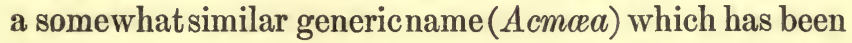

$$
\text { * Point. }
$$


ascribed to Eschscholtz and used for the reception of some marine shells which are allied to Patella. The present genus was (according to Charpentier) named Pupula by Agassiz.

\section{ACME LINEA'TA*, Draparnaud.}

Bulimuslineatus, Drap. Tabl. Moll. p. 67. A. lineata, F. \& H. iv. p. 204, pl. cxxv. f. 7 .

BoDy milk-white speckled with brown, nearly transparent: mantle dark brown : snout very narrow, tumid, and curved, marked transversely with flat, parallel and indistinct wrinkles: tentacles nearly cylindrical, diverging, whitish, very finely wrinkled across, each of them encircled at its base by a ring of dark spots; their extremities nearly pointed : foot rounded in front, with a narrow tail.

SHeLl oblong-cylindrical, semitransparent and glossy, yellowish-brown, marked in the line of growth with remote curved grooves or deep striæ, of which there are from twenty to thirty on the body whorl, as wellas with a few slightand obscure spiral lines : periphery rounded : epidermis of moderate thickness : whorls 6-7, compressed, the last occupying about two-fifths of the shell: spire rounded at the point: suture distinct, but not deep : mouth pear-shaped, effuse at the base, and contracted above into a rather acute angle: outer lip thin and flexuous: pillar lip reflected: inner lip spread on the columella: umbilicus small and nearly concealed by the reflexion of thepillar lip: operculum flat, sunk deep within the mouth, marked with faint and irregular radiatingstriæ; spire formed of only two whorls and a half. L. 00085. B. $0 \cdot 035$.

Var. 1. alba. Shell white or colourless and transparent.

Var. 2. sinistrorsa. Spire reversed.

Habitat : Among decayed leaves in open drains, and under stones which lie close to the ground, in woods throughout a great part of these isles, from Lanarkshire to the extremity of Cornwall, and also in Wales and Ireland (East, West, North, and South), but not everywhere or abundantly. Var. 1. Rejectamenta of 
the River Avon at Bristol; Ballinahinch, Co. Galway (J. G. J.); Killarney (Barlee). Var. 2. A single specimen among the refuse of the Avon at Bristol (J. G. J.). This species, as well as the reversed variety, has been found in our upper tertiary beds at Copford. Gerstfeldt has recorded it from Western Siberia, and Villa from Normandy; but, although it occurs in intermediate countries, I do not find any notice of it as Scandinavian. It inhabits France, Germany, and Switzerland.

A living specimen, which I observed in the North of Ireland, did not seem to be shy or inactive while kept in the shade; but when it was exposed to the glare of the sun's rays, it immediately shut up and disappeared. Dr. Gray says that "the animal walks with its shell nearly perpendicular, twisting it round in a very odd manner, and then letting it suddenly fall again." The striæ on the shell are very irregular in respect of number; and in a specimen now before me they are entirely wanting in some parts; so that I should not be much surprised if the A. fusca of Beck (which he separated from our species on account of its wanting the striæ) should prove to be merely a smooth variety of the present species. Brown has apparently described and figured this variety, in his 'Illustrations of the Land and Freshwater Conchology of Great Britain and Ireland' (p. 29, pl. iv. f. 16), under the name of $A$. minuta.

The present species was first made known by Walker (Test. min. rar. litt. Sandv. p. 12, f.42), and was described by Montagu as Turbo fuscus, but subsequently to the date and publication of Draparnaud's 'Tableau des Mollusques.' Moquin-Tandon considered Walker's shell to be distinct from that of Draparnaud, and has described the former as quite smooth; but Jacob's diagnosis in Walker's work distinctly mentions its being striated. 
After the foregoing part of this volume had been printed, I received a communication of considerable importance as regards the determination of some of the species described by Draparnaud. It consisted of the original types or specimens of that author, from the public museum at Montpellier, and which, through the great kindness of the Director, M. Michaud, I have now had an opportunity of examining and comparing with my own specimens. The following is the result of this examination.

Species

described by Draparnaud.

Cyclostoma simile.

C. anatinum.

Clausilia plicatula.

Helix glabella.

H. sericea.

H. plebeium.

H. pygmæa.

H. nitidula $\beta$.

\section{Species}

described in this work.

Hydrobia similis.

H. ulvæ.

One specimen is C. Rolphii. (The rest are C. plicatula.)

H. rufescens.

One specimen is $H$. hispida, var. subglobosa; and the other is $\mathbf{H}$. revelata.

H. hispida, var.

H. pygmæa.

Two specimens are Zonites radiatulus, and another is Z. purus.

\section{ERRATA.}

Page 49, at the end. The specimen of Dreissena polymorphareferred to by M. Ch. D'Orbigny appears to be recent, and not fossil. 55 , line 15 from top, for " they" read "some of them." ", 155, line 25. VITRINA. Theaccentuating mark ought to beover the first syllable, and not over the second one which is short. 200 , line 25 from top, for "plebeia" read "plebeium."

", 278, line 19, for "C. rugosa" read "Pupa rugosa." 
Thus far I have treated this branch of my subject in a scientific point of view, and I have at the same time endeavoured to illustrate some of the curious ways and instincts of the Mollusca which inhabit the surface of this country. I am not without hope that many others, who possess better opportunities than I have at present, may be induced to institute similar researches, and thus to improve what I have done, as well as correct those errors which have unavoidably occurred in a rather extensive investigation.

There is, however, another aspect in which the matter may be considered; and that is, with reference to our own æsthetic ideas of these humble works of our Common Creator. Other divisions of animated nature have received a large share of attention from philosophers and poets; and their best works in ancient and modern times abound in references to the larger animals, as well as to birds and insects, but more especially to flowers, the simple yet ornate beauty of which appears to affect the mind in a peculiar manner. But the less conspicuous and attractive assemblage of snails, which have been exhibited in the foregoing pages, (although equally interesting to the naturalist) have not been honoured with much notice by the philosopher or poet; and I would venture to make this appeal to such on behalf of my little favourites, trusting that their claims, as our fellowcreatures, to a share of that sympathy which animates the great and stirring intellects of this age may not be entirely overlooked. A gifted and well-read friend has kindly sent me the following result of his examination of the subject in a poetical sense, which will, I hope, be acceptable to some of my fair readers. 


\section{The Snall in Poetry.}

The snail has been but rarely the subject of poetical treatment. Minor poets would be afraid of touching it; and even in the hands of those great masters to whom it has been given to interpret the deeper harmonies of the universe, it is only upon rare occasions that this little animal could fittingly present itself as a link in the chain of their conceptions. One would naturally first look for it in those descriptive poems which deal with agriculture and gardening. But neither Cowper in his 'Garden' nor Virgil in his 'Georgics' appear to have honoured it with their notice. Nor does it enter, I believe, into the pious yet discursive meditations of George Herbert. Nor does Milton make it the subject of any special reference in his magnificent description of the six days' work, and varied wonders of creation. It is not the snail, but the worm, which is there taken as the type of that lower region of animal life. Indeed there appears no great congeniality between the tribes of the 'Helicidæ' and the atmosphere which has been deemed suitable for epic or for serious poetry; they do not readily live and flourish on Parnassus. Nevertheless their cause, as judged at the tribunal of the Muses, is not to be pronounced hopeless; it must be stated, on the contrary, that their humble pleadings have been listened to, and that they have been admitted into the realms of song. They have certainly been neglected by the smaller fry of poets; but they have not been overlooked by the very greatest masters of the art. It is instructive to observe the manner in which the snail has been treated by Homer, Shakspere, and Goethe; from whom, in default of other instances, our examples must needs be drawn. We shall there find 
the snail, not as the uninviting little creature it would appear to the common eye, but under the light of imagination's ray. We may enter the realms of fantasy, and we shall find it among those intruders which had to be chased from the cradle of the fairy-queen. We shall find it, centuries earlier, in Homer's mock-heroic poem, where the belligerent frogs are represented as using the shells of water-snails for their helmets. But the snail has been raised to a much higher eminence in the pcetic sphere. Indeed, could a lonely snail be discovered on the loftiest peak of Teneriffe or Chimborazo, would not the little animal, elated at that extreme height, become a fit object for surprise and wonder, and partake of the sublimity of the situation? Well-supposing only that we pass from the material to the moral world-in a similar situation Goethe has placed it in that wild vision of the Walpurgis-night. There, upon the top of the Harz mountains, amidst that enchanted throng and tumultuous rabblement of witches, sorcerers, dæmons, owls, bats, and all creatures of the night celebrating high festival under the melancholy moon, in the "region of misery and tribulation," did an adventurous and preternaturally sensitive snail detect the presence and unmask the incognito of no less a person than Mephistopheles himself, who in these words describes the occurrence :-

"Siehst du die Schnecke da? Sie kommt heran gekrochen ; Mit ihrem tastenden Gesicht

Hat sie mir schon was abgerochen.

Wenn ich auch will, verlaügn' ich hier mich nicht."

This is beyond a doubt the most imposing appearance which the little animal has made in literature.

The cases above cited, in which the snail appears as actually taking part in the movement of the poem, in which she is, so to speak, one of the characters of the 
drama, must of course be distinguished from those in which she appears only by way of simile, or comparison; the movement of the poem being meanwhile interrupted. The most interesting of the latter class is to be found in Shakspere's 'Venus and Adonis,' a piece in which the rich romantic or quasi-mythological colouring is so high as to permit the introduction of such imagery without any perceptible loss of poetic dignity. The following is the simile alluded to :-

"Or as the snail, whose tender horns being hit,

Shrinks backward in his shelly cave with pain, And there, all smother'd up, in shade doth sit,

Long after fearing to creep forth again;

So, at his bloody view, her eyes are fled Into the deep dark cabins of her head."

It would be difficult to find another equally beautiful reference to the sensitive characteristic of the animal. We cannot fail to observe that Homer, in accordance with the sculpturesque tendency of Greek art, fixes his attention more on the outward shelly covering; but the modern poets, in obedience to their more 'subjective' tendencies, give theirs rather to the inner sentient nature of the inhabitant of the shell.

But after taking this hurried glance from the summit of Mount Parnassus, we must descend into the plains of prose; and having thus refreshed ourselves with a draught from the Castalian spring, we will present the Geologists with a distant retrospect, which may be more interesting to most of them than the view we have been enjoying, although some of that learned body are not ungifted with a vivid imagination.

The difficult and vexed problem of geographical distribution is so intimately connected with the science of 
Geology, that any reliable information with respect to the present range of the European Mollusca cannot fail to assist in the elucidation of this question ; but I would again venture to express an earnest hope that, until sufficient data have been collected, no more theories, crude although plausible, may be put forth. It may be said that they are easily made, and that by their discussion some useful results are obtained; but it must not be forgotten that the eyes of our scientific compeers in Europe are upon us, and that our reputation for accuracy, as well as our position as naturalists, may be compromised if we erect a fine superstructure on a foundation of sand, instead of digging patiently but steadily, until we reach the solid rock.

I propose to show, in the following Table,

1st, All the species of land and freshwater Mollusca now living in the British Isles, arranged in the natural order of their classification.

2ndly, The extra-British distribution of any of these species, north of a line drawn in the meridian of Bordeaux, which may be assumed as an arbitrary point of demarcation between the two extremes of climate in Europe*. These species may be termed "northern" forms.

3rdly, The like distribution, of any of the species comprised in the first category, south of the same line-being therefore "southern" forms.

And 4thly, The occurrence of any of the above-mentioned species in a subfossil state, in the upper tertiary strata of this country. With respect to the term "Upper Tertiaries," Mr. Prestwich has kindly supplied me with the following definition :

"By our upper Tertiaries I should be disposed to

* Draparnaud, in his "Tableau des Mollusques," proposed nearly the same line of division between the North and South of France, the latter being the olive-district. 
mean all the Pliocene and Pleistocene strata, i.e. all the beds from the Coralline Crag inclusive up to the Alluvial and Peat deposits. This division is convenient, as the tertiary strata of the Isle of Wight end with upper Eocene, or possibly lowermost Miocene, whilst in the London district there are no traces of Miocene, and even the upper Eocene is wanting; the gap, therefore, between what may be called the Lower Tertiaries and the Upper Tertiaries in this country is very considerable and well marked."

TABLE showing the species of Land and Freshwater Mollusca which have been described in the foregoing part of this volume-their foreign range-and the occurrence of any of them as Upper Tertiary fossils. This mark (-) signifies their occurrence in the district indicated by the column.

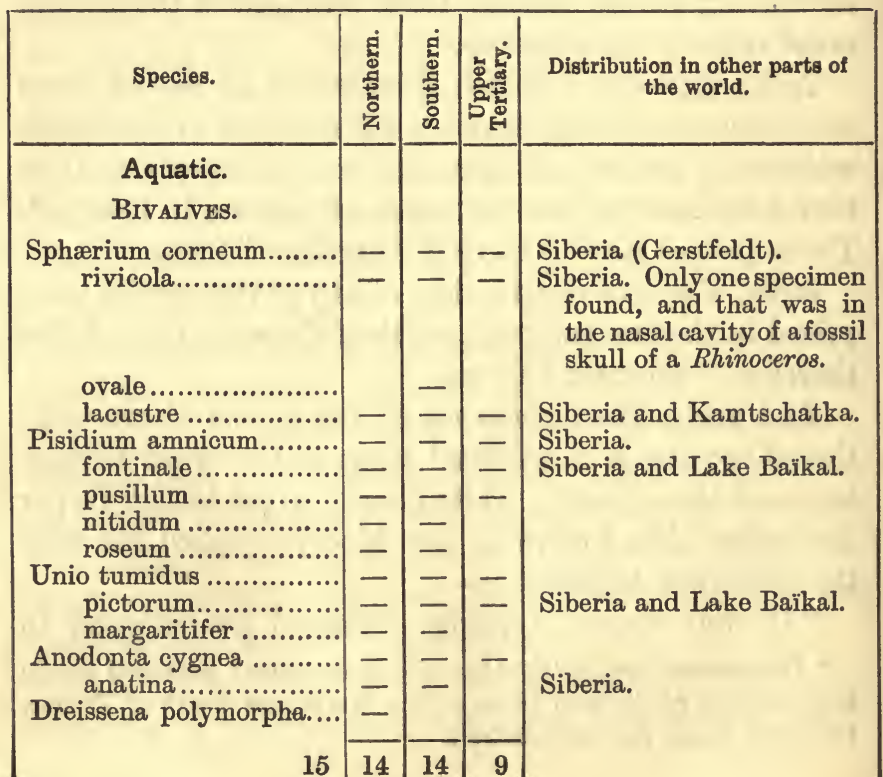




\begin{tabular}{|c|c|c|c|c|}
\hline Species. & 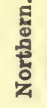 & 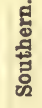 & 递 & $\begin{array}{l}\text { Distribution in other parts of } \\
\text { the world. }\end{array}$ \\
\hline \multicolumn{5}{|l|}{ Aquatic (continued). } \\
\hline Neritina fluviatilis......... & & 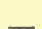 & & \multirow{6}{*}{ Siberia. } \\
\hline Paludina contecta........... & - & - & & \\
\hline vivipara................. & 一 & - & - & \\
\hline Bythinia tentaculata.. ... & 一 & 一 & - & \\
\hline Leachii.................. & 一 & 一 & - & \\
\hline Hydrobia similis............ & - & 一 & & \\
\hline \multirow[t]{2}{*}{ Valvata piscinalis........... } & - & 二 & 二 & \multirow{3}{*}{$\begin{array}{l}\text { Siberia. Var. depressa, R. } \\
\text { Lena. } \\
\text { Siberia and Kamtschatka. }\end{array}$} \\
\hline & & & & \\
\hline \multirow{8}{*}{ 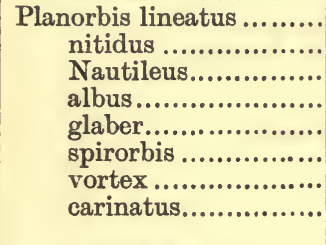 } & - & - & - & \\
\hline & - & - & - & \multirow{3}{*}{$\begin{array}{l}\text { Siberia. } \\
\text { Siberia. }\end{array}$} \\
\hline & - & 一 & - & \\
\hline & - & - & - & \\
\hline & - & - & - & \\
\hline & - & - & - & Siberia. \\
\hline & - & - & - & Siberia. \\
\hline & - & 一 & - & $\begin{array}{l}\text { Siberia and mouth of the } \\
\text { River Ussuri. }\end{array}$ \\
\hline \multirow{2}{*}{ 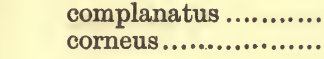 } & - & - & - & \multirow{5}{*}{$\begin{array}{l}\text { Siberia. } \\
\text { Siberia and Steppes of } \\
\text { Kirgis. } \\
\text { Siberia. } \\
\text { Siberia; North America. } \\
\text { Siberia. }\end{array}$} \\
\hline & 一 & - & - & \\
\hline contortus ............... & - & - & - & \\
\hline Physa hypnorum........... & - & 一 & - & \\
\hline fontinalis ................. & - & - & ? & \\
\hline $\begin{array}{r}\text { Limnæa glutinosa.......... } \\
\text { involuta................ }\end{array}$ & - & - & & \multirow{7}{*}{$\begin{array}{l}\text { Siberia; Afghanistan. } \\
\text { Siberia. } \\
\text { Siberia. } \\
\text { Siberia and Kamtschatka. } \\
\text { Siberia; Afghanistan. } \\
\text { Irkoutsk. }\end{array}$} \\
\hline peregra.............................. & - & - & - & \\
\hline auricularia .............. & - & - & - & \\
\hline stagnalis................. & - & - & - & \\
\hline palustris ................. & - & - & - & \\
\hline truncatula ............. & - & - & - & \\
\hline \multirow[b]{2}{*}{ Ancylus fluviatilis......... } & - & - & & \\
\hline & - & - & - & \\
\hline Number of aquatic spe- & - & - & - & \\
\hline cies.................47 & 45 & 45 & 34 & \\
\hline Terrestrial. & & & & \\
\hline Arion ater..................... & - & - & & Siberia. \\
\hline $\begin{array}{l}\text { hortensis................. } \\
\text { Geomalacus maculosus }\end{array}$ & - & & & \\
\hline
\end{tabular}




\begin{tabular}{|c|c|c|c|c|}
\hline Species. & 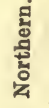 & 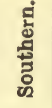 & 赑 & $\begin{array}{l}\text { Distribution in other parts of } \\
\text { the world. }\end{array}$ \\
\hline $\begin{array}{c}\text { Terrestrial (continued). } \\
\text { UNIVALVES. }\end{array}$ & & & & \\
\hline Limax gagates.............. & - & - & & \\
\hline ntarginatus............ & - & - & - & \\
\hline flavus .................... & - & - & & \\
\hline agrestis ................ & - & - & - & Siberia. \\
\hline arborum................. & - & & & \\
\hline $\begin{array}{l}\operatorname{maximus} \ldots \ldots \ldots \ldots \ldots . . . . . . \\
\text { Testacella Haliotidea..... }\end{array}$ & 一 & - & . & \\
\hline $\begin{array}{l}\text { Testacella Haliotidea..... } \\
\text { Succinea putris............. }\end{array}$ & - & - & - & Siberia ; Afghanistan. \\
\hline 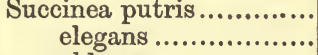 & - & - & - & $\begin{array}{l}\text { Afghanistan. } \\
\text { Aforistan. }\end{array}$ \\
\hline 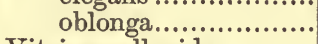 & - & - & - & \\
\hline Vitrina pellucida............ & - & - & & Siberia. \\
\hline Zonites cellarius............ & - & - & - & N. America. \\
\hline alliarius ................. & & - & - & \\
\hline nitidulus ............... & - & - & - & \\
\hline purus .................... & - & - & - & Siberia. \\
\hline radiatulus ............... & - & - & 一 & \\
\hline nitidus................... & - & - & - & \\
\hline excavatus................. & 一 & - & & \\
\hline $\begin{array}{l}\text { crystallinus .............. } \\
\text { fulvus.................. }\end{array}$ & - & - & - & Siberia. $\mathrm{N}$ A merica \\
\hline $\begin{array}{l}\text { fulvus..................... } \\
\text { Helix lamellata.............. }\end{array}$ & 二 & - & - & Siberia ; N. America. \\
\hline $\begin{array}{r}\text { Helix lamellata................ } \\
\text { aculeata ................ }\end{array}$ & - & - & - & \\
\hline pomatia................. & - & - & & \\
\hline aspersa .................. & - & 一 & & \\
\hline nemoralis................. & - & - & - & N. America. \\
\hline arbustorum ............. & - & - & - & \\
\hline Cantiana ............... & - & - & & \\
\hline Cartusiana .............. & - & - & & Siberia. \\
\hline rufescens................ & 二 & $\overline{-}$ & - & \\
\hline concinna ................. & 二 & 一 & - & Siberia. \\
\hline 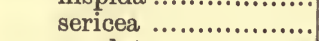 & - & - & - & Irkoutsk ; Caucasus. \\
\hline revelata ................. & & 一 & & \\
\hline fusca..................... & - & - & & \\
\hline 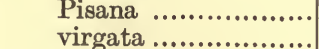 & - & - & & \\
\hline 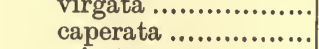 & & - & & \\
\hline ericetorum ............. & - & - & 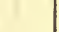 & \\
\hline rotundata.................. & - & - & - & \\
\hline rupestris.................. & - & - & & \\
\hline pygmæa...$\ldots \ldots \ldots \ldots$ & 一 & 一 & & Siberia. \\
\hline & & & - & \\
\hline
\end{tabular}




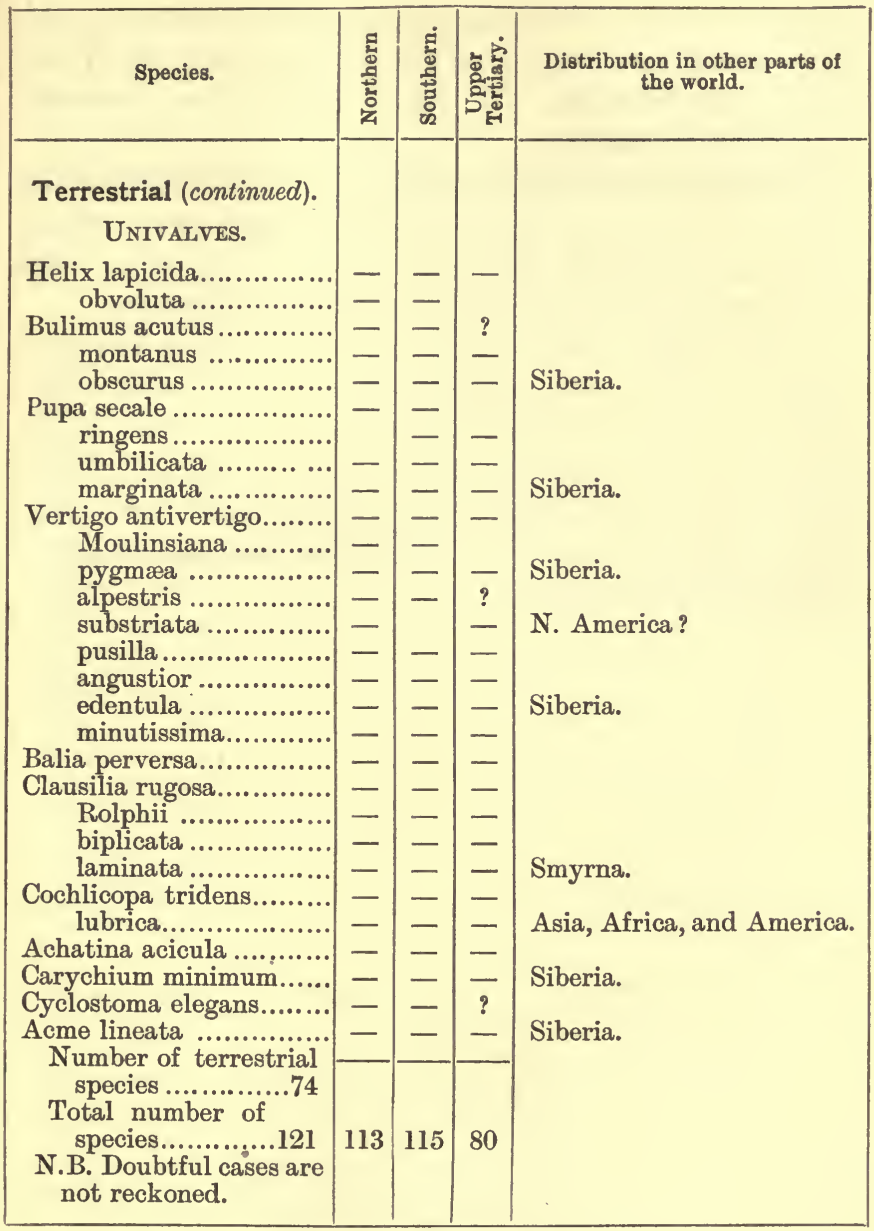

Besides the species enumerated in the above list, four more occur in our upper tertiary strata, but are not now found living in this country. One of them (Hydrobia marginata) is aquatic and inhabits the South of Europe. 
The other three (viz. Helix fruticum, H. incarnata, and $H$. ruderata) are terrestrial and inhabit both the North and South of Europe. $\quad H$. fruticum and $H$. ruderata are also Siberian species.

It will be seen that, with only two exceptions (viz. Zonites alliarius and Pupa ringens), all the species which occur in our upper tertiaries are northern forms, and that very few are exclusively northern or southern.

In the body of this work the term "North of Europe" has been used in the ordinary sense, and not with reference to the somewhat arbitrary line of demarcation proposed in the foregoing Table. The authority can be given for every locality; but to have done this would have taken a great deal of extra space and unnecessarily encumbered the work. 


\title{
ALPHABETICAL LIST OF AUTHORS AND WORKS
}

\author{
REFERRED TO OR CONSULTED
}

IN THE PREPARATION OF THIS VOLUME.

Adanson, Mrohel. Histoire Naturelle du Sénégal. Coquillages. Paris, 1757, 4to, with 19 plates and a map.

ALBERS, J. C. Die Heliceen nach natürlicher Verwandtschaft systematisch geordnet. Berlin, 1850, 8vo.

AlDER, Joshua. A Catalogue of the Land and Freshwater Testaceous Mollusca found in the vicinity of Newcastle-upon-Tyne, with remarks. In Trans. Nat. Hist. Soc. Northumb., Durh. and Newc. Newcastle, 1830,4 to, pp. 16 (published separately).

ALDFR, J. Supplement to the above Catalogue. 1833,4 to, pp. 5.

ANNALS OF NATURAL History from 1838 to 1840 ; and ANNALs AND Magazine of Natural Hrstory, 1st, 2nd, and 3rd Series, from 1841, and still in progress; containing many interesting contributions on the subject of the British Land and Freshwater Mollusca by Messrs. Gray, Hanley, Thompson, Eyton, Lonsdale, W. Clark, Hincks, Rev. A. M. Norman, and others.

Anthony, J. G. On the Byssus of Unio. In Ann. \& Mag. Nat. Hist. (1841) vi. p. 77.

ARADAS e MAGgrore. Catalogo ragionato delle Conchiglie viventi e fossili di Sicilia. 1839.

Baudon, Auguste. Catalogue des Mollusques du Département de l'Oise. In Mém. Soc. Acad. Oise, 1853. Beauvais, 8vo, pp. 20 (published separately).

BAUDON, A. Essai monographique sur les Pisidies Françaises. Paris, 1857 , 8vo, pp. 55, with 5 plates of beautifully executed figures:

BeCK, H. Index Molluscorum præsentis ævi, Musæi principis augustissimi Christiani Frederici. Hafn., 1838, 4 to.

BeNorT, LUIGI. Illustrazione sistematica critica, inconografica de' Testacei estramarini della Sicilia ulteriore e delle isole circostanti. Napoli, 1857-1860, 4to, quaderni 3 (still in course of publication).

Benson, W. H. Occurrence of Clausilia Mortilleti, Dumont, in Kent. In Ann. \& Mag. Nat. Hist. July 1856, p. 74.

BerkelikY, Rev. M. G. A description of the Anatomical Structure of Cyclostoma elegans. In Zool. Journ. iv. p. 278, pl. xxxiv.

BeTTA, EDOARDo DE. Malacologia terrestre e fluviatile della Valle di Non nel Tirolo Italiano. Parte 1. Molluschi terrestri. Verona, 1852, 8 vo, pp. 144, with a plate. 
Binnex, A. The Terrestrial Air-breathing Mollusks of the United States (edited by A. Gould). Boston, 1851, 8vo.

BlaINville, H. DE. Manuel de Malacologie et de Conchyliologie. Paris, 1825,2 vols. 8 vo.

BorLASE, WILLIAM. The Natural History of Cornwall. Oxford, 1758, folio, with 20 plates.

BoubÉE, NÉRÉE. Bulletin d'Histoire Naturelle de France, pour servir à la statistique et à la géographie naturelle de cette contrée. Première année, $3^{e}$ section, Mollusques et Zoophytes. Paris, 1832-5, 8vo, pp. 40.

BouchaRd-ChanteriauX. Catalogue des Mollusques terrestres et fluviatiles observés jusqu'à ce jour à l'état vivant, dans le Département du Pas-de-Calais. Boulogne, 1837, 8vo, p. 142-230, with a plate (in Mém. Soc. d'Agric. \&c. de Boul.).

Bouchard-Chantrreaux. Ponte de l'Ancylus fluviatilis. In Act. Soc. Linn. Bord. v. 1833, p. 210, pl. vii.

BodchaRd-ChantereaUX. Observations sur les Hélices Saxicaves du Boulonnais. In Ann. des Sc. Nat. 4 Série, Zool. 1861, p. 197-218, with a plate.

Bodrguignat, J. R. Amênités malacologiques. In Guér. Rev. et Mag. Zool. 1853-1860, with plates.

Bourguignat, J. R. Monographie des espèces Françaises du genre Sphcerium. In Mém. Soc. Phys. Bord. 1851 (published separately at Bordeaux, 8 vo, pp. 56 , with 4 plates).

Bourguignat, J. R. Etude synonymique sur les Mollusques des Alpes maritimes publiés par A. Risso en 1826. Paris, 1861, 8vo, with a plate.

BRARD, C. P. Histoire des Coquilles terrestres et fluviatiles qui vivent aux environs de Paris. Paris and Geneva, 1815, 12mo, with 10 coloured plates.

BROWN, THOs. Illustrations of the recent Conchology of Great Britain and Ireland. London, 1845 , roy. 8vo, with plates.

Brown, T. Description of several new British Shells. In Edinb. Journ. Nat. Hist. i. 1827.

BRDGUIÈRE, J. G. Encyclopédie Méthodique, tome vi. (Hist. Nat. des Vers). Paris, 1789-1792.

Brdmati, Lionardo (Abate). Catalogo sistematico delle Conchiglie terrestri e fluviatili osservate nel territorio di Monfalcone. Goritz, 1838, 8 vo, with a plate.

Camluadd, Fréderic. Des Clausities et de leur Clausitium. In Journ. Conch. Paris, iv. 1853, p. 419.

ChARPENTIER, JKAN DE. Catalogue des Mollusques terrestres et fluviatiles de la Suisse. Neuchatel, 1837, 4to, pp. 28, with two plates.

Charpentier, J. DE. Essai d'une Classification naturelle des Clausilies. In Journ. Conch. Paris, iii. 1852, p. 357.

Cherres, Colrard Des. Catalogue des Testacés terrestres et fluviatiles des environs de Brest et de Quimper (Finistere). In Act. Soc. Linn. Bord. 1830, pp. 17 (published separately).

Clarke, Rev. B. J. On the Species of the Genus Limax occurring in Ireland. In Ann. Nat. Hist. xii. 1843, p. 332.

Cocks, W. P. Contributions to the Falmouth Fauna. 1845.

Costa, EMander MENDez DA. Historia Naturalis Testaceorum Britanniæ, or the British Conchology (in English and French). London, 1778, 4to, with 17 coloured plates. 
Coxf, Wruliam. Travels in Switzerland. London, 1789, 3 vols. 8vo. (With an appendix to the third volume, by Studer, under the title of Faunula Helvetica.)

Cuvikr, Grorges. Leçons d'Anatomie Comparée. Paris, 1805, 5 vols. 8 vo.

Cuvikr, G. (le Chevalier). Mémoires pour servir à l'Histoire et à l'Anatomie des Mollusques. Paris, 1817, 4to.

Draparnaud, J. P. R. Tableau des Mollusques terrestres et fluviatiles de la France. Montpellier, 1801, 8vo, pp. 116.

Draparnatd, J. P. R. Histoire Naturelle des Mollusquest errestres et fluviatiles de la France. Montpellier and Paris, 1805, 4to, with 13 plates.

DROUET, HeNRI. Enumération des Mollusques terrestres et fluviatiles vivants de la France Continentale. Paris, 1854, 8vo.

Drouet, H. Eléments de la Faune Açoréenne. 1861, 4to, pp. 245.

Dumont et MorTillet. Catalogue critique et malacostatique des Mollusques de Savoie et du bassin du Léman. 1st part. Geneva, 1857, 8vo, pp. 104.

DUPUY, D. (l'Abbé). Essai sur les Mollusques terrestres et fluviatiles et leurs Coquilles vivantes et fossiles du Département du Gers. Auch and Paris, 1843 , 8vo, pp. 140 , with a plate.

DUPUY, D. (l'Abbé). Histoire Naturelle des Mollusques terrestres et d'eau douce qui vivent en France. Paris, 1847-52, 4to, with 31 plates.

Faure-Biguet. Sur une nouvelle espece de Testacelle. In Bull. Soc. Philom. Paris, 1802, p. 98, pl. v.

Férussac, J. B. I. D'Audebard Baron dK. Concordance Systématique pour les Mollusques terrestres et fluviatiles de la Grande Bretagne, avec un aperçu des travaux modernes des Savants Anglais sur les Mollusques. In Journ. Phys. xc. 1820 (published separately in 4to, pp. 28).

F́́russao (père et fils). Histoire Naturelle générale et particulière des Mollusques terrestres et fluviatiles, tant des espèces que l'on trouve aujourd'hui vivantes, que des dépouilles fossiles de celles qui n'existent plus ; classés d'après les caractères essentiels que présentent ces animaux et leurs coquilles. Euvre posthume. Paris, 1819, 2 vols. folio, followed by Tables and a Prodromus, and 168 plates.

Fleming, John, D.D. A History of British Animals. Edinburgh, 1828.

Forbes, EDward. Malacologia Monensis : a Catalogue of the Mollusca inhabiting the Isle of Man and the neighbouring sea. Edinburgh, 1838, 8 vo, pp. 63 , with 3 plates.

Forbes and HANLEY. A History of British Mollusca and their Shells. London, 1853, 4 vols. 8vo, with 64 plates of animals and 132 plates of shells.

Gasparn, B. Mémoire physiologique sur le Colimaçon (Helix pomatia). In Majendie, Journ. Physiol. ii. p. 295 (and an abstract of the above, with notes by Professor T. Bell, in Zool. Journ. i. 1824, p. 93 ; ii. 1824, p. 174).

Gassins and Fischer. Monographie du genre Testacelle. Paris, 1856, 8 vo, pp. 56, with 2 plates.

GEOFFROY. Traité sommaire des Coquilles, tant fluviatiles que terrestres, qui se trouvent aux environs de Paris. Paris, 1767, $12 \mathrm{mo}$.

GERstFrLDT, G. Ueber Land- und Süsswasser-Mollusken Sibiriens und des Amur-Gebietes. Petersburg, 1859 , 4to, pp. 44 , with a plate. 


\section{LIST OF AUTHORS AND WORKS QUOTED.}

GmkLIN, J. F. Caroli a Linné Systema Naturæ. Leipzig, 1788, 10 vols. 8 vo.

Gould, Adgustus A. Report on the Invertebrata of Massachusetts. Cambridge (U. S.), 1841, 8vo, with 213 figures.

Gras, ALBIN. Description des Mollusques fluviatiles et terrestres de la France, et plus particulièrement du Département de l'Isère. Grenoble, 1846 , 8vo, with 6 plates.

GRATELOUP, DE, Le Dr. Distribution géographique de la famille des Limaciens. Bordeaux, 1855, 8vo, pp. 33.

GRATELOUP, DF. Essai sur la Distribution géographique, orographique ct statistique des Mollusques terrestres et fluviatiles vivants du Département de la Gironde. Bordeaux, 1858, 1859, 8vo, pp. 196.

GratelOUP et RAULIN. Catalogue des Mollusques terrestres et fluviatiles vivants et fossiles de la France continentale et insulaire, par ordre alphabétique. Bordeanx, 1855, 8vo, pp. 56.

Gray, John EDWARD. New British Species of Mollusca. In London Medical Repository, xv. 1821, p. 239.

GRAY, J. E. Remarks on the Difficulty' of distinguishing certain Genera of Testaceous Mollusca by their Shells alone, and on the anomalies in regard to habitation of certain species. In Philosophical Transactions, cxxv. 1835, p. 301.

GRAY, J. E. A Manual of the Land and Freshwater Shells of the British Islands (by William Turton, M.D.). New edition. London, 1840, 8vo, with 12 plates.

GRAX, J. E. Description of a new species of Sphcerium found near London (in Ann. \& Mag. Nat. Hist., June 1856, p. 465); and on a second new species of Sphcerium from the Paddington Canal (in Ann. \& Mag. Nat. Hist., July 1856, p. 25).

GURTTARD. Observations qui peuvent servir à former quelques caractères de Coquillages. In Mém. Acad. Sc. Paris, 1756, p. 145.

Hartmann, J. D. W. von. System der Erd- und Fluss-Mollusken der Schweitz und des benachbarten Landes. In Steinmüller, Neue Alpina, Wintherthur, vii. Band i. 1821, 8vo, p. 194. Also in Sturm, Deutschlands Fauna, vi. 5 Heft. Nürnberg, 1821 , $18 \mathrm{mo}$, pp. 60 , with 3 plates.

HFLD, F. Aufzahlung der in Bayern lebenden Mollusken. In Isis, 1836, p. 271 ; and 1837, p. 304.

HERRMANNSEN, A. N. Indicis generum Malacozoorum primordia, nomina subgenerum, generum, familiarum, tribuum, ordinum, classium ; adjectis auctoribus, temporibus, locis, systematicis atque litterariis, etymis, synonymis. Cassel, 2 vols. 8vo, 1846-9 ; and Supplement and Corrigenda, 1852.

Hox, THOMAS. Account of a Spinning Limax or Slug. In Linn. Trans. i. 1790 , p. 183.

HuTton, Thomas. On the Land-shells of India. In Journ. Asiat. Soc. Beng. iii. 1834, p. 81, 520.

JhFrrexs, John Gwrn. A Synopsis of the Testaceous Pneumonobranchous Mollusca of Great Britain. In Linn. Trans. xvi. 1830, p. 323; and Supplement to same, p. 505.

JkFFrexs, J. G. Notes on Swiss Mollusca. In Ann. \& Mag. Nat. Hist., January 1855, pp. 16.

JEFrREYs, J. G. Shropshire Mollusca. In Ann. \& Mag. Nat. Hist., Oct. 1855, p. 464.

JEFFreYs, J. G. Contributions to the Conchology of France. In Ann. \& Mag. Nat. Hist., Dec. 1856, p. 471. 
JeFFreys, J. G. Gleanings in British Conchology. In Ann. \& Mag. Nat. Hist., January 1858, p. 39; August 1858, p. 117 ; February 1859, p. 186 ; September 1859, p. 189.

JEFFREYS, J. G. On the Mollusca of the Upper Harz. In Ann. \& Mag. Nat. Hist., Nov. 1860 , p. 348.

JrNyns, LeoNard, Rev. A Monograph on the British species of Cyclas and Pisidium. In Cambr. Phil. Trans. 1833, 4to, with 3 plates.

JanYNS, L. Note on the smaller British species of Pisidium. In Ann. \& Mag. Nat. Hist., August, 1858, p. 104.

JoHnston, GEORGE. A List of the Pulmoniferous Mollusca of Berwickshire and North Durham. In Trans. Berw. Nat. Hist. Soc. 1838, p. 154.

JoURNAL DE CONCHYLIOLOGIE. Paris, tomes i.-viii. 1850-60 ; and $3^{e}$ sér. t. i. 1861 (still in progress).

KIokx, J. Specimen inaugurale exhibens Synopsin Molluscorum Brabantiæ australi indigenorum. Lovanii, 1830,4 to, pp. 97, with a plate.

KLEIN, J. T. Tentamen Methodi Ostracologicæ, sive dispositio naturalis Cochlidum et Concharum in suas classes, genera et species. Lugduni Batavorum, 1753, 4to, with 12 plates.

KRYNICKI, J. Conchylia tam terrestria quam fluviatilia, et e maribus adjacentibus imperii Rossici indigena. In Bull. Soc. Nat. Mosc. 1st ser. x. i. 1837, p. 50.

Küster, H. C. Grosses Conchylienwerk von Martini und Chemnitz. New edition, by Philippi, L. Pfeiffer, and Dunker, under the direction of H. C. Küster. Nürnberg, 1837-55, Parts 1 to 148, 4to, with plates.

Lamarok, J. B. M. Histoire Naturelle des Animaux sans Vertèbres. New edition. Paris, $1835-45,11$ vols. 8 vo.

LeAch, William Elford. A Synopsis of the Mollusca of Great Britain. London, 1852, 8vo, with 13 plates.

Lightroot, J. An Account of some minute British Shells, either not duly observed, or totally unnoticed by authors. In Phil. Trans. Ixxvi. 1786 , p. 160 , pl. i.-iii.

Linné, Carolus a. Fauna Suecica, sistens animalia Sueciæ regni. Holmiæ, 1746, 8vo. Another edition, 1761.

LiNNt, C. A. Systema Naturæ, per regna tria naturæ, secundum classes, ordines, genera, species, cum characteribus, differentiis, synonymis, locis. Editio decima. Holmiæ, 1758, 2 vols. 8vo. Editio duodecima, Holmix, 1766 to 1767,3 vols. 8 vo.

Lister, Martin. Historiæ Animalium Angliæ tres tractatus. London, 1678 , 4to, with plates.

LISTER, M. Observations concerning the odd turn of some Shell-snails. In Phil. Trans. iv. p. 10.

Lowr, E. J. On the Growth of Land-shells. In Proc. R. S. vii. 1854, p. 8.

Lowk, R. T., Rev. Primitiæ Floræ et Faunæ insularum Maderæ et Porto-Sancto. In Cambr. Phil. Trans. iv. 1833, 4to, with two plates. (Lately republished in a separate form, 8vo.)

Macgillivray, William. A History of the Molluscous Animals of the Counties of Aberdeen, Kincardine, and Banff. London, 1843, 8vo.

MAGASIN DE Zoologir. Edited by Guérin-Méneville. Paris, 1831-45, 15 vols. $8 \mathrm{vo}$, with plates.

MALAKOZOOLOGISOHE BLÄTTER (a continuation of the Zeitschrift für Malakozoologie), edited by Menke and L. Pfeiffer. Cassel, 1854-61, and still in progress, $8 \mathrm{vo}$. 
MaLM, A. W. Zoologiska Observationer. Götheborg, 1851-5, 3 häftet, $8 \mathrm{vo}$, with plates.

MATON and RACKETT. A Descriptive Catalogue of the British Testacea. In Linn. Trans. 1807, viii. p. 17-250, 4 to, with 6 plates.

Menke, K. T. Zeitschrift für Malakozoologie, and Malakozoologische Blätter. Cassel, 1846-62, 8vo.

Michaud, A. L. G. Complément de l'Histoire Naturelle des Mollusques terrestres et fluviatiles de la France, par Draparnaun. Verdun, 1831, 4 to, with 3 plates.

MIDDENDORFF, A. T. von. Grundriss für Geschichte der Malakozoographie Russlands. In Bull. Soc. Nat. Mosc. 1 sér, xxi. i. 1848, p. 424.

MILLER, J. S. A List of Freshwater and Land Shells occurring in the environs of Bristol, with observations. In Ann. Phil. 2nd ser. vii. 1822, p. 376.

Montagd, Grorge. Testacea Britannica, or Natural History of British Shells, marine, land, and freshwater. London, 1803, 2 vols. 4to, with 16 plates and 2 vignettes. Supplement to the above, with additional plates. London, 1808,4 to.

Montrort, DenYS DE. Conchyliologie Systématique et Classification Méthodique des Coquilles. Paris, 1808-10, 2 vols. 8vo.

MoQUin-TANDON, ALFRED. Histoire Naturelle des Mollusques terrestres et fluviatiles de France. Paris, 1855, 2 vols. large 8vo, with an Atlas of 54 plates.

MORELET, ARTHur. Description des Mollusques terrestres et fluviatiles du Portugal. Paris, 1845, large 8vo, with 14 plates.

MorkLet, A. Catalogue des Mollusques terrestres et fluviatiles de l'Algérie. In Journ. Conch. iv. 1853, p. 280.

MORTON, J., Rev. Natural History of Northamptonshire. London, 1712 , folio.

Moseley, M. H. On the Geometrical Forms of Turbinated and Discoid Shells. In Phil. Trans. 1838, p. 351, with a plate.

Moulins, Charles DEs. Catalogue des espèces et variétés des Mollusques Testacés terrestres et fluviatiles observés jusqu'à ce jour, à l'état vivant, dans le Département de la Gironde. In Bull. Soc. Linn. Bord. ii. 1827, p. 39, pl. ii.; and Supplement, 1829, t. iii. p. 211.

MoULINS, C. DES. Mollusques terrestres et fluviatiles à ajouter au Catalogue de la Gironde. In Ann. Soc. Linn. Bord. xvii. 1851, p. 421.

MOUSSON, ALBERT. Coquilles terrestres et fluviatiles recueillies dans l'Orient par M. le Dr. A. Schlaefli. Zurich, 1859, 8vo, pp. 71.

Mousson, A. Coquilles terrestres et fluviatiles recueillies par M. le Prof. J. R. Roth dans son dernier voyage en Palestine. Zurich, 1861, 8vo, pp. 68.

MÜLLER, AUGUST. Ueber einige vaterländische Landschnecken. In Wiegmann's Archiv, vii. 1838, p. 209, pl. iv. f. 46.

MÜLLER, ОTHO FREDERICK. Vermium terrestrium et fluviatilium Historia. Hafniæ et Lipsiæ, 1774, 2 vols. 4to. (Only the second volume treats of the Mollusca.)

Nilsson, Sukno. Historia Molluscorum Sueciæ terrestrium et fluviatilium. Lundæ, 1822, 8vo.

Norman, Alfred Merle, Rev. The Inland Mollusca of Somersetshire. In Proc. Somersets. Archæol. \& Nat. Hist. Soc. x. 1860. Taunton, 1861, 8 vo, pp. 23.

Normand, N. A. J. Coup d'œil sur les Mollusques de la famille des Cyclades, observés jusqu'à ce jour dans le Département du Nord. Valenciennes, 1854, 8vo. 
Nunneley, Thomas. A Description of the Internal Structure of varions Limaces found in the neighbourhood of Leeds. In Trans. Phil. \& Lit. Soc. Leeds, i. 1837, p. 41.

Payraudead, B. C. Catalogue descriptif et méthodique des Annelides et des Mollusques de l'île de Corse. Paris, 1826, 8vo, with plates.

Prannant, Thomas. British Zoology. London, 4th edit., 1766-7, 4 vols. $8 \mathrm{vo}$, with plates.

Petiver, JACOBUS. Gazophylacii Naturæ et Artis decades decem. Lon. don, 1702-10, folio.

PFEIFrer, KARL. Naturgeschichte Deutscher Land- und Süsswasser Mollusken. Cassel and Weimar, 1821-8, 3 vols. 4to, with plates.

PFEIFFer, LUDWIG. Monographia Heliceorum viventium. Leipsig, 18471853, 3 vols. 8vo; and Monographia Pneumonopomorum viventium. Cassel, 1852, 8vo.

Philippi, Rodolph Armand. Enumeratio Molluscorum Siciliæ, tum viventium, tum tellure tertiaria fossilium. Berolini, 1836, 4to, with 12 plates. And second volume, Hallis, 1844, 4to, with 16 plates.

PhilIPPSSON, LAURENTIUS MÜNTRR. Dissertatio historico-naturalis sistens nova Testaceorum genera. Lundæ, 1788, 8vo, pp. 23.

PICARD, Casimir. Histoire des Mollusques terrestres et fluviatiles qui vivent dans le Département de la Somme. In Bull. Soc. Linn. Nord. Abbeville, i. 1840 , 8vo, p. 150.

PlotT, ROBERT. Natural History of Staffordshire. Oxford, 1668, folio.

PLOTT, R. Natural History of Oxfordshire. Oxford, 1676.

PoIRET, J. L. M. Coquilles fluviatiles et terrestres observées dans le Département de l'Aisne et aux environs de Paris. Prodrome. Paris, et Soissons, an ix. (1801), 12mo, pp. 119.

Porro, Carro. Malacologia terrestre e fluviale della provincia Comasca. Milano, 1838 , 8vo, with 2 plates.

Potinz et Mrohaud. Galerie des Mollusques, on Catalogue méthodique, descriptif et raisonné des Mollusques et Coquilles du Muséum de Douai. Paris, 1838-44, 2 vols. large 8vo, with 70 plates.

Prentice, Charles. On the occurrence of Clausila Mortilleti near Cheltenham. In Ann. \& Mag. Nat. Hist. May 1856, p. 446.

Prime, Trmple. List of the known species of Pisidium, with their Synonymy. Boston, 1859, 8vo, pp. 10.

Polteney, Richard. Catalogues of the Birds, Shells, and some of the most rare Plants of Dorsetshire, from the new additions of Mr. Hutchins. London, 1799, folio, with plates.

Puton, E. Essai sur les Mollusques terrestres et fluviatiles des Vosges. In Stat. départ. des Vosges. Epinal, 1847 (published separately).

Quatrefages, Armand DE. Embryogénie des Unio. In Comptes-rendus Inst. xxix. 1849, p. 82.

Rang, Sander. Manuel de l'Histoire Naturelle des Mollusques et de leurs Coquilles, ayant pour base de classification celle de M. le Baron Cuvier. Paris, $1829,18 \mathrm{mo}$, with 6 plates.

REAUMUR, R.A.F. DE. Des différentes manières dont plusieurs espèces d'animaux de mer s'attachent au sable, aux pierres, et les uns aux autres. In Mém. Acad. Sc. Paris, 1711, p. 100, pl. ii. iii.

RÉcloz, C. A. Notice sur le genre Nerita, et sur.le sous-genre Neritina, avec le Catalogue Synonymique des Neritines. In Journ. Conch. i. 1850, pp. 131, 277. 
Requikn, E. Catalogue des Coquilles de l'Tle de Corse. Avignon, 1848, 8 vo, pp. 109.

Revur hT Magasin De Zoologir. Edited by Guérin-Méneville. Paris, 1849 , and still in progress, 8 vo.

Risso, A. Histoire Naturelle des principales productions de l'Europe méridionale, et particulièrement de celles des environs de Nice et des Alpes maritimes. Paris, 1826, 5 vols. 8vo, with plates and a map. (The 4th volume contains the Mollusca.)

ROSSMASSLER, E. A. Iconographie der Land- und Süsswasser Mollusken mit vorzüglicher Berücksichtigung der europäischen noch nicht abgebildeten Arten. Dresden and Leipzig, 1835-54.

Roth, J. R. Molluscorum species quas itinere per Orientem facto, Comites clariss. Schuberti, doctores Erdl et Roth collegerunt, recensuit J. R. Roth. Dissertatio inauguralis. Monachii, 1839, 4to, pp. 27, with 2 plates.

Saint-Simon, Alfred DE. Miscellanées Malacologiques. Premiere décade. Toulouse, $1848,8 \mathrm{vo}, \mathrm{pp} .4$.

SAULCX, F. DE. Listes des Mollusques terrestres et fluviatiles trouvés dans la vallée de Barèges (Hautes-Pyrénées). In Journ. Conch. iv. 1853, p. 266.

Scacchi, Aroanghlo. Catalogus Conchyliorum regni Neapolitani quæ usque adhuc reperit. Neapoli, 1836, 8vo, pp. 18.

SoHMIDT, ADOLF. Die kritischen Gruppen der europäischen Clausilien. Leipzig, 1857, large 8vo, with 11 plates.

ScholTz, Heinrich. Schlesien's Land- und Wasser-Mollusken. Breslau, 1843, 8vo ; and Supplement, 1853.

Schröter, J. S. Die Geschichte der Flussconchylien welche in den Thüringischen Wassern leben. Halle, 1779, 4to, with 11 plates.

Schumacher, C. F. Essai d'un nouveau système des habitations des Vers testacés. Copenhagen, 1817, 4to, with 22 plates.

Scopoli, J. A. Introductio ad Historiam Naturalem, sistens genera Lapidum, Plantarum et Animalium hactenus detecta, caracteribus essentialibus donata, in tribus divisa, subinde ad leges naturæ. Pragæ, 1777, 8 vo.

ShkPPARD, RkvetT, Rev. Descriptions of seven new British Land and Freshwater Shells, with observations upon many other Species, including a List of such as have been found in the County of Suffolk. In Linn. Trans. xiv. 1825 , p. 148.

Shuttlkworth, R. J. Diagnosen neuer Mollusken. In Mittheil. Naturf. Gesellsch. Berne, 1852, 8vo, pp. 12.

Siebold, K. T. von. Observations sur l'organe auditif des Mollusques. In Müll. Arch. 1841, p. 148; and in Ann. Sc. Nat. 2e sér. xix. 1843, p. 193, pl. ii. B.

Stabile, GiUshppe (Abbate). Delle Conchiglie terrestri e fluviali del Luganese. Lugano, 1845, 8vo, with 3 plates.

STABILI, G. Prospetto Sistematico-statistico dei Molluschi terrestri e fluviali viventi nel territorio di Lugano. Milano, $1859,8 \mathrm{vo}, \mathrm{pp} .67$.

STUDER. Faunula Helvetica. Vermes testacea. In Coxe's Travels in Switzerland. London, 1789, 3 vols. 8vo.

Swainson, Wrlliam. A Treatise on Malacology, or the Natural Classification of Shell-fish. London, 1840, 8vo.

Terver. Catalogue des Mollusques terrestres et fluviatiles observés dans les possessions Françaises au nord de l'Afrique. Paris et Lyon, 1839, $8 \mathrm{vo}$, with 4 plates. 
Tномӓ, C., Dr. Verzeichniss der im Herzogthum Nassau, insbesondere in der Umgegend von Wiesbaden lebenden Weichthiere. Wiesbaden, 1849,8 vo.

Thompson, William. Description of Limneus involutus, Harvey, with an account of the Anatomy of the animal by John Goodsir. In Ann. \& Mag. Nat. Hist. v. 1840 , p. 21, with a plate.

Troscher, F. H. Ueber die Gattung Amphipeplea, Nilss. In Wiegm. Arch. ii. 1836, p. 257, pl. ix. x.

TURTon, William. A Conchological Dictionary of the British Islands. London, $1819,12 \mathrm{mo}$, with 28 plates.

TURTON, W. Conchylia Insularum Britannicarum. Exeter, 1822, 4to, with 20 plates.

Turron, W. Description of new British Shells. In Zool. Journ. ii. 1825, p. 361 , pl. xiii.

Turton, W. Conchological Notices. In Zool. Journ. ii. 1826, p. 564.

Turton, W. A Manual of the Land and Freshwater Shells of the British Islands. London, 1831, small 8vo, with 10 plates.

VILLA, A. \& G. B. Catalogo dei Molluschi della Lornbardia. In Notiz. nat. e civ. Lomb. i. 1844. Milano, 8vo, published separately, pp. 10. And Supplement, 1853.

WALKER, GEORGE. Testacea minuta rariora, nuperrime detecta in arena littoris Sandvicensis ; a Gul. Boys. London (1784), 8vo, with 3 plates.

WhitkAVES, J. F. On the Land and Freshwater Mollusca inhabiting the neighbourhood of Oxford. Oxford, 1857, 8vo, pp. 20.

WirgmanN, A. F. A. Archiv für Naturgeschichte. Berlin, 1835-44.

Wood, Srarlat V. A Monograph of the Crag Mollusca (Palæontographical Society's publications). London, 1848-56, 2 vols. 4to, with plates.

ZeitsohriFT FÜR MALAKOzoologiE, by Menke and afterwards in conjunction with L. Pfeiffer. Hanover and Cassel, 1844-53, 8vo, with plates.

Zoological Journal, The. London, 1824-35, 8vo, with plates.

Zoologist, THE. London, 1843 to the present time, and still in course of publication; containing many interesting contributions on the subject of the British Land and Freshwater Mollusca by the Rev. Dr. Gordon, Rev. A. M. Norman, Messrs. Stretch, Smith, Ashford, Tapping, King, Taylor, Bridgman, Templer, E. J. Lowe, Hawker, Choules, Captain Hutton, and others. 



\section{INDEX to VOL. I.}

The synonyms, as well as the names of spurious species, and of species, genera, and other groups which are not described in this volume, are in italics.-The figures in smaller type refer to the page in which the description of species, genera, and higher groups will be found.

Achatina, Lam., 149, 150, 287, $288,289,295,296,297,302$. acicula, Müll., 296, 297, 298, 307. dentiens, Rossm., 289. Acicula, Risso, 295, 307. Acicula, Hartm., 307. Acmoea, Esch., 307. ACME, Hartm., 307. fusca, Beck, 309. lineata, Drap., 308. minuta, Brown, 309.

Alasmodon, 31.

Alcea, Jeffr., 265. revoluta, Jeffr., 269. substriata, Jeffr., 261.

Alasmodonta margaritifera, F. \& H., 37. Ammonite, 78.

Amphipeplea, 101, 104.

Amplexus, 174.

ANCYLUS, Geoffr., 71, I18.

Capuloides, Jan, 120. deperditus, Ziegl. (\& Dup.), 121. fluviatilis, Müll., 119, 120, 121, $122,123$.

gibbosus, Bourg., 120.

lacustris, Linn., 120, I22.

oblongus, F. \& H., 122, 123. spina-rosce, Drap., 123.

ANoDonta, Lam., 39.

anatina, Linn., 43.

Cellensis, C. Pfeiff., 43. complanata, Ziegl., 44.
ANodonta (continued). cygnea, Linn., 4r. cygnea (part.), F. \& H., 43. ponderosa, C. Pfeiff., 43. rostrata, Kok., 42. ventricosa, C. Pfeiff., 44. Aplexa, Flem., 98. Aplysia, 78.

Aquatic, $\mathbf{I}$.

ARION, Fér., 126, 130.

ater, Linn., 127, 128, 139.

Empiricorum, Fér., 127.

fasciatus, Nilss., 128.

flavus, Fér., 127.

hortensis, Fér., I28.

Assiminia

Grayana, 65.

Auricula, Klein, 5.

Auricula, Lam., 299.

Auriculacea, Lam., 299.

Azeca, Leach, 289.

Nouletiana, Drap., 291.

tridens, F. \& H., 290.

Balcca, Leach, 272, 273.

Balea, Prideaux, 271, 273. fragilis, F. \& H., 273. Sarsii, Phil., 275.

Balia, Prid., 149, 150, 27r, 272. perversa, Linn., 273 .

Bithinia, Gray, 59. humilis, Boub., 63. 
Bithinia (continued).

Leachii, 61.

tentaculata, 60.

ventricosa, Gray, 62.

BIVALVES, $\mathbf{x}$.

Buccinum, 297.

acicula, Müll., 289, 297.

glabrum, Müll., 117.

glutinosum, Müll., 102.

palustre, Müll., 113.

peregrum, Müll., 104.

terrestre, Mont., 299.

truncatulum, Müll., 115.

Bulimi, 174, 232.

Bulimus, Scopoli, 114, 149, 150, 23I, 232, 241, 253, 276, 289, 291.

acutus, Müll., 232, 233.

anatinus, Poir., 66.

articulatus, Lam., 235.

articulatus, Turt., 235.

auris-Midce, 299.

clavulus, Turt., 240.

decollatus, 61, 240.

fibratus, 299.

glans, Brug., 287.

Guadaloupensis, Brug., 239.

Lackhamensis, F. \& H., 235.

leucostoma, Poir., 118.

lineatus, Drap., 308.

Menkeanus, 292.

montanus, Drap., 235, 239.

obscurus, Müll., 236, 237, 239, 243.

octonus, Brug., 289.

quadridens, 289.

tridens, 289, 292.

tuberculatus, Turt., 239.

ventricosus, Drap., 232, 234.

Bulin, Adans., 5, 231.

Bulla

fluviatilis, Turt., 99.

fontinalis, Linn., 98.

hypnorum, Linn., 96, 97.

rivalis, Mat. \& Rack., 100.

Bythinella, Moq.-Tand., 63.

BYTHINIA, 59, 304.

Leachii, Shepp., 6r.

tentaculata, Linn., 60.

Cocilianella, Bourg., 295, 296. Anglica, Bourg., 295.

Liesvillei, Bourg., 296.
Coecilioĩdes, Beck, 295, 296.

Cardium

Casertanum, Poli, 24.

Carocolla, 174.

Carychime, 124, 299, 300.

CARYCHIUM, Müll., 299, 300. minimum, Müll., 269, 300, 302.

Chitotrema, 174.

Cionella, Jeffr., 288, 289.

Clausiuia, Drap., 149, 150, 272 , $275,276,277,287,289,291$, 292.

bidens, Drap., 286.

biplicata, Mont., 283, 285, 286.

derugata, Fér., 286.

dubia, Drap., 279, 282.

Everetti, Mill., 279.

labiata, 286.

laminata, Mont., 284, 286.

lineolata, Held, 284.

Mortilleti, Dum., 282.

nigricans, Mat. \& Rack., 278.

obtusa, C. Pfeiff., 280.

papillaris, Drap., 287.

parvula, Stud., 280.

plicatula, Drap., 281, 282, 310.

Rolphii, Gray, 236, 28r, 282, 283, $284,310$.

rugosa, Drap., 275, 278, 281, 282.

rugulosa, Ziegl., 279.

similis, Charp., 284.

solida, Drap., 286, 287.

ventricosa, Drap., 284.

vivipara, Held, 284.

Clausilice, 276, 278.

Cochlicopa, Risso, 149, 150, 287, $288,289,297,302$.

lubrica, Miill., 289, 292, 294, 295, 297.

tridens, Pult., 289, 290, 294.

CONCHIFERA, $\mathrm{I}$.

Conovulus, Lam., 55, 76, 299, 302.

Corbicula, 3.

Crepidula, 45.

Cyclas, Drap.

calieulata, Drap., 10.

cornea, F. \& H., 5.

flavescens, Macg., 6.

fontinalis, Drap., 20.

fontinalis, Nilss., 25.

lenticularis, Norm., 22.

nucleus, Stud., 6. 
Cyclas (continued).

ovalis, Fér., 8.

rhomboidea, Say, 10.

rivalis, Dup., 6.

rivalis, Drap., 7.

rivicola, Leach, 7 .

Ryckholtii, Norm., 11.

Scaldiana, Norm., 6.

solida, Norm., 3.

Cyclostoma, зо3, 304.

acutum, Drap., 68.

anatinum, Drap., 59, 63, 310.

contectum, Millet, 56 .

elegans, Müll., 304, 306, 307.

ferrugineum, Lam., 307.

impurum, Drap., 61.

marmorea, Brown, 307.

simile, Drap., 62, 64, 310.

sulcatum, 303.

vitreum, Drap., 68.

Cyclostomatide, 302.

Cyclostome, Lam., 304.

Cyrena, 3.

fluminalis, 3.

Cyrenastrum, Bourg., 3.

Delphinula, Lam., 304.

Dreissena, Van Bened., 46. polymorpha, Pall., 47.

DREISSENIDA, 45.

Elisma, Leach, 232.

Eulima

stenostoma, 296.

GASTEROPODA, 5I, 304.

Geomalacus, Allm., I29.

maculosus, Allm., I29.

Glandina, Schum., 287, 297.

Gulnaria

lacustris, Leach, 105.

Helices, 173, 174, 218, 232.

HeLiCID \&, 124, I49.
Helix, Linn., 149, 150, 158, I72, $174,232,243,246,253,269$, $288,289$.

aculeata, Müll., 176.

acuta, Miüll., 233.

albella, Linn., 229.

albella, Flem., 229.

alliaria, Mill., 161.

Altenana, Kickx, 195.

aperta, Born, 184, 185.

arbustorum, Linn., 186, ז88, 190.

aspersa, Müll., 178, 181, 182, 184, 185.

auricutaria, Linn., 108.

bidens, Chemn., 172.

bidens, Müll., 286.

bidens, Linn., 287.

Bulimoides. Moq.-Tand., 232.

ccelata, Stud., 196.

candidula, Stud., 211.

Cantiana, Mont., 190, 193, 194, 209.

caperata, Mont., 2r3, 215.

Carthusiana, Drap., 191.

Carthusiana, F. \& H., 192.

Carthusianella, Drap., 194.

Cartusiana, Müll., 191, 192, 231.

cellaria, Müll., 159.

cespitum, Drap., 218.

chersina, Say, 171.

cingenda, Mont., 209.

circinnata, Stud., 196.

clandestina, Hartm., 196.

clara, Held, 169.

cochlea, Brown, 92.

complanata, Linn., 91, 92.

concinna, Jeffr., I96, 198.

conica, Drap., 232.

conspurcata, Drap., 215.

contorta, Linn., 94.

cornea, Linn., 93.

Corvus, Gmel., 114.

costata, Müll., 225.

crenella, Mont., 225.

depilata, C. Pfeiff., 198.

Draparnaudi, Shepp., 84.

edentula, Drap., 172.

electrina, Gould, 165.

elegans, Drap., 216.

ericetorum, Müll., 216.

ericetorum, Nilss., 217.

excavata, Bean, 168.

explanata, Müll., 229.

fasciolata, Poir., 215.

fossaria, Mont., 117. 
HrLIX (continued).

fragilis, Mont., 111.

fruticum, Müll., 174.

fulva, Müll., 171, 172.

fusca, Mont., 204, 205.

fusca, Poir., 206.

Gibbsii, Leach, 194.

Gigaxii, Charp., 214.

glabella, Drap., 196, 310.

glabra, Stud., 162.

glaphyra, Say, 160.

globularis, Jeffr., 202.

Goodallii, Mill., 239.

granulata, Ald., 202.

grisea, Linn., 184.

Hammonis, Ström, 165.

Helmii, Gilb., 163, 164.

hispida, Linn., 196, 197, r98, 200 , 202, 310.

hortensis, Penn., 184.

hortensis, Müll., 186, 187.

hybrida, Poir., 186.

incarnata, Müll., 174, 202, 206.

instabilis, Ziegl., 217.

intersecta, Poir., 215.

Itala, Linn., 218.

Kirbii, Shepp., 224.

Lackhamensis, Mont., 236.

lamellata, Jeffr., I75, 245.

lapicida, Linn., 227.

limbata, Drap., 192.

limosa, Linn., 108.

lineata, Walk., 79.

lineata, Olivi, 211, 213.

lubrica, Müll., 288, 289, 292.

lucida, Pult., 161.

lucida, Drap., 161.

lucorum, 178.

lutea, Moṇt., 105.

maritima, Drap., 211.

minuta, Stud., 224.

montana, Stud., 196.

Mortoni, Jeffr., 171.

muscorum, Linn., 248, 249, 251.

muscorum, Mont., 248.

muscorum, Miull., 252.

Naticoides, Drap., 185.

neglecta, Drap., 211.

nemoralis, Linn., 151, I85, 187, 207.

Nilssoniana, Beck, 217.

nitens, Gmel., 164.

nitens, Mat. \& Rack., 164.

nitens, Mich., 163, 164.

nitida, Drap., 161.

nitida, Müll., 167.
HeLIX (continued).

nitidosa, Fér., 167.

nitidula, Drap., 163, 164, 167, 310.

obliterata, Hartm., 217.

obscura, Müll., 237.

obvoluta, Müll., 229, 230, 231,

236, 289.

occidentalis, Récl., 204.

octanfracta, Mont., 118.

octona, Linn., 68, 299.

octona, Penn., 299.

pallida, Don., 191.

paludosa, Da Costa, 227.

perversa, Müll., 280.

petronella, Charp., 169.

picea, Ziegl., 189.

Pisana, Müll., 207, 213.

planorbis, Linn., 91.

plebeium, Drap., 200, 310.

pomatia, Linn., I77, 178, 182.

Ponentina, Mor., 204.

pulchella, Müll., 224, 227.

pupa, Linn., 239.

pura, Ald., 164.

putris, Linn., 151.

pygmæa, Drap., 223, 310.

radiata, Da Costa, 220.

radiatula, Ald., 166, 169.

revelata, Mich., 202, 204, 206,

207, 310.

revelata, Fér., 202, 204.

revelata, Bouch.-Ch., 204, 206.

rhodostoma, Drap., 209.

rhombea, Turt., 91.

rotundata, Müll., 218, 229.

rotundata, Turt., 220.

ruderata, Stud., 174.

rufescens, Penn., 191, I94, 195,

196, 197, 198, 230, 310.

rufescens, Gmel., 196.

rufescens, Grateloup, 196.

rufilabris, Jeffr., 193.

rupestris, Stud., 220, 223, 224.

Scarburgensis, Áld., 175.

seminulum, Rossm., 175.

sericea, Müll., 198, 201, 202, 204.

sericea, Ald., 199.

sericea, Drap., 204, 310.

sericea, Phil., 200.

Somershamiensis, Shepp., 229.

spinulosa, Mont., 176.

spirorbis, Linn., 84.

stagnalis, Linn., 111.

striata, Müll., 215.

striata, Drap., 215.

striatula, Linn., 167, 215. 
HeLIx (continued).

striatula, Müll., 167, 21 .̆.

striatula, Olivi, 167.

striatula, Gray, 167.

subcylindrica, Linn., 295.

submaritima, Rossm., 211.

tentaculata, Linn., 60.

terebra, Turt., 92.

terrestris, Penn., 215.

Trochiformis, Mont., 172.

Trochilus, Müll., 239.

Turtoni, Flem., 219.

umbilicata, Mont., 220, 222.

umbrosa, Partsch, 198.

unifasciata, Poir., 211.

variabilis, Drap., 213.

ventricosa, Müll., 243.

virgata, Da Costa, 2ro, 211, 212 ,

213, 214, 215, 218, 234.

viridula, Menke, 168, 169.

vitrina, Fér., 168, 169.

vitrina, Wagn., 169.

vivipara, Linn., 57, 58.

vortex, Linn., 88.

zonaria, Penn., 209.

Hydrobia, Hartm., 63, 304.

Ferussina, 69.

marginata, Mich., 64, 69.

similis, Drap., 64, 310.

ulvce, 67, 310 .

ventrosa, Mont., 66.

Kelliadoe, 2.

\section{LAMELLIBRANCHIATA, I.}

Limacella, Brard, 132.

concava, Brard, 134.

obliqua, Brard, 135.

parma, Brard, 139.

unguiculus, Brard, 133.

LIMAOIDE, 124, 125.

Limax, Linn., тзо.

agrestis, Linn., ז34, 135, 139.

anguiformis, Mor., 129, 130.

antiquorum, Fér., 139.

arboreus, F. \& H., 135.

arborum, Bouch.-Ch., 133, I35, 138.

ater, Linn., 127, 182.

brunneus, Drap., 139.

brunneus, Bouch.-Ch., 139.

carinatus, Risso (\& Leach), 133.

cinctus, Müll., 129.

cinereo-niger, Nilss., 138.
Limax (continued).

cinereus, Müll., 137, 138.

filans, Hoy, 136.

flavus, Linn., r33, 140.

flavus, Müll., 127, 134.

fuscus, Müll., 129.

gagates, Drap., I31, 133, 143.

Livonicus, Schrenck, 136.

marginatus, Müll., r32.

maximus, Linn., I37, 138.

parvulus, Norm., 139.

Sowerbii, Fér., 132, 133.

tenellus, F. \& H., 139.

tenellus, Müll., 140.

variegatus, Drap., 134.

LIMNAA, Brug., ror.

auricularia, Linn., I08, 109, 110,

115.

Burnetti, Ald., 103, 104.

cornea, 115.

glabra, Müll., 112, xт7, 299.

glutinosa, Müll., IO2, 103.

involuta, Thomps., ro3.

palustris, Mïll., 108, II3.

peregra, Müll., ro4, 107, 111, 112,

117, 119.

stagnalis, Linn., II I, 112, 113.

truncatula, Müll., 114, II5,

119.

LIMNAID必, 77, 300.

\section{Limnaeus}

auricularius, F. \& H., 108.

Burnetti, F. \& H., 104.

glaber, F. \& H., 117.

glutinosus, F. \& H., 102.

involutus, F. \& H., 103.

lineatus, Bean, 106.

palustris, F. \& H., 113.

pereger, F. \& H., 104.

stagnalis, F. \& H., 111.

truncatulus, F. \& H., 115.

Limnea

intermedia, Fér., 105, 107.

Limneus

acutus, Jeffr., 109.

elongatus, Drap., 118.

minutus, Drap., 117.

ovatus, Drap., 105, 106.

tinctus, Jeffr., 114.

Lithoglyphus

Naticoides, Fér., 70.

Litiopa

bombyx, 68 .

Lutea, 101.

Lymnea, Brug., 101. 


\section{Mangelia}

nivalis, 296.

Margarita, 71.

Margaritana, 31 .

Melampus, Montf., 55, 76, 299, 306.

Murex, 300.

Mya

margaritifera, Linn., 37. ovalis, Mont., 33. pictorum, Linn., 34.

Mysca

Batava, Turt., 37.

Mytilidae, 29, 46.

Mytilus, 29, 46.

anatinus, Linn., 43.

avonensis, Mont., 40, 43.

cygneus, Linn., 41.

dentatus, Turt., 42.

incrassatus, Shepp., 42.

paludosus, Tutt., 42.

polymorphus, Pall., 47.

radiatus, Müll., 42.

stagnalis, Gmel., 42.

Zellensis, Gmel., 42.

Myxas, 101.

\section{Natica}

Kingii, F. \& H., 70.

Nautilus, 80.

lacustris, Lightf., 81.

Nerita, 53, 63.

elegans, Müll., 304.

fasciata, Müll., 57.

fluviatilis, Linn., 53.

obtusa, Stud., 74.

piscinalis, Müll., 72.

NERITIDE, 52.

Neritina, Lam., 52, 63.

Batica, Lam., 54.

fluviatilis, Linn., 53 .

Neritostoma, Klein, 5.

\section{Onchidium}

Celticum, 300.

Otina, 76, 299.

Paludestrina, D'Orb., 64.

Paludina, Lam., 55, 304. anatina, 62.

contecta, Millet, 56 .

diaphana, Mich., 68.

Listeri, F. \& H., 56.

marginata, Mich., 69.
Paludina (continued).

meridionalis, Risso, 65.

muriatica, Lam., 68.

similis, 62.

ventricosa, Menke, 60 .

viridis, 62.

vivipara, Linn., 58.

Paludinella, Pfeiff. \& Lov., 64.

Paludinine, 55.

Parmacella, 141.

Patella, 119, 308. fuviatilis, List., 121. lacustris, Linn., 121, 122, 123.

PECTINIBRANCHIATA, $5 \mathrm{I}$.

Pedipes, Adans., 306.

Physa, Lam., 95. acuta, Drap., 98, 100. alba, Turt., 100.

contorta, Mich., 100. elongata, Say, 97.

fontinalis, Linn., 98, 99.

hypnorum, Linn., 96.

Sowerbyana, D'Orb., 100.

subopaca, Lam., 100.

Pinna

fluviatilis, Sander, 49.

Pisidium, C. Pfeiff., r6.

amnicum, Müll., 20.

arcaforme, Malm, 28.

australe, Phil., 22.

cinereum, Ald., 21.

conicum, 4.

fontinale, Drap., 20.

Henslowianum, Jen., 20, 21.

nitidum, Jen., 25.

obtusale, C. Pfeiff., 24.

pallidum, Gass., 22.

pulchellum, Jen., 21.

pusillum, Gmel., 23.

Recluzianum, Bourg., 4.

roseum, Scholtz, 26.

sinuatum, Bourg., 26.

tetragonum, Norm., 28.

ventricosum, Prime, 24.

Planorbis, Guett., 78, 228.

albus, Müll., 83, 85, 86 . carinatus, Müll., 89, 92. complanatus, Linn., 91 . compressus, Mich., 89, 90. contortus, Linn., 94 . corneus, Linn., 93.

cristatus, Drap., 82.

disciformis, Jeffir., 90.

Draparnaldi, Jeffr., 84.

glaber, Jeffr., $85,88$. 
Planorbis (continued).

gyrorbis, v. Seck., 86.

intermedius, Charp., 93.

lacustris, F. \& H., 79.

lovis, Ald., 86.

leucostoma, Mich., 88, 151.

lineatus, Walk., 79, 82.

lutescens, Jeffr., 90.

marginatus, Drap., 84, 91, 92.

Nautileus, Linn., 82 .

nitidus, Müll., 80, 8r.

Rossmässleri, Auersw., 86.

rotundatus, Poir., 88.

similis, Müll., 94.

spirorbis, Müll., 87, 89, 93.

spirorbis, Moq.-Tand., 87.

spirorbis, Drap., 84.

submarginatus, Crist. \& Jan,

93.

turgidus, Jeffr., 93.

turritus, Müll., 98.

umbilicatus, Müll., 92.

vortex, Linn., 88, 90, 93.

PNEUMONOBRANCHS, 76.

Polyphemus, Montf., 287, 288.

PULMOBRANCHS, 76.

\section{PULMONATES, 76.}

\section{PULMONIFERS, 76.}

PULMONOBRANCHIATA, 76.

PULMONOBRANCHS, 76.

PUPA, Lam., 149, 150, 240, 241, $243,251,252,253,264,272$, $276,279$.

Anglica, F. \& H., 244.

Anglica, Moq.-Tand., 257.

antivertigo, Drap., 253.

arctica, v. Wall., 257.

avena, 243.

avenacea, 243.

bigranata, Rossm., 250.

borealis, Mor., 261.

Callicratis, Scacchi, 271.

Charpentieri, Shuttl., 257.

columella, v. Mart., 269.

costulata, Nilss., 271.

cylindracea, Da Costa, 249.

Desmoulinsiana, Jeffr., 257.

doliolum, 241.

edentula, Drap., 268.

fragilis, Drap., 275.

inornata, Mich., 269.

marginata, Drap., 241, 248, 249, $252,253$.
PUPA (continued).

milium, Gould, 262.

minuta, Stud., 271.

minutissima, Hartm., 251, 270.

Moulinsiana, Dup., 255.

muscomum, F. \& H., 249.

muscorum, Drap., 271.

obtusa, Flem., 271.

ovata, Say, 255.

pusilla, Biv., 254.

pusilla, F. \& H., 263.

pygmoea, Drap., 257.

ringens, Jeffr., 241, 244, 246, 248, 251.

ringens, Mich., 246.

rugosa, Drap., 310.

secale, Drap., 238, 241, 242, 246.

Sempronii, Charp., 248.

Shuttleworthiana, Charp., 261.

substriata, F. \& H., 261.

tridens, 241.

triplicata, Stud., 271.

umbilicata, Drap., 222, 241, 245, 246, 248, 251, 252.

Venetzii, F. \& H., 265.

Pupce, 240, 255.

Pupula, Agass., 308.

\section{Rissoa}

anatina, F. \& H., 64.

castanea, Jeffr., 69.

ventrosa, F. \& H., 66.

Rissoœ, 63.

Scalaria, Lam., 304.

Segmentina, Flem., 80.

Solarium, 220.

SPHARIIDE, I.

Spharium, Scop., 4.

Brochonianum, Bourg., 11.

citrinum, Norm., 6.

corneum, Linn., 5 .

lacustre, Müll., ro.

ovale, Fér., 8.

pallidum, Gray, 8.

Pisidioides, Gray, 6.

rivicola, Leach, 7 .

Stagnicola

elegans, Leach, 112.

Styloides, Fér., 288.

Soccinka, Drap., 149, I5o, 156.

abbreviata, Mor., 155.

arenaria, Bouch.-Ch., 155.

elegans, Risso, I53, 154. 
Succinka (continued).

gracilis, Ald., 154 .

oblonga, Drap., 153, I 54, 155.

Pffeiferi, Rossm., 154.

putris, Linn., 150, I5 $, 153,154$.

\section{Tellina}

amnica, Müll., 20.

cornea, Linn., 5.

Henslowana, Shepp., 21.

lacustris, Müll., 10.

pusilla, Gmel., 22, 23.

rivalis, Müll., 7 .

Teredo, 49, 229, 276.

Terrestrial, I24.

Testacella, Cuv., $4^{\circ}$ et seq. Altce-ripoe, 147.

Deshayesii, 147.

Europcea, De Roissy, 147.

Haliotidea, Drap., I45, 147.

Maugei, Fér., 144, 147, 148.

Medii-Templi, Tapp., 146.

scutulum, Sow., 145, 147.

Testacclloe, 144, 156.

TEstachllide, 124, I40, 149.

Testacellus, Faure-Big., 141.

Theba, Risso, 209.

Tichogonia

fluviatilis, Erichs., 46.

Trochus, 71.

perspectivus, 220.

sylvaticus, List., 248.

Truncatella, 304.

T'urbo

bidens, Mont., 280.

biplicatus, Mont., 283.

chrysalis, Turt., 252.

fasciatus, Penn., 235.

glaber, Da Costa, 295.

Helicinus, Lightf., 227.

juniperi, Mont., 243.

laminatus, Mont., 284.

Leachii, Shepp., 61.

Nautileus, Linn., 82.

nigricans, Mat. \& Rack., 280.

Offtonensis, Shepp., 269.

perversus, Linn., 273.

sexdentatus, Mont., 255, 259.

stagnorum, Baster, 68.

thermatis, Gmel., 68.

tridens, Pult., 289, 290.

ulvae, Penn., 66.
Turbo (continued). ventrosus, Mont., 66. vertigo, Mont., 267.

Turtonia

minuta, 4.

UnIo, Philipps., 3 r.

amnicus, Ziegl., 37.

Batavus, 31.

curvirostris, Norm., 35.

littoralis, 31.

margaritifer, Linn., 37.

margaritiferus, F. \& H., 37.

nana, Lam., 37.

nanus, Dup., 37.

Philippi, Dup., 36.

pictorum, Linn., 34 .

rhomboideus, 31 .

Roissyi, Mich., 38.

sinuata, Lan., 38.

tumidus, Philipps., 32.

UNIONIDE, 28.

UNIVALVES, 5 I.

Vallonia, 174.

Valvata, Müll., 72. antiqua, Morr., 73 .

cristata, Müll., 74.

depressa, C. Pfeiff., 72.

minuta, Drap., 75.

piscinalis, Müll., 72.

planorbis, Drap., 75 .

spirorbis, Drap., 75.

VALVATIDE, 70.

Vkrtigo, Müll., 149, 150, 251, 252,

$253,256,260,264,272,289$.

alpestris, Ald., 258, 259.

alpestris, Fér., 261.

Anglica, Fér., 246.

angustior, Jeffr., 265.

antivertigo, Drap., 253, 256, 257, $259,264$.

curta, Held, 262.

cylindrica, Fér., 271.

edentula, Drap., 264, 268, 270.

hamata, Held, 267.

heterostropha, Leach, 264.

minutissima, Hartm., 270.

Moulinsiana, Dup., 255, 257, 258, 259.

nana, Mich., 267.

nitida, Fér., 269.

octodentata, Stud., 255. 
Vertigo (continued). palustris, Leach, 255. plicata, A. Müll., 267. pusilla, Müll., 252, 253, 263, 266, 267, 268. pygmæa, Drap., 252, 255, 256, 257, 259, 260, 261. rupestris, 253.

septemdentata, Fér., 255.

substriata, Jeffr., 255, 26I, 264. Venetzii, Rossm., 567.

VITRINA, Drap., 150, 155, 159. depressa, Jeffr., 157. diaphana, Drap., 156, 158. Dillwynii, Jeffr., 157. Draparnaldi, Cuv., 157. Draparnaldi, Jeffr., 157. major, Fér., 157. pellucida, Müll., r 56, 158. semilimax, Fér., 141.
Vitrince, 143, 158.

ZoniTES, De Montf., 143, 150, 156, I $58,160,220$.

alliarius, Mill., 16ז, 162, 168.

cellarius, Müll., I59, 160, 161, $162,164,230$.

crystallinus, Müll., 170.

excavatus, Bean, r68, 169.

fulvus, Müll., I7r.

glaber, 162.

nitidulus, Drap., r63, 165.

nitidus, Müll., 163, 165, 167, 170. purus, Ald., I64, 166, 169, 310. radiatulus, Ald., 166, 168, 310 .

Zospeum, Bourg., 296.

Zua, Leach, 289.

lubrica, F. \& H., 292.

Zurama, 174. 


\title{
EXPLANATION OF PLATES.
}

\author{
Frontispiece. \\ Unio margaritifer, and pearl.
}

Plate I.

Figure 1. Sphorium rivicola, showing, the donble tube and foot. 2. Hinge of the shell.

3. Pisidium amnicum, showing the single tube and foot. 4. Hinge of the shell.

5. Unio pictorum, showing both orifices and the foot. 6. Hinge of the shell.

\section{Plate II.}

Figure 1. Anadonta anatina, showing both orifices and the foot. 2. Hinge of the shell.

3. Dreissena polymorpha, showing the two orifices and tubes in an inverted position and the byssus attached to the fragment of a valve of an Anatina. 4. Shell. 5. Inside of hinge.

\section{Plate III.}

Figurc 1. Neritina fluviatilis, showing the snout, tentacles, position of the eyes, and the foot. 2. Shell. 3, 4. Operculum.

5. Paludina vivipara. 6. Shell, showing the operculum in situ.

7. Bythinia tentaculata. 8. Shell, showing the operculum in situ. 9. Back view of shell.

10. Hydrobia similis. 11. Shell, showing the operculum in situ. 12. Natural size.

13. Valvata cristata, showing the branchial plume and filament. 14. Shell of $V$. piscinalis. 15. Operculum of same.

\section{Plate IV.}

Figure 1. Planorbis corneus, showing the body and attachment of the foot. 2, 3. Shell.

4, 5. Physa fontinalis, showing the digitated lobes of the mantle. 6, 7. Shell.

8. Limnaca peregra, showing the respiratory opening to the right. 9,10 . Shell of $L$. stagnalis.

11, 12. Ancylus fluviatilis, showing the front and under side. 13, 14. Shell. 


\section{Plate V.}

Figure 1. Arion ater, showing the tentacles, eyes, shield, position of the respiratory opening, and slime-gland at the tail. 2. Same at rest.

3. Geomalacus maculosus (from Brit. Moll. pl. F.F.F*. f. 5).

4. Limax maximus, showing the position of the respiratory opening. 5. Shell or Limacella.

6. Testacella Haliotidea, showing the labial palps (below the tentacles) and the position of the shell. 7. Shell. 8. Egg.

\section{Plate VI.}

Figure 1. Succinea putris. 2. Shell.

3. Vitrina pellucida. 4. Shell.

5. Zonites cellarius. 6. Shell.

7. Helix aspersa. 8. Shell.

\section{Plate VII.}

Figure 1. Butimus acutus. 2. Shell of var. inflata.

3. Pupa umbilicata. 4. Shell. 5. Natural size.

6. Vertigo pygmaea, showing the two tentacles. 7. Shell. 8. Natural size.

9. Balia perversa. 10. Shell. 11. Natural size.

12. Clausilia laminata. 13. Shell. 14. Clausilium.

15. Cochlicopa lubrica. 16. Shell. 17. Natural size.

18. Achatina acicula. 19. Head and tentacles. 20. Shell. 21. Natural size.

\section{Plate VIII.}

Figure 1. Carychium minimum, showing the position of the eyes. 2. Shell. 3. Natural size.

4. Cyclostoma elegans, showing the snout and position of the eyes. 5. Shell. 6. Operculum.

7. Acme lineata, showing the position of the tentacles and eyes. 8, 9. Shell. 10. Natural size. 11. Operculum magnified. 


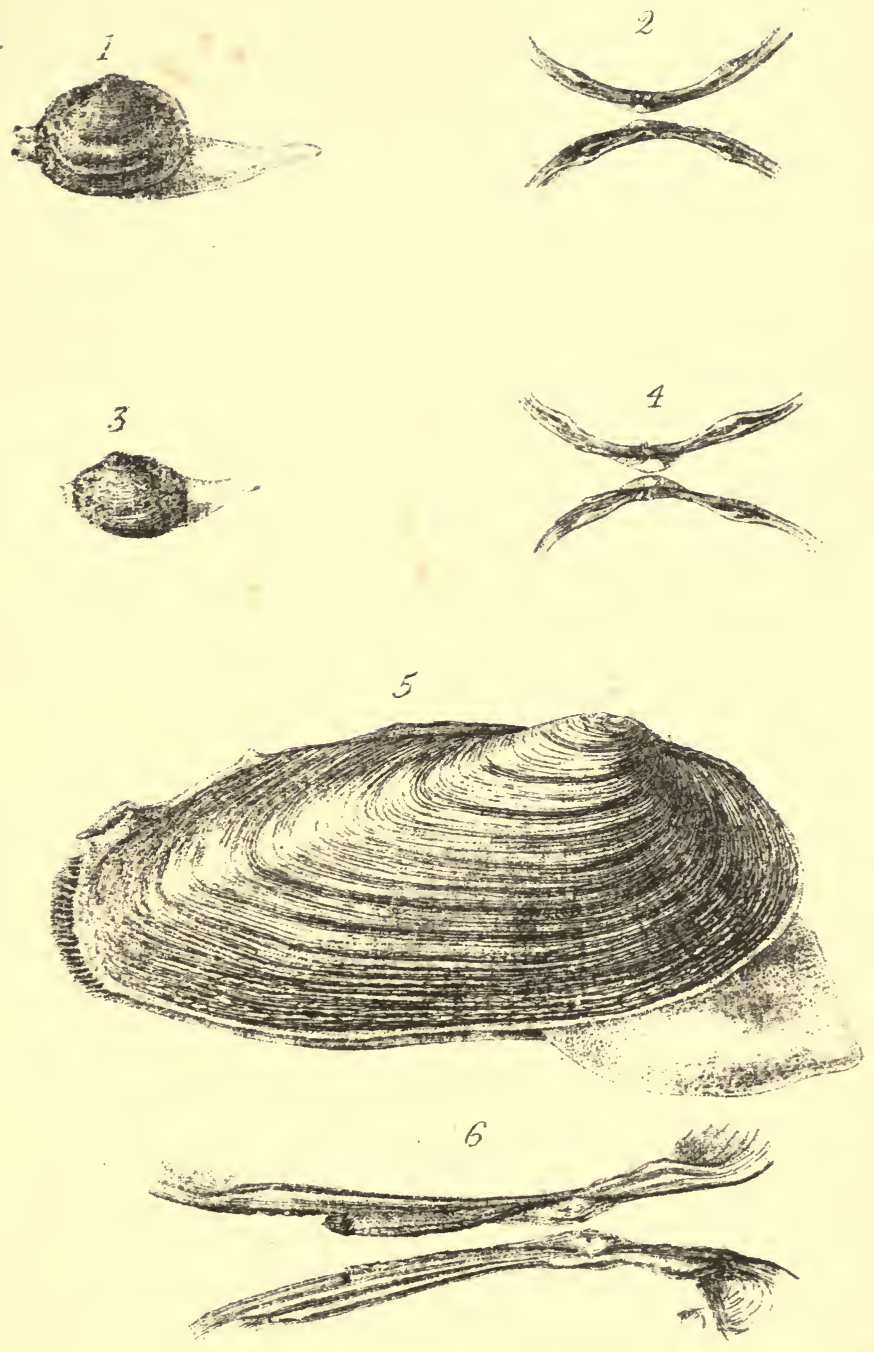

1.2. Spherwm

34 Pisidium.

5. 6. Enio 


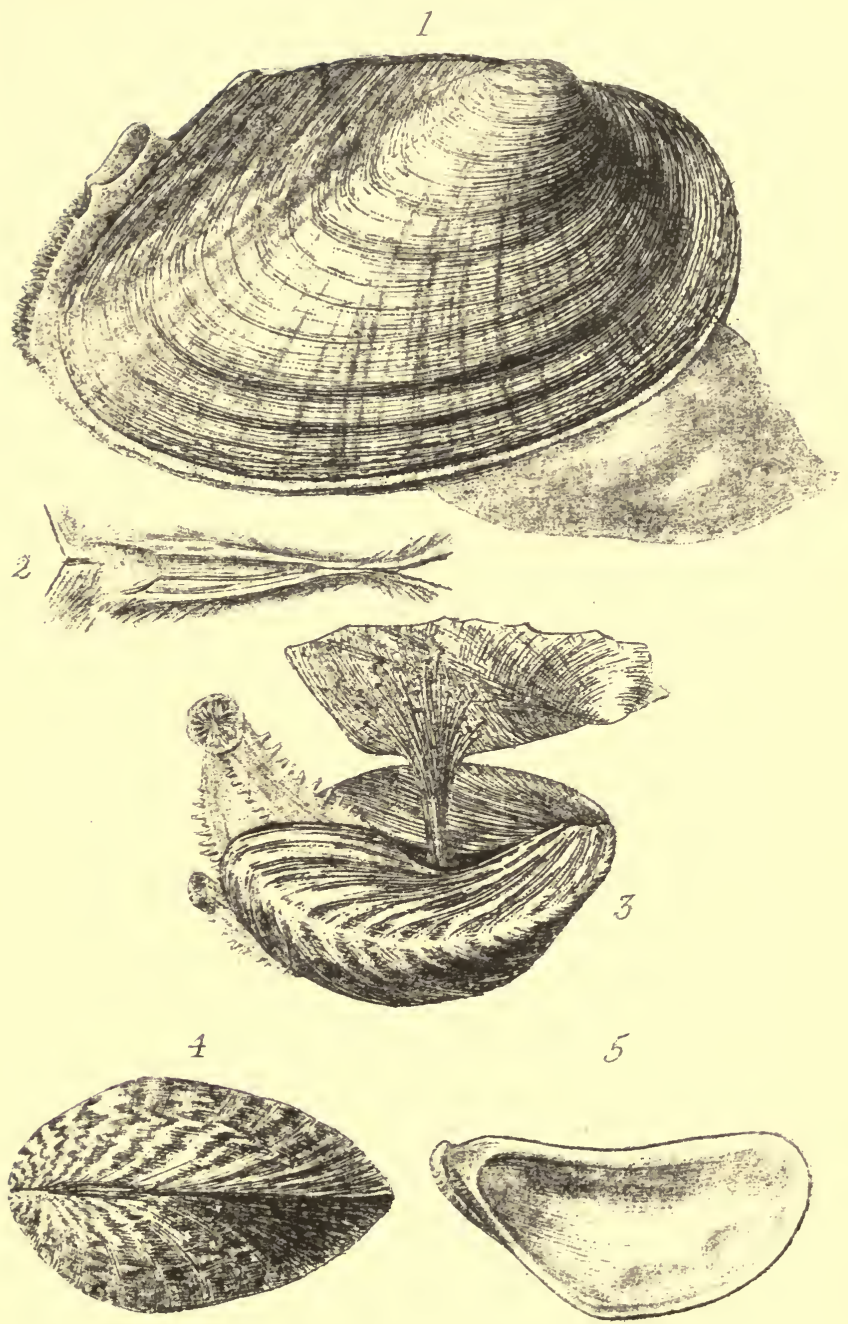

1. 2. inostomers

3.5 Urezssertin 


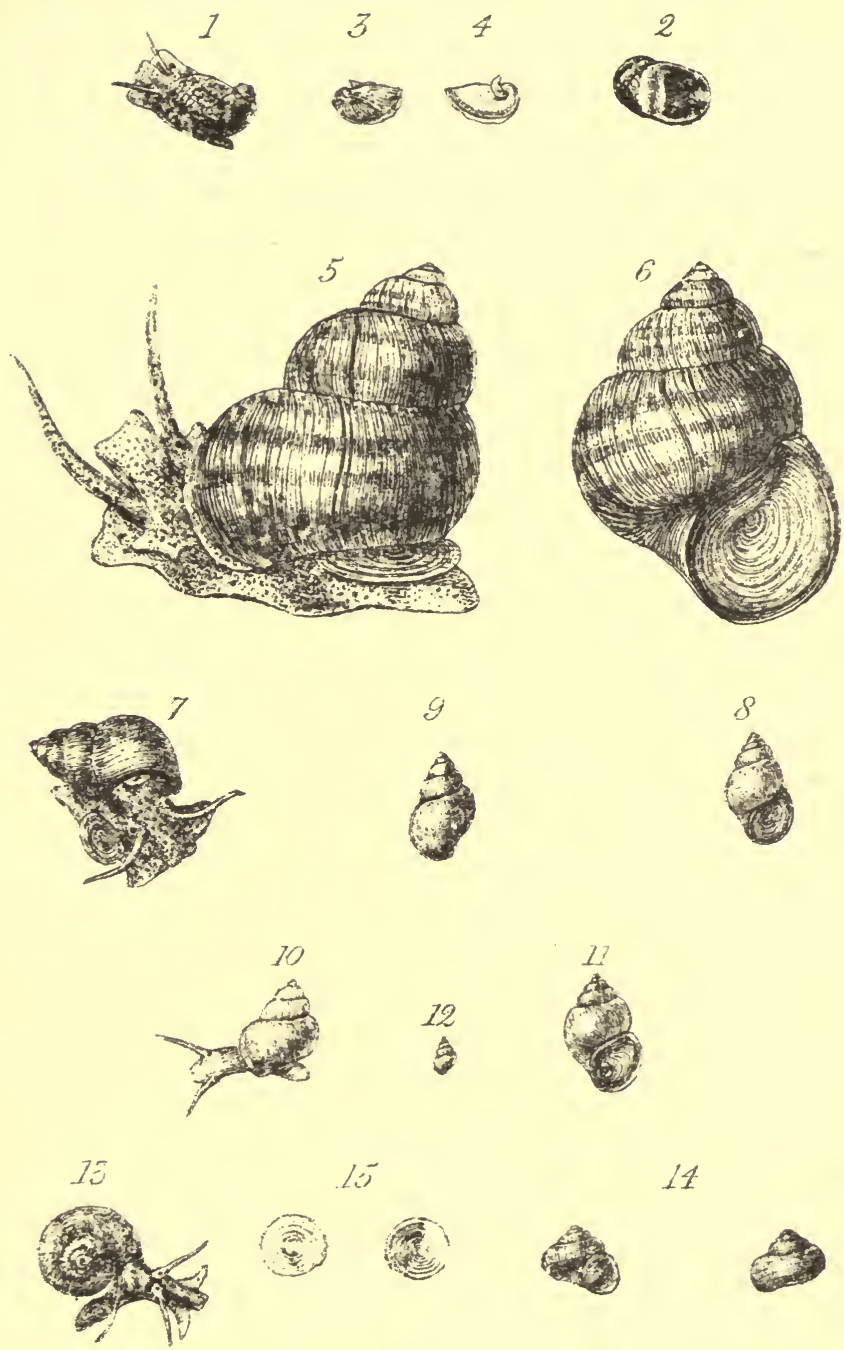

14

$$
\text { 1-7. Heritina }
$$$$
5 \text { ó Paludinn }
$$

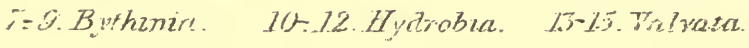




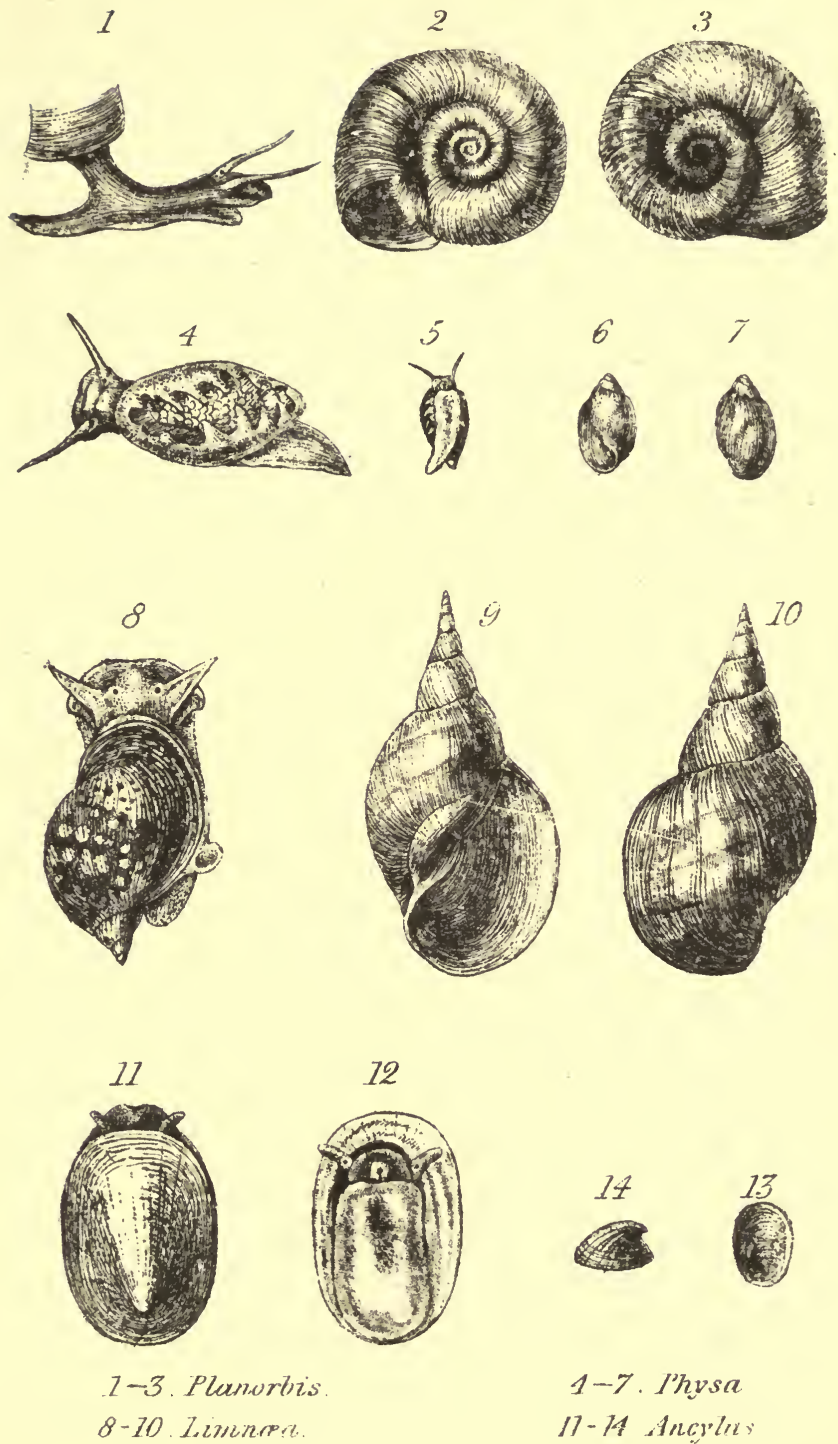

$$
\begin{aligned}
& \text { 1-7. Ihysa } \\
& 11-14 \text { Ancyles }
\end{aligned}
$$





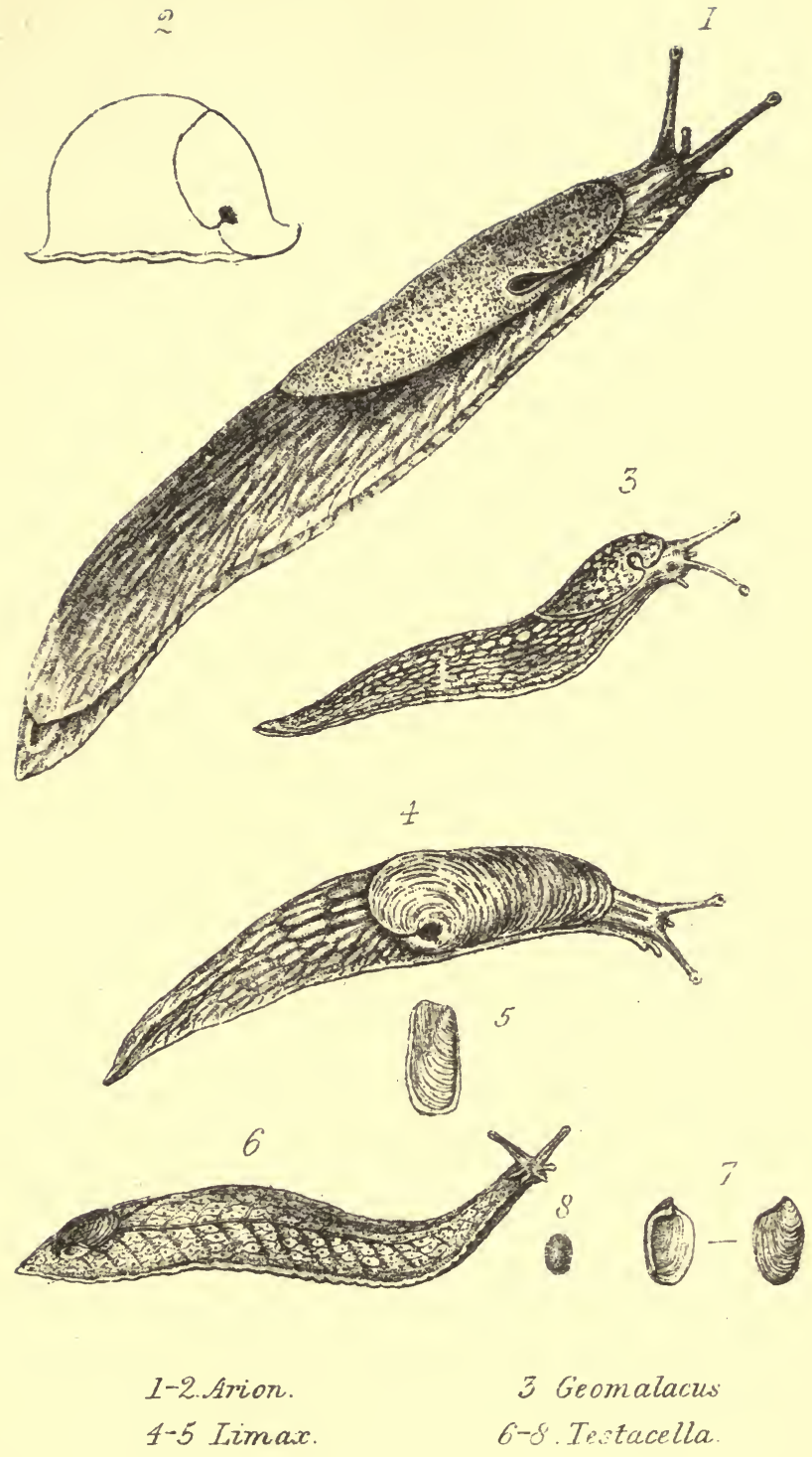




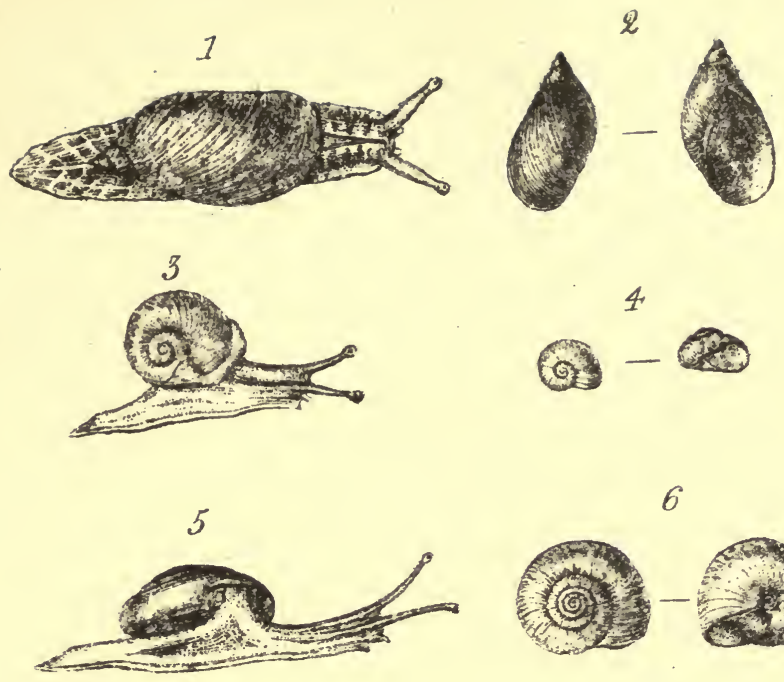

6

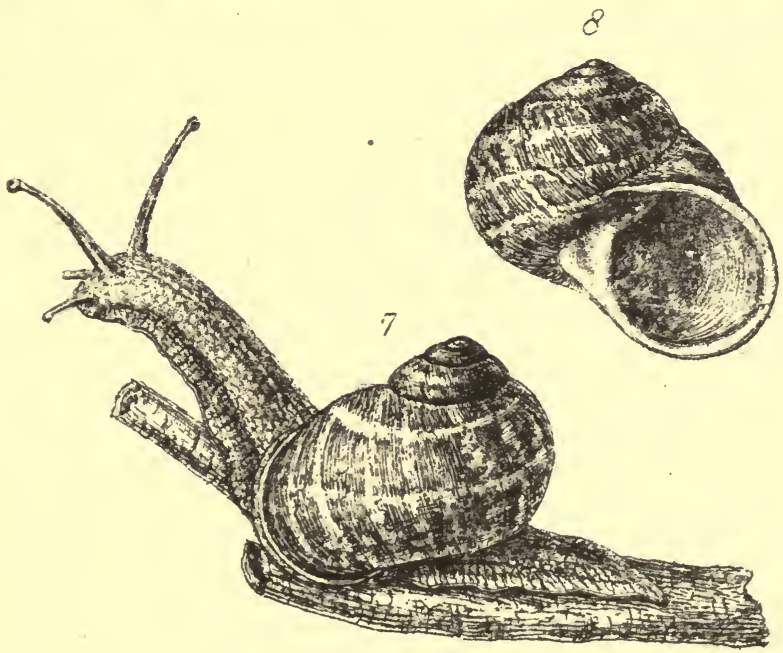

I-2. Succinea

3-i: Vitrna

5-6. Zonite.

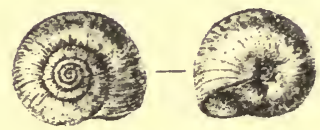

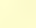




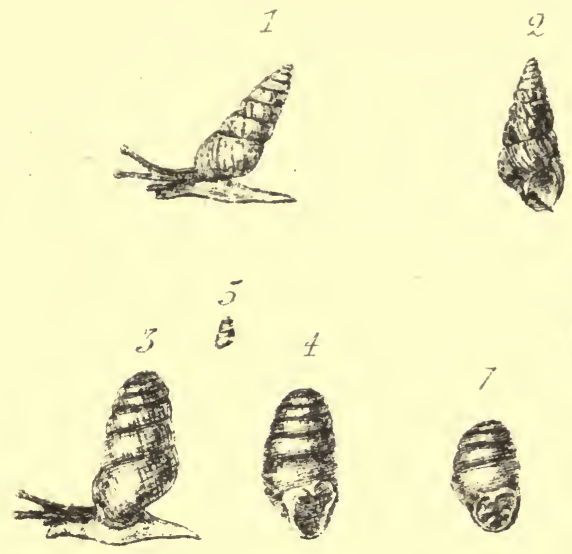

3
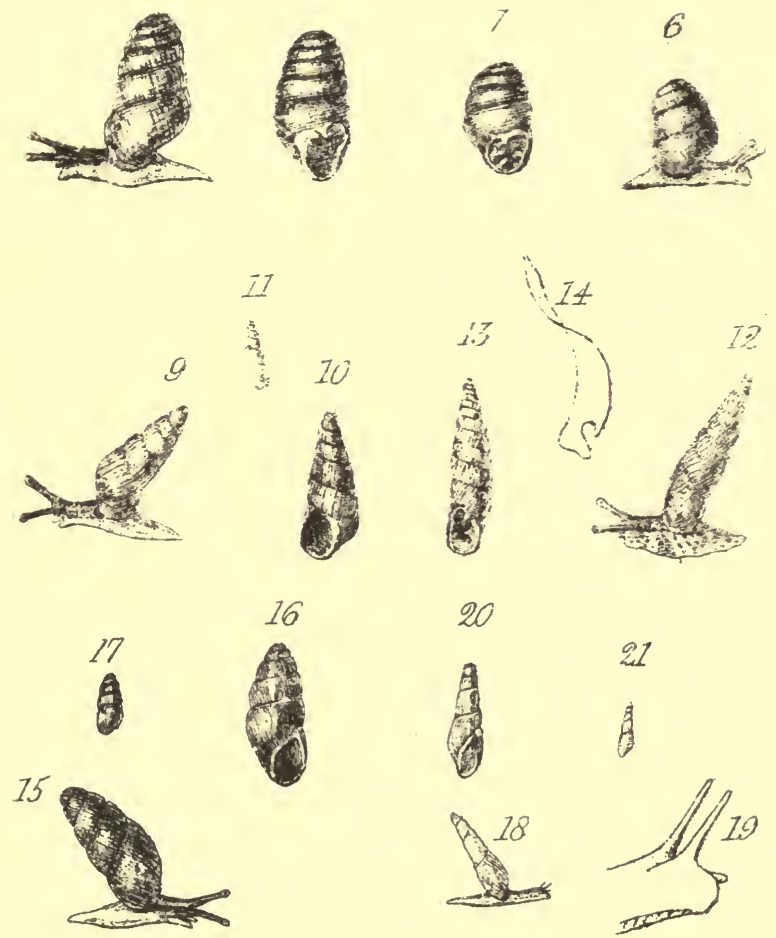

20

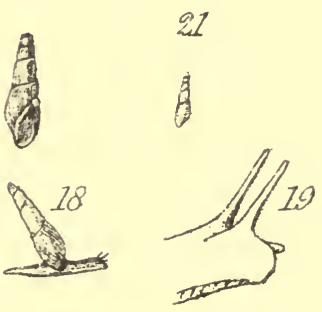

1-2. Bulimus. 3-5 Prifa. 6-8 Tertigo. 9-ll. Balia. 12:11. Clausiiia. 15-17 Cochizcona. \&-2] ichatina. 


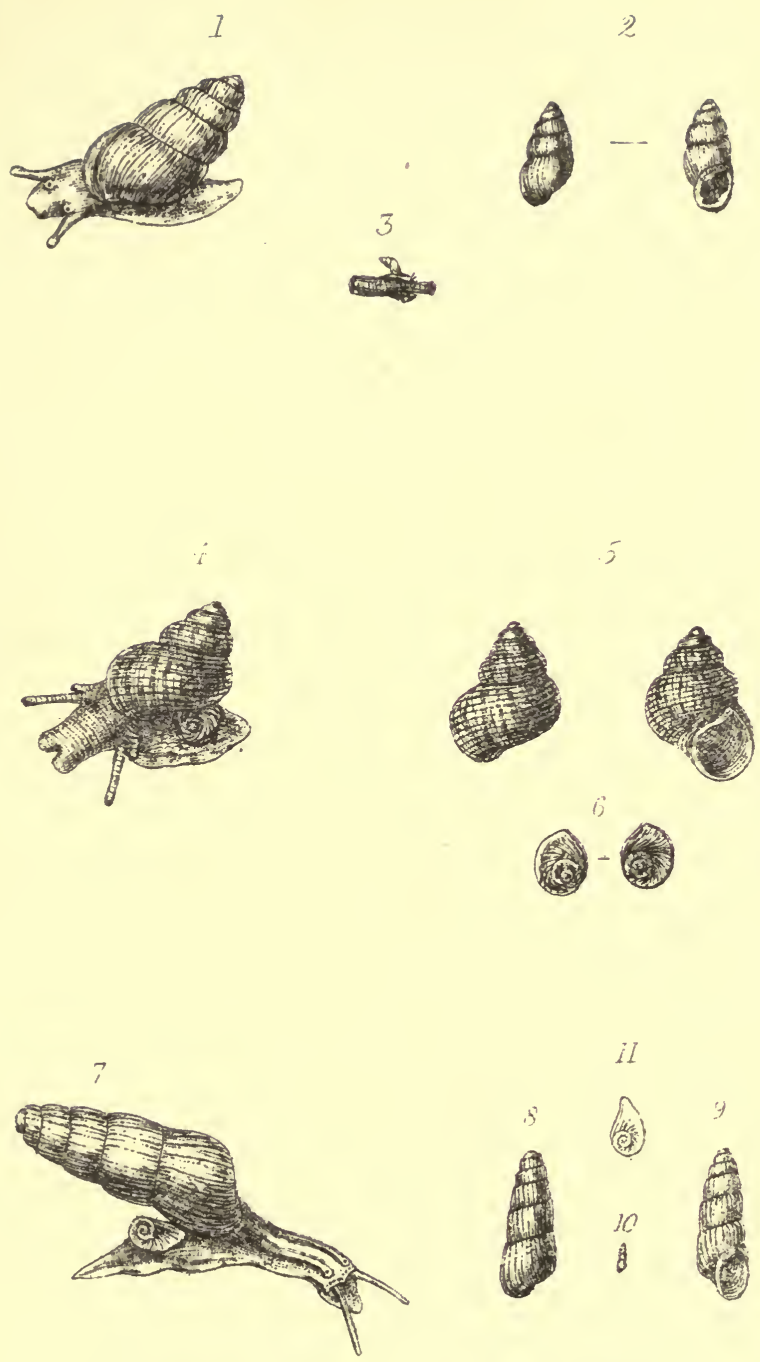

il

1-3. Carychium.

4-6. C.jolostnma

-11 . Acme. 


THIS BOOK IS DUE ON THE LAST DATE STAMPED BELOW

RENEWED BOOKS ARE SUBJECT TO IMMEDIATE RECALL

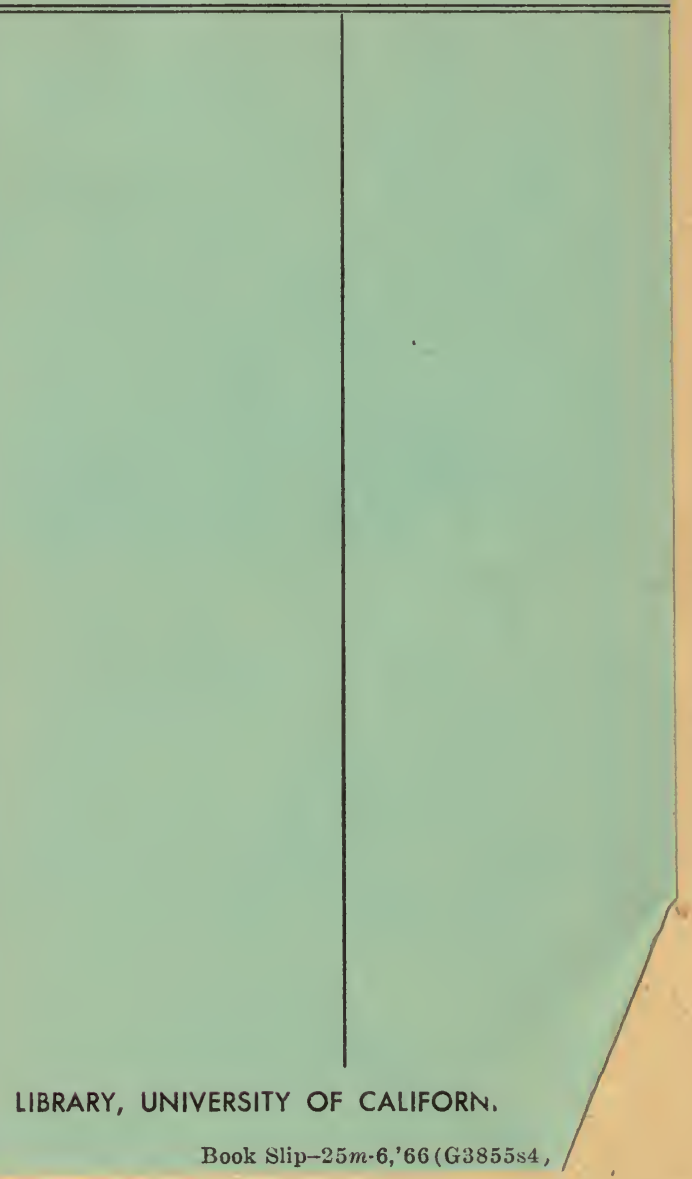




\section{№ 473399}

Jeffreys, J.G. British conchology.

QL425

G7

$\mathrm{J} 46$

v.1 
a

bolige

Angens

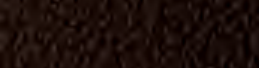

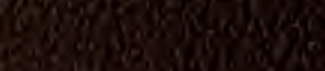

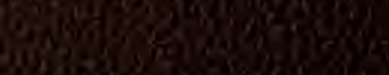

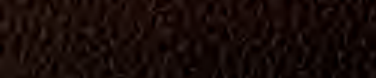

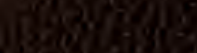

Signos

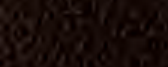

(2)

arkons

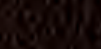

(x)

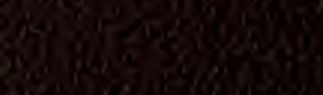

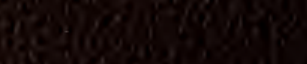

Q

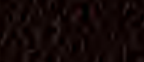

16.

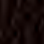

arging

atgons.

(1) 